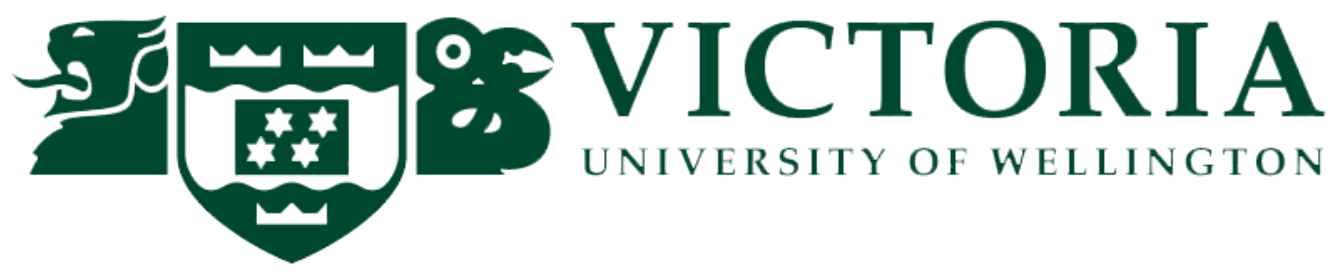

\title{
Influences of fisher attitudes and behaviour on regulation non-compliance: A case study from the Marlborough Sounds, New Zealand recreational blue cod fishery
}

\author{
By Alyssa S. Thomas
}

\author{
A thesis \\ submitted to Victoria University of Wellington \\ in fulfilment of the requirements for the degree of \\ Doctor of Philosophy \\ in Environmental Studies \\ Victoria University of Wellington \\ April 2015
}




\section{Abstract}

Although it has been noted that fisheries is $90 \%$ managing people, most management regimes focus solely on the other $10 \%$; the biological aspect. Furthermore, despite the growing popularity of recreational fishing and increased awareness of its biological effects, there exists even less literature on the human dimensions in this domain than in commercial fisheries. In New Zealand, the Marlborough Sounds recreational blue cod fishery is strictly regulated, due to its popularity and a top-down management regime, with limited fisher involvement. Despite substantial biological information on the fishery, there is only one piece of human dimensions research, carried out before the current management regime came into force. This thesis responds to calls for greater integration of human behaviour into fisheries analyses and management. Specifically, the aim is to explore fisher attitudes towards and compliance with the fishery regulations.

The research presented here is a combination of intercept and online surveys of over 500 fishers and is interdisciplinary in nature. Four related studies, aimed towards publication, provide important insights for a more inclusive management style in the future. The first chapter examines fisher attitudes and the factors shaping them, a poorly understood area. Responses reveal that although overall, fishers were dissatisfied with the current regulations, inexperienced and non-locally-resident fishers display more positive attitudes towards the regulations. The second core chapter examines regulation non-compliance, a worldwide fisheries problem that can undermine the effectiveness of a management regime. As rulebreaking behaviour is often a sensitive behaviour, two indirect methods (Randomized Response and Item Count) are tested against direct questioning in estimating violations of three recreational blue cod fishing regulations. Results show mixed effectiveness for the indirect methods, with a significantly higher estimate of non-compliance estimate obtained for only one of the three regulations. The third core chapter uses structural equation modeling to examine the drivers of non-compliance with the size and daily limits for blue cod. Knowledge of these drivers is essential to increasing voluntary compliance with the regulations and these results demonstrate that social norms are the largest influence for both the regulations. Finally, the fourth core chapter examines the potential effects of the maximum size limit on the number of blue cod discarded as well as fisher satisfaction and compliance. A scenario approach reveals that either increasing or eliminating the maximum size limit could offer significant gains compared with the control scenario. 
The four chapters contribute to the global literature on subjects including fisher attitudes, estimating sensitive behaviours, drivers of non-compliance, discards in recreational fisheries and natural resource management. Taken together, the results reaffirm the benefits of including the human dimensions in fisheries management regimes. For the Marlborough Sounds recreational blue cod fishery, a shift away from the current, top-down and biologically focused management regime is suggested. I also argue that a more inclusive management strategy may be the best chance for success and allow the fishery to be saved for future generations; a goal shared by both fishers and management.

\section{Keywords}

adaptive management, attitudes, conservation management, deterrence theory, drivers of non-

compliance, experience and residency influence, fisher satisfaction, fisheries management, illegal fishing, indirect questioning, mixed-methods research, recreational fishing, regulation knowledge, regulatory discards, sensitive behaviours, slot-limit, social psychological models, violation rates, voluntary compliance 


\section{Acknowledgements}

Where do I start? I am so proud of what I have achieved in the past 3.5 years but there is no way I could have done it without help from so many people. First and foremost, I need to thank my supervisors, Dr. Taciano Milfont and Dr. Michael Gavin, for their tremendous help. I have learned so much throughout the PhD process and their feedback and guidance has been invaluable. They have been fully supportive throughout the process, being generous with their time and providing vital input and advice. Taciano and Mike, thank you again for your time, commitment and continually challenging me to complete the thesis to the best of my ability.

Ralph Chapman has also been a big help over these last six months as my Victoria based supervisor. I'd also like to thank Richard Arnold in statistics for his help. The office staff (Kate, Cheryl and Alan) and Monika Hanson for all their help with various questions and issues; much appreciated. A special thank you also goes to Rewi Newnham for funding assistance to present my results at two conferences. My former officemates Francesco, Pablo and Tapuwa, thanks for the friendship and assistance with any number of random questions.

To all the fishers that participated in this research at any point, thank you!!! Thank you for taking time to share your knowledge and thoughts with me. This research would not have been possible without your help and I hope that the results can make some difference to the current situation in the Sounds. A special thank you goes to Pierro and Barbara Rocco for providing a place to stay on that first visit, Hugh Shields for the feedback and assistance in spreading the word about the online survey, and to Mark Baxter for his continual help and feedback. I would also like to thank the Marlborough Express, Nelson Mail and several fishing magazines for publishing articles on my research. Thanks to Daryl Crimp for having me a guest on his radio show, "Fishing with Crimpy".

The School of Psychology at Victoria University is gratefully acknowledged for a grant. I'd also like to thank everyone that generously donated money for fieldwork: Erin and Tim Arnold, Martin Carrick, Spencer Clubb, Adele Fergus O-Brien, Dayaram Ganda, Kayla McGrady, Ben Millett, Brenda Oliver, Lisa McLaren, Kea Moore, Stuart Meklejohn, Chris 
Ponniah, Christy Starner, Erica Stoltz, Reca Trammel and Amy Van DeLaar. My flatmates and friends for putting up with my stress levels and hearing me go on and on about this PhD. Paul Blaschke, Genevieve Grant, Sanne Martha and Laura Warman for assisting with proofreading; thank you! Another special thanks to Matt Bush for general advice on the process and continual words of encouragement.

Of course this would not have been possible without my parents and their critical financial assistance and unconditional support. Mum and Dad, thank you for supporting me financially so I could pursue this passion and gain the experience to help get a job doing what I love.

To everyone I have mentioned above and anyone who I managed to forget, thank you again. 


\section{Table of Contents}

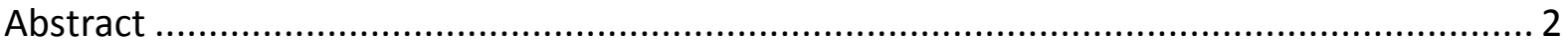

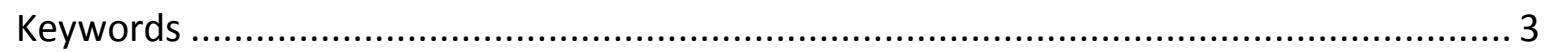

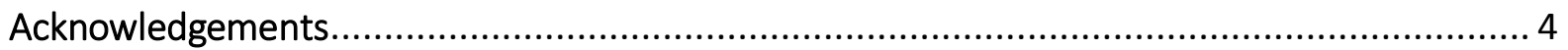

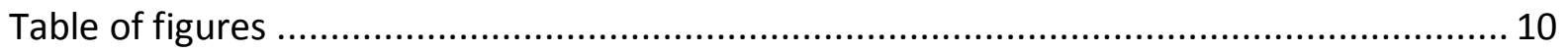

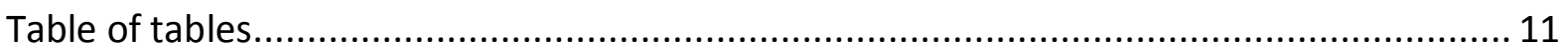

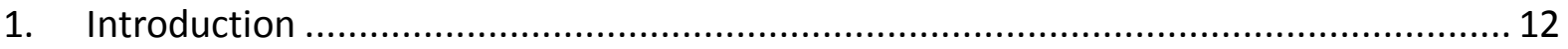

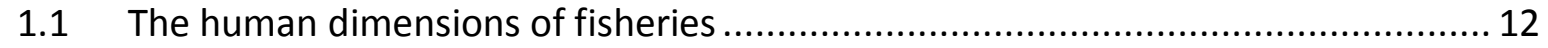

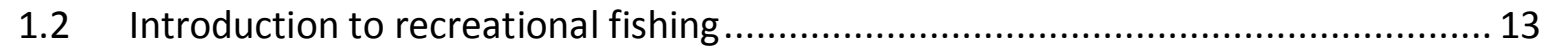

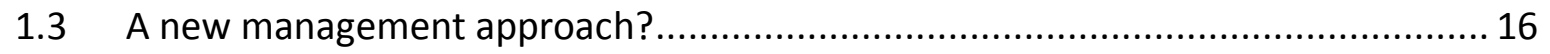

1.4 The problem of regulation non-compliance .................................................... 19

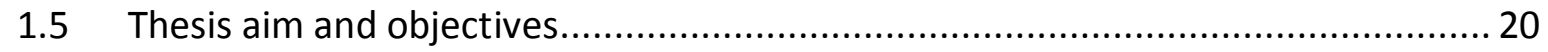

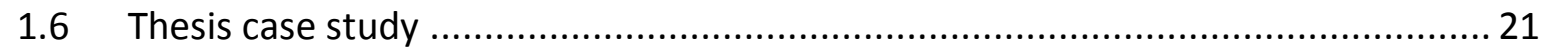

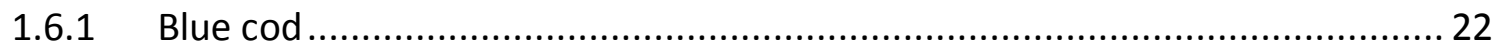

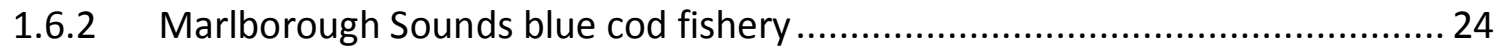

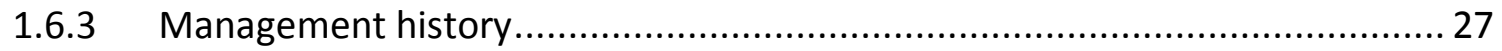

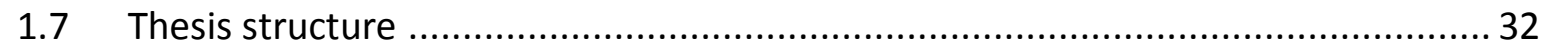

2 What determines fishers' knowledge of and attitudes towards regulations? ............... 35

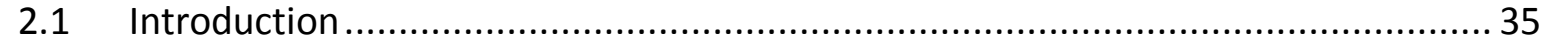

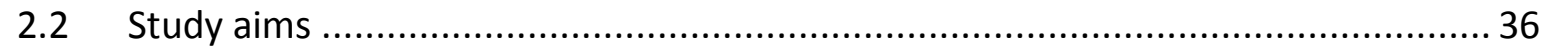

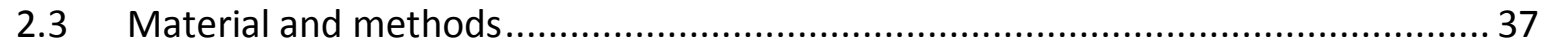

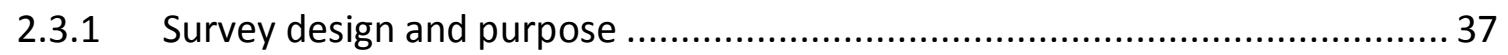

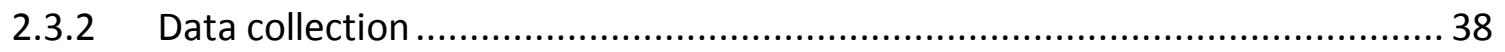

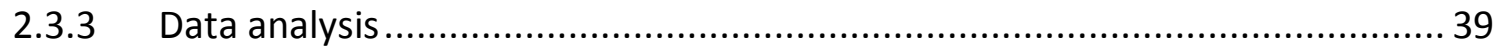

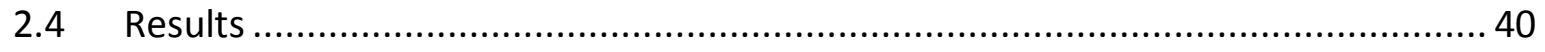

2.4.1 Overall satisfaction with the blue cod regulations ...................................... 41

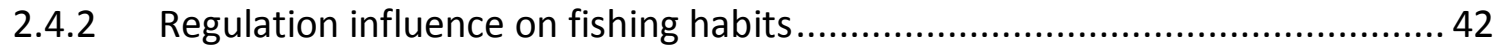

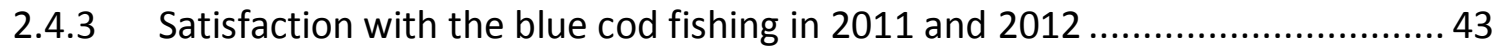

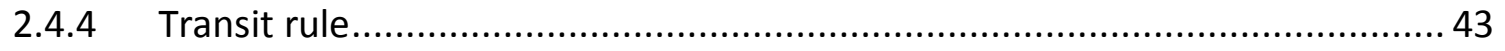

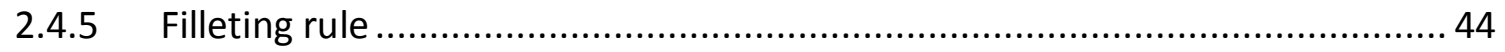

2.4.6 Blue Cod Management Group (BCMG) .................................................. 44

2.4.7 Modeling fishers' overall satisfaction ....................................................... 45

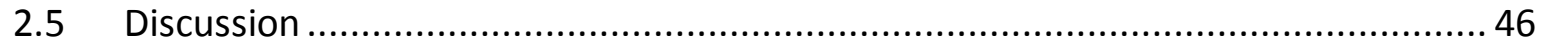

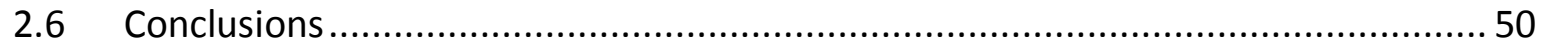

3 Estimating non-compliance among recreational fishers: Insights into factors affecting the usefulness of the Randomized Response and Item Count Techniques.... 


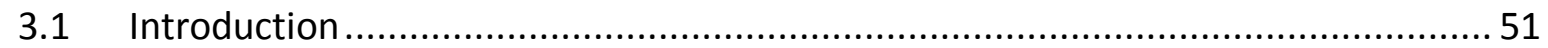

3.1.1 Measuring and monitoring non-compliance........................................... 51

3.1.2 Randomized Response Technique (RRT) .................................................... 53

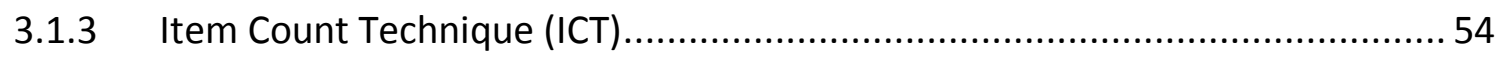

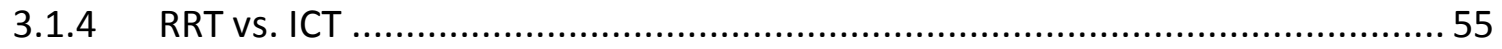

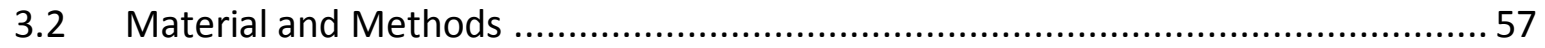

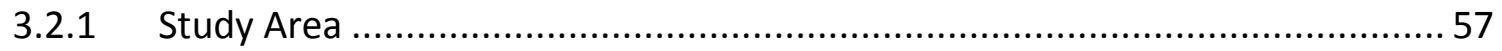

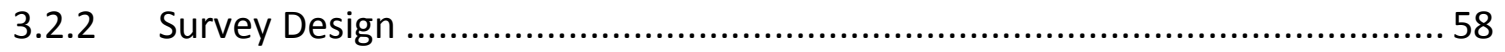

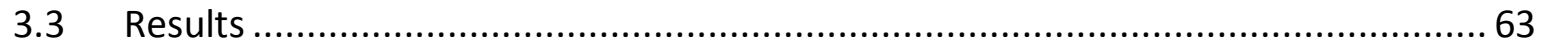

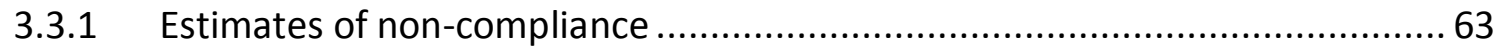

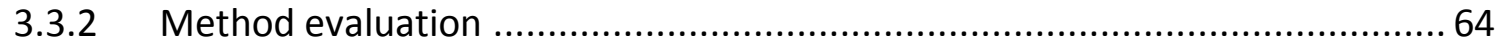

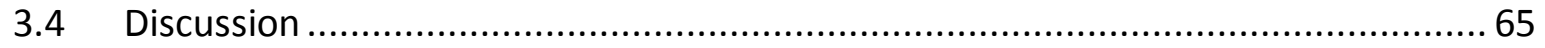

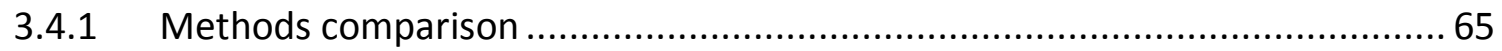

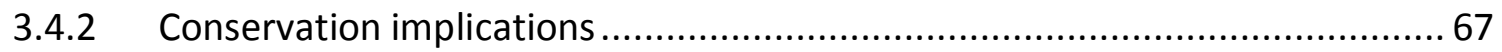

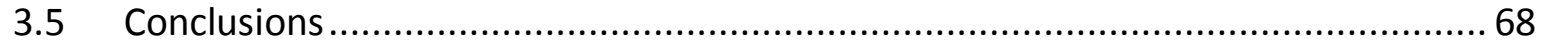

4 Social norms drive compliance with recreational fishery regulations ........................ 71

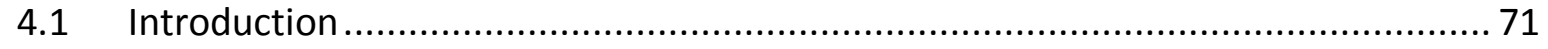

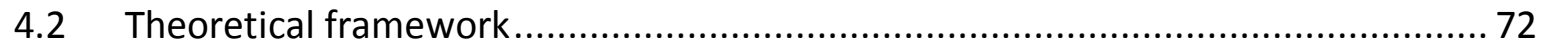

4.2.1 Understanding compliance in recreational fisheries .................................. 75

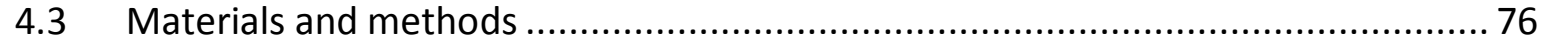

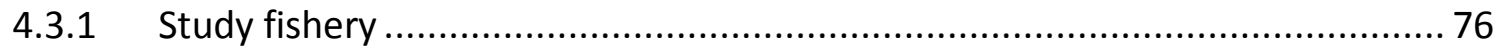

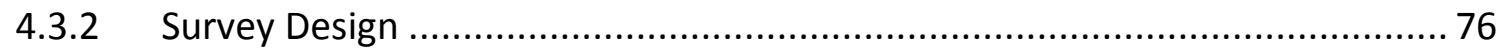

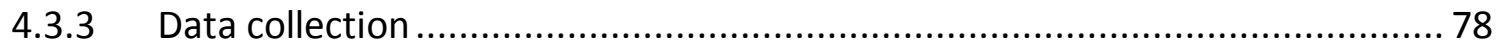

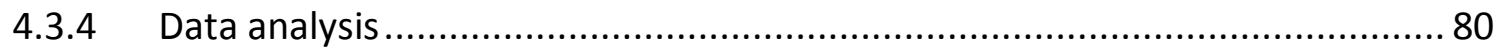

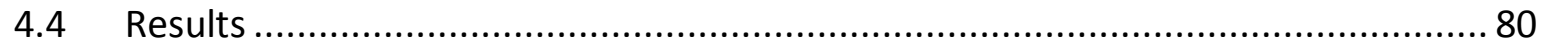

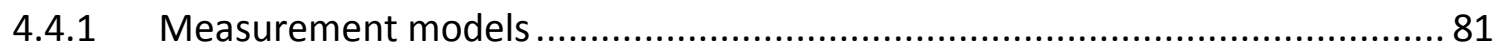

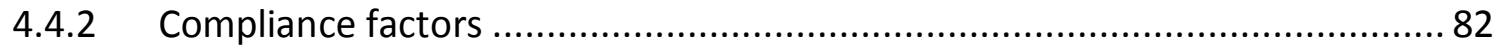

4.4.3 Structural equation models and model selection .................................... 85

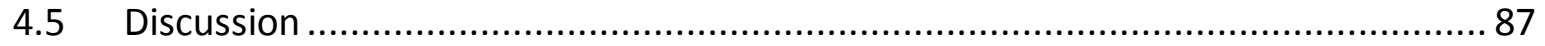

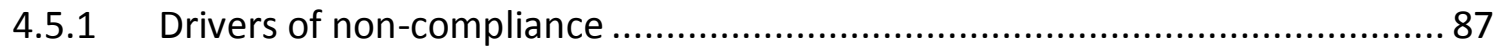

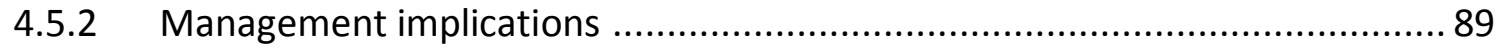

5 Managing the impact of fishery regulations on discard rates, compliance and fisher

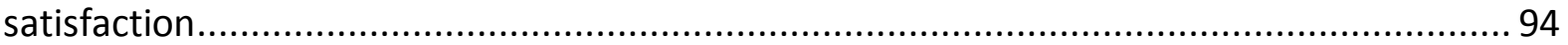

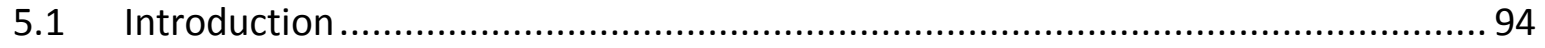

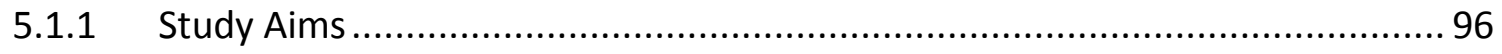

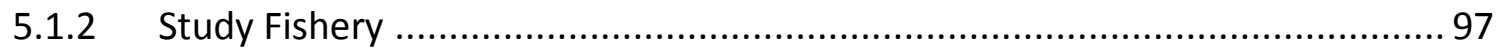




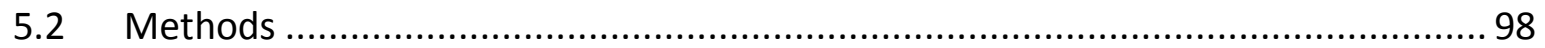

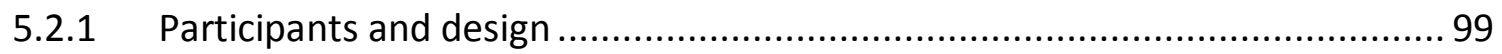

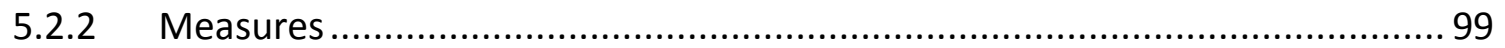

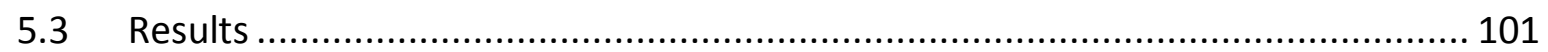

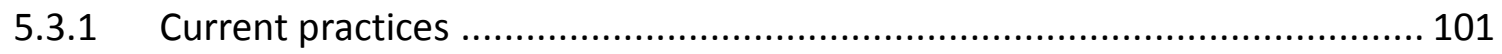

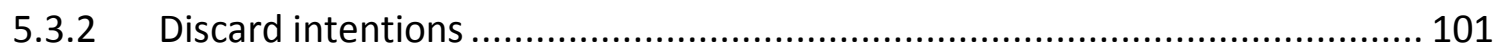

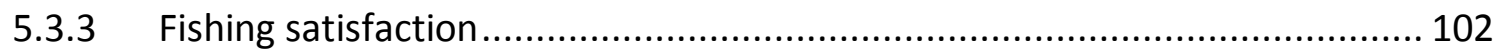

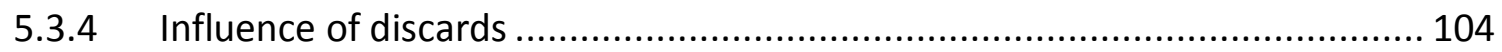

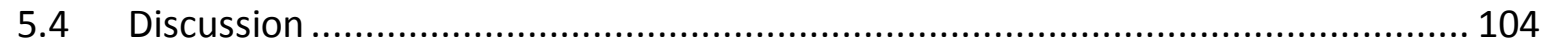

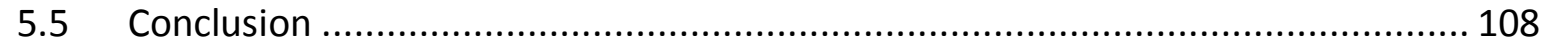

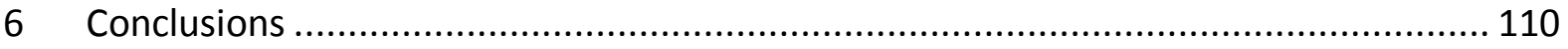

6.1 Objectives, major contributions and policy recommendations ......................... 111

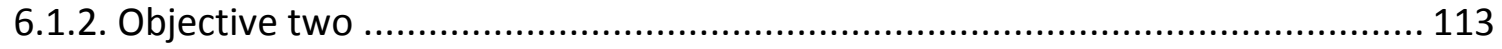

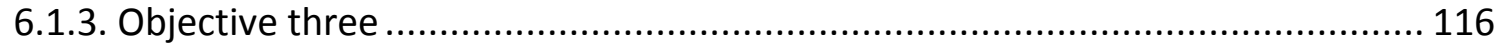

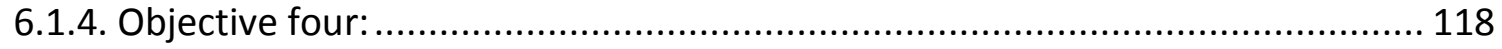

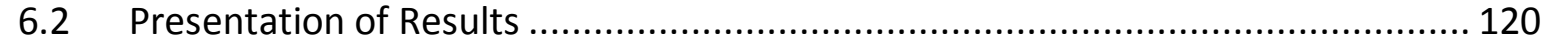

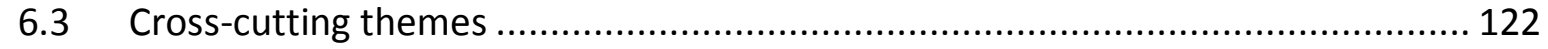

6.3.1 The value of researching fisher attitudes and behaviour ............................ 124

6.3.2 The current top-down management regime should be rethought................ 126

6.3.3 The need for targeted behavioural interventions in response to non-

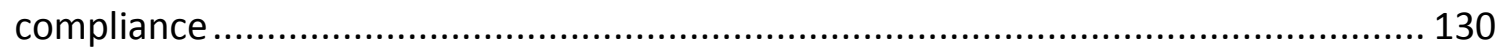

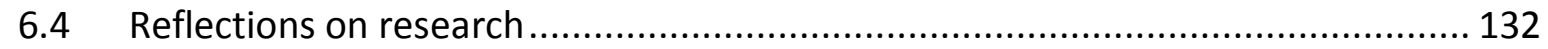

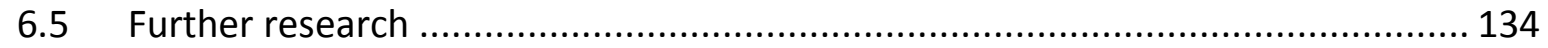

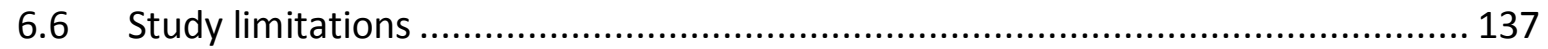

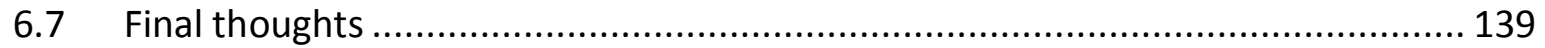

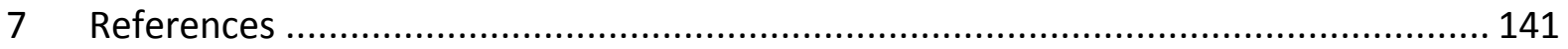

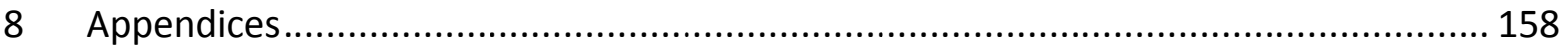

8.1 Management history of the Marlborough Sounds recreational blue cod fishery . 158

8.2 Blue Cod Management Group Code of Practice ............................................ 159

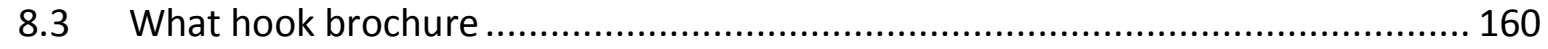

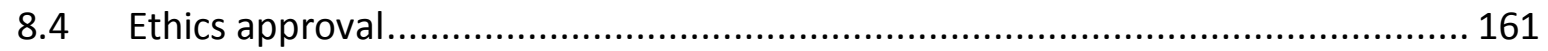

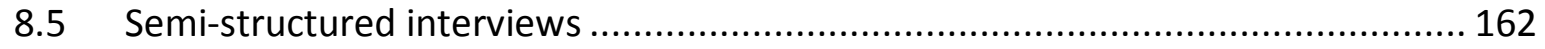

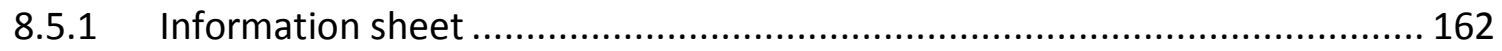

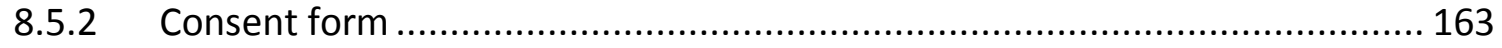

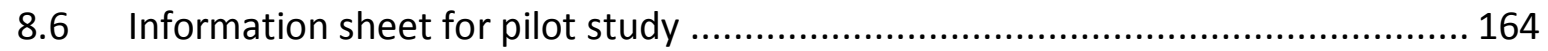

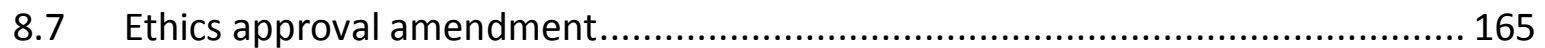




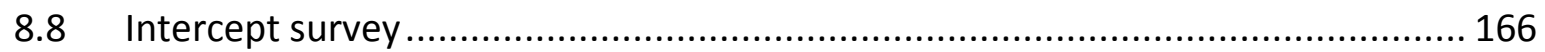

8.9 Measures used to predict compliance with blue cod fishing regulations ............. 167

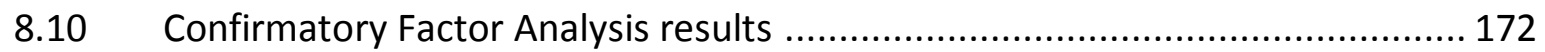

8.10.1 Fit indices for measures used to predict compliance: all regulations ............ 172

8.10.2 Fit indices for measures used to predict compliance: daily limit .................. 173

8.10.3 Fit indices for measures used to predict compliance: size limit ................... 174

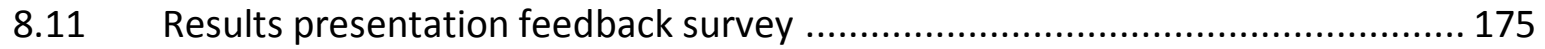

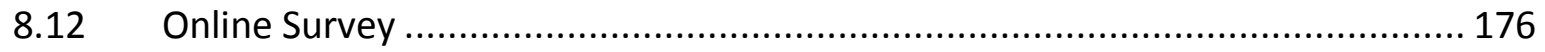




\section{Table of figures}

Figure 1-1: Map showing the location of the Marlborough Sounds, New Zealand.

Figure 1-2: Location of the Challenger East Management Area (dark blue) and Marlborough Sounds

(small light blue area).

Figure 2-1: Map showing the location of the four study sites in the Marlborough Sounds (shaded) . 39 Figure 2-2: Fisher satisfaction with the blue cod fishing regulations by: (a) local fishing experience and $(b)$ residency.

Figure 3-1: Map showing the location of the Long Island Marine Reserve (boxed) in the Marlborough Sounds.

Figure 3-2: A comparison of non-compliance estimates from three methods, Randomized Response

Technique (RRT), Item Count Technique (ICT) and direct questioning (DQ).

Figure 4-1: Model of pro-environmental behaviour from Bamberg and Möser (2007)

Figure 4-2: Fisher agreement with the five drivers of non-compliance that applied to both

regulations. 83

Figure 4-3: Distribution of scores for the regulation-specific drivers of non-compliance................... 85

Figure 4-4: Graphical output of the selected best-fitting model for fishers' compliance with the daily limit regulation. 86

Figure 4-5: Graphical output of the selected best-fitting model for fishers' compliance with the size limit regulation.

Figure 5-1: Changes in (a) discards and (b) fishing satisfaction levels under three experimental size limit scenarios for recreational blue cod fishing in the Marlborough Sounds. 103

Figure 6-1: Spectrum of fisheries management arrangements Error! Bookmark not defined. 


\section{Table of tables}

Table 2.1: Summary of statistical test results for between group differences of fishers' attitude, knowledge and influencing factors.

Table 2.2: Summary of structural equation models for variables predicting fishers' overall satisfaction with the blue cod regulations.

Table 4.1: Summary of the seven compliance models tested and the factors included in each model.

Table 4.2: Summary of model fit indices for the seven structural equation models to explain fishers' compliance with the daily and size limits for blue cod.

Table 6.1: Summary of policy recommendations for the Marlborough Sounds recreational blue cod fishery. 


\section{Introduction}

\subsection{The human dimensions of fisheries}

Fishing has been an important source of food and income for human populations for many centuries (Cowx 2002; Kaplan and McCay 2004). But despite the multiple benefits from fishing, the industrialisation of the last century has often led to the overexploitation of fisheries (Christensen 2011). Today fisheries across the world are in crisis (Food and Agriculture Organization of the United Nations 2012). They face issues including declining abundance, increased discards and by-catch of seabirds, marine mammals and non-target fish species, poor economic returns and ecosystem-level impacts (Hilborn 2007b), such as habitat degradation (Halpern 2003). In response to this, there is a growing recognition that the social and ecological aspects of fisheries management are linked (Berkes 2010) and to understand an ecosystem requires understanding not only what is being conserved, but also the perspective of who is to conserve that resource (Johannes 1978).

In addressing this issue fisheries researchers and managers have called for greater integration of human behaviour research into fisheries management (Hunt et al. 2013; Larkin 1978; Radomski et al. 2001; Royce 1983) as it currently does not receive sufficient attention (Fulton et al. 2011). They argue that human dimensions research is a vital component of management strategies and should be included from the start (Kaplan and McCay 2004), thereby increasing the capacity for improved decision making by managers (Enck and Decker 1997). As fish populations are tightly linked to fishers' actions, fisheries management should jointly addresses human (both fishers and non-fishers) behaviour in addition to conservation issues (Cowx et al. 2010). Human dimensions research can offer valuable information on fisher behaviour, perceptions, motivations, attitudes and well-being which can increase the level of compliance to fishery management regulations (Hunt et al. 2013; Kaplan and McCay 2004).

Since a fishery is essentially a "human phenomena" (McGoodwin 2006), to manage a fishery solely on the basis of biological, economic and ecological concerns yet disregarding the knowledge of the local fishers, is to risk failure (Granek et al. 2008; Jentoft and McCay 1995; McGoodwin 2006). Furthermore, in neglecting the connections between fishers and fish, and focusing only on biology, fisher responses to regulations are likely to be seen as 
externalities affecting the biologically focused management strategy (Arlinghaus et al. 2008), despite their actions playing a key role in the success or failure. The result has been a lack of sufficient focus on the social dimensions of fishery (Kaplan and McCay 2004). Although the fishery management regulations also affect the human communities, fishery managers are not normally responsible for managing any social, cultural and economic effects that may result (Kaplan and McCay 2004).

Some changes to the approach and direction of management strategies are thus urgently needed as researchers call for more "ecosystem based management", which acknowledges the links between the social and biological systems (Hall-Arber et al. 2009). There is a pressing need to integrate biological and social sciences with the aim of providing insights into the dynamics of the entire social-ecological system of recreational fisheries. This greater incorporation of lessons from the social sciences is needed to understand the human constraints on reconciling resource use and conservation (Arlinghaus 2004; Arlinghaus and Cooke 2009) and should be central to the management process (Kaplan and McCay 2004).

In light of these considerations, this thesis comprises human behaviour research exploring the human dimensions aspect of the recreational blue cod fishery in the Marlborough Sounds, New Zealand. More specifically, it will focus on fisher attitudes and behaviour with an emphasis on how they relate to non-compliance with management regulations in this fishery. This introductory chapter will start with an overview of why recreational fishing is an important field of research, why non-compliance in fisheries is an important management concern and how fisher participation in fishery government and management may influence non-compliance. The Marlborough Sounds blue cod fishery, its history and present management approach will be reviewed to provide background information. Finally, the four studies that comprise this thesis will be introduced.

\subsection{Introduction to recreational fishing}

Recreational fishing can be defined as the "fishing of aquatic animals that do not constitute the individual's primary resource to meet nutritional needs and are not generally sold or otherwise traded on export, domestic or black markets" (EIFAC (European Inland Fisheries Advisory Commission) 2008 p.21). Most of the research on fisher attitudes, 
behaviour and compliance has focused on the commercial sector. For example, despite numerous studies on compliance in commercial (Hønneland 2000; Sutinen et al. 1990) and artisanal (small-scale subsistence or commercial fishing with little technology) (Gelcich et al. 2009; Viteri and Chávez 2007) fisheries, there appears to be none in recreational fisheries. Similarly, recreational fisher attitude studies (e.g., Page and Radomski 2006; Sauer et al. 1997) comprise the minority of the literature. Nonetheless, recreational fishing is both widespread and growing in popularity in many countries (Arlinghaus and Cooke 2009). There has also been growing concern over the potentially significant ecological effects of recreational fishing (Coleman et al. 2004; Cooke and Cowx 2004; Post et al. 2002).

Today, recreational fishing is a popular leisure activity in which approximately $10.6 \%$ of the world's population participates (Arlinghaus and Cooke 2009), with an estimated range of 220 (World Bank 2012) to 700 million (Cooke and Cowx 2004) people. It is an important activity in $76 \%$ of the world's exclusive economic zones; and although recreational fishing is more wide-spread in high-income countries (Mora et al. 2011), the sector is growing in both popularity and economic importance in less developed regions (Arlinghaus and Cooke 2009; Coleman et al. 2004). Recreational fishing also generates relevant economic activity through the demand of goods and services to support the activity, with the economic benefits reviewed by Arlinghaus and Cooke (2009) and Weithman (1999). As an example, in South Australia the $31 \%$ of the population that fish at least once a year spend $\$ 350$ million annually on recreational fishing (South Australian Recreational Fishing Industry Review Committee (SARFIRC) 2001).

The recreational take of fish is usually underestimated or neglected (Christensen 2011), despite landings (the amount of fish harvested) potentially equalling or exceeding commercial take for popular species (Coleman et al. 2004). Annual exploitation rates (proportion of biomass taken through fishing) of over $50 \%$ have been reported in multiple recreational fisheries (Lewin et al 2006) with a rainbow trout fishery in Canada showing a maximum exploitation rate of 72 to $81 \%$ (Cox and Post 2002). Furthermore, as there are often more non-commercial than commercial fishers for certain species and/or areas, recreational users can have an equivalent or larger effect than commercial users (Eliason 1999). This has shown to be the case for certain fish species in areas such as California (Schroder and Love 2002) and Australia (McPhee et al. 2002). Cooke and Cowx (2004) even 
estimated that at the beginning of the $21^{\text {st }}$ century, the total worldwide recreational take was $14 \%$ higher than that of commercial fisheries. Similarly, in some instances recreational fisheries can also be far more extensive spatially even though less intensive per unit area (Mora et al. 2011). Finally, even after the halt of commercial fishing some fish species' populations fail to recover until recreational fishing is also stopped (Denny and Babcock 2004; Denny et al. 2003; Shears and Usmar 2006).

As the potential ecological effects from recreational fishing have been thoroughly reviewed elsewhere (Coleman et al. 2004; Cooke and Cowx 2006; Lewin et al. 2006), only a brief overview of some of these concerns is provided. Compared with commercial fishing, recreational fishing can have many of the same biological effects. However, it is more concentrated with a focus on the higher trophic levels that leads to changes in the structure, function and productivity of the entire ecosystem (Botsford et al. 1997; Friedlander and DeMartini 2002; Jackson et al. 2001; Myers and Worm 2003; Pauly et al. 2005; Vitousek et al. 1997). Ecological effects such as truncation of the size and age structure of the fish, lowered biomass and alterations to the community composition (Jouvenel and Pollard 2001; Westera et al. 2003; Young et al. 1999) may occur and selective exploitation of larger fish may result in lower reproductive success through evolutionary pressure (Jørgensen et al. 2007). Fish may also be targeted, intentionally or accidentally, during the reproductive period having negative consequences on individual fish fitness and the reproductive success of the species (Cooke et al. 2002). Another area of concern is that potentially billions of fish worldwide are caught and then released with the assumption that they will survive (Arlinghaus et al. 2007; Cooke and Cowx 2004). However, given that post-release mortality rates range from close to zero to over 90\% (Bartholomew and Bohnsack 2005), this assumption may not always be valid. Finally, even though there are no examples of recreational fishing alone leading to the extinction of a species (Arlinghaus et al. 2002), the collapse of several fisheries in Canada could be attributed to recreational fishing (Post et al. 2002) and there is still the possibility of significant population declines or other effects such as changes to the sex ratio (Lewin et al. 2006).

In New Zealand, many people regard fishing and gathering seafood as a vital part of their way of life (Ministry of Fisheries 2010c). Indeed, recreational fishing was the sixth most popular sport or recreational activity in $2007 / 2008$, with $~ 19.5 \%$ of the population 
participating (Sport and Recreation New Zealand 2009) and an estimated 25,000 tonnes of fish taken (Ministry of Fisheries 2014a); compared with 413,000 tonnes commercially (Seafood New Zealand 2014). Although recreational fishers have common property access rights to New Zealand waters, this does not guarantee unrestricted utilization. The Fisheries Act (New Zealand Parliament 1996) can be used to prohibit or restrict access rights (Flothmann et al. 2010). Even if access rights are secured, there are usually multiple regulations that fishers must follow: input-based regulations like bait restrictions or number of hooks, and/or output-based regulations such as quantity and size of different species fishers may keep. There may also be voluntary suggested best practices designed to minimise the mortality of discarded fish. These practices may include using a large hook, wearing wet gloves or using a wet rag to handle the fish and pinching or removing the barb on the hook (Ministry of Fisheries 2009). Even though recreational fishing regulations should not interfere with the recreational fishers' livelihoods in a strict economic sense, regulations that affect a 'way of life' (often for generations) can prove just as controversial (Taylor and Buckenham 2003).

\subsection{A new management approach?}

The increasing numbers of recreational fishers coupled with a greater awareness of both the scale and potential biological effects of this activity has led to calls for more effective management strategies (Arlinghaus and Cooke 2009). Historically, central government agencies have been primarily responsible for managing the world's fisheries (Berkes 2010), but their continued depletion has demonstrated the frequent failings of this approach (Arlinghaus and Mehner 2005). In the majority of cases governments have either failed to halt population declines (Froese and Proelß 2010) or exacerbated the depletion (e.g., Nussman et al. 2005). The former was the case in Canada with the infamous cod collapse (Finlayson and McCay 1998; Hutchings and Myers 1994); when the government ignored warnings that Northern Cod stocks were overestimated. By the time quotas were reduced it was too late and in 1994 the fishery was at less than $5 \%$ of the 1990 level (Mason 2002). A review of the status of 90 marine stocks (Hutchings 2000) showed that for many of the fisheries (including cod, haddock and flatfishes) there was little or no recovery even after 15 years and that $41 \%$ of the stocks had continued to decline. A conventional topdown approach to management, in which the government controls the process, may also be 
viewed as insensitive to both the fishers and their communities (Burton 2003; Grafton and Lane 1998). Fishers are usually not quick to accept government intervention, especially when it does not "make sense in the way they see their problem, know their industry, and have learned to understand nature" (Jentoft et al. 1998 p. 434). Fishers often demand a 'real' voice in the management because they have little confidence in the government's management ability (Jentoft and McCay 1995; Nielsen and Vedsmand 1997) and, in commercial and artisanal fisheries, depend on the resource for their livelihood.

The goal of a management strategy should be not only to conserve the fish stock, but to also fulfil the normative obligations of equity, fairness and trust to the stakeholders (Jentoft 2000). However, under the top-down approach, fisher input and agreement is often not asked for nor considered (Jentoft et al. 2010). Case studies of fisheries where the management system is failing are normally characterized by debated scientific advice (between fishers, managers and/or scientists), inadequate communication between user groups, and high levels of non-compliance with the imposed regulations (Rice and Connolly 2007). This has led to a "near universal" call for the top-down approach of fisheries management to be reviewed (e.g., Jentoft et al. 1998; Sharp 1997; Townsend 1995) and increasing interest in community-based management of fisheries (Berkes 1989; Schlager and Ostrom 1992). Indeed, most researchers now contend that stakeholder involvement is a critical component of successful management (Fulton et al. 2011) and that governments can and should involve fishers in a meaningful way (Plinkerton 1989).

Greater fisher involvement can enable fisheries managers to make use of fishers often-detailed knowledge of the fishery including: the time and place fish species are usually caught, stock structure, spawning grounds and juvenile habitat, catch rate and details of spatial or other changes in fishing effort and practices (Johannes and Neis 2007), seasonal fluctuations in species abundance, distribution of different ecosystems and resource use (Smith 1994 as cited in Wells and White, 1995). Involving fishers enables the inclusion of this information when designing management strategies and can help ensure a more ecologically sound management approach (Jentoft et al. 1998). As regulation effectiveness is one of the factors that can influence compliance behaviour (Hønneland 2000), governments would do well to make use of such knowledge (Mackinson 1998). 
There are also further advantages to increasing fisher participation, including: promoting community ecosystem development, helping equalize fisheries allocations, decreasing excessive investments by fishers in new technology, and reducing conflicts between the government, scientists and fishers (McGoodwin 2006; Plinkerton 1989). It can also help address one of the biggest challenges in fisheries management, the implementation and enforcement of regulations (Rosenberg 2007). Successful fisheries management necessitates a high level of compliance with the regulations, which usually does not hold true (Muth and Bowe 1998; Sullivan 2002); potentially undermining the effectiveness of management strategies (Sullivan 2002). For example, a minimum size limit is designed to protect juvenile fish. However, if fishers still take this size fish then recruitment (fish reaching a certain size or reproductive stage) into the fishery is compromised with not enough young fish entering the population. A participatory and legitimate policy making process offers the highest likelihood of a sustainable fishery (Mora et al. 2011) as high levels of voluntary compliance can counteract low levels of enforcement (Castilla and Defeo 2005). Experience suggests that fishers are more likely to follow regulations that they have assisted in designing (Jentoft 1989) as compliance and participation are frequently linked (Smith et al. 1997).

However, fisher participation alone does not guarantee the success or legitimacy of a management regime and not all forms of participation will be viewed as legitimate (Wilson and McCay 1998). For example, governments can choose to consult with user groups, but may still decide to disregard the advice or recommendations received. Sometimes the consultation is used only as a symbolic gesture to appease fishers (Jentoft and McCay 1995; Wilson and McCay 1998) or to legitimize a new regulation (Silver and Campbell 2005). There is also the quandary of which stakeholder groups are represented, how well their members are represented and who decides which groups are involved (Jentoft 1989). A comanagement approach (where fishers share responsibility with the government for managing the fishery) may fail because of social (e.g., too much disagreement among stakeholders) and institutional (e.g., lack of management of commitment) factors, not because of the principle behind the approach (Jentoft et al. 1998). Reasons for failure can include difficulties with participating stakeholders reaching agreement or inadequate representation (Costanza et al. 1998). 


\subsection{The problem of regulation non-compliance}

Illegal, unreported and unregulated fishing is one of the leading causes of fisheries management failures worldwide (Boonstra and Bach Dang 2010; Sutinen et al. 1990). It is also an important area of fisher behaviour to understand as even low levels of noncompliance can undermine the effectiveness of the management regime (Sethi and Hilborn 2008) and there is a pressing need for more information on rule-breaking behaviour (Wellsmith 2011). However, regulation non-compliance can be a sensitive subject (Gavin et al. 2009; Solomon et al. 2007). The number of violators caught is usually only a small proportion (Elffers et al. 2003) of the actual number and other estimation methods such as logbooks and permits may not always be accurate as they are easily modified (Gavin et al. 2009). Recreational fisheries also present further difficulties due to the large areas fished and number of participants, a lack of reporting obligations and a wide range of fishing practices (McCluskey and Lewison 2008). Without access to accurate non-compliance estimates, evaluating the effectiveness of a regulation and prioritising management responses to non-compliance is challenging. Although a greater consideration of fisher attitudes can offer insights into which regulations may be frequently violated (Kuperan and Sutinen 1998; Viteri and Chávez 2007), new methods for obtaining estimates of noncompliance are needed. Several indirect techniques have been developed and some even tested in fisheries (Blank and Gavin 2009; St John et al. 2010); but the overall results on their effectiveness are mixed.

More information on fisher attitudes and behaviours relating to non-compliance is urgently needed in order to move beyond the usual response of increasing enforcement and/or penalties (fines, loss of license). This approach risks further alienating fishers and is also expensive, in terms of both human and financial resources (Keane et al. 2008). Targeted interventions to address the issue of non-compliance are also not possible without a greater understanding of fisher attitudes. Nonetheless, understanding the drivers of regulation noncompliance is not straightforward as there are a multitude of potential factors (e.g., regulation knowledge, probability of detection, the behaviour of other fishers) as well as several competing behavioural models (e.g., economic, normative) that are detailed in chapter four. 
Historically a fisher's compliance decision was viewed as a calculated evaluation of the potential benefits and risks (Al-Subhi et al. 2013; Kuperan and Sutinen 1998). Yet recent studies have demonstrated that numerous factors besides self-interest (e.g., moral norm, participation in the management process) govern fisher behaviour (Gezelius and Hauck 2011; King and Sutinen 2010). Understanding why fishers comply with a regulation is important if the fisheries management wishes to encourage fishers to voluntarily comply with the regulations instead of being 'forced to' out of fear of discovery and/or sanctions. Chapter four provides a detailed account of compliance theory, which has been well researched in commercial fisheries, even though there are only a few studies in recreational fisheries (e.g., Page and Radomski 2006).

\subsection{Thesis aim and objectives}

To help answer these questions, research is needed on recreational fishers, their actions and subsequent outcomes. Understanding and predicting the behaviour of fishers is another important area of enquiry since "fisheries management is $10 \%$ biological resource management and 90\% people management" (Fulton and Adelman 2003 pg. 4). The present research seeks to help fill this gap by exploring the human dimensions aspect of the current blue cod management regime in the Marlborough Sounds, New Zealand. Specifically, this case study explored fisher attitudes towards and compliance with several of the regulations governing recreational blue cod fishing. The study objectives and results have implications for a more participatory management regime, although that type of management model was not a focus of this thesis research. Instead, the results of the studies draw conclusions supporting the calls for a shift towards greater fisher participation, as detailed in section 1.3.

The four study objectives are:

(1) Explore how factors such as fishing experience, region of residency, effect of regulations on fishing habits and participation in the management process influence fisher knowledge of and satisfaction with regulations.

(2) Compare the effectiveness of the randomized response technique, item count technique and direct questioning in estimating non-compliance with the daily and size limits for blue cod, as well as a nearby marine reserve in the Marlborough Sounds. 
(3) Test alterative models of drivers of non-compliance with the two main regulations for blue cod and identify the largest influences on a fisher's compliance behaviour.

(4) Evaluate the potential for improving compliance with the size limit through minimizing discards and maximising fisher satisfaction.

\subsection{Thesis case study}

In New Zealand, there has been very little research into the human dimensions aspect of fisheries, despite its importance as a commercial and recreational activity (Sport and Recreation New Zealand 2009). In particular, the Marlborough Sounds recreational blue cod (Parapercis colias) fishery provides a timely case study in this area of inquiry. As with most important New Zealand fisheries, there exists substantial biological data (e.g., Beentjes and Carbines 2005a; Blackwell 1998, 2009) on the species including abundance, movement patterns, habitat, age and growth. Many of these biological studies have been carried out in the Marlborough Sounds (Beentjes and Carbines 2012; Blackwell 2002; Cole 1999; Davidson 2001).

However, there appears to be only one human dimensions-related piece of research (Batstone et al. 2009). Carried out by a private research institution, the report aimed to characterise the Marlborough Sounds recreational fishers. In addition to gathering sociodemographic information, their study also looked their values (i.e., what constitutes a good fishing trip) and motivations (i.e., to catch fish for a meal) for fishing in the Sounds. Relevant findings included that the most important motivations for fishing were: for relaxation, to share experiences with other people, to be outdoors and for family recreation. Similarly, fishers were most likely to agree with statements such as: "I would rather catch one or two big fish then ten small fish", "a fishing trip can be worthwhile even if no fish are caught", but had mixed opinions on "the more fish I catch, the happier I am" and disagreed that a "worthwhile fishing trip is one in which many fish were caught" (Batstone et al. 2009 p. 22).

The following section will explain why the Marlborough Sounds blue fishery was selected for this research, as well as provide an introduction to the Marlborough Sounds region and the blue cod. This fishery is an excellent opportunity to undertake social science research for the following reasons: 
(1) As well as being an important commercially fished species (Ministry of Fisheries 2014a), blue cod is one of the most popular recreational fisheries (Ministry of Fisheries 2011b), making effective management crucial.

(2) The Marlborough Sounds blue cod fishery in particular suffers from an extremely high level of recreational fishing pressure (Cole et al. 2000) and is therefore tightly regulated with a complex suite of regulations. However, high amounts of anger and frustration from fishers surround the current management approach (Bell 2014b; Moore 2012).

(3) A severe decline in the blue cod population caused the fishery to be temporarily closed in 2008. Such closures are usually an acknowledgement that the management has failed (Gell and Roberts 2003; Roberts 1997; Worm et al. 2006). Although the Marlborough blue cod fishery has since been reopened, it can be argued that a change in management strategy is needed to prevent a recurrence.

(4) The government has signalled its intention to review the management strategy later in 2014 after the results of a stock survey are available (Bell 2014b). However, basing the review solely on biological information risks ignoring an important component of the fishery (fisher behaviour) and may not be sufficient to ensure its future.

(5) A more participatory approach to management will have a greater chance at success when the spatial extent of fishing effort and fish distribution are limited (Jentoft et al. 1998), criteria which the Marlborough Sounds recreational blue cod fishery meets as the management area is clearly defined by the area's geology.

\subsubsection{Blue cod}

The blue cod (Parapercis colias) is a bottom-dwelling fish species endemic to New Zealand. They can grow over $50 \mathrm{~cm}$ in length, weigh up to four $\mathrm{kg}$ (Carbines 2004) and live for 20 to 30 years (the maximum recorded is 32) (Paul 2000). Blue cod was a significant species in the traditional Māori catch of pre-European times and is still taken under customary allowance (Carbines 2000). The species has also been commercially fished since 1900 (Rapson 1956) with annual landings between 1000 and 1500 tonnes (t) from 19301970 (Carbines 1999a). But in the 1970s, landings declined between 500 and 600t before increasing again in the mid-1980s (Paul 2000). More recently, in 2012/2013 2200t were caught, out of the 2681t Total Allowable Catch (TAC) (Ministry of Fisheries 2014a). Blue cod 
are also highly sought-after by amateur fishers: it is the second most commonly landed recreational fish species in New Zealand and the most common on the South Island (Ministry of Fisheries 2001).

This slow-growing fish (Blackwell 1998) normally inhabits reef edge habitats (Cole et al. 2003), light foul (reef edges, shingle/gravel, and biogenic structures) or sand close to rocky outcrops shallower than 150m (Paul 2000). Blue cod are voracious and opportunistic carnivores, feeding on invertebrates and other fish (including juvenile blue cod) (Jiang and Carbines 2002; Paul 2000). Male blue cod grow faster and to a larger size than females (Carbines 1998b), with a range of factors influencing fish growth; including sex, habitat quality and fishing pressure relative to location. Size-at-maturity also varies with location. For example, in the Marlborough Sounds maturity is reached at $21-25 \mathrm{~cm}$ at an age of three to four years (Rapson 1956); but in Southland it is at $28 \mathrm{~cm}$ and six years for females and $26 \mathrm{~cm}$ and four years for males (Carbines 2004). Reproduction occurs annually with an extended spawning period during late winter and spring (Rapson 1956).

Blue cod are protogynous hermaphrodites; they begin their lifecycle as a female and at some point are triggered (internally or externally) to change sex to male. Generally the sex change starts after $30 \mathrm{~cm}$ but the removal of large males from the population (i.e., from fishing) can accelerate this natural change (Beentjes and Carbines 2005b). Males usually dominate areas experiencing higher fishing pressure, such as the Marlborough Sounds, by a 2:1 ratio. In comparison, two relatively less fished areas in New Zealand have both larger and more abundant blue cod, along with a more balanced sex ratio, even favouring females at times (Beentjes and Carbines 2005b). The average size and abundance of blue cod populations also declines with increased fishing intensity (Beentjes and Carbines 2012). For example, blue cod present in the Long Island Marine Reserve in the Marlborough Sounds were on average four $\mathrm{cm}$ longer than those in adjacent, fished areas (Cole et al. 2000). This can also affect the reproductive potential of the population as larger fish produce more batches of eggs (Crossland 1977; Zeldis and Francis 1998). Blue cod are also highly territorial with most remaining in the same area (100 $\mathrm{m}$ to one $\mathrm{km}$ ) for most of their life (Carbines 2004; Carbines and McKenzie 2004; Cole et al. 2000; Mace and Johnston 1983).

Even though commercial potting or lining does not catch juvenile blue cod, they are still vulnerable to trawlers (Carbines 1999a) and recreational fishers, especially those that 
do not use large enough hooks. Habitat modification (oyster dredging, trawling) (e.g. Carbines et al. 2004; Jiang and Carbines 2002) can also affect blue cod. Jiang and Carbines (2002) showed that blue cod in areas recently dredged by the oyster fishery or in areas that showed little sign of recovery had a less varied diet than blue cod living in more complex, recovering habitat. Another study on blue cod habitat changes (Carbines et al. 2004) found that more complex habitats were also home to a greater abundance of fish that were also $20 \%$ larger on average. Dredging for both scallops and oysters occurs in the Marlborough Sounds on a commercial scale (Keeley et al. 2009; Ministry for Primary Industries 2014), potentially negatively affecting the blue cod fishery.

The blue cod is not unique in being negatively affected by habitat degradation but its biological characteristics put this species under increased risk of overexploitation. The blue cod's slow growth, small range and hermaphroditic nature mean they are subject to localised depletion, especially from heavy fishing pressure (Bradford 1998; Teirney et al. 1997). This has been the case in the Marlborough Sounds (Blackwell 2002), where there is intense fishing pressure over a relatively short time period. The extended spawning season also makes it challenging to implement seasonal closures during this critical time. Overall, these biological characteristics mean blue cod is likely to need more active management than other recreationally-fished species, even in the same area. This in turn increases the information requirements, both biological and social, needed for effective and comprehensive management of the fishery.

\subsubsection{Marlborough Sounds blue cod fishery}

The Marlborough Sounds is a deep series of drowned river valleys situated at the northeast end of the South Island, New Zealand (Carbines 2000) (Fig. 1.1) covering over 500,000 ha (Marlborough District Council 2014). The area comprises two major sounds: Queen Charlotte Sound bounded to the east by Arapawa Island, and Pelorus Sound bounded to the west by D'Urville Island. Both Sounds have complex coastlines and provide a variety of habitats from sheltered reefs to exposed rocky coasts and offshore islands (Carbines 2000). 


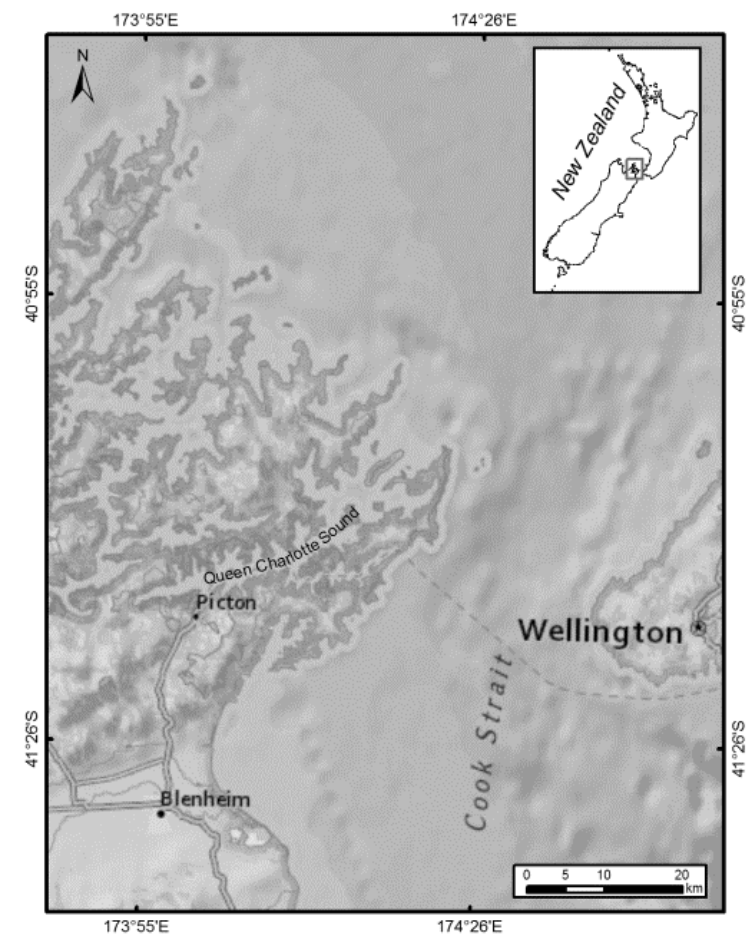

Figure 1.1: Map showing the location of the Marlborough Sounds, New Zealand.

Although the Marlborough Sounds is part of blue cod quota management area BCO7/Challenger Area (Fig. 1.2), it has different, stricter recreational limits for blue cod than the rest of this area. Within New Zealand, this fishery is also unique in that recreational fishers, as opposed to commercial fishers, catch the majority of the blue cod. Out of the 343 tonnes Total Allowable Catch for the Sounds blue cod fishery in 2010, only 70t was for commercial fishers, as opposed to $177 \mathrm{t}$ for recreational fishers (Ministry of Fisheries 2014a). 


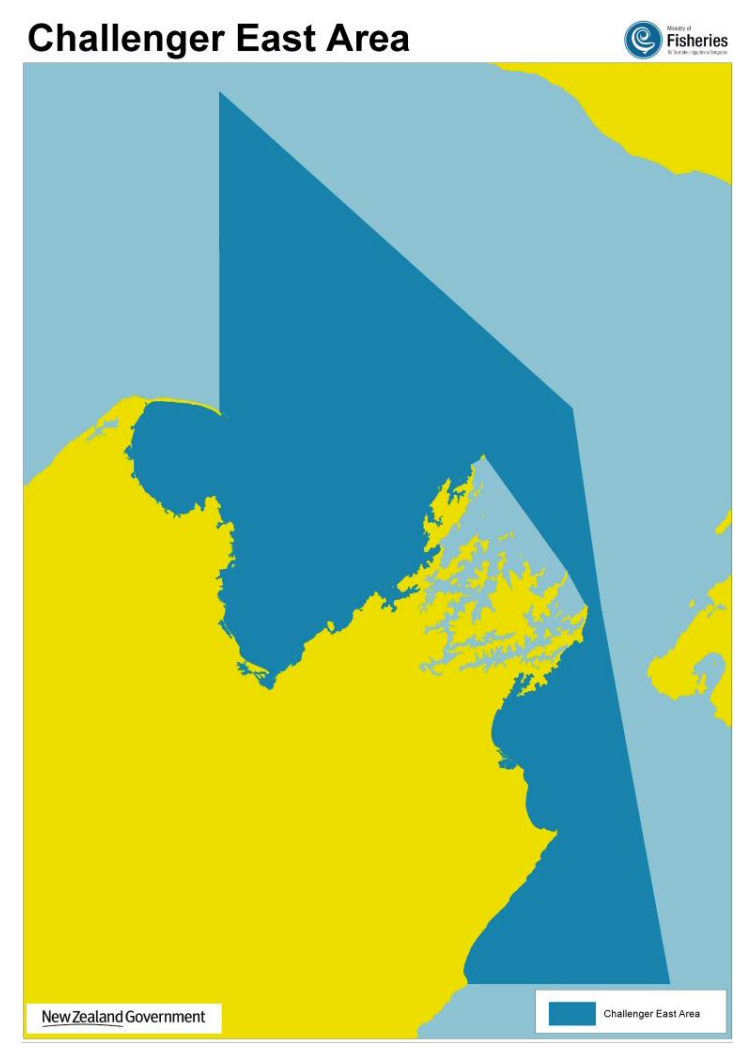

Figure 1.2: Location of the Challenger East Management Area (dark blue) and Marlborough Sounds (small light blue area). From http://www.fish.govt.nz/NR/rdonlyres/95E5A7C8-BE65-49BO-ADA7-4D6182BFB377/0/Marlborough_Sounds_Area_Map_final.pdf

Commercial fishing of blue cod in the Marlborough Sounds is confined to a small but regionally significant fishery in the outer Marlborough Sounds; there has not been any commercial fishing in the inner Sounds for 50 to 60 years (Blackwell 2002; Henderson 2009). This is a voluntary agreement rather than a formal exclusion, with commercial fishers agreeing to leave this area for recreational fishers. Despite the lack of commercial fishers, the fishing pressure from recreational fishers can be intense, especially in January (Cole et al. 2000). The warm climate, sheltered and accessible nature of the Marlborough Sounds, coupled with excellent fishing opportunities, has made it a popular destination for both holidays and fishing. A 2009 report (Batstone et al. 2009) estimated the number of fishers at over 9000 for summer $2008 / 2009$. There has also been expansion of the three local marinas, new holiday homes and a $40 \%$ increase in trailer registration in the region and nearby between 1993 and 2003 (Ministry of Fisheries 2008a). Furthermore, recent years have also seen technological advancements: the boats are larger and more sophisticated with GPS and fish finders (Ministry of Fisheries 2008a). These changes have led to increased pressure on the local fishery, particularly for the blue cod. 
Catch per unit effort (CPUE) data from 1995/1996 showed proportionally lower numbers in the inner Marlborough Sounds and proportionally higher in the outer Sounds (Blackwell 1998). Furthermore, a continued decrease from the extreme inner to extreme outer Pelorus Sound indicated localised depletion from higher fishing pressure closer to the land (Blackwell 1998). A 1998/1999 stock survey showed that the outer Sounds had significantly higher numbers of male blue cod than the inner Sounds, presumably because the larger male fish are more likely to be taken by recreational fishers (Blackwell 1998; Carbines 2000).

\subsubsection{Management history}

As far back as a 1973 to 1976 survey, the decreasing size of Marlborough Sounds blue cod was apparent, compared with 1938/1939 data (Beentjes and Carbines 2005b). Because of the concentrated fishing pressure and its previously discussed implications, the Sounds regulations have been regularly modified in order to sustain the blue cod population (Appendix 1). In 1986 the Minimum Legal Size (MLS) for blue cod caught in the Marlborough Sounds was $30 \mathrm{~cm}$, with each person allowed to keep 12 a day (Daily Bag Limit or $\mathrm{DBL}$ ), a decrease from 20 the year before.

More changes came in 1993 when the MLS was increased to $33 \mathrm{~cm}$ and the DBL dropped to 10. However, recreational fishers voiced concerns about the number of undersized blue cod discarded, while trying to catch a legal-sized fish, and their survival rate (believing these small fish had a high mortality rate). In response to these concerns, further changes were made just a year later with the MLS decreased to $28 \mathrm{~cm}$ and the DBL dropped to six (Carbines 1999b). The new limits lasted almost ten years. But 2003 National Institute of Water and Atmospheric Research (NIWA) data showed the Sounds blue cod population had declined by 50\% between 1995-1996 and 2001 (Blackwell 2006). An increase in the MLS (to $30 \mathrm{~cm}$ ) and $\mathrm{DBL}$ reduction (to three) followed the release of this data.

Nonetheless, a 2007 study by NIWA (Blackwell 2009) showed that these reductions had failed to both stop the decline and start the population's recovery. In particular, the data showed a 57\% decline in juvenile blue cod since 2004. Furthermore, the data pointed to a complete lack of blue cod of any size within the Inner Queen Charlotte Sound. In response to this, in March 2008 the Ministry of Fisheries opened consultation on a variety of 
measures aimed at halting the blue cod population decline in the Marlborough Sounds. These included (Ministry of Fisheries 2008c):

- Temporary closures of parts of the Sounds to all hook and line fishing for at least three years

- Further reduction of the daily bag limit from three to two blue cod per person per day, the introduction a daily boat limit of six blue cod and restricting fishers to only one daily bag limit, even on multi-day trips

- Requiring fishers to land all blue cod whole or gutted so fish can be easily measured by fisheries officers

- A requirement for fishers to retain all blue cod at or above the minimum legal size of $30 \mathrm{~cm}$, to a maximum of two fish per person/day, and then move to target other species or stop fishing (to prevent high-grading)

- Strengthening and formalising voluntary agreements with commercial fishers to prevent targeting of blue cod in large areas of the Queen Charlotte and Pelorus Sounds

Other measures proposed by the local stakeholder group SoundFish were (Ministry of Fisheries 2008d):

- Limiting all hook and line fishers to one hook per line and use of only large hooks $(6 / 0)$ or greater to avoid catching juvenile blue cod

- Setlining to use large hooks of size $10 / 0$ or greater

- Amending the boundaries of the Marlborough Sounds to include Croisilles Harbour to the west and Port Underwood to the east (to prevent depletion in nearby popular fishing areas)

In their initial position paper (Ministry of Fisheries 2008c) the Ministry noted that the previous regulatory measures had all failed to reduce the recreational fishing pressure on blue cod to sustainable levels. This suggested that stronger measures were necessary, leaving few options besides the proposed temporary area closures. The next month over 300 recreational fishers attend two public meetings organised by a local fishing 
organization. Attendees challenged the results of the NIWA studies, with many fishers saying there were plenty of large blue cod. Fishers also questioned the rushed nature of the consultation, with less than six weeks between the announcement and the close of submissions (Option 4 2008) and that paper copies of the proposal were not readily available (Ministry of Fisheries 2008d).

In all, over 1000 submissions were received on the subject. Common issues raised by fishers included: inadequate consultation, a need to lower the discard rate (rather than limiting the take), lack of acknowledgement of the potentially significant levels of predation by shags and seals, and ignoring local knowledge on this subject. From the numerous stakeholders, the proposal was mainly met with strong negative reactions. Although some submitters agreed that 'urgent' or 'drastic' action was needed, there was opposition to most of the suggested measures including reducing the bag limit (not necessary as there were plenty of cod, previous reductions had not been effective), the boat limit (six was too low and unfair to many fishers as they would not be allowed their DBL) and temporary closures (blue cod not in serious enough trouble to stop fishing for other species, a good idea but rotational closures would be better) (Ministry of Fisheries 2008d). Several groups also mentioned that implementation of these proposals should be matched by a reduction in the fishery's commercial catch.

Finally, there was concern over the Ministry's approach to targeting only recreational fishing. Individual stakeholders and organisations noted that terrestrial activities, such as land use changes resulting in sedimentation, nutrient-runoff, erosion and pollution, as well as aquaculture operations in the Sounds (salmon and mussel) could have a significant effect on blue cod habitat (Ministry of Fisheries 2008d). Although acknowledged in the position paper, no steps were taken to address these causes as the Ministry viewed them as having a negligible effect, especially compared with recreational fishing. Despite the strong opposition to the proposal, on 3 July 2008, the Minister of Fisheries announced the closure of the Marlborough Sounds blue cod fishery for the next four years: October 2008-October 2012. This ban prohibited recreational fishers from taking blue cod from anywhere within the enclosed Marlborough Sounds Area. Fishing for other species was still allowed but any blue cod caught had to be returned to the water immediately (Ministry of Fisheries 2008b). 
Less than a year later, in May 2009, the new Minister of Fisheries (from another political party) announced the ban would end "sooner rather than later". The announcement was met with relief by local fishers and business owners (Orman 2009) as the ban was extremely unpopular. The Minister set up the Blue Cod Management Group (BCMG) and charged the group with drafting a management plan for the Marlborough Sounds blue cod fishery that would allow it to reopen ahead of the initial four-year closure. This group was comprised of six members of the Marlborough/Nelson community representing the interests of recreational fishers. In late August 2010 the group's draft plan for managing the Sounds blue cod population was released for public consultation (Blue Cod Management Group 2010). The three goals of their plan were: (1) Rebuild localised blue cod populations in depleted areas, (2) Prevent further depletion of localised populations, and (3) Provide for amateur use of fishery without compromising long-term sustainability. Specifically, their plan put forth eleven recommendations:

1. Restrict fishers to two hooks per line,

2. Set the DBL to two blue cod per person per day,

3. Implement a maximum daily boat limit of ten blue cod for all vessels,

4. Allow accumulation of only two daily bag limits for blue cod,

5. Increase the MLS to $33 \mathrm{~cm}$,

6. Introduce a maximum legal size (MaxLS) of $45 \mathrm{~cm}$ to protect large fish-a $12 \mathrm{~cm}$ 'slot' in total,

7. Close the Marlborough Sounds to recreational blue cod fishing 1 September to 30 January each year (during spawning),

8. Establish a no-take zone for finfish around Maud Island (a scientific reserve) to provide a protected spawning ground,

9. Require all amateur fishers targeting/taking blue cod to possess a fishing permit,

10. All blue cod must be kept whole or gutted in order to facilitate easy measurement by compliance staff,

11. Extend the Marlborough Sounds boundaries.

Once again there was varied support for the different recommendations. The majority of submissions expressed support for the decreased daily bag limit (Ministry of Fisheries 2010a) but charter boat operators warned that adoption of these proposals, especially the 
DBL of two, would force them to go out of business (Howie 2010). Although two thirds of submissions were supportive of the idea of the seasonal closure, many expressed concern over the timing as many fishers can only visit during the December-January summer holidays (Ministry of Fisheries 2010a). In April 2011 the fishery reopened with a suite of new regulations:

- $B C M G$ recommendations \#1, 2, 5, 8 and 10 were adopted as recommended.

- No accumulation of the DBL is allowed (\#4).

- The MaxLS, \#6, was set at $35 \mathrm{~cm}-\mathrm{a} 5 \mathrm{~cm}$ 'slot' in total, as the science suggested the majority of blue cod fell into the 25 to $35 \mathrm{~cm}$ range.

- Recommendations numbers 3,9 and 11 were not adopted in any form.

- Number 7, the closed season, was changed to 1 September to 19 December every year as to not exclude fishers who can only visit during the December-January holidays.

These regulations are valid for the whole Marlborough Sounds fishery zone (Fig. 1.2) (Ministry of Fisheries 2011a). Additionally, the two fish limit applies to the possession of blue cod inside the Marlborough Sounds, regardless of where they were caught, as there is no available test to determine the origin of the fish (Ministry of Fisheries 2008a). This regulation is normally referred to as the 'transit rule'. In addition to these legal requirements, a Code of Practice (Appendix 2) was also developed to educate fishers on how their fishing practices could help ensure the survival of any discarded fish. Similarly, a "Which Hook" poster (Appendix 3) was also prepared in order to encourage fishers to use the best type and size of hook to catch their preferred species of fish.

Even though these regulations have been viewed as an improvement on the ban, they still have not been without complaint (Nicoll 2012a). The largest source of frustration is over the 30 to $35 \mathrm{~cm}$ 'slot rule' as many fishers struggle to catch two cod that are small enough to keep and have to throw back more than ten fish in order to get one within the slot (Moore 2012). The fate of these discarded fish is what worries and frustrates many fishers (Thomas, unpublished field notes) as if not properly caught and handled, many of these fish will die upon being returned to the water (Bartholomew and Bohnsack 2005; Carbines 1999b; Powell et al. 2011). Additionally, shags and barracouta often prey on the 
discarded fish (Ministry of Fisheries 2008d). Because of these concerns, many fishers view the slot rule as doing more harm than good (Thomas et al. 2014b). Despite these frustrations, the current Minister of Fisheries has announced the regulations would not be reviewed until results of a 2014 stock assessment are available, possibly not until 2015 . The Minister has stressed a need to continue making decisions on the best science available to him (Moore 2012), currently the results of the 2010 blue cod survey. The most recent biological data show that the adult blue cod biomass in the areas closed to fishing had increased since 2007 but that pre-recruit (blue cod $<30 \mathrm{~cm}$ ) biomass in most of these same areas has remained at low levels or continued to decline (Beentjes and Carbines 2012).

In light of these fisher concerns and the continued decline of the blue cod population, a more participatory approach that includes the human dimensions is worth consideration. The four studies comprising this thesis can supplement the forthcoming biological data and assist, if desired, in employing a more integrated management approach. Specifically, the results will provide robust measures of fisher attitudes and behaviour that can be used to assess effectiveness of rules. As the success of the current management approach is somewhat constrained by compliance with the regulations, more information on fisher attitudes and behaviour would be beneficial as they can be key factors in fishers compliance decisions. Finally, surveying fishers on their views on the management regime could help alleviate some frustrations with the current approach, and their lack of involvement, by providing a forum to express their views on the regulations.

\subsection{Thesis structure}

This thesis provides an insight into several of the human dimensions aspects of the current Marlborough Sounds blue cod management regime. It explores several facets of fishers' attitudes and behaviour, complementing the already available and forthcoming body of biological information on this fishery. The bulk of the thesis is covered in four core chapters. Each chapter is presented as a stand-alone study, either published or to be published as a journal article. As there are multiple authors for the papers, clarification on the role of the authors is needed: I was responsible for the designing the studies, data collection and analysis, and manuscript writing. My supervisors, Taciano Milfont and Michael Gavin, provided advice and comments on the chapter drafts. 
- Chapter two, recently published in Marine Policy (Thomas et al. 2014b): This chapter focuses on two of the regulations unique to this fishery, the requirement to keep blue cod whole or gutted, while at sea, and the transit rule. In particular this study examines fisher knowledge of and satisfaction with these two regulations as these factors can influence compliance decisions (Kuperan and Sutinen 1998; Martin 1995). The influence of fishing experience and region of residency on these variables is explored along with other factors such as influence of the regulations on fishing habits and participation in the management process.

- Chapter three, recently published in Biological Conservation (Thomas et al. 2014a): Non-compliance with regulations can negatively affect the success of a fisheries management strategy (Gigliotti and Taylor 1990; Sethi and Hilborn 2008). However, estimating non-compliance can be challenging due to the sensitive nature of the subject (Gavin et al. 2009) and the nature of recreational fishing (e.g., no permits) only increases this challenge (McCluskey and Lewison 2008). Indirect techniques such as randomized response and item count have shown potential in providing higher and more accurate estimates of non-compliance than traditional direct questioning. Chapter three compares these three methods in estimating noncompliance with the two main blue cod regulations, the daily and size limits, and the nearby marine reserve.

- Chapter four: The estimates of rule violations from chapter three, although important, are still only a first step in addressing the problem of regulation noncompliance. There are increasing calls for more research into the drivers of noncompliance (Robbins et al. 2006) as identifying these can be used to increase voluntary compliance with the regulations. Chapter four utilises the estimates of non-compliance from the previous chapter to examine what instrumental (e.g., probability of detection) or normative (e.g., guilt) factors are the largest drivers behind non-compliance with the daily and size limits for blue cod in the Marlborough Sounds. This is done via structural equation modeling using a range of factors from several disciplines.

- Chapter five, under review for ICES Journal of Marine Science: Not all caught fish are kept and even low mortality rates of the discarded fish have the potential to 
undermine the effectiveness of the regulations and affect the sustainability of the fishery (Coggins et al. 2007; Douglas et al. 2010). The final study in the thesis uses a scenario approach in a between-group experimental design to evaluate three different size limits, the current and two alternatives (fisher-suggested), in terms of both fisher satisfaction and minimizing the amount of fish discards. The aim was to determine how compliance with the size limit could be increased, while addressing the need to maintain a more balanced sex ratio, through minimising discard and increasing fisher satisfaction.

- Chapter six: Finally, the concluding chapter brings together all four studies and reviews the contribution of the human dimensions research to the Marlborough Sounds blue cod fishery. It also discusses practical applications of the results and what, if any changes, to the current management strategy are suggested by this research. 


\section{What determines fishers' knowledge of and attitudes towards regulations?}

\subsection{Introduction}

There is growing recognition that social and ecological factors are linked, ultimately determining the resilience of fisheries (Ludwig et al. 1993; Silver and Campbell 2005). In particular, fishers' knowledge of, and positive attitudes towards the regulations, are critical for fisheries management and conservation efforts (Fisher 1997). Awareness of regulations can significantly influence fishers' decisions to comply (Martin 1995; Schill and Kline 1995), as the effectiveness of a rule is limited by an individual's knowledge and understanding of it (Keane et al. 2011). For example, Pierce and Tomcko (1998) suggested that much of the $29 \%$ non-compliance rate for five Minnesota lakes was due to a lack of awareness of the applicable regulations, while Page and Radomski (2006) found that fishers less aware of the regulations were more likely to be non-compliant among multiple fisheries. Fisher attitudes can also affect compliance behaviour, with even low levels of non-compliance potentially undermining the management regime's effectiveness (Gigliotti and Taylor 1990; Sethi and Hilborn 2008). Negative attitudes may also reflect fishers' perceptions of the legitimacy of key regulations, which can affect the probability of non-compliant behaviour (Kuperan and Sutinen 1998; Viteri and Chávez 2007). In support of this, Page et al. (2004) observed that fishers' negative attitudes towards regulations were strongly associated with noncompliance.

Despite their importance, the key factors shaping fishers' knowledge of regulations and attitudes are often poorly understood and frequently not taken into consideration. Knowledge and attitudes are shaped by a complex web of variables, including local fishing experience, area of residency, satisfaction with the fishery resource, how regulations influence fishing practices and involvement in the management process. For example, more experienced fishers tend to exhibit greater regulation knowledge as do fishers living near the regulated area as they have had more exposure to the rules (Page and Radomski 2006; Schill and Kline 1995). Fishers that are satisfied with the fishing may be more likely to hold positive views on the regulations (Richardson et al. 2005), as are those that are the least affected by them (Pita et al. 2013). In addition, many studies have suggested that greater 
fisher participation in the management process can greatly increase regulation knowledge and agreement (Jentoft and McCay 1995; Jentoft et al. 1998; van Hoof 2010).

\subsection{Study aims}

This study investigated the degree to which five factors influence fisher knowledge of and satisfaction with the regulations of the blue cod fishery in New Zealand's Marlborough Sounds: residency, fishing experience, regulation influence on fishing practices, satisfaction with the fishery, and perceptions on participation in the management process. Although the Ministry of Fisheries has commissioned multiple reports on the scientific state of the fishery (Beentjes and Carbines 2012; Blackwell 1998, 2002; Carbines 2000), there has yet to be any research on the social dimensions of the current management regime, as well as limited research on this subject in New Zealand in general. This is despite widespread calls to learn how fishers view the regulations (Eggert and Ellegård 2003).

Within the fisheries literature, previous studies on fisher attitudes have mostly focused on commercial fisheries (Foster and Vincent 2010; Pita et al. 2013; Richardson et al. 2005). Similarly, although the effects of participation in the management process have been widely studied in commercial fisheries (Pita et al. 2010; Viteri and Chávez 2007), there appears to be a lack of research in the context of recreational fisheries. Prior investigations into fishers' knowledge of regulations in recreational fisheries have been carried out in the United States (Page and Radomski 2006; Pierce and Tomcko 1998; Schill and Kline 1995) or South Africa (Brouwer et al. 1997; Sauer et al. 1997). The South African studies investigated both regulation knowledge and satisfaction by region, but did not test for significant differences or explore the factors shaping knowledge and attitudes. The relationship between regulation and knowledge was the focus of the United States studies with only one of them (Page and Radomski 2006) examining the influence of socio-demographic variables on that knowledge. There has also been comparatively little research into how regulation influence on fishing practices and satisfaction with the fishery may affect fisher attitudes.

Previous studies have produced contradictory results regarding the role of different factors in influencing fisher knowledge and attitudes towards regulations. For example, while several studies found both residency and fishing experience to be a significant 
influence on regulation awareness in recreational fisheries (e.g., Page and Radomski 2006; Schill and Kline 1995), Pita et al. (2013) found neither to be significant (in a commercial fishery) but showed that the least affected fishers were the most positive. Similarly, Richardson et al. (2005) found experience did not significantly influence fishers' attitudes, whereas Peterson and Carothers (2013) concluded that experience affected attitudes towards changing fishing practices. Another study found that fishers with greater psychological, social and monetary investments in the fishery are likely to voice the strongest opinions in response to management changes (Bryan 2000) supporting the influence of residency. While there is a general consensus that stakeholder participation in the management process is a common feature in management regimes that are succeeding (Fulton et al. 2011), the nature of the participation may influence how it is viewed and its effectiveness in increasing both knowledge and satisfaction (Pita et al. 2010). Even when fishers are involved in the management process, the degree of participation may vary. At one end of the spectrum there is true co-management but in other cases while the fishers are consulted, the final decision-making power rests solely with the government (Jentoft and McCay 1995). Furthermore, groups of fishers may disagree on the most effective way to sustain the fishery (Jentoft and McCay 1995), so limited consultation risks some fishers feeling uninvolved.

\subsection{Material and methods}

\subsubsection{Survey design and purpose}

Following piloting of the survey instrument in October 2012 a nine-question intercept survey (Appendix 8) focusing on the transit and filleting rules was designed. The first question asked fishers to rate their overall satisfaction with the suite of regulations governing recreational blue cod fishing in the Marlborough Sounds. Respondents then rated their satisfaction with blue cod fishing for both 2011 (the year the fishery reopened) and 2012 (the year prior to this study). Responses to these initial questions were on a 5-point Likert scale from 1 (very dissatisfied) to 5 (very satisfied).

For the transit and filleting rules, fishers were first asked whether they correctly knew these rules - "If you go fishing in the Cook Strait are you allowed to bring back more than two blue cod per person/day?" (Transit rule) and "Is the filleting of blue cod at sea 
allowed?" (Filleting rule) - by answering yes, no (the correct answer for both), or do not know. If an incorrect answer was given, the fisher was informed of the correct answer before proceeding. Following the knowledge question a fisher's attitude towards the rule was assessed by asking whether or not they agreed with it ("yes" or "no").

Respondents were also asked how much influence the blue cod regulations had on their fishing in the Marlborough Sounds, which was rated on a 5-point scale ranging from 1 (no influence) to 5 (strong influence). Fishers were then asked if they had previously heard of the Blue Cod Management Group and, if yes, an open-ended question of what they thought the group's purpose was or what the group had achieved in the past was also answered. Finally, respondents were asked how many years they had been fishing in the Marlborough Sounds and which region they lived in. The 14 options for area of residence were taken from the New Zealand census. Apart from these questions, any additional information offered, either to qualify a response or in general, was written down. Fishers were asked for clarification if any comments were unclear but otherwise the interviewer recorded everything while assuring fishers that their concerns were being taken seriously in this research.

\subsubsection{Data collection}

Potential respondents were approached and invited to take part in a short face-toface survey on blue cod fishing. Fishers were approached at the three marinas in the Marlborough Sounds (Waikawa, Picton and Havelock), as well as Waikawa Bay (Fig. 2.1). Waikawa Marina is the second largest marina in New Zealand (600 berths) and the main launching point for the Queen Charlotte Sound. Picton Marina is smaller (232 berths) but has a larger proportion of commercial and charter boats in the berths than Waikawa. Havelock Marina (340 berths), located in the small township of Havelock, is the main launch location for the Pelorus and Kenepuru Sounds. Waikawa Bay is a small, enclosed bay in the Queen Charlotte Sound and popular recreation area with a beach, swimming, picnic areas, barbeques and a launching ramp. Launching from this site costs only $\$ 5$, compared with $\$ 15$ at the marinas but there are no berths. 


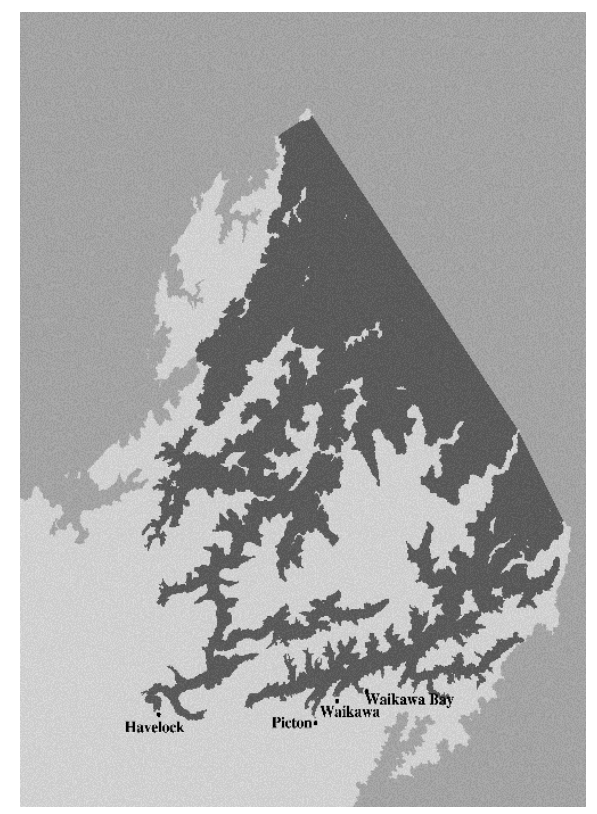

Figure 2.1: Map showing the location of the four study sites in the Marlborough Sounds (shaded) New Zealand map sourced from LINZ (Crown Copyright reserved) and Marlborough Sounds map modified from Ministry of Fisheries 2011(a).

Face-to-face surveys were carried out over six weeks in January and February 2013, during the time of the highest fishing effort in the Marlborough Sounds. The survey took place every day when fishers were expected to be out (i.e., not when it was raining heavily or too windy). Fishers using the launching ramps at each site were surveyed only upon return in order to avoid asking them twice in a day. If it was not obvious they had been fishing (i.e., the presence of fishing rods), it was asked if they went fishing in the Marlborough Sounds. In order to avoid response bias, only one person from each fishing boat was surveyed, usually the husband (in the case of families) or the person nominated by the rest of the fishing party.

\subsubsection{Data analysis}

Region of residence was divided into two groups: Marlborough or all of the other 13 regions. Based on distribution years of fishing experience in the Sounds was divided into five groups (i.e., 1-9 years, 10-19 years, 20-29 years, 30-39 years or 40+ years) in order to allow comparisons between groups. For ANOVA post-hoc, Gabriel's procedure was used as sample sizes were slightly different across groups (Field 2009). To minimise Type 1 error, a Bonferroni correction of 10 was applied to post-hoc tests for experience, with the new criterion for significance $\alpha=0.005$. When the Chi Square requirement of cells with an expected count of at least five was not met, a Fisher's exact test was used instead. 
The responses were manually coded for the question on the Blue Cod Management Group's role and then the coding confirmed with a member of the BCMG. The response 'manage the blue cod fishing stock' was viewed as too easily determined from the group name and did not necessarily indicate knowledge of the group's role. Acceptable answers included one or more of the following: working and/or consulting with the Ministry, developed the rules (although not strictly true), published a brochure on 'suggested best practices', a lobby group, or a group representing fishers. All additional comments were analysed using NVivo and coded for eleven themes: regulations, transit rule, filleting rule, daily limit, slot rule, discards, ban, closed season, influence, responsibility, and enforcement. If a comment related to multiple themes, it was coded under all those applicable.

\subsection{Results}

Out of the 313 fishers approached, 311 agreed to participate in the intercept survey ( $99 \%$ response rate). $89 \%$ were male and $56 \%$ resident in the Marlborough area and had an average of $21.6(S D=16)$ years local fishing experience. Table 2.1 provides a summary of the overall results by the two considered socio-demographic groups, with post-hoc results summarised in text. 
Table 2.1: Summary of statistical test results for between group differences of fishers' attitude, knowledge and influencing factors.

\begin{tabular}{|c|c|c|}
\hline & Local fishing experience & Region of residency \\
\hline $\begin{array}{l}\text { Overall regulation } \\
\text { satisfaction }\end{array}$ & $F(4,299)=7.01, w^{2}=.07^{* * *}$ & $t(284.39)=-4.11, \mathrm{~d}=-.47^{* * *}$ \\
\hline Regulation influence & $F(4,298)=3.58, \underline{u}^{2}=.03^{* *}$ & $t(307)=2, d=.23^{*}$ \\
\hline $\begin{array}{c}\text { Fishing satisfaction } \\
2011 / 2012\end{array}$ & $F(4,217)=.252$ & $t(221)=-2.62, d=.37^{* *}$ \\
\hline $\begin{array}{l}\text { Transit rule: } \\
\text { knowledge }\end{array}$ & $X^{2}(8)=19.90, \emptyset=.19^{*}$ & $X^{2}(2)=.64$ \\
\hline $\begin{array}{l}\text { Transit rule: } \\
\text { agreement }\end{array}$ & $X^{2}(4)=4.87$ & $X^{2}(1)=14.24, \emptyset=-.22^{*}$ \\
\hline $\begin{array}{l}\text { Filleting rule: } \\
\text { knowledge }\end{array}$ & $\begin{array}{c}\text { Fisher's Exact }(8)=17.86, \\
\emptyset=.17^{*}\end{array}$ & $X^{2}(2)=12.24, \emptyset=.20^{* *}$ \\
\hline $\begin{array}{l}\text { Filleting rule: } \\
\text { agreement }\end{array}$ & $X^{2}(4)=9.71, \varnothing=.18^{*}$ & $X^{2}(1)=.96$ \\
\hline BCMG awareness & $X^{2}(4)=11.14, \emptyset=.19^{*}$ & $X^{2}(1)=5.34, \emptyset=.13^{*}$ \\
\hline BCMG knowledge & $X^{2}(4)=7.90$ & $X^{2}(1)=.32$ \\
\hline
\end{tabular}

\subsubsection{Overall satisfaction with the blue cod regulations}

Fishers reported a negative level of satisfaction with the blue cod regulations $(M=$ $2.47, S D=1.39$ ), as the mean score was significantly lower than the middle (neither satisfied nor dissatisfied) of the response scale $(t(310)=-6.78, p<.001, d=0.39)$. Qualitative comments made by the fishers during the survey also supported this finding. To illustrate, some fishers expressed feelings of frustration and anger by calling the rules "poorly conceived", "completely stupid" and "shocking and ridiculous". The size limit was particularly contentious even though it was not specifically asked about; with many of the fishers citing the size limit as the reason behind their low satisfaction with the regulations.

Post-hoc comparisons (Fig. 2.2) indicated that local fishing experience influenced differences in satisfaction level between two groups: the most experienced fishers $(M=$ $1.78, S D=1.25)$ were significantly less satisfied with the regulations than the least experienced fishers $(M=2.99, S D=1.35, p<.001)$. Additionally, fishers living in the Marlborough Region had a lower level of satisfaction $(M=2.19, S D=1.31)$ than those fishers living outside Marlborough $(M=2.83, S D=1.40, p<.001)$. 


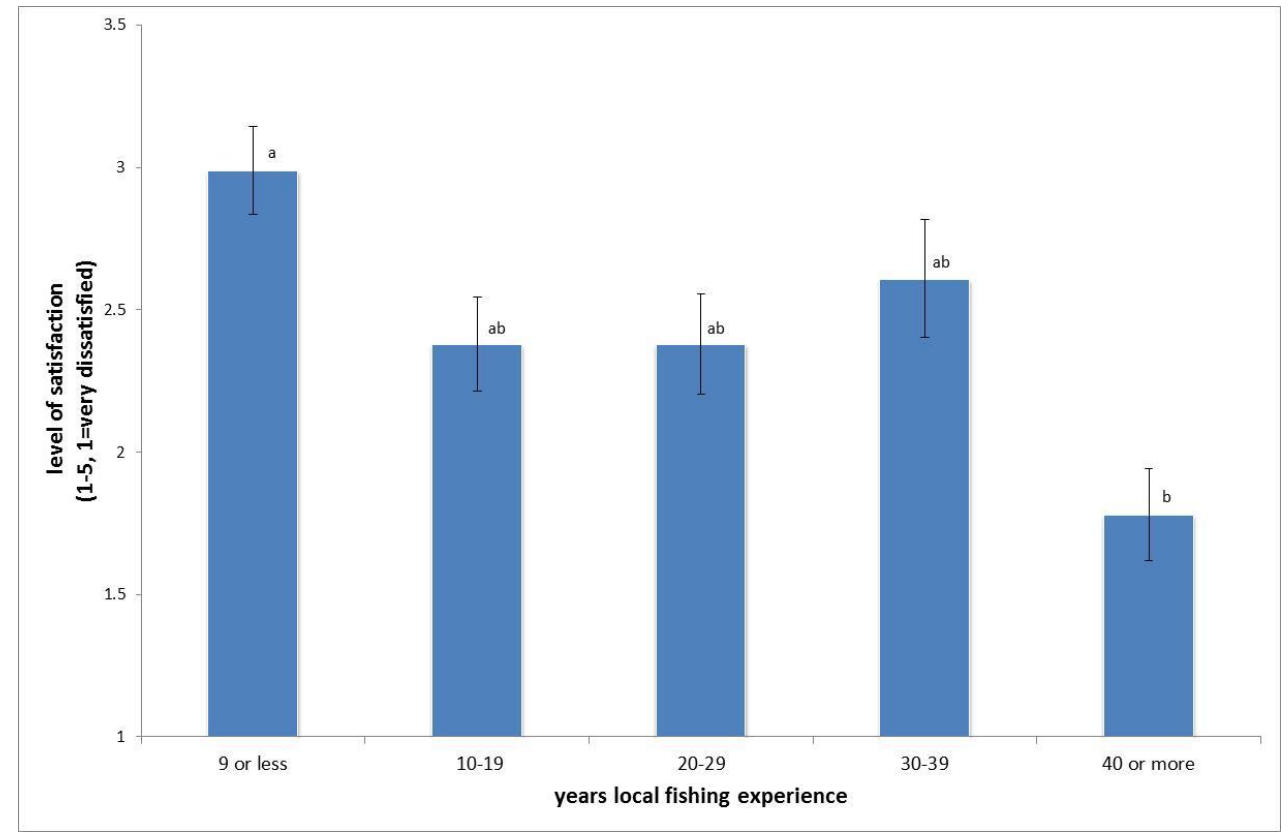

b

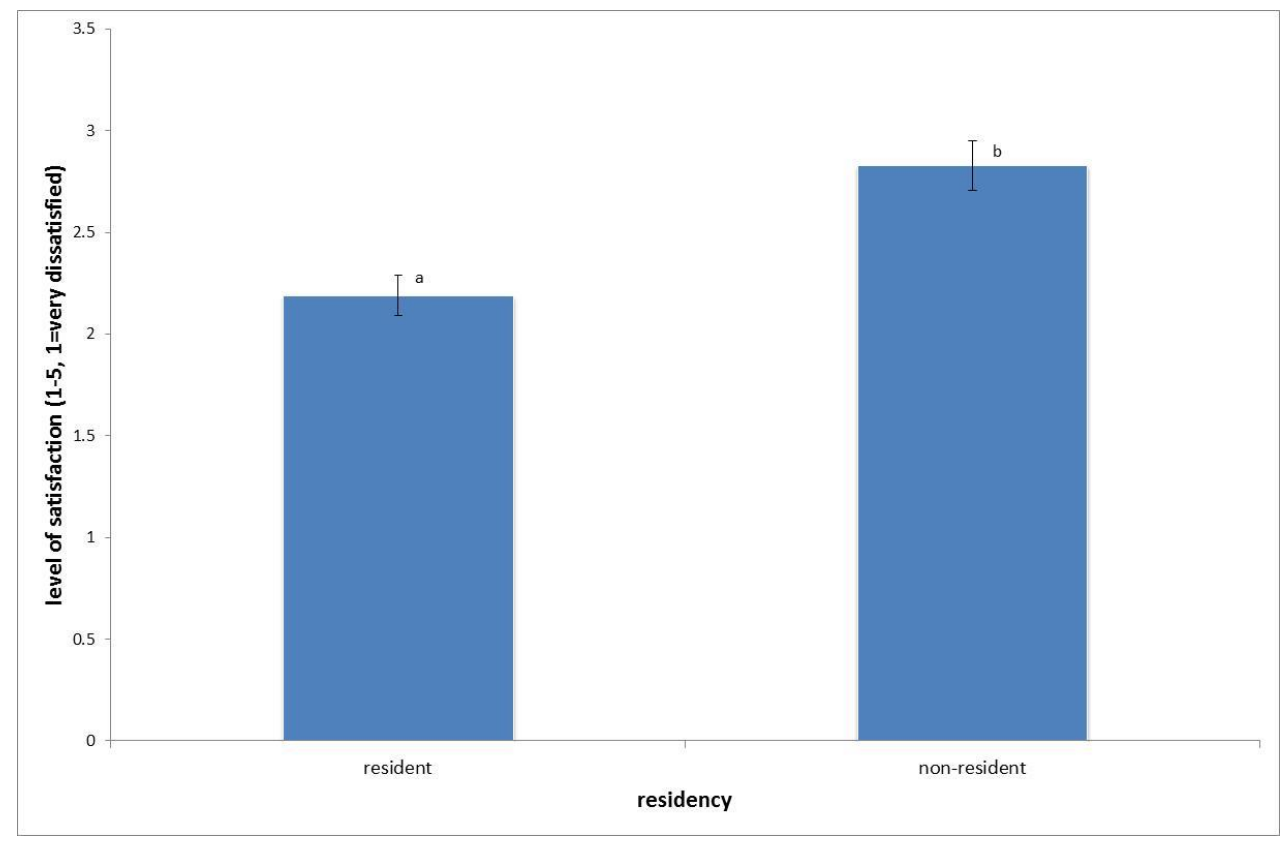

Figure 2.2: Fisher satisfaction with the blue cod fishing regulations by: (a) local fishing experience and (b) residency. Different letters indicate significant differences between levels of satisfaction

\subsubsection{Regulation influence on fishing habits}

Fishers reported that overall the blue cod regulations did influence $(M=2.38, S D=$ 1.49) their fishing habits, $t(309)=4.53, p<0.001, d=0.42$ ) and Marlborough-based fishers $(M=2.53, S D=1.55)$ perceived a greater influence than fishers from other regions $(M=$ $2.19, S D=1.39)$. Additionally, fishers with fewer than 10 years of experience $(M=2.07, S D=$ 
1.46) viewed the blue cod regulations as having less of an influence than fishers with 40 or more years of experience $(M=2.98, S D=1.47)$.

In answering this question, many fishers stated that the transit rule had a strong, negative influence on their fishing experience. Since the reopening of the Sounds, it no longer made sense for them to spend the time and petrol to go outside the Sounds to fish when they were still bound by the same limits as fishers within the Marlborough Sounds. Conversely, other fishers reported that the rules had little influence on their fishing habits, as they owned a holiday home, which was their primary reason for visiting the Sounds. Some of these fishers stated that they now went fishing for blue cod elsewhere in New Zealand where the regulations were less restrictive.

\subsubsection{Satisfaction with the blue cod fishing in 2011 and 2012}

There was no statistically significant difference in satisfaction across the two years ( $t$ $(223)=-0.51, p=0.610$ ) so satisfaction ratings for both years were combined for further analyses. Overall, the fishers were marginally satisfied $(M=3.20, S D=1.15)$ with the blue cod fishing itself in 2011/2012 ( $t(223)=2.65, p=0.009, d=0.18)$; as many fishers commented that they were able to usually take home their limit of blue cod. Region of residency was the only socio-demographic variable influencing satisfaction with the blue cod fishing in 2011/2012. Marlborough-based fishers were less satisfied $(M=3.06, S D=1.20)$ than non-Marlborough fishers $(M=3.46, S D=0.99)$ with the blue cod fishing across both years.

\subsubsection{Transit rule}

Significantly more fishers correctly answered the question on transit rule knowledge (60\%) than incorrectly (23\%) or did not know $(17 \%), X^{2}(2)=104.65, p<0.001$. Post-hoc analyses revealed that fishers having less than 10 years of experience were more likely (Std. Residual = 3.1) to answer 'don't know' than fishers with more experience. Significantly more fishers (66\%) disagreed with the transit rule than agreed with it $(34 \%), X^{2}(1)=28.85, p<$ 0.001 . However, results revealed that only region of residency significantly influenced transit rule agreement. Marlborough-based fishers were less likely to agree with the transit rule $(75 \%$, Std. Residual $=-2.0)$ than non-Marlborough fishers $(54 \%$, Std. Residual $=2.3)$. 
Many of the fishers who did not know about the rule commented that they did not go fishing outside the Marlborough Sounds area. While some of the fishers recognised the necessity of the transit rule in assisting with enforcement, larger issues with the rule seemed to outweigh this consideration. Specifically, many fishers viewed the transit rule as unfair to Sounds fishers, as Wellington-based boats fishing in the Cook Strait were allowed to take back larger sizes and numbers of blue cod as there is no equivalent rule for them. Based on these concerns fishers referred to the transit rule as "daft", "ridiculous", or "a joke".

\subsubsection{Filleting rule}

In response to the question on knowledge of the filleting rule, $92 \%$ correctly answered "no", compared with "yes "(5\%) or "did not know" $(3 \%), X^{2}(2)=475.96, p<0.001$. In particular, non-Marlborough fishers were more likely to answer 'don't know' (Std. Residual $=2.2)$. More fishers agreed with the filleting rule $(71 \%)$ than disagreed with it $\left(X^{2}(1)\right.$ $=55.54, p<0.001)$. Comments by the fishers revealed that most of them recognised the filleting rule as "the only way" for effective enforcement of the size limit and several commented it was "fair enough". Moreover, it was mainly viewed as no more than a minor inconvenience as it did not significantly affect their fishing habits.

\subsubsection{Blue Cod Management Group (BCMG)}

The fishers were evenly split on whether or not they had previously heard of the Blue Cod Management Group $\left(X^{2}(2)=0.03, p=0.865\right)$. Of the 154 fishers responding they had previously heard of the Group, only $49(34 \%)$ provided accurate details on the BCMG's role $\left(X^{2}(1)=145.88, p<0.001\right)$.

Among the fishers who had heard of the BCMG, correct knowledge of the group's role had no influence on awareness of $\left(X^{2}(2)=3.12, p=0.210\right)$ or agreement with $\left(X^{2}(1)=0.48\right)$, $p=0.491$ ) the transit rule. Similarly, there were no statistically significant differences for awareness of $\left(X^{2}(2)=2.01, p=0.366\right)$ or agreement with the filleting rule $\left(X^{2}(1)=0.42, p=\right.$ 0.516). Finally, overall satisfaction with the blue cod regulations was also not influenced by knowledge of the group $\left(X^{2}(4)=6.22, p=0.183\right)$. Conversations with the fishers revealed that many of them perceived the BCMG is nothing more than a token gesture by the 
Ministry in response to calls for greater fisher involvement and that the new regulations were pre-determined.

\subsubsection{Modeling fishers' overall satisfaction}

Finally, five structural equation models were formed to examine the main predictors of fisher's overall satisfaction with the blue cod regulations (Table 2.2). As previous analyses had revealed no significant differences among groups for agreement with the filleting rule or knowledge of the BCMG, these two variables were excluded from the models. The first model considered the two socio-demographic variables previously analysed, residency and local fishing experience. Model 2 consisted of the other two predicting factors, influence on fishing habits and satisfaction with the fishing itself. The third model added transit rule agreement to the first model (residency and local fishing experience), while model 4 included transit rule agreement in addition to influence on fishing habits and satisfaction with the fishing. The final model included all five predictor variables. For this analysis local fishing experience was included as the original continuous variable.

An information-theoretic approach with the Akaike information criteria (AIC) was used in model evaluation to compare the fit and parsimony of the different models (Burnham and Anderson 2002). Out of the five models considered, the first model could be considered the best fit as it had the lowest AIC and the $\triangle$ AIC was more than 4 for the next best option (model 2), which explained the same amount of variance (0.10). Model 1 also had the highest CFI (0.94) of the five models. Of the two variables considered in this model both were significant, with experience a larger predictor of overall satisfaction $(b=-0.24$, $p<.001)$ than residency $(\beta=-0.21, p<.001)$. Fishers who had limited local fishing experience and were not residents of the Marlborough Area expressed greater overall satisfaction with the blue cod regulations. 
Table 2.2: Summary of structural equation models for variables predicting fishers' overall satisfaction with the blue cod regulations.

\begin{tabular}{lcccccccc}
\hline & $\mathbf{X}^{\mathbf{2}}$ & $\mathbf{d f}$ & $\mathbf{X}^{\mathbf{2}} / \mathbf{d f}$ & $\mathbf{C F I}$ & $\mathbf{R M S E A}$ & $\mathbf{A I C}$ & $\boldsymbol{\Delta A I C}$ & $\mathbf{R}^{\mathbf{2}}$ \\
\hline Model 1 & 2.85 & 1 & 2.85 & 0.94 & 0.08 & 18.85 & - & .10 \\
Model 2 & 7.63 & 1 & 7.63 & 0.79 & 0.15 & 23.63 & 4.78 & .10 \\
Model 3 & 7.80 & 2 & 3.90 & 0.91 & 0.10 & 31.80 & 12.95 & .13 \\
Model 4 & 10.86 & 3 & 3.62 & 0.85 & 0.09 & 32.86 & 14.01 & .16 \\
Model 5 & 18.40 & 7 & 2.63 & 0.89 & 0.07 & 58.40 & 39.55 & .20 \\
\hline
\end{tabular}

Note. Variables included in which model are as follows: Model 1 = residency, local fishing experience; Model 2 = influence on fishing habits, fishing satisfaction; Model 3 = residency, local fishing experience, transit rule agreement; and Model $4=$ influence on fishing habits, fishing satisfaction, transit rule agreement; and Model 5 = residency, local fishing experience, influence on fishing habits, fishing satisfaction, transit rule agreement.

\subsection{Discussion}

Overall fishers appear to have a high level of knowledge of the regulations. The lower level of awareness of the transit rule (60\% vs. $92 \%$ for the filleting rule) is partly due to it not being relevant unless fishing outside the Marlborough Sounds. As the transit rule does not apply during the closed season this complexity is also a factor, as more complex regulations are likely to lead to lower levels of knowledge (Sullivan 2002). Given that a large percentage of fishers do not know this rule, non-compliance because of lack of knowledge may be an issue. In contrast, the high level of awareness of the filleting rule could be due to it being a simple regulation (Schill and Kline 1995) that applies to all fishers. The finding that more experienced fishers display higher levels of knowledge is consistent with previous studies (Oh and Ditton 2006; Salz and Loomis 2005), as is increased knowledge among local fishers (Page and Radomski 2006; Schill and Kline 1995).

The results show that overall the current management approach has created widespread discontentment and low levels of satisfaction among recreational fishers. But in line with previous studies showing that attitudes are not always consistent between regulations (Sullivan 2002), fisher attitudes were almost completely opposite between the two specific rules studied; with $66 \%$ of fishers disagreeing with the transit rule but $71 \%$ of them agreeing with the filleting rule. Based on fishers' comments it appears that perceived fairness and influence on fishing habits largely explained this difference, which is consistent with previous findings (Pita et al. 2013). Marlborough residents in particular viewed the transit rule as unfair and also complained about how it affected their fishing habits. Conversely, most fishers did not seem bothered by the filleting rule and believed it was 
reasonable. This suggests that it would be worthwhile for managers to explore attitudes towards each regulation separately as despite overall dissatisfaction, a high level of agreement with some regulations is still possible.

Research on fisher attitudes is also changing from considering fishers as one homogeneous group towards acknowledging the heterogeneity among the fishers, and subsequently differences in their knowledge, attitudes and behaviours (Hunt et al. 2013). Fishery managers are increasingly attempting to consider these differences when evaluating management schemes (Radomski et al. 2001). In this regard, the influence of residency and local fishing experience provides some important insights as both of these variables negatively influenced regulation satisfaction. Older fishers are more likely to have experienced more generous regulations to compare with the current ones. For example, the daily bag limit for blue cod has dropped from 20 in 1985 to the two fish limit today and there was only a minimum size limit in place (as opposed to the current minimum and maximum size limit) until 2011. Given these increasingly strict regulations, it should not be surprising that more experienced fishers have more negative attitudes than less experienced fishers. These fishers are also normally set in their fishing habits and more likely to view changes or new rules in a negative light; as demonstrated by the comments of a very experienced (50 years) fisher, who disagrees with the filleting rule because he has "done it for years".

Local fishers may struggle to see improvements in the fishery since they go fishing more often and changes to the blue cod stock are likely to be gradual. This also means the rules will have a greater influence on these fishers as they can afford to be more particular about their fishing. Furthermore, people who are visiting the Sounds primarily for fishing are a minority, as most list being outdoors, family recreation, and relaxation as more important reasons for their visits (Batstone et al. 2009). Therefore, these non-resident fishers are not as affected by the rules, as there are other parts to the experience they can still enjoy. This was demonstrated by comments by many fishers that the primary reason they visited the Sounds was because they owned a holiday home, and being able to fish was an additional bonus. From a management perspective, these findings suggest that more experienced and local fishers may initially be more hesitant to accept new regulations, and may require more focus in terms of communication and management effort. These results are also related to 
the idea of psychological distance (Evans et al. 2014) suggesting the proximity to an issue might influence attitudes towards the specific issue.

As the Blue Cod Management Group is currently the only official forum for fisher input, it is worrisome that half of the fishers had not previously heard of it. The further confusion surrounding the nature of the BCMG's role also highlights the need for work in increasing awareness of the management and government structures. The finding that knowledge of the BCMG's role did not significantly influence fisher attitudes is contrary to some previous research (Fulton et al. 2011) but does fit with Pita et al. (Pita et al. 2010) cautioning that the nature of the participation may be key. There are varying degrees of participation and government may choose to not listen to the recommendations and treat consultation as a merely symbolic gesture aimed at releasing the frustration of user groups (Jentoft and McCay 1995). Based on some of the comments relating to the BCMG, this may be the case for the Marlborough Sounds blue cod fishery. Conversely, it has also been noted that fishers with more negative attitudes regarding the management regime tend to believe they have not been consulted or involved in the process (Pita et al. 2010), so the low responses to the BCMG questions may also reflect the low level of overall satisfaction with the regulations.

Although the selected regression model for overall satisfaction was significant, it did not explain a large amount of the variation in fisher attitudes (10\%). This is not entirely surprising, as there are other variables that may have a significant influence, such as regulation effectiveness and fairness (Tyler 1990). Given the large number of negative, unprompted comments on the size limit, including agreement with this regulation is likely to significantly increase the explanatory value and fit of the model. But even without the additional predictors, the importance of considering residency and local fishing experience when designing regulations is once again highlighted. Consultation should ensure fishers of different levels of experience are represented, along with those from other areas. Similarly, any formal fisher groups involved in the management process would also benefit from a more diverse makeup.

Many fishers expressed their frustration with refusals of the Ministry of Fisheries to consider their feedback on the new regulations. Instead, the Ministry has expressed their commitment to managing the blue cod fishery on the basis of the best scientific information 
available (Moore 2012). However, increasing calls for more inclusive/bottom-up management strategies mean the knowledge requirements on fisher attitudes and behaviour are also increased. This information includes a greater understanding of how different groups of fishers are affected by a regulation and how they would respond (Fulton et al. 2011). The present study contributes to the former by showing that although residency and local fishing experience are important influences on fisher attitudes, less commonly studied factors such as influence on fishing habits and satisfaction with the fishing should also be considered. The variation among groups also suggests a variety of approaches will be needed as concerns and priorities will differ; presenting further challenges for a more participatory management regime.

The results presented have management implications and offer suggestions for designing cost-effective measures to increase the effectiveness of the current management program. Since knowledge of the blue cod regulations appears to be fairly high overall, blanket efforts to improve fisher knowledge are unlikely to make a significant difference to compliance levels. Instead, a more effective approach would be to see what groups of fishers are most likely to not know specific regulations, and design education programmes to specifically target these fishers. While positive attitudes are not essential for successfully managing a fishery, they can help improve compliance and thus reduce enforcement expenses (McClanahan et al. 2005). This study suggests that exploration of fisher attitudes towards the regulations and the factors that shape them can offer information that could greatly assist fisheries managers in successfully managing the fishery. Furthermore, rather than the normal response of imposing additional or revised rules, stricter enforcement or increasing the severity of sanctions (Jentoft 2004), fisheries managers should investigate the human dimensions aspects for other options.

The negative attitudes expressed by the fishers and the lack of influence of knowledge of the BCMG also suggest that fisher participation may need to be rethought. If participation in the management process is to positively influence satisfaction as hoped, it must not end once the new regulations are in place. Instead, fisheries managers should continue to ensure fisher participation, both actual and perceived, in order to promote satisfaction. Assessing fisher knowledge of and attitudes towards the specific regulations, as done in this study, is one way to fulfil this requirement. 


\subsection{Conclusions}

Richardson et al. (2005) said "there is an urgent need to understand fishers' attitudes and the influences that act upon them, as this may further understanding of current behaviour as well as helping to predict likely responses to new management strategy" (p. 214). To that end, this study is the first to examine how the new suite of blue cod fishing regulations in the Marlborough Sounds affects the fishers. The results show that when reviewing regulations, fisher knowledge of and attitudes towards the proposed changes should be carefully considered. Yet the results do reveal difficulties in designing regulations that are accepted by all fishers, as factors such as experience and region of residence can significantly affect both knowledge and attitudes. The wide range displayed by the fishers in this study also has important management implications. This suggests that when involving fishers in the process, care must be taken to ensure a wide range of demographics is represented. Without this representation, management bodies are more likely to lack the knowledge of how proposed regulation changes would affect certain groups. Research into fisher knowledge and attitudes, and how it varies between sociodemographic groups, can offer important insights into successfully designing regulations accepted by a majority of fishers. This can help bring about higher levels of voluntary compliance, creating a better chance of saving the fishery for both the fish and fishers. 


\section{Estimating non-compliance among recreational fishers: Insights into factors affecting the usefulness of the Randomized Response and Item Count Techniques}

\subsection{Introduction}

\subsubsection{Measuring and monitoring non-compliance}

Non-compliance with conservation regulations has become a significant problem worldwide (Eliason 1999; Gavin et al. 2009). It threatens conservation efforts (Bose and Crees-Morris 2009), contributes to over-exploitation of natural resources, hinders the recovery of both biological populations and ecosystems (Agnew et al. 2009), lowers genetic diversity (Whitehouse and Harley 2001), disrupts ecosystem stability and productivity (Gubbay 1995), and has wider consequences for food supplies (Brashares et al. 2004) and the human communities that depend on them (Pratt et al. 2004).

Fisheries are not immune to this threat (Sumaila et al. 2006), as $80 \%$ of the world's marine fish stocks are either fully exploited or overexploited (Food and Agriculture Organization of the United Nations 2012). Illegal, unreported and unregulated (IUU) fishing is a major contributor to fisheries' collapses worldwide (United Nations General Assembly (UNGA) 2006), and IUU is often cited as one of the principal causes behind the failure of fisheries management programmes (Boonstra and Bach Dang 2010; Sutinen et al. 1990). This non-compliance is due, at least in part, to the common property nature of the resource and the expense of monitoring and enforcing regulations (Anderson 1989), which are often numerous and constantly changing (Jentoft 2004).

Historically, governments and conservation organisations have been hindered by a lack of knowledge on the full extent of illegal resource use, as the number of people caught breaking the law is estimated to be only a small percentage of violators (Elffers et al. 2003). This discrepancy is important as effective management will be difficult without knowledge of the true amount of non-compliance (Smith et al. 1989). This has resulted in calls to prioritise better data collection on wildlife crimes (Wellsmith 2011), particularly on the proportion of non-compliance and to quantify how much of the resource is being lost (Smith 
and Anderson 2004). However, determining the extent of non-compliance in a fishery presents both practical and methodological challenges (Hønneland 1999) due to limited data and monitoring (Gallic and Cox 2006; Riddle 2006). Recreational fishing also presents further challenges due to its spatial and temporal variation, the wide range of gear and practices used, and the lack of reporting obligations (McCluskey and Lewison 2008).

Information on non-compliance is often unlikely to be freely given by resource users as they may fear repercussions and/or prosecutions (Gavin et al. 2009; Keane et al. 2008; Solomon et al. 2007). Admission can also lead to either psychological consequences (e.g., guilt, shame or embarrassment) or to other consequences such as discovery and sanctions (Lee and Renzetti 1990). In turn, asking about sensitive issues, such as IUU fishing, in surveys has been shown to result in high non-response rates (Tourangeau and Yan 2007). Even with completely anonymous self-administered surveys and guarantees of anonymity, individuals would still need a high level of confidence in the confidentiality of the research to admit to the sensitive behaviour (Metzger and Dalton 1991).

Other methods of estimating non-compliance such as field observations (Ainsworth and Pitcher 2005), observer programs (Gubbay 1995) and logbooks (Hatcher and Gordon 2005) suffer from drawbacks that limit their usefulness (e.g., Gavin et al. 2009; Witmer 2005). More recently, attention has turned to alternative ways of asking sensitive questions on self-administered surveys. Examples include randomized response (Warner 1965), item count (Miller 1984), nominative (Miller 1985) and three-card (Droitcour and Larson 2001) techniques. These techniques guarantee anonymity and also minimise the respondent's feeling of risk/level of threat associated with revealing sensitive or potentially incriminating information; thereby increasing both the response rate and reliability when including sensitive subjects on questionnaires or during interviews (Lee 1993). Moreover, these indirect methods do not reveal sensitive behaviour at the individual level, but still allow for interpretation at the aggregate level (Fox and Tracy 1986). Previous studies (LensveltMulders et al. 2005b) have shown the potential for these methods to elicit higher estimates of sensitive behaviours than the traditional model of direct questioning.

Here we test the effectiveness of two indirect questioning methods, the Randomized Response Technique (RRT) (Warner 1965) and Item Count Technique (ICT) (Miller 1984), at providing more accurate estimates of recreational fishery regulation violations when 
compared with traditional direct questioning. Since the introduction of these methods numerous studies have shown that both can provide significantly higher estimates of illegal resource use than direct questioning (i.e. when the individual is directly asked if they have broken a law) (e.g., Krebs et al. 2011; Solomon et al. 2007). Randomized response has been successfully used in the marine environment to examine non-compliance with trout fishing in the USA (Schill and Kline 1995), abalone (Haliotis rufescens) collection in California (Blank and Gavin 2009), and fly-fishing in Wales (St John et al. 2010). However, the Item Count Technique has yet to be tested in the field of natural resource management, despite the pressing need to quantify wildlife crimes (Wellsmith 2011).

Although both RRT and ICT have the advantage of their indirect approach, this is also a disadvantage because it introduces another source of random error into the responses, resulting in a larger standard error which requires a larger sample size to obtain statistically significant results (Himmelfarb 2008). Additionally, recent studies (e.g., Tsuchiya et al. 2007) have called for further research into the characteristics, such as data collection method, method version, research subject and sensitivity, of both RRT and ICT and modifications that may influence their usefulness. To that end the present research offers useful insights into how to maximise the potential of these two indirect techniques.

\subsubsection{Randomized Response Technique (RRT)}

The Randomized Response Technique, developed by Stanley Warner (Warner 1965) has been shown to provide higher estimates than direct questioning in multiple fields including social security fraud (Lensvelt-Mulders et al. 2005a), abortion (Abernathy et al. 1970) and illegal resource use in a National Park (Solomon et al. 2007). Although RRT still usually underestimates the proportion of the population participating in the sensitive behaviour, it often has a smaller deviation from the known proportion than direct questioning, making it a more accurate method (Lensvelt-Mulders et al. 2005b). RRT underestimation of the occurrence of a sensitive behaviour may be due to a number of possibilities, including respondents either not following the instructions or still refusing to answer the question truthfully (van der Heijden et al. 2000), respondents not fully understanding how their privacy is being protected or suspecting a trick (Clark and Desharnais 1998), or respondents taking this method less seriously than direct questioning and not answering honestly. It has been suggested that this last possibility is especially true 
for 'innocent' respondents (Fox and Tracy 1980), although a study on Dutch social security fraud found no basis for this view (Landsheer et al. 1999).

This study used the paired-alternative version of the RRT, also known as the 'two unrelated questions model' (Fox and Tracy 1986). The respondent begins by performing a randomizing event, such as flipping a coin. She then randomly chooses one of two questions, either the sensitive question of interest or a question regarding the randomizing event (e.g., "did you see the head of the coin?"). The answer is recorded as either "yes" or "no" without revealing the question selected. The researcher can then use the probabilities of choosing the sensitive question and the outcome of the randomising event (e.g., $50 \%$ chance of seeing head of coin), along with the number of "yes" responses to estimate the number of individuals who have performed the sensitive behaviour. Because responses can never be directly linked to the respondent or sensitive question, the method encourages higher response rates and more truthful answering.

\subsubsection{Item Count Technique (ICT)}

First proposed by Miller (1984) and first formally tested by Dalton et al. (1994), ICT has mainly been used in the social sciences to investigate socially desirable attitudes, such as voter turnout (Holbrook and Krosnick 2010b) and attitude towards immigration (Janus 2010), as well as estimating sensitive topics such as sexually risky behaviour (LaBrie and Earleywine 2000), sexual assault (Krebs et al. 2011) and shoplifting (Tsuchiya et al. 2007). A meta-analytical review found that ICT provided significantly higher estimates than direct questioning in 30 out of the 48 cases (Holbrook and Krosnick 2010b).

ICT involves drafting a short list of three to five innocuous items given to half of the respondents. Although the items do not have to be related to the survey topic, doing so can be advantageous as it often makes more sense to research participants (Chaudhuri and Christofides 2007). Respondents are asked to report only the total number of items that apply to them. Because only a number is reported, the researcher has no way of knowing which specific items applied. The other half of the respondents receives a list with the same set of items, along with an additional item about the sensitive topic, and is again instructed to provide only a total number. The difference in means of the total number of items reported from the two lists provides an estimate of the proportion of respondents engaging 
in the sensitive behaviour. The assumption underlying this method is that true random sampling gives two study groups that are on average statistically equivalent. Thus, any difference in the means between the two groups can be directly attributed to the sensitive item (Dalton et al. 1994).

However, concerns about sample size and the associated standard error have led to a modification by Droitcour et al. (1991), which is used in this study. This alternative version of ICT uses four lists:

List 1: short list of innocuous items (A).

List 2: $A+1$ sensitive item.

List 3: a different short list of innocuous items (B).

List 4: $B+1$ sensitive item.

The first half of the sample receives lists 1 and 4 while the second half receives lists 2 and 3, so that all respondents reply to a list containing the sensitive item. Two estimates are then calculated, one based on the difference between $A$ lists (i.e., Lists 1 and 2), and one on the difference between B lists (i.e., Lists 3 and 4). These two estimates are then averaged to obtain an overall estimate of the occurrence of the sensitive behaviour. This ICT version is commonly known as the two-list version, as each participant responds to two lists.

\subsubsection{RRT vs. ICT}

To date there have been just two studies comparing the efficiency of RRT vs. ICT (Coutts and Jann 2011; Wimbush and Dalton 1997) and neither was applied in a natural resource context/setting. Wimbush and Dalton (1997) explored employee theft at four levels $(\$ 5.00-$ $\$ 9.99, \$ 10.00-\$ 24.99, \$ 25.00-\$ 49.99$ and $>\$ 50.00)$ using self-administered questionnaires, and found mixed results. Although RRT provided higher estimates than direct questioning for the three lower levels of theft (which also had the highest estimates), ICT produced higher estimates than direct questioning for all four levels (with the fourth level corresponding to the lowest estimate under direct questioning). But when RRT and ICT estimates were compared, no significant difference was observed for any theft level.

More recently, Coutts and Jann (2011) compared RRT and ICT in an online study of 2075 participants recruited through a German access panel. They found that ICT provided higher 
estimates than RRT for five of the six common sensitive and/or illegal behaviours investigated in their study (keeping too much change, using public transportation without paying, shoplifting, using marijuana, driving even though the blood alcohol level was almost certainly over the legal limit and infidelity). However, only two of the higher estimates were significant (marijuana use and infidelity) and several of the RRT estimates were negative (due to the version used). Finally, when compared to direct questioning ICT provided a significantly higher estimate for just one of the behaviours, marijuana use.

Overall, ICT may be preferred over RRT for two reasons. The first is simplicity as RRT requires the use of a randomizing device, but ICT involves only providing a total number of items. In turn, ICT is often perceived as easier to conduct and understand (Glynn 2010). The second reason is trust with recent studies (Coutts and Jann 2011; Lavender and Anderson 2009) hypothesizing that greater trust in ICT derives from the need to only provide a number and not respond to specific items on the list. It is thus easier for respondents to understand why ICT affords privacy (Imai 2011; Lavender and Anderson 2009). The lack of a randomizing device may also help increase respondents' trust, as with RRT respondents need to believe the device outcome is truly random (Coutts and Jann 2011). The one drawback to ICT, when compared to RRT, is the standard error. Coutts and Jann (2011) found that ICT had a standard error approximately three times higher than all five RRT versions tested. This relative inefficiency is an argument for the use of the two-list version of ICT as it cuts the standard error in half.

Even though two previous RRT studies (Coutts and Jann 2011; Holbrook and Krosnick 2010a) also used an online survey, the version of RRT used led to 'impossible' estimates (i.e., either less than $0 \%$ or greater than $100 \%$ ). This result was one of the reasons that led Coutts and Jann (2011) to conclude that ICT was preferable to RRT. Under the paired-alternative version of the RRT used in the study, neither of these types of estimates is possible. Consequently, RRT cannot be dismissed as less effective than ICT on that basis.

Most importantly, in the previous comparison studies between RRT and ICT, the methods were tested on different sample populations. Comparing methods with different sample sets may lead to erroneous conclusions about preferred methods; as differences in sample populations, instead of differences in the method used, may be responsible for the observed differences in estimated rates of non-compliance. To our knowledge this study is 
the first to test ICT in natural resource management and test the two methods online using the paired-alternative version of the RRT and the two-list version of ICT. It is also the first to compare the methods using the same sample populations. The comparisons yield important conclusions regarding the preferred methods for the study of non-compliance in conservation.

\subsection{Material and Methods}

\subsubsection{Study Area}

The Marlborough Sounds recreational blue cod fishery has been previously described in section 1.6.3. Additionally, the study detailed in this chapter also includes an additional location within the larger study area. The community-established Long Island Marine reserve is a strictly no-take zone in the Queen Charlotte Sound (Figure 3.1, boxed). The large area of the Marlborough Sounds makes effective enforcement challenging and location of the marine reserve in the Outer Sounds further adds to this management concern, yet monitoring of species within the reserve shows no evidence of illegal take (Davidson et al. 2009) and there were no recorded violations in 2012 (Grose 2014). A singular violation of any of blue cod regulations or the marine reserve is considered a serious non-commercial offense (New Zealand Parliament 1971) and carries an infringement fee of $\$ 250-\$ 500$ (Bright 2012). Under certain circumstances, such as a large-scale violation, prosecution can occur whereby any property used in the violation (e.g., boat) is forfeit to the Crown upon conviction (Bright 2012). A maximum penalty of $\$ 20,000$ may also apply (New Zealand Parliament 1971). 


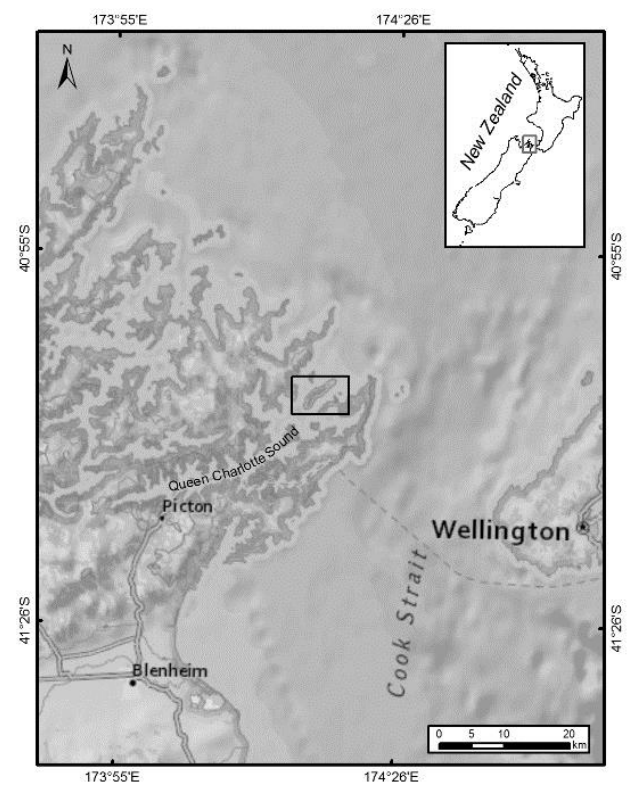

Figure 3.1: Map showing the location of the Long Island Marine Reserve (boxed) in the Marlborough Sounds.

\subsubsection{Survey Design}

We piloted the survey on 84 recreational fishers in the Marlborough Sounds in October 2012 with the instructions and wording for the RRT and ICT questions modified based on observations from this stage. The final survey was carried out online using the survey platform Qualtrics (www.qualtrics.com). Online surveys are increasingly utilised in conducting research in a variety of fields (Couper et al. 2007), including testing RRT (Holbrook and Krosnick 2010a), ICT (Krebs et al. 2011) and a previous comparison study (Coutts and Jann 2011). Internet surveys offer several advantages to traditional methods such as mail and telephone surveys: low cost, increased timeliness, direct data entry and greater geographic reach (de Leeuw 2008; Groves et al. 2009; Smyth and Pearson 2011; Sue and Ritter 2012). Other benefits include easier use of contingency questions and complex skip patterns (Dillman et al. 2009).

We used the online format for five reasons. First, it allowed us to cover a large geographic area with minimal cost, an important feature as fishers come from all over New Zealand and even overseas to fish in the Sounds. Second, as saltwater fishing in New Zealand does not require a license, there was no sampling frame available for a mail-based survey. Third, using a web-based survey also allowed easy use of screening questions. This meant respondents who did not fish in the Queen Charlotte Sound, the location of the marine reserve, were not asked the sensitive questions on this subject. A fourth beneficial 
feature of the online format was the ability to minimise non-response by requiring respondents to answer a question before moving on to the next one, especially useful because of the sensitive nature of some questions. Finally, respondents were likely to view this format as less intrusive and more private than in-person surveys as there is no interviewer present, providing a greater feeling of anonymity (de Leeuw 2008).

The initial contact with most survey participants was through face-to-face intercept surveys carried out over six weeks in January-February 2013 (summer) at four boat launch locations (the three area marinas in the Marlborough Sounds and a nearby bay) in the Marlborough Sounds as part of a larger study (Thomas et al. 2014b). Based on these initial contacts, 311 email addresses of fishers were collected and all were valid. Potential respondents were emailed the survey link approximately one week after intercept, a reminder approximately two weeks after being sent the initial link, and a final reminder about a week before the close of the survey. Recruitment also took place via email to fishers previously interviewed, newspaper, radio, magazine and flyers in order to enlarge the sample size and minimise sampling biases.

Informed consent was used in this study, with the first page asking for participants' agreement to take part in the research. Respondents were assured that all responses would remain confidential and that no responses could be traced back to an individual and were therefore anonymous. The survey started with several general questions on fishing in the Marlborough Sounds to introduce the study, which are not reported here. Next we asked if the respondent had fished in the Queen Charlotte Sound, which is the location of the Long Island Marine Reserve. Fishers who answered "yes" received all the remaining questions, but those who responded "no" were not shown the RRT and ICT questions on the Long Island Marine Reserve, as this sensitive behaviour would not be applicable to them.

\subsubsection{Participants}

Respondents were asked about non-compliance with three different blue-cod related fishing regulations in the Marlborough Sounds (detailed below). Although the questions referred to 2012, respondents were instructed to answer for the most recent year they had been fishing in the Sounds if they had not been in 2012. In this way all fishers were able to participate in the survey. However, for the present study we only used data from 
those fishers who had fished in the Sounds in 2012. While 418 fishers completed the survey through the direct questions, only 320 indicated that they had been fishing in the Marlborough Sounds in 2012. Of those respondents, only 217 had been fishing in the Queen Charlotte Sound and answered the questions on the marine reserve.

The final sample was thus comprised of 320 fishers, with $82 \%$ male and $45 \%$ from the Marlborough region. Fisher age ranged from 22 to 88 years $(M=54, S D=12)$, while Sounds fishing experience ranged from one to 70 years $(M=28, S D=17)$. It is important to note potential biases with the sampling protocol used. Respondents previously convicted of non-compliance with one of the three regulations could have been included in the sample but we did not ask this question. Fishers who did not use one of the boat ramps surveyed, or used the ramps on a different day, had less of a chance of taking part in the survey. The sample was also not random so results may be biased towards more interested respondents. Given these potential sampling biases, readers should be cautious when generalising the results of the present study.

\subsubsection{Sensitive Behaviours}

We gathered data on three sensitive questions:

1) While fishing in the Marlborough Sounds in 2012 did you keep a blue cod that was less than $30 \mathrm{~cm}$ or more than $35 \mathrm{~cm}$ in length?

As blue cod are protogynous hermaphrodites (Carbines 1998a; Ministry of Fisheries 2008d), the maximum size limit was introduced to protect the larger female fish by leaving large males in the population to suppress a sex-change. Non-compliance with the maximum size could therefore negatively affect the sex ratio as well as the population's reproductive potential as larger fish have been shown to produce more batches of eggs (Crossland 1977; Zeldis and Francis 1998). Violations of the minimum length can also be detrimental. For example, Gigliotti and Taylor (1990) showed that for the northern pike (Esox lucius), a 10\% rate of non-compliance decreased the number of legal-sized fish caught by $10 \%$, while $20 \%$ non-compliance resulted in a $19 \%$ decrease.

2) While fishing in the Marlborough Sounds in 2012 did you keep more than two blue cod per person in a day? 
When the fishery reopened, the daily bag limit was put at two in an effort to allow blue cod populations to increase by keeping recreational catch at sustainable levels (Ministry of Fisheries 2010a). Non-compliance with the daily limit would interfere with the rebuilding and maintaining of the blue cod populations at healthy levels, putting the future health of the fishery at risk.

\section{3) In 2012 did you go fishing in the Long Island Marine Reserve?}

Established by the local community in April 1993, the Long Island Marine Reserve has been effective in allowing the blue cod population to recover from recreational fishing pressure. Within seven years of its establishment, blue cod were $125 \%$ more abundant in the reserve than in nearby fished areas (Davidson 2001). Furthermore, from April 2004 to 2009 , large blue cod $(>330 \mathrm{~mm}$ ) represented only $1.6 \%$ of the fish caught at control (fished) sites, compared with $29.4 \%$ at the reserve sites (Davidson et al. 2009).

\subsubsection{Question Format and Instructions}

We included a short introduction to the section emphasising that in addition to the anonymous and confidential nature of the survey, the questions were asked in a way that guaranteed additional privacy.

The following steps were used for the three RRT questions:

1) An introductory statement: "In order to keep your answer a secret, you will randomly be asked one of two questions: either (a) the result of a coin toss or (b) about fishing in the Marlborough Sounds. There is no way anyone can know either the result of the coin toss or which question you answered. This means you can be completely honest with your answers."

2) Next, the respondent was directed to click on a link to open a new tab (www.coin.co.nz/coin-tosser.htm) and to flip the virtual coin only once. They were asked to remember the result of the coin toss and then return to the survey. While a previous study used an electronic coin (Coutts and Jann 2011), we used a third party website as we hypothesised that participants would be more trusting of this mode.

3) The survey platform randomly selected one of two questions to show the respondent, either the coin toss result or the rule-breaking behaviour (provided above), 
which was not recorded. This selected question was answered on the next screen under a new question ("Now please answer the above question by selecting yes or no").

4) Finally, steps two and three were repeated for each of the three sensitive behaviours: keeping undersized or oversized blue cod, keeping more than the daily limit for blue cod, and fishing in the Long Island Marine Reserve.

For ICT, the process was as follows:

1) The respondent was provided with the following instructions: "Below are a number of fishing related activities that you may have done in 2012. Please carefully read the individual activities and note, in your head, how many you have done at least once. Even if you have done that activity more than once, it only counts as ' 1 '. The activities apply to all locations unless otherwise specified.

When you are done, please answer at the bottom of each list only the TOTAL NUMBER of activities that you have done for each list."

2) Once again, the survey platform randomly selected which lists (Appendix 5) were to be answered. In this case, either the odd $(1,3,5)$ or even $(2,4,6)$ lists were displayed to the respondents. The four non-sensitive items differed for every list while lists 1 and 2 included the size limit, 3 and 4 the daily limit, and 5 and 6 the marine reserve. An example of a list including a sensitive behaviour is:

- Shared your catch with someone.

- Was a member of a fishing club.

- Kept a blue cod less than $30 \mathrm{~cm}$ or more than $35 \mathrm{~cm}$ in length while in the Marlborough Sounds.

- Watched a fishing show on TV.

- Caught a trophy fish.

3) The respondent answered by selecting a number from 0-4 or 0-5, depending on the list, as offering only these choices limited confusion with the technique.

Participants responded to four evaluative statements on both RRT and ICT using a five-point Likert scale (1=strongly disagree to $5=$ strongly agree). These questions were: '। 
understood why my answer would not be known', 'I felt comfortable answering honestly', 'I found this method confusing', and 'I believed my privacy was protected with this method'.

Finally, respondents were asked directly if they had engaged in each of the three rule-breaking behaviours towards the end of the survey. This meant all respondents provided answers under all three methods tested. Formulas used for data analysis were taken from Tracy and Fox (1981) for RRT and Droitcour et al. (1991) for ICT.

\subsection{Results}

\subsubsection{Estimates of non-compliance}

While estimates differed between the three behaviours, all methods found the size limit regulation to be the most often violated, followed by the daily limit and finally the marine reserve (Figure 3.2). Based on the findings, we estimated that the size limit regulation was violated by the greatest proportion of fishers, with over $30 \%$ noncompliance, whereas non-compliance with the daily limit was estimated at $\geq 10 \%$. In contrast, non-compliance with the marine reserve was estimated as close to zero.

RRT provided a significantly higher estimate (42\%) than ICT (14\%) or direct questioning (29\%) for size limit violations $(z=3.29, p=0.0010 ; z=2.15, p=0.0320$; respectively). For the daily limit the RRT estimate of $21 \%$ was not significantly higher than either ICT $(11 \%)$ or direct questioning $(12 \%)(z=1.26, p=0.2078 ; z=1.60, p=0.1092$; respectively). Non-compliance with the marine reserve was estimated at $6 \%$ under RRT, but again this was not significantly different than estimates using ICT $(4 \%, z=0.19, p=0.8472)$ or direct questioning $(0 \%, z=0.87, p=0.3828)$. While there were no significant differences between ICT and direct questioning for the daily limit or marine reserve $(z=-0.25, p=$ $0.8065 ; z=0.49, p=0.6219$ respectively), direct questioning actually provided a significantly higher estimate of non-compliance with the size limit than ICT $(z=-2.16, p=0.0310)$. 


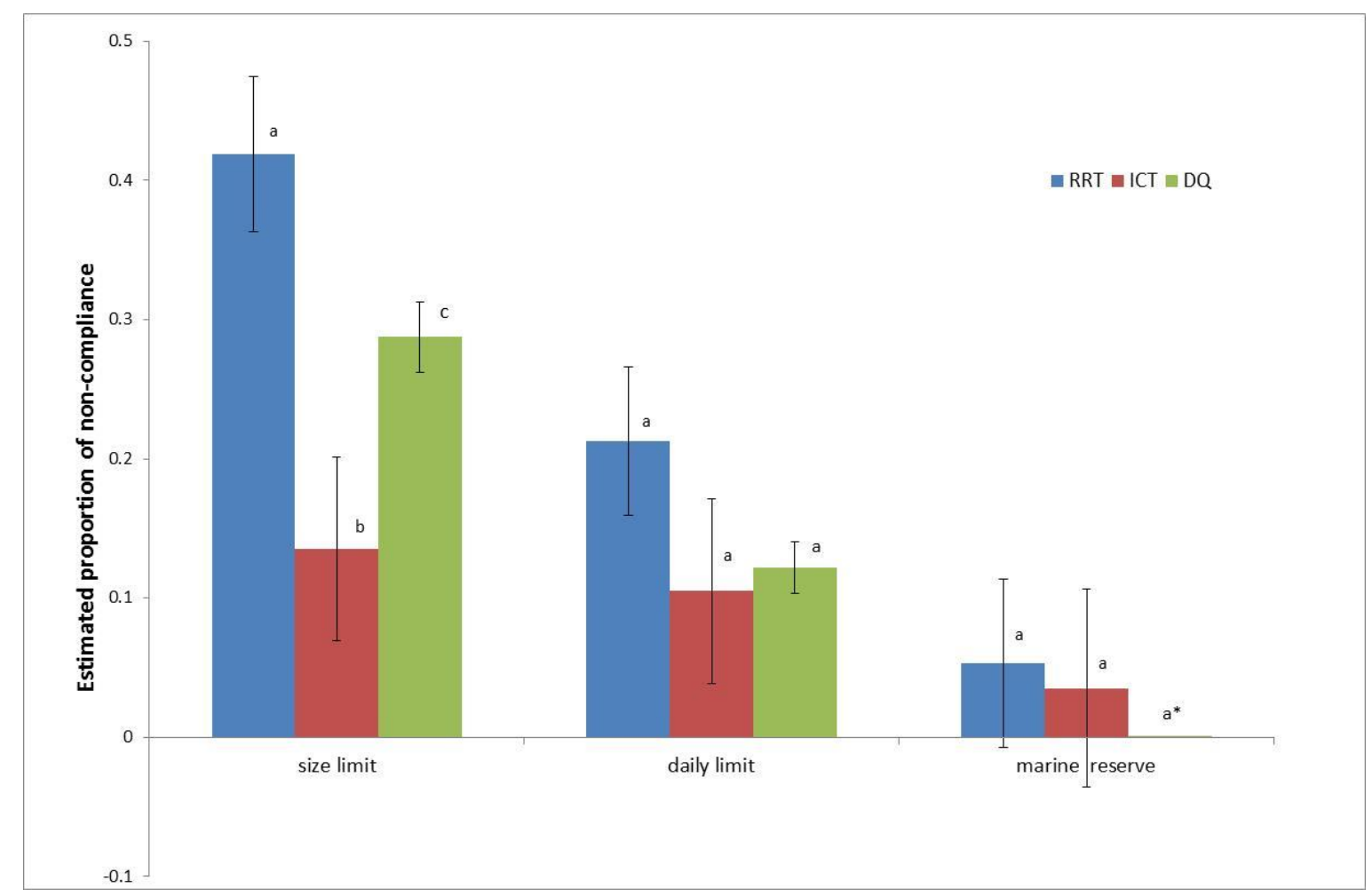

Figure 3.2: A comparison of non-compliance estimates from three methods, Randomized Response Technique (RRT), Item Count Technique (ICT) and direct questioning (DQ). Bars represent the standard error and the same letter represents no statistically significant difference ( $p>05)$. * The standard error could not be estimated as there was no variability in the sample.

\subsubsection{Method evaluation}

Responses $(N=320)$ to the four evaluative questions were not normally distributed, so the Wilcoxon signed-rank test was used to test if median responses significantly differed from the scale middle point ( $3=$ neither agree nor disagree). Respondents understood why their answer would not be known for both RRT (Mdn=4, $t=6.38, p<0.001)$ and ICT (Mdn $=$ $4, t=8.55, p<0.001)$. They also felt comfortable answering honestly under both techniques $(M d n=4, t=14.850, \mathrm{p}<0.001 ; M d n=4, t=14.817, p<0.001$, respectively) and felt their privacy was protected with both methods $(M d n=4, t=10.36, p<0.001 ; M d n=4 t=10.56$, $p<0.001$ respectively). However, while the fishers were neutral on RRT being confusing $(M d n=3, t=1.82, p=0.069)$, they disagreed that ICT was confusing ( $M d n=3, t=-2.906, p=$ 0.004 ) as the response distribution was skewed towards the lower end of the scale.

The Wilcoxon signed-rank test was also used to test for significant differences in evaluations between the methods. Only two of the four evaluation questions showed significant differences between RRT and ICT scores. Respondents believed it was easier to 
understand why their answer would remain unknown with ICT $(Z=2.990, p=0.003, r=-$ $0.17)$ and also found ICT less confusing than RRT $(Z=-5.364, p<0.001, r=-0.30)$.

\subsection{Discussion}

The present study compared the effectiveness of two indirect techniques, Randomized Response (RRT) and Item Count (ICT), in providing more accurate estimates of recreational fishery regulation violations than direct questioning (DQ). We compared these three questioning methods for three sensitive behaviours (size limit, daily limit and fishing in a marine reserve) in the same sample population in the context of the blue cod fishery in the Marlborough Sounds, New Zealand. Consistent with previous studies, we found that none of the methods provided the highest estimate of non-compliance for all regulations. Instead, factors such behaviour sensitivity and frequency appeared to influence the effectiveness of indirect techniques when compared to direct questioning.

\subsubsection{Methods comparison}

Of the non-compliance estimates for the three sensitive behaviours, only the size limit revealed significant differences between the three methods with RRT giving a higher estimate than ICT and DQ. Surprisingly, DQ actually provided a higher estimate than ICT for this behaviour. While the poor performance of ICT (compared with either of the other two methods) is inconsistent with some previous comparisons (e.g., Janus 2010; Wimbush and Dalton 1997), RRT's higher estimation than DQ is in line with earlier research (e.g., Abernathy et al. 1970; De Jong et al. 2010; Solomon et al. 2007).

The lack of significant differences between the methods for two of the sensitive behaviours (daily limit and marine reserve) shows several considerations to using these indirect methods. First, when violation rates are low, such as fishing in the marine reserve, no additional gains are likely from the use of either indirect technique, mainly due to large variances (Droitcour et al. 1991). Second, and in line with previous findings (Coutts and Jann 2011), both indirect methods have a much larger standard error than that associated with direct questioning (0.05-0.07 vs. 0.02); although using the two-list version of ICT appears to have provided significant gains in this area (with standard errors only .01 higher than those for RRT). 
Moreover, it seems that indirect methods are most useful when respondents perceive the questions as sensitive, associating some risk with honest answering (LensveltMulders et al. 2005b), and the effectiveness increases with perceived sensitivity (Wimbush and Dalton 1997). The lack of significant differences between RRT and ICT for honest responding and privacy protection reveals the role of question sensitivity. Since respondents viewed both indirect methods the same in terms of answering honestly and protecting their privacy, the lack of estimate differences for two of the questions is partly due to variances in the perceived sensitivity of the behaviours. The high estimates for two of the behaviours via direct questioning further suggest that question sensitivity can help determine when the use of an indirect method is likely to increase honest answering.

The version of RRT or ICT used can also influence how well they perform. To illustrate, the RRT version used, paired-alternative, confers a higher degree of privacy protection than the forced choice version used in some previous RRT vs. ICT studies (Coutts and Jann 2011; Holbrook and Krosnick 2010a). It gives respondents a 50\% chance of answering the innocuous question, higher than other RRT versions. Of the previous studies that found that respondents believed ICT offered more privacy protection than RRT, Coutts and Jann (2011) used several forced choice RRT versions online; while Lavender and Anderson (2009) used an in-person survey format as well as a forced choice version. Consequently, using the paired-alternative version of RRT negated this apparent advantage of ICT, as confirmed by a lack of difference in respondents' evaluation of privacy protection under both methods.

Besides question sensitivity, our results might also reflect the online mode of the survey. As mentioned, the use of the same sample population and survey mode enhanced the comparison of the different methods. At the same time, the online format may have offered greater perceived anonymity than the in person or telephone questionnaires used by studies that found ICT to provide higher estimates than direct questioning (Janus 2010; LaBrie and Earleywine 2000; Wimbush and Dalton 1997). The use of an internet-based survey appears to have allowed for increased reporting of the sensitive behaviours under direct questioning, resulting in little additional benefit from the use of an indirect technique. Our findings are more in line with Holbrook and Krosnick (2010b) and Krebs et al. (2011), who found no significant differences between ICT and direct questioning estimates when 
using anonymous, self-administered web-based surveys. However, in our study direct questioning actually offered a significantly higher estimate than ICT for the size limit.

Despite RRT successfully providing higher estimates than either ICT or direct questioning for one of the sensitive behaviours, results of the respondents' method evaluation suggest that there are still further improvements to be made. Specifically, changes could be made to increase the respondents' understanding of and reduce confusion with how RRT protects their anonymity. For example, including a video demonstrating the method using role reversal (e.g., Solomon et al. 2007) may help clear up some confusion. Another critical area for further research is the influence of the survey mode on the perceived sensitivity of the questions, as discussed above. Future studies should seek to directly measure sensitivity across different survey modes in order to determine how the method of delivery affects the willingness of respondents to provide honest answers under both direct and indirect methods. Further research into the effectiveness of the different techniques under a variety of geographical, cultural and political contexts could also offer important insights.

\subsubsection{Conservation implications}

It is reassuring to see that non-compliance with the Long Island Marine Reserve is almost non-existent as this bodes well for the continued recovery of those local blue cod populations. The low level of violations shows that fishers are not opposed to all restrictions on blue cod fishing. More exploration into why so few people fish in the marine reserve, despite the presence of larger and more abundant blue cod, could offer valuable insights into increasing compliance with the size and daily limits for blue cod. Marine reserve boundaries are also more difficult to mark than terrestrial protected areas (Sethi and Hilborn 2008) so it may not be apparent if a fisher is in violation without carefully checking GPS coordinates. Overall the lack of fishing in the Long Island Marine Reserve may be that its community-led establishment confers a higher degree of legitimacy than the government imposed daily and size limits (Jentoft and McCay 1995; Kuperan and Sutinen 1998; Nielsen 2003), but this would need to be explored in further research.

However, the amount of estimated non-compliance with the two main blue cod regulations is distressing and is potentially compromising the long-term sustainability of the 
fishery. This is especially true for the size limit with the $42 \%$ non-compliance rate still probably an underestimate, as some respondents will not answer honestly even under an indirect method (van der Heijden et al. 2000). These results have important consequences for the recovery of the fishery less than three years after reopening. Considering that studies have shown that even small levels of non-compliance can undermine the effectiveness of regulations (Gigliotti and Taylor 1990; Sethi and Hilborn 2008), 20 or 30\% non-compliance could have detrimental consequences for the fishery's health. For example, with an estimated 9000 fishers in 2009 (Batstone et al. 2009), even a small proportion of fishers exceeding the daily limit could significantly affect the blue cod harvest level in the Sounds. Under a worst case scenario, the large amount of violations with both the size and daily limits may prevent the blue cod fishery from recovering and thus lead the Ministry of Fisheries to increase the length of the seasonal closure or completely close the fishery again.

Estimates from this study could be used to help prioritise management actions, as enforcement efforts are expensive and impractical given the large area of the Sounds and numerous holiday homes and boat ramps. This study suggests that the size limit regulation needs the most and earliest attention given the scale of non-compliance. The Ministry has previously noted that in order for regulations to be effective, support from the fishers is needed (Ministry of Fisheries 2008d). The non-compliance estimates suggest that fishers' buy-in with the size regulations is low, possibly contributing to the high level of violations. However, this study did not differentiate between keeping undersized and oversized blue cod, an important next step for future research.

\subsection{Conclusions}

Although this study was the first to test ICT in the field of natural resource management, this technique was not effective in providing higher estimates than direct questioning. This paper also responds to calls for greater investigation into the influence of survey mode and method version (Tsuchiya et al. 2007). Our results show that the combination of a webbased survey and the paired-alternative version of RRT helped provide higher noncompliance estimates than ICT for one of the regulations, contrary to several previous studies (Coutts and Jann 2011; Wimbush and Dalton 1997). We hypothesize that the effectiveness of indirect methods, such as RRT and ICT, largely depends on the perceived sensitivity and frequency of the behaviour in question. If sensitive and/or frequent enough 
then we would see a difference between methods for that particular behaviour, such as the size limit. Below these thresholds there is no additional benefit to using an indirect questioning technique, thus we would expect to see no differences across methods. The survey mode is a third factor to take into consideration, as it appears to influence the minimum sensitivity and/ or frequency required for use of indirect methods, with an online survey raising these levels. Most importantly, this study was the first to test all methods on the same sample population, eliminating any potentially confounding socio-demographic factors.

Ideally non-compliance information could be gathered from known offenders, but as this is not usually possible the present research demonstrates that under certain conditions indirect questioning is an effective way to obtain this important information. Survey mode, behaviour sensitivity and frequency should be taken into account to determine if an indirect method is actually needed, as direct questioning may suffice for internet-based surveys or non-sensitive topics. If an indirect method is likely to increase honest answering, we suggest that the paired-alternative version of RRT can be used to obtain more accurate estimates of non-compliance. 


\section{Social norms drive compliance with recreational fishery regulations}

\subsection{Introduction}

One of the leading causes of fisheries management failures is non-compliance with regulations (Boonstra and Bach Dang 2010; Sutinen et al. 1990). Even low levels (10\%) of violations can negatively affect populations (Gigliotti and Taylor 1990; Sethi and Hilborn 2008), undermining regulation efficiency, cost effectiveness and the legitimacy of the management regime (Bose and Crees-Morris 2009; Nielsen and Mathiesen 2003). Knowing why fishers break the rules is therefore a pressing management problem (Jagers et al. 2012). Yet in order to effectively and efficiently address non-compliance, fishery managers must first understand the primary drivers of the rule-breaking behaviour (Gavin et al. 2009; Kuperan and Sutinen 1998) through expanded social science inquiry (Robbins et al. 2006).

An understanding of the factors influencing behavioural restraint can improve the management of natural resources (Abbot and Mace 1999) by lowering non-compliance (Kritzer 2004) and providing solid advice to policy makers (Johannesen 2005) on how they can bring about the desired behavioural changes (Keane et al. 2008; Viteri and Chávez 2007). Compliance levels are often positively influenced by enforcement levels (Abbot and Mace 1999; Leader-Williams et al. 1990); which are frequently limited by a lack of resources (Keane et al. 2008), especially in developing countries (Holmern et al. 2007). Since behavioural restraint can also occur voluntarily (Brechin et al. 2002), there is a critical need to increase compliance without solely relying on expensive enforcement (Kuperan and Sutinen 1998; Leader-Williams and Milner-Gulland 1993; Stern 2008). Grabosky and Braithwaite (1986) even argue that fisheries managers are most likely to secure compliance if enforcement is kept to a minimum while relying on voluntary compliance most of the time.

However, compliance decisions are usually motivated by a complex mix of factors, including enforcement, moral norms, legitimacy and the behaviour of others (Kuperan and Sutinen 1998), as choosing to break a rule is rarely a simple decision (Jagers et al. 2012). To date, no studies have explored more than a single influence on a fisher's compliance behaviour in a recreational fishery. This lack of knowledge is despite a growing awareness 
(Cooke and Cowx 2004) of the effects from recreational fishing on fish populations (Denny and Babcock 2004; Eliason 1999; Post et al. 2002; Schroder and Love 2002; Shears and Usmar 2006). In this study I examine the drivers of non-compliance with two recreational fishing regulations in the Marlborough Sounds, New Zealand. Structural equation modeling was utilised to test seven alternative models against each other to best predict regulation non-compliance. To my knowledge, this is the first time that such a modeling approach has been used in the fisheries compliance literature. Furthermore, the use of psychological models to understand the drivers of non-compliance in fisheries appears to be lacking despite the success of the models in predicting behaviour in other disciplines (Armitage and Conner 2001). Importantly, the research also contributes to the fields of natural resource management and psychology by providing a practical test of the predictive value of the models.

\subsection{Theoretical framework}

The problem of enforcement and compliance in fisheries has been recognised since the 1950s, but a study by Sutinen and Anderson (1985) was the first comprehensive attempt at understanding this issue. Although non-compliance was originally viewed as a calculated decision based on risk evaluation (instrumental model), more recent studies have argued that external influences on individuals are more prevailing (normative model). These two opposing models dominate the compliance literature.

An instrumental view of compliance after Becker (1968) was the first model tested. Under this model, fishers were believed to act as rational agents (Nielsen and Mathiesen 2003) and non-compliance is perceived to be the outcome of the expected net gain from breaking the law, the risk of detection, the probability of conviction, and the severity of punishment (King and Sutinen 2010). If the expected illegal gain is greater than the three combined risks, the individual is predicted to violate. Under this model, a lack of compliance is perceived to be the result of inadequate enforcement (Sutinen et al. 1990). Furthermore, this instrumental view assumes fishers are unwilling to voluntarily comply with restrictions, but must be compelled to follow them (May 2004). 
The second alternative model tested was the Theory of Planned Behaviour (Ajzen 1991), a well-known framework for modeling behaviour (Armitage and Conner 2001). In this study TPB represents the simplest version of a normative model of compliance.

According to this model, behavioural intentions are the most proximal determinant of behaviour, and an individual's intention to perform a particular behaviour is in turn predicted by three socio-cognitive factors: attitudes, subjective norms, and perceived behavioural control (an individual's estimate of their ability to perform a specified behaviour). However, intention was not included as a factor due to the potentially sensitive nature of non-compliance; so the study modelled behaviour directly. The six variables included in these two models were combined into a third model representing both the instrumental and basic normative views of compliance.

For the third model, the instrumental model was combined with the Theory of Planned Behaviour for a total of six variables. This model represents a combination of the two opposing models of compliance: both the instrumental and normative views. The aim of including this model was to test the explanatory power of these two models when they are combined, rather than their variables tested against each other.

Four normative factors (outcome fairness and effectiveness, involvement in decisionmaking process and meaningful rule) were used as measures of the management regime's legitimacy and tested together as the fourth model. Fishers may also violate because they view the rules as unfair and/or do not trust the management body as a rule-maker (Jagers et al. 2012). This so-called legitimacy is usually tied to a specific political authority system (Nielsen and Mathiesen 2003). Higher levels of compliance can thus be achieved through enhanced legitimacy (Bavinck 1996; Ostrom 2000) which is often linked to formal participation in the management process (Jentoft and Mikalsen 2004; Read et al. 2011). Outcome fairness can be defined as who gets more of the resource under the regulation and outcome efficiency is how well the regulation objectives are achieved (Tyler 1990). Although procedural fairness and effectiveness are included in Tyler's (1990) model of legitimacy, fishers interviewed in a pilot study did not mention these factors, nor did any news articles, so they were not included in the model.

A framework of pro-environmental behaviour by Bamberg and Möser (2007) that combines the self-interest model of planned behaviour with pro-social motives driving proenvironmental behaviour was the fifth model tested. These authors conducted a meta- 
analysis of 46 studies and proposed eight psycho-social factors that influence proenvironmental behaviour: the TPB factors plus problem awareness, attribution, guilt, and moral norm. These authors conducted a meta-analysis of 46 studies and proposed eight psycho-social factors that influence behaviour: problem awareness, attribution, social norm, guilt, perceived behavioural control, attitude, moral norm and intention (see Figure 4.1). Compliance with the fishery regulations can be seen as a form of pro-environmental behaviour. In following the daily limit for blue cod, fishers are forgoing maximising their take to leave fish for others and the future. For compliance with the size limit, fishers must leave the larger blue cod that they would normally take (and even target). By choosing to comply with the regulations the fishers decide to not act entirely in their self-interest and maximise their catch, but must instead consider other fishers both now and in the future.

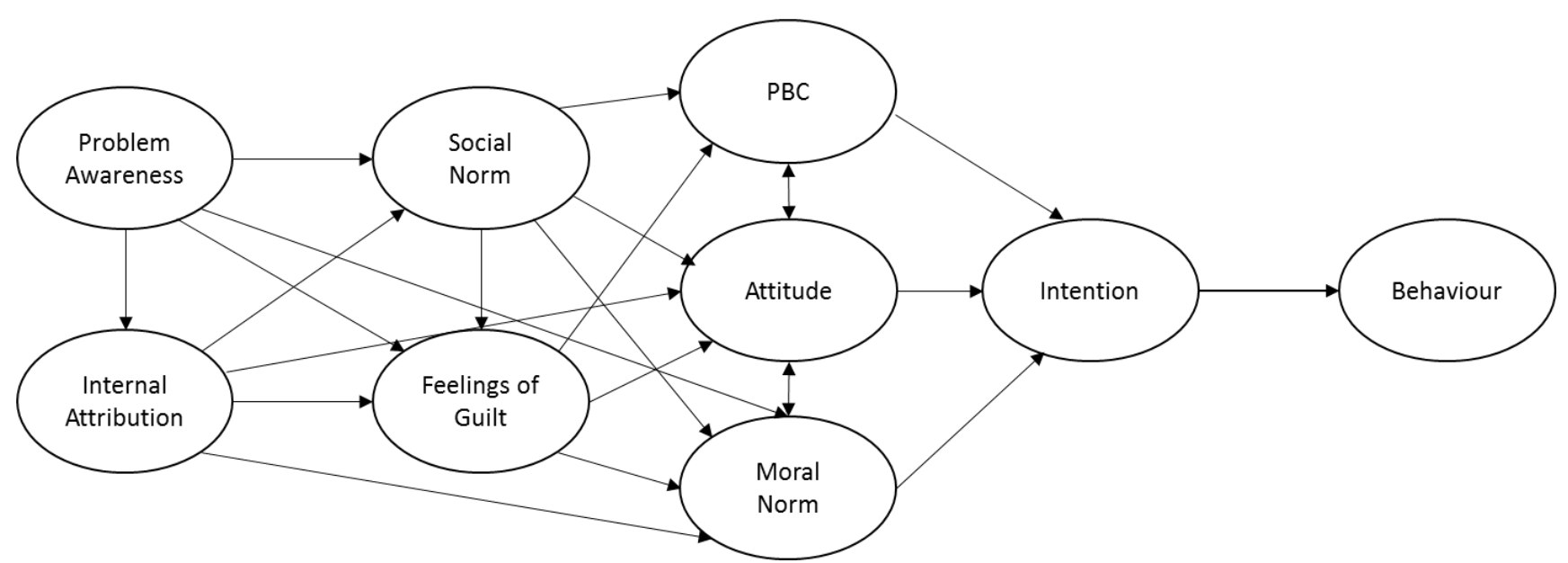

Figure 4.1: Model of pro-environmental behaviour from Bamberg and Möser (2007)

For the sixth model, a modified version of this pro-environmental framework was utilised. Whereas in the original Bamberg and Möser (2007) model the social norm influenced an individual's behaviour indirectly, the modified version added a direct path from the social norm to compliance. Previous studies (Armitage and Conner 2001; White et al. 2009) have demonstrated that social norms can directly influence behaviour. Social norms have previously been shown to be influential in commercial fisheries (e.g., Nielson and Mathiesen 2003) so this model was used to test for a direct effect on compliance. 
Finally, a seventh and fully inclusive model was formed. This model contained all 15 variables from the other six models and one new variable, regulation knowledge. Other compliance research (e.g., St John et al. 2011) strongly supports this inclusion; as without correct regulation knowledge non-compliance may be widespread. Besides instrumental and psycho-social factors, there are also other important drivers of non-compliance. Regulation knowledge can also be an important driver of non-compliance (Page and Radomski 2006; St John et al. 2011). If a regulation is unclear then effective enforcement is undermined (Akella and Cannon 2004). Similarly, if the rules are not widely known, then it is difficult for the behaviour to change (Keane et al. 2011). This final model therefore includes both the self-interest and pro-environmental behaviour variables while also including the legitimacy variables (the fourth model) suggested to be important influences in small-scale fisheries (Hauck 2008).

\subsubsection{Understanding compliance in recreational fisheries}

Despite the absence of a universal model for compliance in fisheries, it is generally agreed that non-compliance cannot be understood based on only one factor ( $\mathrm{H} \varnothing$ nneland 1999). A framework more complex than just economics and enforcement is needed (Gezelius 2006; Hatcher et al. 2000; Kuperan and Sutinen 1998; Nielsen 2003), especially for recreational fisheries where economic gain would not be a concern. However, the aforementioned research has only examined compliance in commercial or artisanal fisheries. To date, no studies have explored the drivers of compliance in a recreational fishery, at least beyond the role of regulation knowledge (Page and Radomski 2006).

As there are often more non-commercial than commercial fishers, for certain species and/or areas, recreational users can actually have an equivalent or larger effect than commercial users (Eliason 1999), which has shown to be the case for some individual fish species (Schroder and Love 2002). For example, the collapse of several fisheries in Canada could be attributed to recreational pressure (Post et al. 2002). Additionally, even after the halt of commercial fishing, some species' populations fail to recover until recreational fishing is also stopped (Denny and Babcock 2004; Denny et al. 2003; Shears and Usmar 2006). Thus, it is worthwhile to explore the drivers of non-compliance in recreational 
fisheries, especially as compliance in small-scale fisheries needs to be understood within a different framework: achieving social justice, legitimacy and deterrence (Hauck 2011).

\subsection{Materials and methods}

\subsubsection{Study fishery}

The reader is referred to section 1.6.3 for a detailed description of the Marlborough Sounds recreational blue cod fishery. The non-compliance rates ( $>30 \%$ for the size limit and $>10 \%$ for the daily limit) from chapter three suggest it could be worthwhile to explore why fishers are violating these two regulations.

\subsubsection{Survey Design}

The framework of pro-environmental behaviour proposed by Bamberg and Möser (2007) was used as the starting point for the questionnaire design. However, intention was not included as a factor due to the potentially sensitive nature of the behaviours in question; so this study modelled behaviour directly. In addition to these seven factors, nine other factors were also included based on the literature and other behavioural and compliance models reviewed above. This resulted in seven alternative models to be tested in choosing the best in predicting a fisher's compliance decision predicting (Table 4.1). 
Table 4.1: Summary of the seven compliance models tested and the factors included in each model.

\begin{tabular}{|l|l|}
\hline Model & Factors \\
\hline $\begin{array}{l}\text { Instrumental (Becker } \\
1968)\end{array}$ & $\begin{array}{l}\text { probability of detection, probability of conviction and penalty if } \\
\text { convicted }\end{array}$ \\
\hline $\begin{array}{l}\text { Theory of Planned } \\
\text { Behaviour (Ajzen } \\
1991 \text { ) }\end{array}$ & $\begin{array}{l}\text { attitude, social norm (descriptive and injunctive) and perceived } \\
\text { behavioural control }\end{array}$ \\
\hline $\begin{array}{l}\text { Instrumental and } \\
\text { Theory of Planned } \\
\text { Behaviour } \\
\text { combined }\end{array}$ & $\begin{array}{l}\text { probability of detection, probability of conviction, penalty if convicted, } \\
\text { attitude, social norm (descriptive and injunctive) and perceived } \\
\text { behavioural control }\end{array}$ \\
\hline $\begin{array}{l}\text { Legitimacy (Nielsen } \\
\text { and Mathiesen 2003; Tyler } \\
\text { 1990; Viteri and Chávez } \\
\text { 2007) }\end{array}$ & $\begin{array}{l}\text { meaningful rule, involvement in decision-making process, fairness and } \\
\text { effectiveness }\end{array}$ \\
\hline $\begin{array}{l}\text { Bamberg and } \\
\text { Möser (2007) }\end{array}$ & $\begin{array}{l}\text { factors from the Theory of Planned Behaviour plus problem } \\
\text { awareness, attribution, guilt, moral norm (see figure 4.1) }\end{array}$ \\
\hline $\begin{array}{l}\text { Modified Bamberg } \\
\text { and Möser }\end{array}$ & $\begin{array}{l}\text { factors from the Bamberg and Möser model plus addition of direct } \\
\text { path from social norm to non-compliance, based on the Theory of } \\
\text { Planned Behavior }\end{array}$ \\
\hline Fully Inclusive & $\begin{array}{l}\text { factors from the modified Bamberg and Möser model plus probability } \\
\text { of detection, probability of conviction, penalty if convicted, } \\
\text { meaningful rule, involvement in decision-making process, regulation } \\
\text { fairness and effectiveness, regulation knowledge }\end{array}$ \\
\hline
\end{tabular}

The first model tested was the instrumental model of compliance (Becker 1968) as previously described. Deterrence factors (probability of detection, probability of conviction and penalty if convicted) have been examined in commercial fisheries but here I explore their relevance in a recreational fishery. Specifically, probability of detection was measured as perceived enforcement rather than the actual (observed) probability of detection. A respondent's perception of enforcement is a more effective measure of the deterrence value as an individual will act on their perception of the odds of being detected (Akella and Cannon 2004). The second alternative model tested was the Theory of Planned Behaviour (Ajzen 1991), also described earlier in this chapter. The six variables included in these two models were combined into a third model to be tested, representing a combination of the instrumental and basic normative views of compliance. Four additional factors from the enriched model (outcome fairness and effectiveness, involvement in decision-making process and meaningful rule) were used as measures of the management regime's legitimacy and tested together as the fourth model. Although procedural fairness and effectiveness are included in Tyler's (1990) model of legitimacy, fishers interviewed in a pilot 
study did not mention these factors, nor did any news articles, so they were not included in the current study.

The framework of pro-environmental behaviour by Bamberg and Möser (2007), described in a previous section, was the fifth model tested. For the sixth model, a modified version of this framework was utilised. Whereas in the original Bamberg and Möser (2007) model the social norm influenced an individual's behaviour indirectly (through attitude, perceived behavioural control and moral norm), the modified version added a direct path from the social norm to compliance. Previous studies (Armitage and Conner 2001; White et al. 2009) of the Theory of Planned Behaviour have demonstrated that social norms can directly influence pro-environmental behaviour. Finally, a seventh and fully inclusive model was formed. This model contained all 15 variables from the other six models and with the addition of one new variable, regulation knowledge. Other compliance studies (e.g., Nkonya et al. 2008; St John et al. 2011) strongly support this inclusion; as without correct regulation knowledge non-compliance may be widespread.

Previous fisheries compliance studies that have considered normative factors have only included only the injunctive social norm, or an individual's perception of what others believe to be the appropriate conduct. Yet the descriptive social norm, or what an individual believes others are doing, can actually have a very strong influence on an individual's behaviour (Cialdini 2007). Thus, injunctive and descriptive social norms were measured separately and included in the relevant models as two factors determining the overall social norm. In total, 16 factors were tested (Appendix 9) and even though the majority of the potential compliance factors have previously been tested in fisheries, this study was the first to test the influence of problem awareness, attribution, guilt and attitude.

Piloting for the survey was conducted with eight fishers several months prior to data collection and their feedback was incorporated into the final questionnaire design. The final survey was carried out online using the survey platform Qualtrics (www.qualtrics.com).

\subsubsection{Data collection}

Participant recruitment was described in the previous chapter (section 3.2.2) as the current study was part of the same online study. In order to introduce the study, the questionnaire started with several general questions on fishing in the Marlborough Sounds which are not reported here. This was followed by three questions asking participants to 
provide the correct daily limit, minimum and maximum sizes for blue cod. The next three sections focused on the potential drivers of non-compliance. All but one of the 16 factors were measured using three or four statements, as this is the optimal number of indicators for a latent variable construct (Hall et al. 1999), and at least one statement per factor was reverse scored to minimize bias. For the majority of questions agreement was measured using a 5-point Likert-type scale anchored by 1 (strongly disagree) and 5 (strongly agree). The probability of conviction was assessed using a single question with five choices ranging from very high to very low.

Fishers first responded to statements covering the five factors that applied to both regulations: meaningful rule, involvement in decision-making process, problem awareness, attribution and probability of detection. The next section introduced the daily limit (two blue cod per person/per day) and instructed the respondent to answer the next set of questions which included the remaining 11 factors that were regulation-specific. In the subsequent section, the same set of statements was used for the size limit ( 30 to $35 \mathrm{~cm})$, with minimal wording changes to refer to the different regulation. Previous studies (Curcione 1992; Nielsen and Mathiesen 2003) have shown that compliance is not necessarily constant across a fishery and a violation of one or more regulations may be actually considered socially and morally acceptable; making it important to evaluate each regulation separately.

Finally, towards the end of the survey participants were directly asked whether they had violated either of the regulations in 2012. Respondents were instructed to answer for the most recent year they had been fishing in the Sounds if they had not been in 2012. In this way all fishers were allowed to participate in the full survey. However, for the present study I only analysed data from those fishers who had fished in the Sounds in 2012. There was also a chance for respondents to comment on anything regarding blue cod fishing in the Sounds as the last question; providing an opportunity to elaborate on answers to previous questions and/or give examples to help illustrate their views.

It should be noted that there are concerns around the use of direct questioning to gather information on illegal resource use (Gavin et al. 2009), including non-compliance with fisheries regulations. Although an online format allows for greater anonymity and more honest answering (de Leeuw 2008), an indirect method may be useful for obtaining more accurate violation estimates. Indeed, the results of chapter three (Thomas et al. 2014a) 
validate this concern, albeit with mixed results. The estimate of non-compliance with the daily limit was not significantly different between direct or indirect questioning (see chapter two), making it a non-issue for this study. However, for the size limit, direct questioning did not perform as well as an indirect method (randomized response technique) with a significantly lower estimate of non-compliance ( $29 \%$ vs. $42 \%)$.

Despite this finding, direct questioning estimates were still used in this study for reasons besides the lack of methodology to further analyse the indirect questioning data. Firstly, the percentage answering "yes" under direct questioning is high enough to effectively model the drivers of non-compliance. The dishonest answering would not invalidate the model but lower the predictive value as it introduces a source of error. The fishers in question would have responded to the Likert-type questions honestly and but then answered "no" on the compliance question even though they had broken that regulation. So although their other answers would fit the pattern of non-compliance, the result would not match up with the expected behaviour; introducing uncertainty in the model. Secondly, some respondents will not answer honestly regardless of method (van der Heijden et al. 2000), meaning underestimation of an unknown amount will still occur.

\subsubsection{Data analysis}

The Wilcoxon signed-ranks test and Wilcoxon matched pairs signed-ranks test were used as data were not normally distributed for all factors (Field 2009). Structural equation modeling was performed using MPlus. Due to the categorical nature of the outcome variables, WLSMV (weighted least square means and variance-adjusted) was used for the estimator. This method, which uses probit regression, has been found to provide the best results for modeling categorical data (Brown 2006; Byrne 2012) and does not assume data are normally distributed (Brown 2006).

\subsection{Results}

The final sample was comprised of 320 fishers, with $82 \%$ male and $45 \%$ from the Marlborough region. Fisher age ranged from 22 to 88 years $(M=54, S D=12)$, while Sounds fishing experience ranged from one to 70 years $(M=28, S D=17)$. Eighty-nine percent of respondents owned a boat and $37 \%$ owned a holiday home in the Sounds. For the questions 
testing regulation knowledge, $91 \%$ of fishers chose the correct daily limit (two), $89 \%$ the correct minimum size $(30 \mathrm{~cm})$ and $94 \%$ the correct maximum size $(35 \mathrm{~cm})$.

\subsubsection{Measurement models}

Prior to testing the full models, the 16 constructs were tested separately for both validity (confirmatory factor analysis, CFA) and reliability (Cronbach's alpha) to determine the best-fitting measurement models. Confirmatory factor analysis was used to ensure the statements satisfactorily measured the underlying and unobserved latent construct. When assessing model fit, both comparative and absolute model fit indices were used with the following cut-offs: chi-squared test/degrees of freedom $\left(x^{2} / d f\right) \leq 3$, comparative fix index $(C F I) \geq .95$, root mean square error of approximation $(R M S E A) \leq 0.06$, and standardized root mean square residual $(S R M R) \leq .08$ (Hu and Bentler 1999). As a measure of reliability, Cronbach's alpha was also calculated and used alongside the CFA results to determine if items needed to be removed from the measurement models. A Cronbach's alpha value of 0.70 or greater generally indicates reliability (Field 2009).

As there is no overall cut-off for a 'valid' factor loading (Byrne 2012), all items with low factor loading were analysed separately. These items were removed if the path was not significant, or if removal increased the model fit and/or Cronbach's alpha to an acceptable level. For daily limit attitude, two paths were not significant but one was retained in order to keep three items. Models with only three items (e.g., attribution, probability of detection) were initially not identified during CFA as there were no degrees of freedom. In order to identify the model two steps were taken: 1 ) the highest loading item was fixed to one and 2) the item with the second-highest loading was fixed to the original loading value. In this way the model had one degree of freedom and could be identified.

After elimination of the low-scoring and non-significant items, all final measurement models met the previously-stated thresholds for CFI and SRMR; although not all $x^{2} / d f$ and RMSEA scores did (Appendix 10). Fourteen (out of 25) models had a Cronbach's alpha score of 0.7 or greater, indicating good internal reliability (Field 2009). Of the remaining eleven constructs, all but three (penalty for daily and size limit and attitude for size limit) were above 0.5 which may suffice (Field 2009). As the final CFA results demonstrated good model fit for each construct, we chose to keep all the potential drivers in the final models. 
Cronbach's alpha can sometimes be increased by adding items to measure. However, with four starting statements for each construct additional items was not a viable option for this survey. Also, for the injunctive social norm, it is also worth noting that three of the four statements asked about other fishers while the fourth asked about family and friends. It is likely this contributed to the lower alphas $(0.54$ and 0.64$)$ for this particular construct.

\subsubsection{Compliance factors}

The Wilcoxon signed-ranks test was used to determine if the factor medians significantly differed from the neutral midpoint of three (Figures 4.2 and 4.3). The results showed that the level of disagreement or agreement given by the fishers was statistically significant for every factor except the effectiveness and fairness of the daily limit. While overall fishers accepted the suite of blue cod regulations as meaningful, and were neutral or positive towards all aspects of the daily limit, they recorded negative scores towards several aspects of the size limit (fairness, effectiveness and attitude) and involvement in the decision-making process. The negative view of fisher involvement was brought up often in the open-ended question on blue cod fishing (at the end of the survey) with fishers complaining that the BCMG recommendations were 'ignored' and that the consultation process was a "sick joke"" and "a shambles". Similarly, the majority of fisher comments on this final question concerned the size limit with the number of fish discarded and their mortality raised as a major concern. Respondents described the size limit using phrases such as: "total stupidity", "wasteful and inefficient" and "unfair and discriminatory".

Comparing the factor means for the daily limit and size limit, the level of agreement or disagreement differed for all but three factors: regulation knowledge probability of conviction and penalty if convicted; with differences reflecting a more negative attitude towards the size limit. 


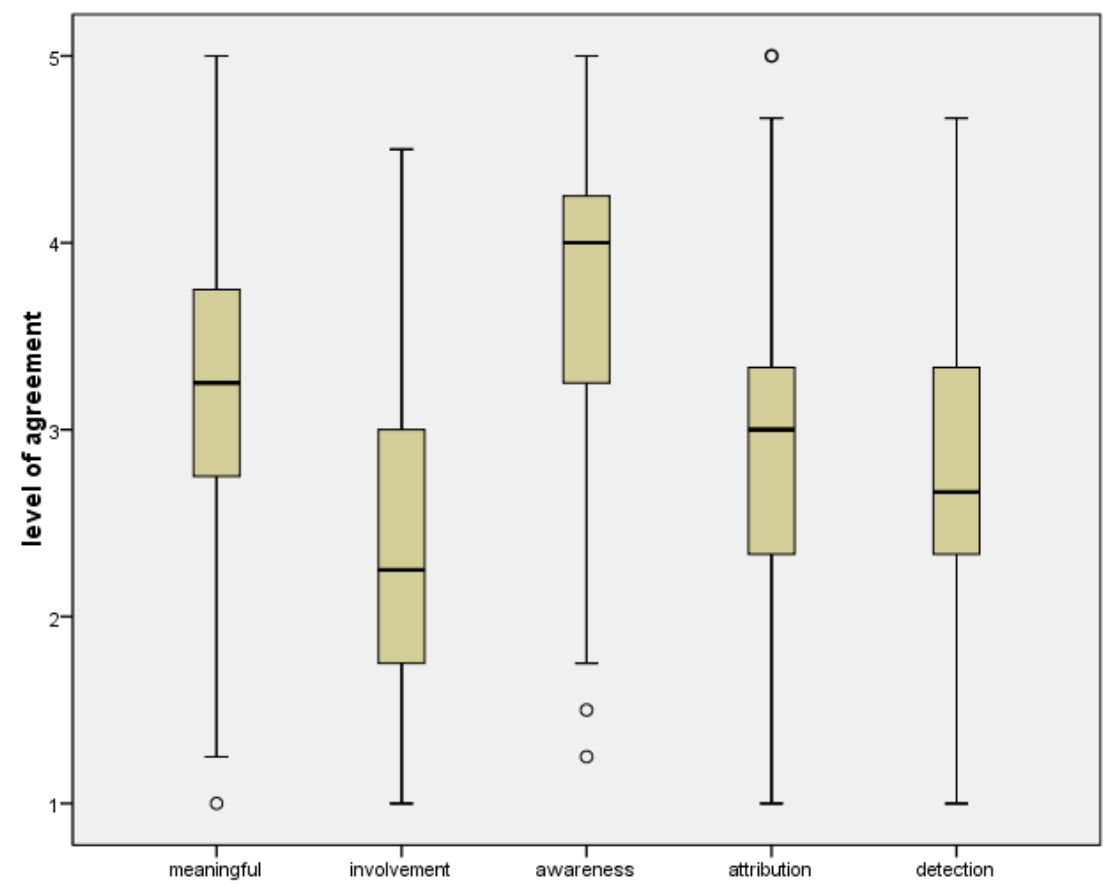

Figure 4.2: Fisher agreement with the five drivers of non-compliance that applied to both regulations. A higher score indicates a more positive attitude. All medians were significantly different from the neutral midpoint of 3 (Wilcoxon signed rank, $\mathrm{p}<.05$ ). $\mathrm{N}=320$.

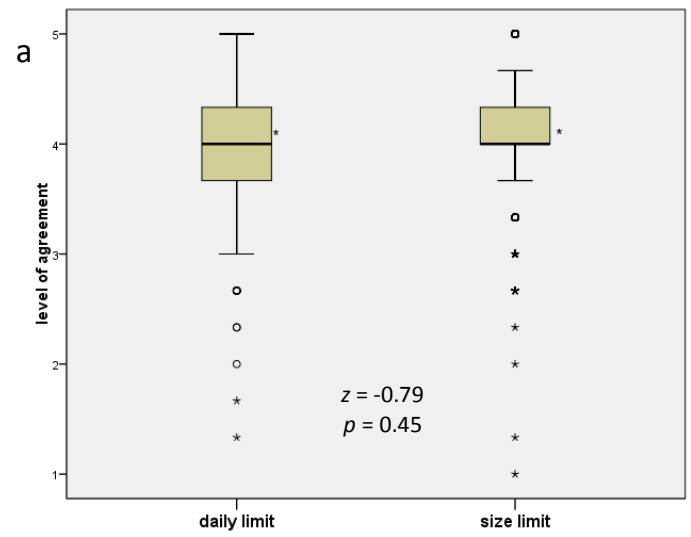

b

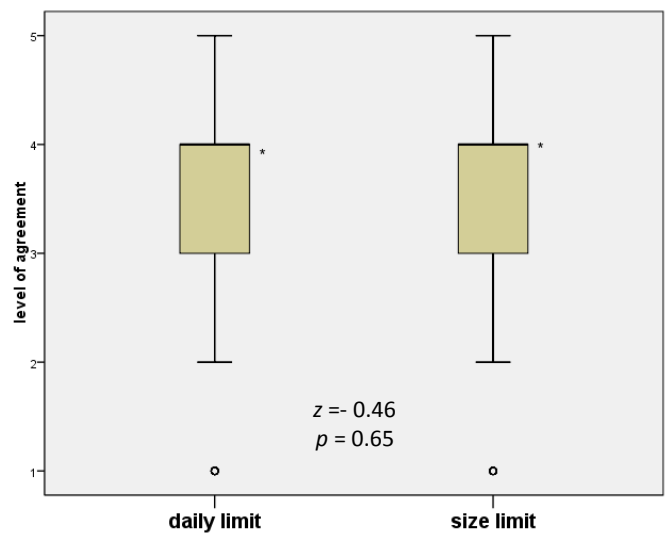

c

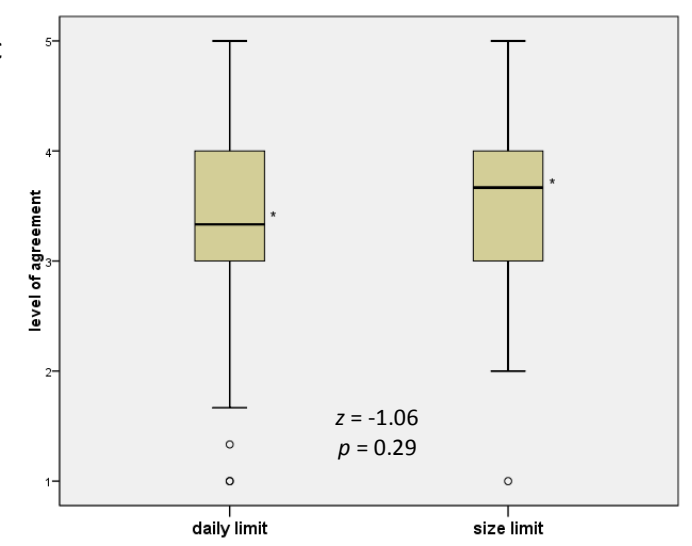



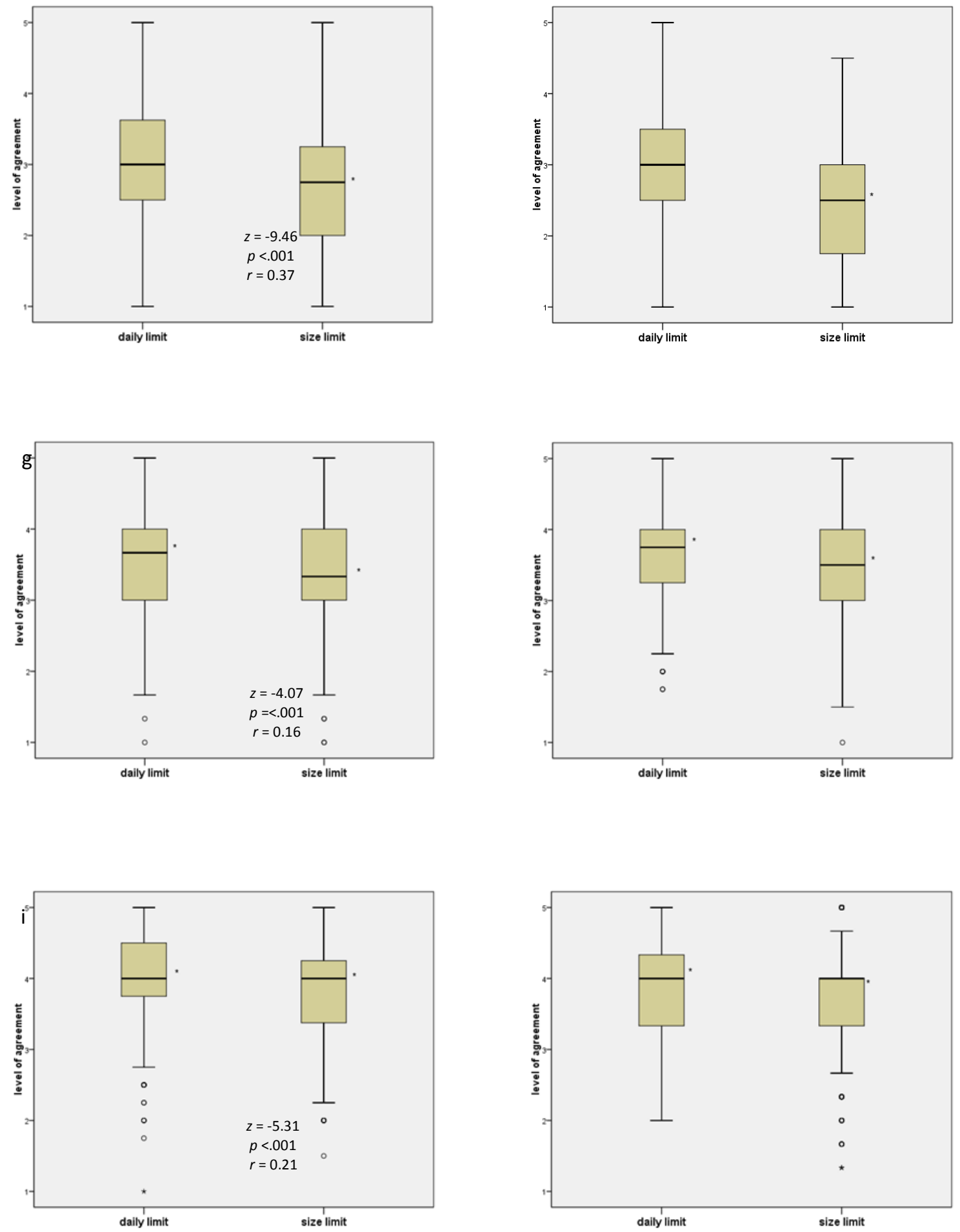

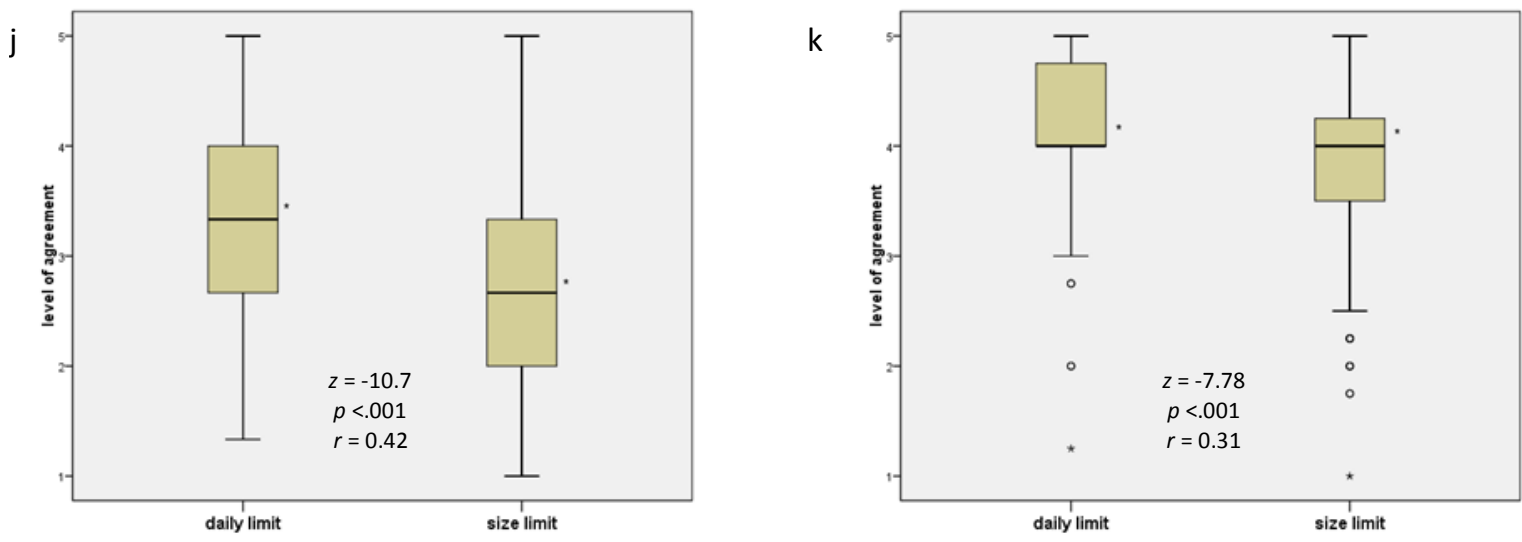

Figure 4.3: Distribution of scores for the regulation-specific drivers of non-compliance. a) regulation knowledge, b) probability of conviction, c) penalty if convicted, d) fairness, e) effectiveness, f) descriptive social norm, g) injunctive social norm, h) guilt, i) perceived behavioural control, j) attitude and k) moral norm. A higher score indicates a more positive attitude. * indicates the median is significantly different from the neutral midpoint of 3 (Wilcoxon signed rank, $p<.05) . N=320$.

\subsubsection{Structural equation models and model selection}

After confirming the best-fitting measurement models, structural equation modeling was then carried out to determine how these factors influenced a fisher's compliance behaviour. The results of the structural equation model testing are presented in Table 1. For all tested models non-significant paths and factors were removed but no additional paths were added except for the inclusive model (model 7).

Table 4.2: Summary of model fit indices for the seven structural equation models to explain fishers' compliance with the daily and size limits for blue cod.

RMSEA = root mean square error of approximation, CFI = comparative fit index and TLI = Tucker-Lewis Fit Index. Shading indicates the best-fitting model for that regulation.

\begin{tabular}{|c|c|c|c|c|c|c|c|c|}
\hline \multirow[t]{2}{*}{ Model } & \multicolumn{8}{|c|}{ Model fit indices } \\
\hline & Regulation & $x^{2}$ & $d f$ & $x^{2} / \mathrm{df}$ & RMSEA & $\mathrm{CFI}$ & TLI & $R^{2}$ \\
\hline \multirow[t]{2}{*}{ 1. Instrumental } & Daily Limit & 2.55 & 1 & 2.55 & $.03(0-.12)$ & .92 & .88 & .08 \\
\hline & Size Limit & 0.12 & 1 & .12 & $.00(.00-.02)$ & 1.0 & 2.39 & .03 \\
\hline \multirow[t]{2}{*}{ 2. TPB } & Daily Limit & 58.97 & 5 & 11.79 & $.19(.14-.23)$ & .55 & .19 & .39 \\
\hline & Size Limit & 142.57 & 4 & 35.64 & $.33(.29-.38)$ & .46 & -.21 & .50 \\
\hline \multirow{2}{*}{$\begin{array}{l}\text { 3. Instrumental + } \\
\text { TPB }\end{array}$} & Daily Limit & 98.27 & 13 & 7.56 & $.14(.12-.17)$ & .43 & .20 & .44 \\
\hline & Size Limit & 218.82 & 13 & 16.83 & $.22(.20-.25)$ & .33 & .08 & .52 \\
\hline \multirow[t]{2}{*}{ 4. Legitimacy } & Daily Limit & 16.01 & 7 & 2.29 & $.06(.02-.11)$ & .72 & .60 & .11 \\
\hline & Size Limit & 10.8 & 5 & 2.16 & $.06(.00-.11)$ & .97 & .95 & .09 \\
\hline \multirow{2}{*}{$\begin{array}{l}\text { 5. Bamberg \& } \\
\text { Möser }\end{array}$} & Daily Limit & 66.36 & 22 & 3.02 & $.08(.06-.10)$ & .91 & .86 & .29 \\
\hline & Size Limit & 55.41 & 15 & 3.70 & $.09(.07-.12)$ & .95 & .91 & .55 \\
\hline \multirow{2}{*}{$\begin{array}{l}\text { 6. Modified } \\
\text { Bamberg \& } \\
\text { Möser }\end{array}$} & Daily Limit & 2.10 & 1 & 2.10 & $.06(.00-.17)$ & .99 & .96 & .37 \\
\hline & Size Limit & 12.62 & 6 & 2.10 & $.06(.00-.10)$ & .99 & .96 & .56 \\
\hline \multirow[t]{2}{*}{ 7. Full Inclusive } & Daily Limit & 143.48 & 48 & 2.99 & $.08(.06-.10)$ & .83 & .76 & .29 \\
\hline & Size Limit & 162.63 & 54 & 3.01 & $.08(.07-.09)$ & .91 & .87 & .56 \\
\hline
\end{tabular}


The reported measures of model fit and the $r$-squared value were used to determine the model that best explained the data. The measures of model fit included three previously used for CFA as well as the TLI (Tucker-Lewis Fit Index). TLI is a non-normalized index of model fit but includes a penalty for overly complex models and is interpreted in the same way as CFI where a good model fit value is $\geq .95$ (Byrne 2012).

For the daily limit regulation, the modified Bamberg and Möser model was the best fitting model and also explained four times the amount of variance ( $37 \%$ vs. $8 \%)$ compared with the next best-fitting model (instrumental). Therefore, the modified Bamberg and Möser was selected as the best determinant of a fisher's decision to comply with the daily limit. Under this model social norm was the only driver $(B=.61)$ of daily limit compliance (Figure 4.4). Descriptive norms ( $B=.73)$ had a stronger contribution to the overall social norm construct compared to injunctive norms $(\beta=.53)$. A stronger social norm increased the probability of a fisher complying with the regulation. All other variables were removed due to a lack of significant paths.

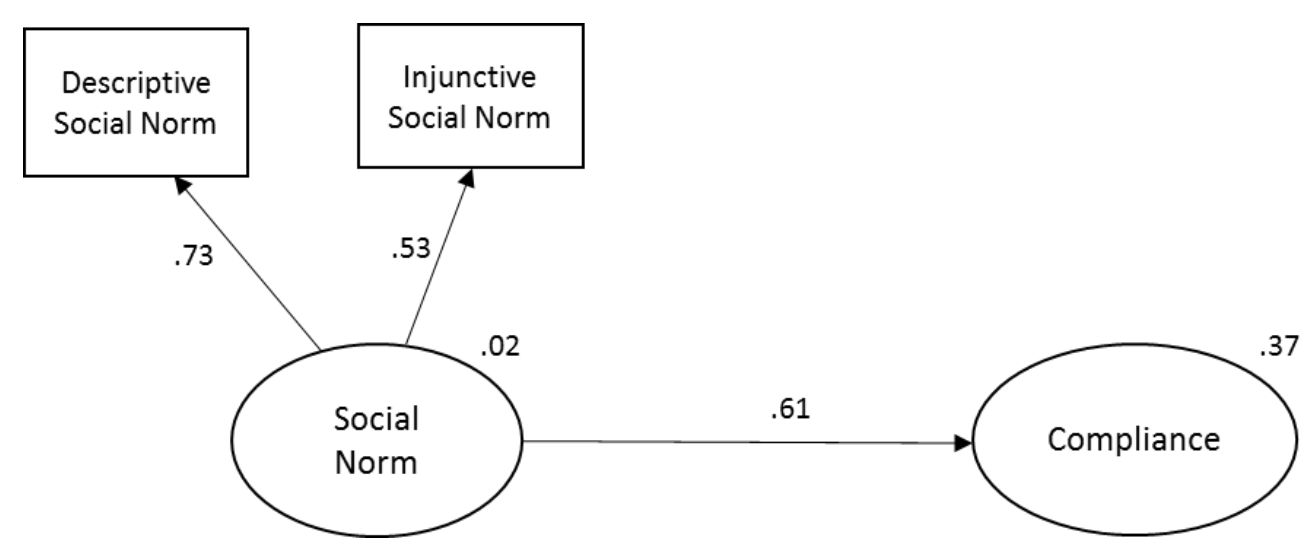

Figure 4.4: Graphical output of the selected best-fitting model for fishers' compliance with the daily limit regulation. Numerical values on arrows are standardized regression coefficients $(B)$ and values in the top right of ovals representing the constructs are coefficients of determination $\left(R^{2}\right)$. Note: $R^{2}$ value for the social norm was unable to be calculated due to only one degree of freedom.

For the size limit regulation, three alternative models had comparable fit: instrumental, legitimacy and the modified Bamberg and Möser. However, the instrumental model explained only $3 \%$ of the variance. Although the RMSEA for the modified Bamberg and Möser model suggests only a moderate fit, CFI and TLI were the highest of any of the tested models. Importantly, the model also explained more than five times the variance of 
the legitimacy-based model (56\% vs. $9 \%$ ) and can be regarded as the best-fitting model for the size limit.

Examining this model (Figure 4.5), social norms have the largest influence $(b=.66)$ on a fisher's decision to comply with the size limit regulation. As the social norm increased, the probability of a fisher complying with the size also increased. For size limit injunctive norms $(B=.78)$ had a stronger contribution to the overall social norm construct compared with descriptive norms $(B=.67)$. A fisher's attitude had a smaller $(B=.19)$ direct influence, with a more positive attitude increasing the probability of compliance. Moreover, problem awareness and feelings of guilt had indirect influences on compliance with the size limit regulation.

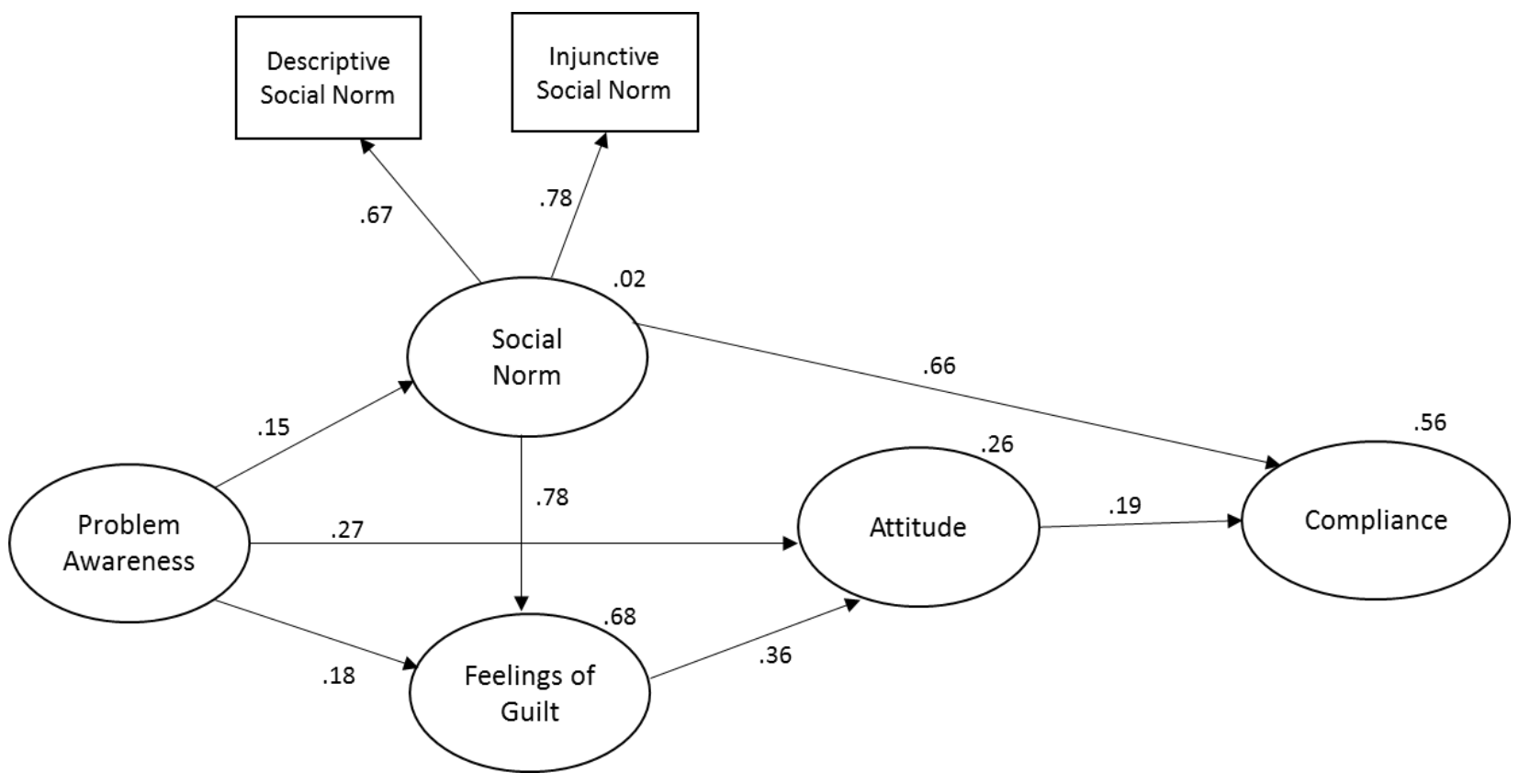

Figure 4.5: Graphical output of the selected best-fitting model for fishers' compliance with the size limit regulation. Numerical values on arrows are standardized regression coefficients $(B)$ and values in the top right of ovals representing the constructs are coefficients of determination $\left(R^{2}\right)$ and the standard error (for the observed variable

\subsection{Discussion}

\subsubsection{Drivers of non-compliance}

This study focused on identifying fishers' reasons for non-compliance with the daily and size limits for recreational blue cod fishing in the Marlborough Sounds, New Zealand. 
Whereas both instrumental factors and normative factors have been shown to be relevant in commercial and artisanal fisheries (Hatcher and Gordon 2005; Hønneland 2000; King and Sutinen 2010; Kuperan and Sutinen 1998), their influence in a recreational fishery was previously unstudied. More importantly, seven alternative models, including instrumental, normative and psycho-social factors, were tested against each other for their ability to explain a fisher's compliance decision.

The current study appears to be the first to use this model testing approach in fisheries research as previous studies tested different factors rather than multiple behavioural models. A key advantage of structural equation modeling is providing information on relationships between the drivers, including both direct and indirect effects, for a more complete understanding. Utilisation of this method provides a robust approach to determining the effectiveness of the multiple and potentially opposing models to predict compliance behaviour. SEM also allows for the model constructs (in this case the potential drivers) to be tested as latent variables.

Overall fishers believed that they were unlikely to be caught and were more negative towards the size limit than the daily limit. For both regulations, the best-fitting compliance model contained no instrumental factors and showed that the overriding influence on a fisher's compliance with either regulation was social norms; what other fishers and family and friends thought of their decision to comply. This finding contrasts with non-compliance in most commercial fisheries which tend to emphasise instrumental factors (King and Sutinen 2010; Nielsen and Mathiesen 2003) rather than normative factors. Although, social norms have proven influential in artisanal fisheries in Malaysia (Kuperan and Sutinen 1998) and commercial fisheries Sweden (Jagers et al. 2012) as well as in other conservationrelated intentions in countries including Argentina (Mastrangelo et al. 2014) and China (Chen et al. 2009). In terms of an overall management strategy to reduce non-compliance, promoting voluntary compliance is likely to be the most effective approach. Increasing enforcement efforts could actually make the situation worse given the median scores for factors such as involvement in the management process and regulation fairness were lower than neutral. The results of this study offer insights into ways in which the Ministry of Fisheries could increase voluntary compliance among fishers.

The best-fitting models explained more than half of the variance in an individual's compliance decision with the size limit (56\%) and more than a third (37\%) of it for the daily 
limit. Although these results, especially the size limit, are strong considering the subject is an illegal and potentially sensitive behaviour, there is still a large proportion of the variance unaccounted for and suggests the need for an adaptive management strategy to reduce uncertainty. One likely source of the remaining variation would be a number of violations being unplanned as opportunistic behaviour can influence compliance decisions (Nielsen 2003). For example, if a fisher was approaching the end of the trip and had yet to catch a legal-sized cod, he may be tempted to keep the next two, regardless of size, in order to not return empty-handed. Similarly, social pressure from someone else on the fishing trip to keep an extra or over-sized blue cod could also result in an unexpected violation.

Additionally, as noted in the methods section, this study utilized compliance estimates from direct questioning which has been shown to underestimate the extent of non-compliance for the size limit (Thomas et al. 2014a). Finally, the Cronbach's alpha for both injunctive social norms and size limit attitude was lower than the usual cut-off value of 0.7. A higher reliability for these construct could increase the predictive ability of the bestfitting model. Under an adaptive management strategy, the results of the behavioural interventions targeting the social norms would be evaluated. The low reliability may hinder the effectiveness of these interventions as there may be a mismatch between the measured injunctive social norm and the one intended to be tested. Further exploration into the drivers of compliance could seek to improve measurement of the injunctive norm construct, potentially by separating other fishers' views from those of family and friends.

\subsubsection{Management implications}

Behavioural interventions to encourage compliance with the regulations would be effective given the importance of social norms in influencing fisher's compliance behaviour. As illegal acts are more likely if individual can rationalize them as being acceptable (Smith and Anderson 2004), the strong influence of a descriptive social norm is important; especially for the size limit with over $40 \%$ of fishers in violation of this regulation. Furthermore, the social reputation of a fisher who violates will not be affected if a large proportion of their peers do the same (Kuperan and Sutinen 1998). However, behavioural interventions targeting the descriptive social norm need to be done in a positive way emphasizing that the majority of fishers 'do the right thing' and comply with the regulations. A focus on the prevalence of the negative behaviour has previously been shown to backfire 
(Cialdini 2007; Cialdini 2003). For example, a newspaper article in 2012 (Nicoll 2012b) focused on how during a two week period one in five fishers broke the size limit. Hearing that so many of their peers violate this regulation may increase the incentive for a fisher to do the same as they are made aware of the frequency of the behaviour and change theirs to 'fit in'.

To help address the descriptive social norm, the Ministry could provide a press release, widely distributed through different media, highlighting high levels of compliance in helping the fishery to recover. The use of control and experimental groups would provide a means to test the effectiveness of this intervention in changing the descriptive social norm. Fishers in both groups could be asked about what they believe other fishers do, and then expose one group to press releases and or/articles on the extent of compliance. After exposure to this information, fishers would be asked the same questions on other fishers' actions to test for any changes. As undesirable behaviours are often overestimated (Borsari and Carey 2003), changing fisher's perceptions of this action could be effective in changing the descriptive norm. Modification of the press release for publication in fishing magazines would also be beneficial to reaching a wide number of fishers as in 2009 , fishing magazines were the most-used source for obtaining fishing information while newspapers were second and the Ministry's website third (Batstone et al. 2009). Although this may have changed, it still underlines the importance of distributing information through channels other than the official website.

The injunctive norm should also be the target of different behavioural interventions and I suggest consideration of the 'block leaders' approach. Under this method information is disseminated by volunteers, with the expectation that it will be most effective if coming from someone more similar and in the same social network (Abrahamse and Steg 2013). Thus fishers not in compliance with the regulations may be more likely to change their behaviour if the intervention comes from someone similar and in the same network (i.e., another fisher) instead of the Ministry. This is likely to be especially true given the prevalence of negative attitudes towards the Ministry and the regulations (Thomas et al. 2014b). The Ministry could work with influential members of the fishing communities, such as long-time fishers and leaders of fishing clubs, to employ tactics to target the injunctive social norm. 
Letters to the editor in the local newspaper (already common) would be a potential behavioural intervention and take relatively little time for the fishers involved. Stern (2000) showed that norms are more important if there is a moral obligation attached to the desired action, so these writings could emphasize how compliance with the regulations is the best course of action as there is a collective responsibility to sustain the fishery for the future (a goal previously expressed by many fishers). Better dissemination of information, especially in non-scientific terms, to fishers regarding the benefits of the size limit to the fishery could also be effective; as during the intercept survey several inquired as to the purpose of the maximum size.

Another important point is the possible influential distinction between the types of norm and regulation. The results depicted in Figures 4.3 and 4.4 suggest that descriptive norms (what fishers believe others are doing) are more important for fostering compliance for daily limit regulation, while injunctive norms (fishers' perception of what others believe to be the appropriate conduct) is more important for size limit. Descriptive norms have been demonstrated to be more effective when the injunctive norm surrounding a specific behaviour is mixed (Jacobson, Mortensen and Cialdini 2011), which is likely to be the case for the size limit.

An individual's self-regulation capacity can also help determine which social norm should be targeted. Injunctive social norms are less effective when the self-regulating capacity is low (Jacobson et al. 2011) such as towards the end of work. On this basis, behavioural interventions during intercepts (at sea or on land) would best target the descriptive social norm. Fishers are likely to have lower self-regulating capacity during this time as they are in the middle of fishing and less likely to have the willpower/desire to make decisions that put their immediate self interest in conflict with long-term interpersonal goals. Furthermore, behavioural interventions are likely to differ in their effectiveness between groups (Abrahamse and Steg 2013). Individuals use social descriptive norms to guide their behaviour especially when the situation is new or ambiguous (Jacobson, Mortensen and Cialdini 2011). Inexperienced fishers and/or fishers new to the Marlborough Sounds may thus be more responsive to behavioural interventions emphasizing that the majority of fishers comply with the daily and size limits.

After establishing social norms as the largest determinant of a fisher's compliance decision, the next step is to identify their influencing factors. The four factors comprising 
legitimacy (outcome fairness and effectiveness, meaningful rule and participation) have been shown to be influential in other small-scale fisheries (Hauck 2011). They are also likely to be important in the Marlborough Sounds (partially through social norms), based on factor scores, interviews and comments, and were a significant influence on the social norm in the fully inclusive model. Ideally these normative factors that affect social views on a regulation should be addressed during the planning stages (Thomassin et al. 2010) as it would be easier than changing attitudes after regulation implementation. Greater consideration of fisher attitudes and increased involvement in the management process has also demonstrated benefits in enhancing legitimacy in other fisheries (Pita et al. 2010; Richardson et al. 2005; Viteri and Chávez 2007).

A study in Newfoundland and Norway (Gezelius 2004) showed how attitudes towards non-compliance can vary; finding that fishers usually turned a blind eye towards violations for food, whereas violations for profit were met with social disapproval. A similar situation is suggested for the Marlborough Sounds where exceeding the daily limit is most likely done out of greed; but a violation of the size limit is rationalized due to concerns over the mortality of the discarded blue cod undermining the regulation's effectiveness. If a fish outside the size limit is injured, the dilemma is likely to be even stronger. As in other fisheries (e.g., Nielsen and Mathiesen 2003) fishers do not see the point of discarding a dead or mortally-injured fish. In response to the open question on blue cod fishing one fisher admitted to keeping blue cod outside of the limit, but only because the fish were badly injured or gut-hooked and bleeding and were going to die. The data suggest fisher concerns surrounding the size limit result in some ambiguity over the decision to comply, resulting in a lower level of guilt, weaker moral and injunctive social norms and finally a higher level of non-compliance with the size limit.

Despite social norms acting as the largest influence on a fisher's compliance decision for both regulations, the significant differences between most of the factor medians demonstrate benefits to examining each regulation separately. It is also important to note that this study did not differentiate between undersized and oversized blue cod, due to the length of the survey. As minimum size limits are one of the most common fisheries management tools (Radomski et al. 2001) that apply to most recreationally caught fish species within New Zealand (Ministry of Fisheries 2014b), most non-compliance is likely to be taking over-sized blue cod. However, further research could be carried out to test this 
assumption and determine if the drivers of compliance differ between undersized and oversized blue cod. Finally, further investigation into why fishers have agreed or disagreed with the specific drivers evaluated could provide important insights into variables that are likely to influence the social norm.

The results of this study, especially the influence of social norms, can help fisheries managers design effective and targeted behavioural interventions, thus saving time and resources. Timely intervention is needed as it can prove impossible to rebuild moral norms once eroded (Nielsen 2003) and this may be true for social norms as well. Ensuring a highly transparent and inclusive review of the regulations later in 2014 would be an important step towards optimizing voluntary compliance and increasing the legitimacy of the management regime; although other actions and behavioural interventions can take place sooner. Under a deterrence-based management strategy fishers comply with the regulations for fear of the consequences, but the failure of this strategy failure is inevitable (Karper and Lopes 2014). Between this and the importance of social norms in the Marlborough Sounds blue cod fishery, addressing the drivers of non-compliance should commence sooner rather than later. 


\section{Managing the impact of fishery regulations on discard rates, compliance and fisher satisfaction}

\subsection{Introduction}

Fishery management often aims to protect fish stocks from overfishing by maintaining sustainable harvest levels while maximising catch rates (Tetzlaff et al. 2013). The most frequently used regulations for achieving these objectives in recreational fisheries are limiting the total catch per day or per trip (i.e., bag or harvest limits) and restricting the size of fish allowed to be kept; i.e., minimum and/or maximum size limits (Radomski et al. 2001). However, not all caught fish are kept, and these catch-and-release discards occur because of regulations or voluntarily. Regulatory discards refer to fish that must be discarded because they exceed quota or trip limits, are caught as non-commercial or incidental by-catch, out-of-season, or do not meet the minimum/maximum size limit for that species (Hill and Wassenberg 1990). The voluntary practice of discarding legally landable fish in the hopes of catching a larger and/or more valuable fish is referred to as "high-grading" (Kristofersson and Rickertsen 2009) and has been recorded in many fisheries (Anderson 1994), including recreational ones (e.g., Bochenek et al. 2012).

In many marine recreational fisheries, both regulatory and voluntary catch-andrelease rates are increasing (Tetzlaff et al. 2013). For example, in Eastern North America over $90 \%$ of some fish species caught are released because they cannot be legally retained (SEDAR (Southeast Data 2009) and in several European countries over half of the fish caught in marine recreational fisheries are released (Ferter et al. 2013). Regulations designed to conserve fish stocks can also unintentionally encourage catch-and-release discarding and high-grading (Copes 1986; Jensen and Vestergaard 2002) by limiting a fisher's catch. In turn, fishers may attempt to maximize their overall catch by discarding the smaller fish caught (Woodward and Griffin 2003). The success of length-based limits as a management strategy depends on the released fish surviving, recovering quickly and not experiencing long-term sub-lethal impairments (Broadhurst et al. 2005; Muoneke and Childress 1994; Waters and Huntsman 1986). 
Clearly the survival of released fish is uncertain, and post-release mortality is the largest source of uncertainty in estimating total fishing mortality (Davis 2002). Even low post-release mortality rates have the potential to undermine the effectiveness of fishery management regulations, affect the sustainability of the fishery (Coggins et al. 2007; Douglas et al. 2010) and prevent stock recovery (Morandeau et al. 2014). Post-release mortality has been found to reduce both size and abundance (Wydoski 1977 as cited in Cooke and Wilde, 2007) and can also have sub-lethal physiological, behavioural and fitness impairments (Cooke et al. 2002). For example, handling a fish can cause the disruption or removal of the external mucous layer covering the fish body, which may in turn increase the risk of pathogenic infections, especially those associated with fungi (Cooke and Wilde 2007). Some studies (Clapp and Clark, 1989; Diodati and Richards, 1996) have found a negative influence of catch-and-release on fish health such as a slower growth rate (but see Pope and Wilde, 2004). Moreover, fish continually exposed to stress from catch-and-release may have weakened immune systems, be more susceptible to disease (Muoneke and Childress 1994), and have altered reproductive output quality, quantity and timing (Davie and Kopf 2006).

Post-release predation by seabirds is another potential source of post-release mortality. In commercial fisheries, fish discards provide an easy source of food for seabirds to exploit (Votier et al. 2004) leading to increased populations (Arcos and Oro 2002; Furness 1984, 2003; Furness et al. 2007; Oro et al. 2004) and modified feeding habits and diets (Blaber and Wassenberg 1989). Modified seabird biology can result (Mañosa et al. 2004; Oro et al. 2004; Oro et al. 1996; Tavecchia et al. 2007), including increasing the short-term breeding and survival performance of seabirds (Tavecchia et al. 2007) and greater site fidelity (Bartumeus et al. 2010).

Fisheries researchers have also called for greater integration of human behavior into recreational fisheries analyses (Arlinghaus 2004; Fulton et al. 2011; Post and Parkinson 2012) and fisher attitudes are becoming increasingly important to management bodies when designing regulations (Eggert and Ellegård 2003). Managers should therefore seek to balance biological, social and economic objectives for the fishery, which may be conflicting (Jentoft and Chuenpagdee 2009; Koehn and Todd 2012). Regulation support from fishers is highly beneficial (Fisher 1997) and can assist in maximising compliance (Kuperan and Sutinen 1998; Viteri and Chávez 2007). As even low levels of non-compliance can undermine 
the effectiveness of the fishery management strategy (Gigliotti and Taylor 1990; Kaplan 1998), there is a pressing need to assess and predict fisher support for both current and alternative regulations (Wilde and Ditton 1999). Since increasing restrictions while maintaining high levels of fisher support may not be simultaneously achievable (Powell et al. 2010), managers should attempt to find regulatory options that promote fisher satisfaction while reducing discards and associated post-release mortality.

\subsubsection{Study Aims}

Within the context of these information requirements for designing and implementing fishery management regulations, this study investigated the most effective size limit regulation for a particular recreational fishery. Specifically, this study aims to help determine how to sustain the recreational blue cod fishery in the Marlborough Sounds, New Zealand by minimizing the number of discarded fish while simultaneously maximizing fisher satisfaction. The research also sought to determine if the number of fish discarded significantly influenced regulation agreement and/or compliance. In order to obtain this information, three different size limit scenarios were used, one current and two alternatives, and evaluated in terms of fish discarded and fisher satisfaction with the regulation. Including a control scenario was important as understanding fisher behaviour under the current regulations is crucial to properly evaluating alterative regulations (Rettig et al. 1989).

Although the literature shows that fisher attitudes can be influenced by the extent to which a regulation affects their fishing habits (Pita et al. 2013; Thomas et al. 2014b; Wilde and Ditton 1999), the effect of discards on both fishing satisfaction and regulation agreement is largely unstudied. Two studies in the United States found that being forced to discard an increasing numbers of flounder decreased fisher satisfaction (Bochenek et al. 2010; Powell et al. 2010), although this was measured in terms of the number of fish kept which is not the most important factor in the Sounds (Batstone et al. 2009). However, todate no research has been carried out on the potential influence of discards on a fisher's compliance decision or regulation agreement. 


\subsubsection{Study Fishery}

As blue cod are protogynous hermaphrodites (Carbines 1998a; Ministry of Fisheries 2008c) the maximum size limit was introduced leave large male blue cod in the population in order to suppress a sex-change in the large female fish. As fishers selectively exploit the larger fish (Lewin et al. 2006), fishing pressure leads to a decrease in the mean female size as well as a sex ratio skewed towards males (Shepherd et al. 2010). This can negatively influence the reproductive potential of populations as larger fish have been shown to produce more batches of eggs (Crossland 1977; Zeldis and Francis 1998). Therefore effective management of blue cod requires measures that protect both sexes (Shepherd et al. 2010).

Since the fishery reopened there is a worry among fishers that the number of blue cod discarded has increased, mainly from the addition of the maximum size and the small $(5 \mathrm{~cm})$ slot (Moore 2012). For example, during the last 14 trips before the new regulations came into effect, one charter boat operator reported an average of 60 blue cod caught with 49 kept; however, during the first 14 trips under the new regulations, the average catch jumped to 358 with 32 kept (Humm 2013). Because of the perceived increase in discards, many fishers do not agree with the maximum size limit and believe the slot rule is doing more harm than good (Moore 2013; Nicoll 2012a). A non-compliance rate of 40\% in 2012 (Thomas et al. 2014a) may reflect this attitude and raises concerns over the effectiveness of the maximum size limit.

In an effort to minimize the mortality of discarded blue cod, a "Code of Practice" pamphlet by the Ministry of Fisheries (Ministry of Fisheries 2009) suggests 'best practices', such as holding the fish behind the head to remove hooks. A previous study (Carbines 1999b) showed that discarded blue cod had an $87 \%$ survival rate overall. Hooking location was shown to be the most important determinant of mortality and large (6/0) hooks were less likely to be lodged in critical locations like the gut or gills.

In addition to direct mortality due to fishing practices, many fishers have expressed concern over the predation of the discarded fish, termed post-release predation mortality (Raby et al. 2014), by seabirds and barracouta (Thyrsites atun) (Ministry of Fisheries 2008d). The Marlborough Sounds is home to four species of shags (Phalacrocorax spp.) with diets consisting mainly of fish (Heather and Roberston 2000). The shag populations appear to be limited primarily by access to food resources, in addition to habitat availability (Bell 2012). 
Fishers have reported both increased predation on the discarded fish by the shags, as well as increased intensity and aggressiveness of the birds' feeding behaviour (Thomas, unpublished field notes).

Given the apparent difficulties in catching two legal-sized blue cod (the current daily bag limit), there are increasing calls for the maximum size to be eliminated (Bell 2014a; Nicoll 2012a). Alternatively, some fishers feel that a $10 \mathrm{~cm}$ slot would be acceptable (Baxter 2012) especially as a $12 \mathrm{~cm}$ slot was initially proposed by the Blue Cod Management Group for the reopening of the fishery (Ministry of Fisheries 2010b). These fisher suggestions were thus used as the two alternative size limits for the current study. Based on conversations with fishers during the pilot study and letters to the editor in the local newspaper, we expected that more fishers would prefer eliminating the maximum size, than increasing it to $40 \mathrm{~cm}$.

Both these alternative options should decrease regulatory discards, as a wider range of fish sizes would be legally landable. However, it was believed that either increasing or eliminating the maximum size would increase the incentive for high-grading which is legal in New Zealand (New Zealand Parliament 1986). Currently, there is no incentive to high-grade with the $5 \mathrm{~cm}$ slot, as it appears that most fishers must discard multiple blue cod just to meet their daily bag limit of two. But removing the current size limit regulation may lead some fishers seeking to maximize the size of the blue cod kept, given the low daily limit of two, by discarding fish close to the minimum size.

\subsection{Methods}

It is often unknown how fishers are likely to react to new regulations (Fulton et al. 2011). For example, the minimum legal size suggested for protecting juvenile fish may be extremely unpopular if much of the catch cannot be retained (Stewart 2008). The present study examined the amount of blue cod discarded from compliance with the size limit (i.e., regulatory discards) within the framework of a scenario approach. Using scenarios allows stronger conclusions regarding action intentions of fishers given distinct size regulations. For example, is the current size limit the best framework for minimizing the amount of blue discarded? If not, what alternative size regulation would best meet this biological goal? Realistic scenarios were created to provide fishers with information regarding specific size limits. The use of scenarios makes it possible to obtain information on drivers of change, 
possible outcomes of the current system and identification of potential responses (Peterson et al. 2003). Previous research, including in other fisheries, has demonstrated that people are able to identify with and understand alternative future options through the use of scenarios (Cinner et al. 2011; Karper and Lopes 2014; Shaw et al. 2009).

\subsubsection{Participants and design}

The reader is referred to chapter three (section 3.2.2) for information on participant recruitment and survey design. This section of the survey was piloted on eight fishers several months prior to survey launch. One of the questions from the study in chapter four, "I do not agree with the slot rule" was also utilized in this study. Several questions on regulation knowledge, as well as questions on fishers' compliance with the daily and size limits were also included. The eight questions comprising this study and described below, were placed at the end of the larger online survey as an independent study. A total of 421 fishers completed this study, with $83 \%$ of the respondents being male and $43 \%$ living in the Marlborough region. Age ranged from 20-77 years $(M=54.08, S D=12.04, M d n=55)$ and local fishing experience was between one and 70 years $(M=27.66, S D=16.66, M d n=25)$. Most fishers (88\%) owned a boat and $35 \%$ of them owned a holiday home in the Marlborough Sounds.

\subsubsection{Measures}

Current fishing practices. The first part of the questionnaire gathered information about current fishing practices. Fishers were asked to complete the sentence: "Currently, on a normal day's fishing, I discard an average of (number) blue cod". The next question asked them to specify what percentage of the blue cod discarded was due to: a) the minimum size rule, b) the maximum size rule, or c) voluntary.

Scenarios. In the second part of the study participants were presented a scenario with distinct information about the size rule for the next blue cod fishing season. We created three experimental groups depending on the type of scenario depicted and the responding fishers were randomly assigned to one of the three. Scenario $1(n=147)$ described no change in circumstances for the next season and served as the control 
condition. Scenario $2(n=133)$ depicted an increase in the maximum size rule (from $35 \mathrm{~cm}$ to $40 \mathrm{~cm})$. Scenario $3(n=141)$ depicted a stronger change in circumstance with the elimination of the maximum size for blue cod. To illustrate, Scenario 2 was presented to participants as follows:

Please take a few minutes to envision what the next blue cod season might be like. Imagine that the Ministry of Fisheries has decided to increase the maximum size for blue cod from $35 \mathrm{~cm}$ to $40 \mathrm{~cm}$ by the next season (starting December 2013). You will then be allowed to keep two blue cod as long as they are between 30 and $40 \mathrm{~cm}$.

Considering this scenario please answer the questions below.

Discard intentions. After reading the given scenario, participants were asked to indicate their discard intentions with three distinct questions: (a) "On a normal day fishing my blue cod discards would be..." (b) "I think my forced discards would be..." and (c) "And I think my voluntary discards would be..." Participants rated the questions on a 5-point Likerttype scale ranging from 1 (much lower) to 5 (much higher).

Fishing satisfaction. After the intention questions, fishers were presented with three questions on fishing satisfaction: 1) "I would enjoy fishing for blue cod under this scenario", 2) "The majority of recreational fishers would not be happy with this scenario", and 3) "This scenario would be less frustrating than the current season". Participants rated the questions on a 5-point Likert-type scale ranging from 1 (strongly disagree) to 5 (strongly agree).

As Levene's test for normality was not met for three of the questions (voluntary discards, fishing enjoyment and other fishers satisfaction), ANOVA was performed using Brown-Forsythe and Gabriel's test was used for post-hoc analyses due to unequal sample sizes in each experimental condition (Field 2009). For the number of discards, some respondents answered with a range (e.g., 10-20) or a minimum (e.g., 20+), which were recoded to the lowest number provided. 


\subsection{Results}

\subsubsection{Current practices}

Out of the 421 fishers who completed the scenario survey, 415 provided answers for the average number of blue cod discarded. These fishers reported discarding an average of 13 blue cod (Range $=0-100, S D=12.33, M d n=10)$ on a normal day's fishing. Of these discarded blue cod, fishers stated that $53 \%$ were because of the minimum size $(S D=24.84)$, $39 \%(S D=23.80)$ because of the maximum size, and $8 \%$ voluntarily $(S D=18.23)$.

A preliminary analysis was carried out in order to eliminate alternative explanations for differences between the three experimental groups. Along with the reported number of blue cod discarded, two additional questions (fishing experience and knowledge of the suggested best practices) from the larger online survey were selected to examine whether the experimental groups differed in important ways. The two additional variables were chosen as both would likely influence the condition (and thus mortality) in which the fish were discarded, the number caught (Bartholomew and Bohnsack 2005; Cooke and Wilde 2007; Muoneke and Childress 1994) and recall bias concerning the amount of discards (Bochenek et al. 2012). No significant differences were found between the three groups regarding average blue cod discards $F(2,412)=2.37, p=.09$, Marlborough Sounds fishing experience $F(2,418)=2.501, p=.08$, and familiarity with the code of practice $F(2,418)=$ $2.86, p=.06$. The lack of differences meant we could be more confident that the results reported below were the effect of the management scenario manipulations. Due to the high level of knowledge of the correct minimum and maximum size limits--89\% and 94\%, respectively--these variables were not utilized to test for between-group differences.

\subsubsection{Discard intentions}

We used Wilcoxon one-sample signed rank tests to determine if medians were significantly different than the scale middle point of three (no change). Results showed that fishers believed that if the size limit was unchanged for the next season (scenario 1) both the overall $(M d n=3 ; H(146)=5.06, p<.001, r=0.30)$ and regulatory discards $(M d n=3$; $H(146)=5.81, p<.001, r=0.34)$ would increase, but voluntary discards would stay the same $(M d n=3 ; H(146)=-0.77, p=0.44)$. ANOVA tests revealed a statistically significant main effect of experimental condition on all three discard intention questions: (1) average discards $F(2$, 
388.54)=118.81, $p<.001, \omega^{2}=.36$; (2) regulatory discards $F(2,408.32)=152.12, p<.001$, $\omega^{2}=.42$; and (3) voluntary discards $F(2,373.85)=11.11, p<.001, \omega^{2}=.05$. Post-hoc tests showed that the main effect was driven by differences for overall and regulatory discards between scenario 1 and scenarios 2 and 3. Although a similar trend was observed for voluntary discards, here the overall effect was due to small differences between all three scenarios as no post-hoc tests were significant (Fig. 5.1a).

Fishers felt that both alternative size regulations would result in fewer discards compared with the control condition: (a) fishers believed their overall blue cod discards would be lower under both scenario $2(M d n=2 ; H(132)=-8.53, p<.001, r=-0.53)$ and $3(M d n$ $=2 ; H(140)=-8.07, p<.001, r=-0.48)$ compared with the current size limit $(M d n=3) ;(b)$ fishers believed their regulatory discards would be lower under both scenario 2 ( $M d n=2$; $H(132)=-8.48, p<.001, r=-0.52)$ and $3(M d n=2 ; H(140)=-8.96, p<.001, r=-0.53)$ compared with the current size limit $(M d n=3)$; and (c) fishers believed their voluntary discards would be lower under both scenario two $(M d n=3 ; H(132)=-5.70, p<.001, r=-0.35)$ and three $(M d n=3 ; H(140)=-3.99, p<.001, r=-0.24)$ compared with the current size limit $(M d n=3)$

\subsubsection{Fishing satisfaction}

One-sample signed Wilcoxon signed rank tests were also run for the three questions on fishing satisfaction using three (no change) as the midpoint. Fishers reported that with no change to the size limit (scenario 1) the next blue cod fishing season would be frustrating $(M d n=2 ; H(146)=-7.22, p<.001, r=-0.42)$ and not enjoyable $(M d n=2 ; H(146)=-5.78$, $p<.001, r=-0.34)$. They also disagreed that other fishers would be happy with this scenario $(M d n=2 ; H(146)=-4.86, p<.001, r=-0.28)$. Analysis revealed a statistically significant main effect of experimental condition on all three fishing satisfaction questions: (1) enjoyment $F(2,408.97)=128.95, p<.001, \omega^{2}=.38$; (2) other fishers' happiness $F(2,412.18)=33.88, p<.001$, $\omega^{2}=.14$; and (3) frustration $F(2,415.03)=236.19, p<.001, \omega^{2}=.53$. However, post-hoc tests again showed that the only significant differences were between the two alternative scenarios and the control scenario (Fig. 5.1b).

Compared with the current regulations $(M d n=2)$, fishers reported that (a) they would enjoy blue cod fishing more under a larger maximum size $(M d n=4 ; H(132)=8.03$, $p<.001, r=49)$ or no maximum size $(M d n=4.0 ; H(140)=8.70, p<.001, r=0.52)$. They also 
believed other fishers would be happier with either a larger maximum size ( $M d n=4 ; H(132)$ $=3.78, p<.001, r=0.23)$ or no maximum size $(M \mathrm{dn}=4 ; H(140)=4.51, p<.001, r=0.27)$ than under the current size limit $(M d n=2)$. Finally, fishers suggested that either a larger maximum size $(M d n=4 ; H(132)=9.02, p<.001, r=0.55)$ or no maximum size $(M d n=4$; $H(140)=9.44, p<.001, r=0.56)$ would be less frustrating than the control scenario $(M d n=$ 2).

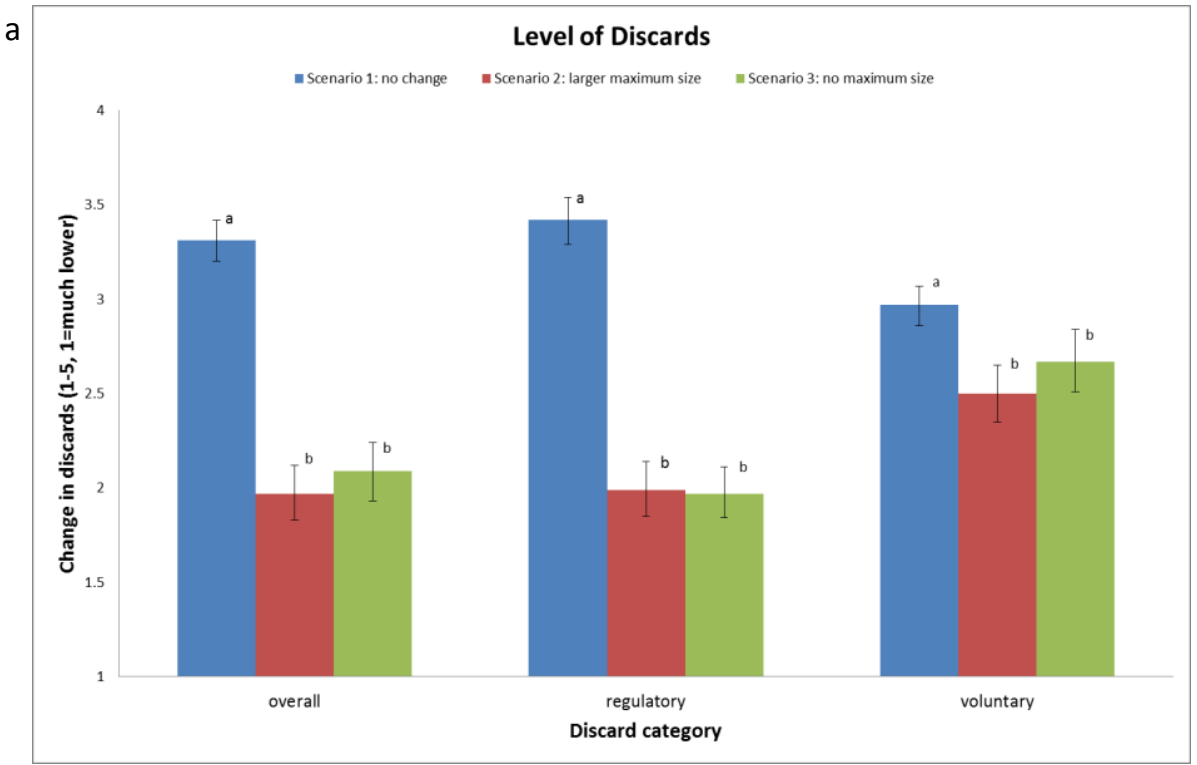

b

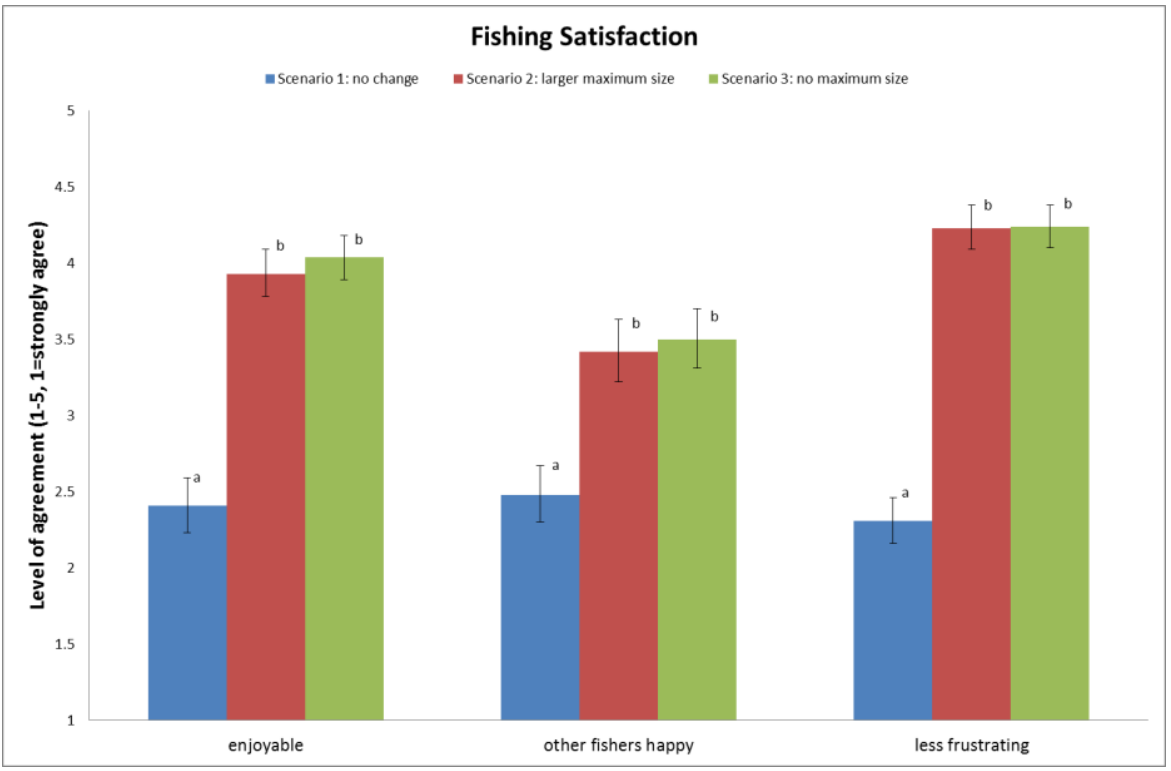

Figure 5.1: Changes in (a) discards and (b) fishing satisfaction levels under three experimental size limit scenarios for recreational blue cod fishing in the Marlborough Sounds. Bars represent $95 \%$ confidence intervals and different letters indicate significant differences. 


\subsubsection{Influence of discards}

The influence of discards on fishing enjoyment, agreement with the rule and compliance with the size limit were explored for all participants across the three scenarios. Spearman's rank order correlations revealed that overall level of discards was negatively associated with fishing enjoyment $(-0.54)$ and frustration $(-0.67, p \leq .01$ for both). Similarly, the amount of regulatory discards was negatively associated with fishing enjoyment $(-0.56)$ and fishing being less frustrating $(-0.70, p \leq .01$ for both). Fishers who felt the alternative scenarios would be more satisfying believed they would discard fewer blue cod.

The number of blue cod discarded on a normal day's fishing also influenced fishers' agreement with the size limit regulation, $H(4)=16.57, p=.002 . r=-0.22$. Post-hoc analysis, using a Bonferroni correction of $p=.005$, revealed this was due to a difference between only two groups. Fishers who agreed $(M d n=10$, mean ranking=171.80) reported discarding more blue cod than those who strongly disagreed $(M d n=10$, mean ranking $=232.78, p=.004, z=-$ 3.52). A fisher's compliance with the size limit was also influenced by the average number of blue cod discarded, $Z(417)=-2.40, p=0.16, r=-.12$. Fishers who violated the size limit reported having to discard more blue cod $(M d n=10$, mean rank=232.71) than fishers who complied with the regulation $(M d n=10$, mean rank=200.71).

\subsection{Discussion}

A major challenge for fisheries management is deciding which of several alternative management scenarios will best ensure the sustainability of the fishery (Hilborn and Walters 1992). Understanding the likely effect of different regulatory scenarios on fishers' actions (such as effort allocation or fish harvesting decisions) is a vital piece of information (Beard et al. 2003; Johnston et al. 2010). This study sought to determine which of three different sizebased regulations (current or two alternatives) would best achieve this goal in the Marlborough Sounds recreational blue cod fishery using both biological (e.g., number of discards) and social (e.g., fishing satisfaction) criteria. It was expected that the two alternative scenarios would be more popular with fishers and decrease regulatory discards. However, the alternative scenarios would also increase the incentive to high-grade, which would be detrimental to the biological goal of sustaining the fishery. Fishers were asked to quantify current discards and the reason (too small, too big or voluntary) in order to provide a baseline for the scenarios. 
Given there were over 9000 recreational fishers in the Marlborough Sounds before the 2008 ban (Batstone et al. 2009) the number of blue cod discarded is concerning. It is worth noting that studies in other fisheries have found that fishers tended to display recall bias and overestimated their discards by 2.2-2.4 times (Bochenek et al. 2012; Sullivan 2003); with their negative attitude towards the size limit potentially leading them to exaggerate their discards. However, even dividing this study's mean by 2.4 gives an average of 6.5 blue cod discarded per fisher/trip; still potentially concerning given the number of fishers. Furthermore, overestimation of discards would be the same across all three conditions as there were no significant differences between the groups. Finally, the discard figures from the charter boat operator presented in the introduction (Humm 2013) add validity to the fishers' claim that the slot rule is resulting in increased discards. Although the maximum size limit was implemented to prevent female blue cod from changing sex by leaving large male blue cod in the population, the number of blue cod discarded suggests this aim may not be fully achieved. If the majority of the released female blue cod do not survive, then they are still being removed from the population and in numbers that are potentially comparable or greater than if fishers were allowed to keep blue cod larger than $35 \mathrm{~cm}$.

Although blue cod have a high survival rate overall (Carbines 1999b) the level of discards may still be a cause for concern as a fish caught on a hook always endures both a physical injury as well as physiological stress (Cooke and Sneddon 2007). Additionally, exposure to air is also harmful to all fish and is correlated with the time it takes for cardiovascular variables to recover; which is crucial for reducing the risk of predation after release (Cooke et al. 2002). The amount of time fish are exposed to air has strongly influenced post-release mortality in commercial fisheries (Benoît et al. 2010; Parker et al. 2003). Compared with only a minimum size limit, the small slot requires more time to correctly measure the fish. Either of the alternative regulations offers a greater range of acceptable sizes, lowering the average measurement time and decreasing the amount of time the fish are exposed to air before being thrown back into the water if required. Injured and stressed animals emit chemical cues that attract predators (Dallas et al. 2010; Jenkins et al. 2004) although post-release predation is an understudied and underappreciated topic (Raby et al. 2014). In the Marlborough Sounds, a 1999 study (Carbines 1999b) did not investigate post-release predation with a justification that a prior study (Davidson 1995) recorded no attacks on released blue cod. However, there are widespread fisher comments 
(Thomas, unpublished field notes) on increasing levels of shag predation, a demonstrated increase in discards, and links between seabird populations and fishery discards (e.g., Furness 2003; Oro et al. 1996). We believe post-release predation of blue cod in the Marlborough Sounds is a crucial area for further research.

Furthermore, despite the complaints regarding the maximum size regulation, fishers report that the majority (53\%) of the blue cod discards were because of the minimum size of $30 \mathrm{~cm}$. This percentage is worrisome since other studies (Davis and Parker 2004; Powell et al. 2011) have found that the smaller fish were the most likely to die after release. In fact, the discarding of juvenile fish likely contributed to the speed of the Newfoundland cod collapse (Myers et al. 1997). Carbines (1999b) found that all blue cod that died in a post-release mortality study were gut or gill hooked, using a small hook, and were less than $33 \mathrm{~cm}$ in length. We suggest further research on fishing practices, such as hook size, is needed to help evaluate the potential biological effects of the current size limit.

In light of the concerns raised about the survival of the discarded fish, both alternative scenarios appear to offer significant gains in this area. As expected, fishers believe that under either alternative scenario their overall and forced discards would decrease. This finding is in line with their reporting that $40 \%$ of the blue cod discarded are because of the maximum size, in addition to previous complaints (Marlborough Express 2012; Simpson 2014) that the current size limit is too restrictive. The lack of significant differences between the two scenarios may be the result of fewer large $(>40 \mathrm{~cm})$ blue cod in the population or reflect reporting bias because keeping this sized cod would be in violation of the size limit. With these considerations, we would not expect to see much of a difference in regulatory discards between these two scenarios.

It is unsurprising that a continuation of the current size limit would lead to an unenjoyable and frustrating fishing season given the high level of discards as well as the negative attitude towards the size limit. It appears that the current size limit is not effectively minimising the number of blue cod discarded, nor promoting fisher satisfaction or compliance with the regulation. This suggests that a different size limit could have significant benefits for both the fishery and fishers. It is therefore encouraging that both alternative scenarios would increase fisher satisfaction while simultaneously decreasing their frustration with the size limit and fishing experience. Respondents also believe other 
fishers would be happy under the two alternative size limits proposed, another positive finding as chapter four showed the strong influence of social norms in driving compliance with the size limit.

Given fisher comments about the 'stupidity' of the maximum size (e.g., Moore 2013), it is surprising to find no significant differences in fisher attitudes between increasing the maximum size to $40 \mathrm{~cm}$ and eliminating it altogether. One possible explanation is that under either alternative scenario, two factors contributing to the current low level of satisfaction would be addressed. Firstly, fishers would be allowed to keep larger $(>35 \mathrm{~cm})$ blue cod that must be thrown back under current regulations. As fishers have no dilemma with discarding smaller fish, a requirement in most recreational fisheries (Tetzlaff et al. 2013), the number of large fish discarded is likely to have a stronger influence on their fishing satisfaction. Previous studies (Petering et al. 1995; Schramm and Dennis 1993) have found that for many fishers catching and keeping larger fish is more important than the number of fish kept. Being able to legally land large blue cod would also decrease the overall number discarded; another influence on fisher satisfaction. Finally, it may be that fishers are not currently catching many blue cod over $40 \mathrm{~cm}$, so not being allowed to keep fish this size would not be a major concern nor significantly influence their satisfaction with that scenario.

We expected that either increasing or eliminating the maximum size would increase voluntary discards, as there would be a greater incentive to high-grade. It is surprising that fishers reported the opposite-they felt both alternative scenarios would actually decrease their voluntary discards. As mentioned above, this may be due to increased satisfaction in being able to legally land a $35-40 \mathrm{~cm}$ sized blue cod. If most fishers were actually happy with this size blue cod, now legally landable, then there would be no reason for them to throw it back. Furthermore, if fishers do not expect to catch a large fish, they are more likely to keep the smaller ones (Chizinski et al. 2014). However, it is worth noting that satisfaction with the size limit is not necessarily static and although fishers may initially be satisfied with a $40 \mathrm{~cm}$ fish, this may change. After a season or two fishers may no longer be happy with a $40 \mathrm{~cm}$ maximum size, especially as there is no maximum size elsewhere in New Zealand (Ministry of Fisheries 2014b).

In addition, high-grading may be a sensitive behavior, and therefore some fishers may not willingly admit to this practice. As there has yet to be any study of high-grading behaviour in recreational fisheries, we suggest that this area is one for future research. 
More information is needed on both the sensitivity and frequency of high-grading in the Marlborough Sounds. As the maximum size limit was designed to protect large female blue cod, more information on the potential effect of an increased size limit on the sex ratio is also needed. A final area of further research would be changes to the quality, quantity or timing of reproduction in blue cod, as observed in other species (Schreck 2010; Schreck et al. 2001). For example, changes to the timing of ovulation may reduce the effectiveness of the current closed season, which is in place to protect the female blue cod during spawning.

Our results suggest that increasing the maximum size rule to $40 \mathrm{~cm}$ for blue cod fishery in the Marlborough Sounds, and thus doubling the size of the slot from $5 \mathrm{~cm}$ to $10 \mathrm{~cm}$, is worth further consideration as fishers believed it would significantly reduce the number of fish discarded as well as increase enjoyment with the fishing experience. Fewer discards could also decrease regulation non-compliance, as fishers would be able to legally keep larger blue cod, and create a more positive attitude towards the size limit, another potential driver of non-compliance. For all three social aspects measured, the $40 \mathrm{~cm}$ scenario did not rate better than the option of no maximum size and is strongly preferred to the current $5 \mathrm{~cm}$ slot. This scenario also offers several advantages in relation to biological goals and current compliance rates: 1) Fishers felt this scenario would result in a significant decrease in their overall discards and 2) a maximum size limit of $40 \mathrm{~cm}$ would protect the largest fish and go towards preventing a skewed sex ratio and boosting the reproductive potential of the population. The size composition of fish currently kept outside of the size limit is unknown but would include a proportion of blue cod over $40 \mathrm{~cm}$, the large males that the maximum size was designed to protect. A $10 \mathrm{~cm}$ slot would also limit the amount of high-grading that could occur, a concern of the Ministry (Marlborough Express 2011).

\subsection{Conclusion}

It has been noted (Hilborn and Walters 1992) that fisher motivations and responses are among the most critical aspects of resource management and that fisher behaviour can counteract otherwise effective management. As a result, there have been calls for greater integration of human behavior into recreational fisheries analyses (Arlinghaus 2004; Post and Parkinson 2012). This research demonstrates the potential of scenario-based experimental studies in providing information that can be used to design regulations that do not result in counterproductive fisher responses. The use of alternative scenarios allows for 
assessment of fisher support for a regulation prior to implementation; decreasing the likelihood of introducing a new regulation that is unpopular with fishers and/or results in a high level of non-compliance. Fisheries managers worldwide should consider the potential benefits of this technique when considering changes to the regulations

This method also provides a way of determining how fishers may be affected by new regulations, minimizing unexpected behavioral results. Specifically our results demonstrate that biological and social goals do not necessarily have to be mutually exclusive, and that regulations most likely to be accepted by the fishers can also contribute towards the biological sustainability of the fishery and lower regulation non-compliance. As there are increasing calls for greater fisher participation in the management process, this finding provides an example of how fisher preferences do not have to contradict regulations suggested by the science. In turn this should help encourage fisheries managers to seek fisher input when reviewing and designing regulations. 


\section{Conclusions}

The overall aim of this thesis was to explore the human dimensions of the current management regime of the recreational blue cod fishery in the Marlborough Sounds, New Zealand. Specifically, the studies sought to investigate fisher attitudes and behaviours and how these relate to non-compliance within the management regime. Links between the current top-down management regime and fisher attitudes and behaviour are drawn; often noting how a change in management approach (to a more participatory model) could potentially address the issues noted and increase voluntary compliance. Four published or publication-oriented studies offer a methodological and/or theoretical contribution to the overall aim. Each study has been presented in stand-alone format, but they are all connected through three cross-cutting themes: (1) the value of researching fisher attitudes and behaviour, (2) rethinking the current top-down management regime, and ( 3 ) the need for targeted behavioural interventions in response to non-compliance.

The thesis is multidisciplinary in nature, drawing on disciplines such as psychology, natural resource management and the human dimensions of, sociology, compliance theory, and fisheries management to meet the aims of each study, and it is hoped that the results will help guide future research on the subject, not just in New Zealand, but worldwide. The research undertaken is in response to the increased calls for more research on the humandimensions aspects of fisheries (Hall-Arber et al. 2009). More broadly, this research contributes to the global literature on the necessity of using human behaviour, rather than solely biological data, in natural resource management (Balmford and Cowling 2006; Schultz 2011). Alongside a growing interest in the human dimensions aspect of fisheries research has come the recognition that fishers are not one homogeneous group but are heterogeneous with different knowledge, attitudes, and behaviour (Hunt et al. 2013). These differences present additional challenges for a participatory management strategy, as multiple approaches will be needed to address the varied concerns, priorities and influences amongst the fishers.

The purpose of this concluding chapter is to first review the key findings of the studies and how they contributed to global literature gaps on this subject. The research was 
designed to supplement the biological research available to the Ministry of Fisheries and, if desired, assist with a forthcoming review of the regulations. To this end the reader is reminded of the specific policy recommendations that arose from each study. In 2009 the Ministry of Fisheries released their long-term strategic direction and goal in a document entitled "Fisheries 2030: New Zealanders maximising benefits from the use of fisheries within environmental limits" (Ministry of Fisheries 2009). Relevant goals, strategies and principles from this document are included throughout this concluding chapter to demonstrate that many of the policy recommendations are aligned with the Ministry's own goals.

After this review, I present new data obtained during a short presentation of the thesis results to fishers. Following this, the four studies are brought together and the three important cross cutting themes are further explored. I then offer some personal reflections on the research and data collection process. Although this research represents an important step in a transition towards a more participatory management process, it has also highlighted areas of further research that would be needed to help ensure the success of the management regime. To conclude this thesis, I provide several thoughts on the importance of the issue and consider what the future holds for this popular fishery.

\subsection{Objectives, major contributions and policy recommendations}

Each of the four studies made different contributions towards the overall thesis aim while also addressing specific knowledge gaps within the literature. The following section summarizes the key findings, contributions and policy recommendations of each individual study.

Objective one: Explore how factors such as fishing experience, region of residency, effect of regulations on fishing habits and participation in the management process influence fisher knowledge of and satisfaction with regulations.

Chapter two (published as Thomas et al., 2014b) addressed this first objective using an intercept survey of 311 fishers and focused on the transit rule (i.e., if in the Marlborough Sounds all blue cod in fishers' possession must meet specific size and catch limits) and the filleting rule (i.e., blue cod not be filleted at sea), as both regulations are unique to the Marlborough Sounds recreational blue cod fishery. Ten questions were used to assess 
fishers' knowledge of and agreement with these two regulations and their participation in the management regime. Seven potential influences on fishers' overall satisfaction were also explored: residency, local fishing experience, regulation influence on fishing practices, satisfaction with the fishery, agreement with the two regulations, and perceptions on participation in the management process.

Residency, local fishing experience, regulation influence on fishing practices, and agreement with the transit rule all demonstrated significant effects on overall satisfaction. Locally resident and more inexperienced fishers were more likely to be satisfied with the regulations as were fishers who did not report a large influence on their fishing habits and agreed with the transit rule. Agreement with the two specific rules studied were opposite, with the majority disagreeing with the transit rule but agreeing with the filleting rule. Overall knowledge of the two regulations researched was high but a greater awareness of the filleting rule reinforces cautions (Sullivan 2002) that more complex rules are likely to result in lower levels of knowledge. Region of residency has previously been shown to positively affect regulation knowledge (Page and Radomski 2006; Schill and Kline 1995) but this study found it did not increase knowledge of the transit rule.

On the subject of participation, only half of the fishers had heard of the Blue Cod Management Group (BCMG), currently the only official forum for fisher participation, and it did not affect their overall satisfaction with the regulations. Involvement in the decisionmaking process is a component of successful fisheries (e.g., Jentoft et al. 1998) and the ongoing acrimonious relationships between fishers and managers are often linked to disempowerment of local stakeholders (Bavington 2002); suggesting this is an area of concern for the fishery.

Although there have been several studies examining recreational fisher attitudes and knowledge (Brouwer et al. 1997; Page and Radomski 2006; Pierce and Tomcko 1998; Powell et al. 2010; Sauer et al. 1997), the majority of research has been in commercial fisheries (Foster and Vincent 2010; Pita et al. 2013; Richardson et al. 2005). Assessing the potential effect of a regulation on fishing habits could assist fisheries management in designing regulations that are more widely accepted. Understanding not only how fishers view the regulations, but also what influences those attitudes, provides useful information in designing widely accepted regulations. As attitude towards a regulation can influence 
behaviour (Ajzen 1991), this knowledge could help minimize regulation non-compliance. Addressing the reasons for fisher attitudes can also assist in minimizing non-compliance by allowing for more targeted behavioural interventions.

The results from this study lead to two key policy recommendations. First, the low level of knowledge surrounding the BCMG and its role demonstrate the need for more familiarity among fishers. As this group is currently the only official form of fisher participation, increasing awareness of the $\mathrm{BCMG}^{\prime}$ s existence and role could benefit the legitimacy of the management regime. Second, a re-evaluation of the governance structure is suggested. The current level of participation does not appear to be satisfactory for the majority of fishers given the negative attitudes and unprompted comments. Pita et al. (2010) caution that participation alone is not enough and that the nature of participation can have significant influences. In the Marlborough Sounds, fisher comments supported this view, as many believed previous efforts to include them in the process had been "token" and the outcomes were "pre-determined". The study's findings suggest that effective participation is an ongoing process that does not stop with regulation implementation.

Furthermore, effective participation needs to take into account the differences in fisher knowledge of and agreement with the regulations. Until recently, the BCMG was composed entirely of fishers from the Marlborough/Nelson region. The lack of members from another region, especially Wellington or Canterbury, could be problematic. There have even been complaints that Nelson was over-represented on the committee, meaning that these fishers did not view the one official forum for participation as representative. Similarly, the committee has been composed of more experienced fishers. The results of the study demonstrate that regulation agreement can be strongly influenced by fishing experience; so managers would benefit from considering when including fishers in the management process.

6.1.2. Objective two: Compare the effectiveness of the randomised response technique, item count technique and direct questioning in estimating non-compliance with the regulations for daily and size limits for blue cod, as well as the nearby marine reserve in the Marlborough Sounds. 
There is a growing call for more accurate information on illegal resource use (Wellsmith 2011), particularly on the extent of use (Smith et al. 1989). Better information on resource use is necessary since a resource management strategy based on only best estimates of use is not guaranteed to be sustainable (Milner-Gulland et al. 2010). Objective two, recently published in Biological Conservation (Thomas et al. 2014a), addressed this issue through an online survey of 320 fishers, detailed in chapter three. The three regulations examined were the daily and size limits for blue cod and the nearby Long Island Marine Reserve. Compliance with each regulation was asked using direct questioning (DQ) and two indirect techniques: Item Count (ICT) and Randomized Response (RRT).

The first key result was that no one method provided the highest (and most accurate) estimate of non-compliance for all three different of the regulations studied. For the daily limit and marine reserve there was no difference between the three methods, but for the size limit RRT provided a significantly higher estimate than both ICT and DQ. The higher estimate from RRT (versus DQ) was consistent with most of the literature on this subject (e.g., Lensvelt-Mulders et al. 2005b; Solomon et al. 2007). Conversely, a lower estimate for ICT than for RRT was contrary to a previous study (Coutts and Jann 2011). Also opposite to previous findings (Holbrook and Krosnick 2010b; Lavender and Anderson 2009) was that direct questioning provided a higher estimate than ICT for the size limit.

Of the three regulations studied, the largest number (42\%) of fishers violated the size limit in 2012; although it is likely to still be an underestimate as some people will not answer honestly under any method (van der Heijden et al. 2000). As even low levels (i.e., $10 \%$ ) of non-compliance can undermine the effectiveness of a regulation (Gigliotti and Taylor 1990; Sethi and Hilborn 2008), this percentage is concerning. Given limited budgets for natural resource management, identifying the most frequently violated regulations is a crucial first step in addressing regulation non-compliance. Based on the estimates from this study, addressing non-compliance with the size limit should be prioritized. Conversely, the lack of fishing within the marine reserve is a very positive result as blue cod eggs and larvae can be dispersed by the strong currents and tides in the Marlborough Sounds (Henderson 2009). Large female blue cod living within the marine reserve boundary have the potential to contribute to the overall blue cod population in the Sounds. 
The main contributions of this study were methodological. First, the version of ICT used, previously tested only once (Droitcour et al. 1991), cut the associated standard error in half making it more comparable to that of RRT. Second, the current study was also the first to test the paired-alternative version of RRT against ICT. Two previous online studies (Coutts and Jann 2011; Holbrook and Krosnick 2010b) used a different version of RRT that led to negative estimates; something that was not possible using the paired-alternative format. Finally, the two previous comparison studies (Coutts and Jann 2011; Wimbush and Dalton 1997) used different sample populations. In using the same sample population for this study, any potential confounding factors were eliminated so that the observed differences are in fact due to the different technique. However, it should be noted that the question order did not vary between respondents, meaning order effects are possible. Nonetheless, I believe the use of a single sample population to compare the three methods is important.

Within the wider literature on estimating sensitive behaviour, this study also addresses a gap on the influence of factors such as data collection method, method version, behaviour subject and sensitivity (Tsuchiya et al. 2007). The results show that the most effective technique for estimating non-compliance depends on several factors including question sensitivity, frequency of the behaviour and survey mode. In fact, an indirect technique will not always be needed as direct questioning may suffice. Even if an indirect method is needed, similar considerations should be made to determine whether RRT or ICT would provide the highest estimates. Although the divergent findings of previous studies have hinted at no one technique being the most effective in all situations, this study is perhaps the first to conclusively support this suggestion.

On a more practical level, the results have value for not just fisheries managers, but also natural resource managers worldwide. Accurately estimating regulation noncompliance is a difficult challenge for managers and this study offers insights into how they might obtain this data. In the face of conflicting results between studies, knowledge of how to choose the best/most appropriate method is important. Consideration of variables such as survey mode and question sensitivity can aid natural resource managers in choosing the method that will maximize honest answering. The finding that an indirect method is not 
always needed is especially important as direct questioning is the most straightforward method and has the lowest standard error.

6.1.3. Objective three: Test alternative models of drivers of non-compliance with the daily and size limits and identify the largest influences on a fisher's compliance behaviour.

Sufficient resources to enforce regulations are often limited (Keane et al. 2008), making it critical to increase voluntary compliance (Kuperan and Sutinen 1998; Stern 2008). In order to effectively address non-compliance this way, fishery managers need to understand the drivers behind rule-breaking behaviour (Gavin et al. 2009). The study detailed in chapter four is in response to this pressing need to understand compliance behaviour (Fenichel et al. 2013; Hunt et al. 2013) especially in recreational fisheries where there has been almost no research on this subject. Structural equation modeling was used to test seven alternative models that included 16 factors from disciplines including fisheries, psychology and natural resource management. The models included a pro-environmental behaviour from a meta-analysis (Bamberg and Möser 2007), the Theory of Planned Behaviour (Ajzen 1991), an instrumental model of compliance (Becker 1968), and a model of four normative factors affecting the legitimacy of the management regime (Tyler 1990).

The major finding was that under the best-fitting model for both regulations, social norms have the largest influence on a fisher's decision to comply. Even though social norms have been found to have some influence in commercial fisheries (Jagers et al. 2012; Kuperan and Sutinen 1998), economic drivers are usually more important (e.g., Hatcher and Gordon 2005; Nielsen and Mathiesen 2003). In addition to the injunctive social norm usually considered, this research also included the descriptive social norm; another strong behavioural influence (Cialdini 2007; Cialdini et al. 1990). The relative contribution of the two types of norms differed; descriptive social norms were more important for the daily limit but injunctive social norms had a stronger influence on compliance with the size limit.

Increasing enforcement efforts would not be the most effective strategy for this fishery and instead the focus could be on influencing the social norms through targeted behavioural interventions. The low levels of agreement for many of the factors (for both regulations) suggest the overall legitimacy of the management regime may be weak, 
negatively influencing the social norms. If this is true then a typical (Hønneland 1999; Nielsen 2003) response of increasing the reliance on instrumental factors could have negative consequences. Instead of lowering non-compliance, it could increase the alreadystrained relationship between the Ministry and fishers, potentially leading to stronger and/or more prevalent negative attitudes and more frequent violations - a so-called vicious circle (Jentoft and Mikalsen 2004).

Although there is extensive literature on compliance in fisheries (Hatcher et al. 2000; Hønneland 1998; King and Sutinen 2010; Sutinen et al. 1990), the majority is descriptive. To my knowledge, the current study is the first to utilize structural equation modeling to test alternative models against each other. An advantage of this method is being able to compare multiple models for fit and explanatory power to determine which one best explains the behaviour in question. It also allows easy identification of the significant behavioural drivers and their relative importance, including both direct and indirect effects. SEM provides a more robust approach to understanding compliance behaviour than looking at potential drivers individually. As with the previous objective, not only fisheries managers but natural resource managers worldwide could benefit from this method.

Additionally, the role of recreational fisheries in the world's fishing crisis (Cooke and Cowx 2004) is becoming more widely recognized. Yet outside of the current study the only driver of non-compliance formally tested is outside a commercial or artisanal fishery is knowledge of the regulations. Given the low influence of economic factors for recreational fishers, understanding why fishers break the rules is crucial for successful management of these fisheries.

As previously alluded to, the main policy recommendation is to increase voluntary compliance with the regulations, primarily through the use behavioural interventions targeting the two social norms. A shift in the management strategy from one biologically based, with little consideration of fisher attitudes towards a more inclusive and participatory strategy could help accomplish this goal. Given the large area of the Marlborough Sounds and large numbers of fishers, complete reliance on enforcement is not feasible, making this policy recommendation both practical and financially sound. Furthermore, the Ministry has also noted optimizing the level of voluntary compliance as one of the actions to reach their objective of "ensuring fisheries management system 
integrity" (Ministry of Fisheries 2009, p. 10). Increasing the legitimacy of the management regime should in turn influence social norms as fishers are less likely to approve of regulation violations if the management regime is regarded as legitimate (Tyler 1990).

6.1.4. Objective four: Evaluate the potential for improving compliance with the size limit through minimizing discards and maximising fisher satisfaction.

The effectiveness of length-based limits is dependent on any discarded fish surviving, recovering quickly and not experiencing long-term sub-lethal impairments (Broadhurst et al. 2005; Muoneke and Childress 1994; Waters and Huntsman 1986). In the Marlborough Sounds, the introduction of the maximum size has significantly increased the number of discarded blue cod (Humm 2013; Moore 2012) leading to growing fisher frustration and calls to either raise or eliminate the maximum size. However, fishers may also voluntarily discard a fish to maximise the size of their catch, called 'high-grading' (Kristofersson and Rickertsen 2009). A section of the online survey sought to evaluate changes to discards using a scenario-based approach (chapter five, under review in ICES Journal of Marine Science).

Responding fishers were randomly assigned to one of three experimental groups that each described a different scenario for the size limit: (1) no change in the regulations for the next season (the control condition), (2) an increase in the maximum size limit (from $35 \mathrm{~cm}$ to $40 \mathrm{~cm}$ ) and (3) the elimination of the maximum size for blue cod. The influence of the amount of discards on fisher's satisfaction within these scenarios, as well as on regulation agreement and compliance, was also explored.

Fishers reported discarding 10 blue cod on a normal fishing trip, 53\% because of the minimum size, $39 \%$ because of the maximum size and $8 \%$ voluntarily. Regardless of gear type and handling practices, a caught fish is subject to some stress and injury (Cooke and Sneddon 2007). Similarly, exposure to air is harmful to fish, influencing post-release mortality (Benoît et al. 2010) and recovery time crucial to reducing the risk of post-release predation (Cooke et al. 2002). Shag predation on the discarded blue cod appears to be increasing in frequency and intensity (Thomas, unpublished field notes) and studies in commercial fisheries (Blaber and Wassenberg 1989; Votier et al. 2004) have shown that seabirds often modify their feeding habits and diets to exploit this easy source of food 
allowing greater breeding success and increased populations (Arcos and Oro 2002; Furness et al. 2007; Tavecchia et al. 2007).

Predicting how fishers are likely to behave under new regulations is normally not known and is an important area of enquiry (Fulton et al. 2011; Hunt et al. 2013). Scenario results showed there was no statistically significant difference in satisfaction with the fishing between a larger slot and no maximum size. Fishers also reported that both alternative scenarios would significantly lower their discards and be less frustrating compared with the current size limit. As a regulation's effect on fishing habits can influence both a fisher's attitude (Thomas et al. 2014b) and compliance (Sutinen et al. 1990), these are positive findings. The discarding of blue cod was also found to have a significant effect on three other important factors. For the three scenarios combined, the number of discards negatively influenced satisfaction with the fishing. Higher levels of satisfaction corresponded to a lower number of discards, consistent with a previous study (Thomas et al. 2014b; Wilde and Ditton 1999) showing that fisher support for a regulation is strongly based on how it affects their fishing experience. Fishers' agreement with the size limit was also influenced by the amount of blue cod they had to discard. Finally, the level of discards directly influenced slot rule compliance as fishers who had violated the rule were found to have a significantly higher amount of discards. Therefore in addition to minimizing the potential for postrelease mortality and predation, decreasing the number of blue cod discarded would also have several positive social influences on the sustainability of the fishery.

Even though catch-and-release mortality in recreational fisheries has been well researched (Bartholomew and Bohnsack 2005; Muoneke and Childress 1994), the influence of discard levels is largely unknown. A previous study (Bochenek et al. 2010) found that being forced to discard greater numbers of fish negatively influenced fisher satisfaction, although satisfaction was measured as the number of fish landed. The amount and size of blue cod kept is not the most important outcome in the Marlborough Sounds (Batstone et al. 2009) and the main fisher complaint has been over the number discarded (Thomas et al. 2014b). However, the correlation between discards and regulation compliance has not previously explored. Our finding that fishers who broke the slot rule discarded greater numbers of blue cod has important implications for the successful management of the 
fishery as enhancing voluntary compliance is crucial to establishing a legitimate management regime that does not rely on enforcement.

Even though the study fishery is the only one in New Zealand to have a maximum size, slot length limits are used in other countries including Australia (Koehn and Todd 2012) and the United States (Page and Radomski 2006). The results of the current study suggest managers exercise caution when setting length limits to ensure they are not too restrictive.

Although biological concerns need to be taken into account, forcing fishers to discard too many fish may end up undermining the regulation aims. However, it is worth noting that the high level of fisher support for an increased maximum size demonstrates that social considerations do not necessarily have to conflict with the regulations suggested by the biological data. The finding also backs up previous calls in the thesis for increased fisher participation in the management process.

Based on the results of this study, the Ministry could consider increasing the maximum size for blue cod to $40 \mathrm{~cm}$. The current level of discards may not be sustainable, especially given the lack of information on post-release predation and fisher practices such as hook size and type used. The high level of discards is also partly responsible for negative attitudes towards the regulation itself and fishing enjoyment. In turn, these are likely to be encouraging non-compliance, potentially undermining the effectiveness of the regulation. As a $10 \mathrm{~cm}$ slot would result in higher levels of fishing satisfaction and regulation agreement through lower levels of discards (a biological concern) and provide less incentive to highgrade than no maximum size. A larger slot would also still leave large male blue cod to suppress female sex change. Taking a more adaptive management approach and listening to fisher feedback could also improve the overall relationship between the Ministry and fishers. Notably it would also meet two stated actions (Ministry of Fisheries 2009) to "optimize the level of voluntary compliance" (p. 10), "review fisheries laws and regulations with a view to reducing compliance costs and improving effectiveness" (p. 8) and apply a "precautionary approach" (p. 12).

\subsection{Presentation of Results}

The literature (e.g., Cho and Trent 2006; Torrance 2012) cautions that reliance on only a single method of data interpretation will not allow the most comprehensive or valid 
account of the issue under study. Stakeholder engagement is an important method of overcoming this limitation (Christ, 2009; Mertens et al. 2010), and member checks/respondent validation is a common approach. Under this process research participants have a chance to verify the accuracy and explanation of the data and offer reactions, ensuring interpretations are a "fair and reasonable reflection" (Torrance 2012, p.4). Lincoln and Guda (1985) have argued this technique is the most important one in terms of establishing credibility of the results. The chance to provide feedback and involvement in the dissemination of findings can also benefit the stakeholders themselves by affecting their knowledge and behaviour (Phillipson et al. 2012). My positionality as a non-Marlborough resident and non-fishing scientist also underlines the importance of this step.

Therefore in June of 2014 I returned to the Marlborough Sounds to present the results of my research to the fishers. The presentation was advertised via flyers around Picton and Havelock, emails to fishers previously interviewed and the local fishing club. The region's newspaper also ran two articles: the first provided a few 'interesting' results and mentioned a presentation would be held in the upcoming weeks, and a second short one announced the date, venue and time. An overview of the results of all four studies was presented although the focus was on practical (e.g., the number of blue cod discarded) instead of methodological (e.g., the effectiveness of the three different methods for estimating non-compliance) contributions. These subjects were more likely to be of interest to the fishers and also allowed them to provide feedback.

Unfortunately, turnout was extremely low with only seven people attending, including one married couple. Attendees were asked to fill out a short survey at the end of the presentation (Appendix 11) to provide feedback on the perceived usefulness of the research and their priorities going forward. There were four questions answered on a 5point Likert-type scale (anchored by $1=$ strongly disagree and $5=$ strongly agree), four open ended questions on the results, and an opportunity for final comments. The couple had similar views so filled out one questionnaire between them, giving a total of six completed questionnaires. Despite this low number and the probable bias in attendance, the answers still provide useful information for the next stage of this research (i.e., a report for the Ministry of Fisheries). 
Overall, fishers ( $n=6)$ were very happy there was research into what they thought of the rules $(M d n=5$, range $=4$ to 5$)$, strongly agreed the research was important $(M d n=5$, range $=4-5)$ and found the presentation informative $(M d n=4.5$, range $=4-5)$. However, they disagreed that the Ministry would take any of the results into consideration $(M d n=2$, range $=1-3$ ). On the question of which regulation they would most liked changed, all fishers $(n=6)$ answered the size limit. Four attendees also believed the size limit was the most important regulation to change, although one fisher answered the transit rule. Another question asked what three results they would most like to be communicated to the Ministry. The responses were mixed overall, but three of the fishers wanted the maximum size limit removed and one wanted it changed to $30-40 \mathrm{~cm}$ (in response to the results of chapter five). Similarly, three fishers wanted an increased minimum size and two gave an answer relating to greater use of the research and fisher's knowledge.

Attendees were also asked what they thought the most interesting result was from the presentation. Although one fisher said there was nothing new learned, three answers concerned non-compliance (e.g., high level for the daily limit), one mentioned that the data support anecdotal knowledge about the ratio of discarded blue to those kept and the final answer was that many fishers would find a larger slot acceptable. Finally, there was a question on which result they thought was the most important. Two of the comments were on the high level of discards and another that the BCMG was not necessarily a public interface. Two fishers took away opposite messages from the results on fisher preference regarding the size limit scenarios (chapter five): one attendee answered "the fact that in a short time so many people have accepted the slot rule and would retain it in a modified version" and the other answered "agreement to change slot rule to maximum size only". Finally, comments on the last question were "good job", "appreciate scientific and impartial input", "thoroughly researched and well-presented", "local knowledge has validity and slot rule useless, "the cod fishery in the Sounds is completely stuffed", and "more information (from the Ministry) to the public on the actual results of the surveys".

\subsection{Cross-cutting themes}

Throughout the discussion on the contribution and policy implications (Table 6.1) of the four studies that comprise the thesis, three themes show up throughout the different 
studies: (1) value of researching fisher attitudes and behaviour, (2) the current top-down management strategy should be rethought and (3) the need for targeted behavioural interventions in response to non-compliance. Studies have called for a greater integration of human behaviour into recreational fisheries analysis (Fulton et al. 2011; Larkin 1978; Post and Parkinson 2012) and together the three themes reaffirm this need. A human dimensions approach to fisheries management could minimize regulation non-compliance and help ensure the sustainability of the fishery.

Table 6.1: Summary of policy recommendations for the Marlborough Sounds recreational blue cod fishery. The associated study and relevant principle or objective from the Ministry of Fisheries' report "Fisheries 2030", are also included

\begin{tabular}{|l|l|l|}
\hline \multicolumn{1}{|c|}{ Policy recommendation } & \multicolumn{1}{|c|}{ Study } & \multicolumn{1}{c|}{ Ministerial } \\
\hline $\begin{array}{l}\text { Increase awareness of Blue Cod } \\
\text { Management Group and their role }\end{array}$ & $\begin{array}{l}\text { Study one } \\
(6.1 .1), \text { chapter } \\
\text { two }\end{array}$ & $\begin{array}{l}\text { Objective 11, Build sector } \\
\text { leadership: "Improve } \\
\text { communication across the sector" } \\
\text { (p. 10). }\end{array}$ \\
\hline $\begin{array}{l}\text { Re-evaluate the governance } \\
\text { structure }\end{array}$ & $\begin{array}{l}\text { Study one } \\
(6.1 .1 .), \\
\text { chapter two }\end{array}$ & $\begin{array}{l}\text { Principle, Best available } \\
\text { information: "Decisions need to be } \\
\text { made on the best available and } \\
\text { credible biological, social and } \\
\text { cultural information from a range } \\
\text { of sources" (p. 12). }\end{array}$ \\
\hline $\begin{array}{l}\text { Prioritize addressing non- } \\
\text { compliance with the size limit for } \\
\text { blue cod }\end{array}$ & $\begin{array}{l}\text { Study two } \\
\text { (6.1.2), chapter } \\
\text { three }\end{array}$ & $\begin{array}{l}\text { Objective 5: "Ensure sustainability } \\
\text { of fish stocks" (p. 9). }\end{array}$ \\
\hline Increase voluntary compliance & $\begin{array}{l}\text { Study three } \\
(6.1 .3), \text { chapter } \\
\text { four }\end{array}$ & $\begin{array}{l}\text { Objective 14: Ensure management } \\
\text { system integrity: "Action=optimise } \\
\text { the level of voluntary compliance } \\
\text { with fisheries laws and } \\
\text { standards..." (p. 10). }\end{array}$ \\
\hline $\begin{array}{l}\text { Behavioural interventions to } \\
\text { target both injunctive and } \\
\text { descriptive social norms }\end{array}$ & $\begin{array}{l}\text { Study three } \\
(6.1 .3), \text { chapter } \\
\text { four }\end{array}$ & $\begin{array}{l}\text { Principle, Effective management } \\
\text { and services: "Use least cost-policy } \\
\text { tools to achieve objectives where } \\
\text { intervention is necessary and } \\
\text { ensure services are delivered } \\
\text { efficiently" (p. 12). }\end{array}$ \\
\hline $\begin{array}{l}\text { Consider increasing the maximum for blue cod to 40cm } \\
\text { (6.1.4), chapter }\end{array}$ & $\begin{array}{l}\text { Objective 2, Cost-effective } \\
\text { management and services: } \\
\text { "Action=Review fisheries laws and } \\
\text { regulations with a view to reducing } \\
\text { compliance costs and improving } \\
\text { effectiveness" (p.8). }\end{array}$ \\
\hline
\end{tabular}




\subsubsection{The value of researching fisher attitudes and behaviour}

The thesis results demonstrate how a greater understanding of fisher attitudes and behaviour can significantly assist with an effective management regime and lower noncompliance; an important area of study (Fulton et al. 2011; Hunt et al. 2013). These potential benefits were first apparent in chapter two where the intercept survey showed how fisher attitudes varied between groups of fishers, depending on experience and area of residency (Thomas et al. 2014b). The results also reinforced a growing realization (Hunt et al. 2013; Oh et al. 2005) that fishers are not a homogenous group. Nonetheless, management strategies are often aimed at the 'average fisher' who, in reality, may not exist. In evaluating potential regulation changes, fishery managers should aim for comprehensive consultation across a broad range of fishers. The use of scenarios can provide an opportunity to learn how the proposed changes could affect the fishing experience for the different groups of fishers. Even though one group of fishers may be accepting of a proposed regulation, another group may be negatively influenced, such as not being able to catch their daily limit. Poor consideration of these differences may create feelings of resentment towards the management, which can lead to regulation noncompliance (Robbins et al. 2006).

Fishers' rule-breaking behaviour is important to understand, as it is the leading cause of management failures (Boonstra and Bach Dang 2010), but difficult to research due to its potential sensitivity. However, knowing the extent of regulation compliance can assist fisheries managers in evaluating the effectiveness of a regulation, as high levels of violations may be indicative of a lack of fisher support and/or suggest practical difficulties in complying with the regulation (Hønneland 1999). Understanding fishers' attitudes may provide information useful to determining the most effective approach to estimating noncompliance. For example, chapter three (Thomas et al. 2014a) demonstrated that behaviour frequency and sensitivity should be considered in method selection. Instead of assuming rule-breaking behaviour is sensitive for all regulations, greater insight into fisher attitudes may show that assumption to be invalid. For example, non-compliance with one or more regulations may be an everyday topic of discussion among many fishers. Knowing this a researcher may decide that direct questioning, which has the smallest standard error, is the most appropriate method to estimate non-compliance. 
Without taking into account the reasons behind fishers' rule-breaking behaviour the response to non-compliance would consist of strengthening enforcement efforts and/or increasing penalties. Given the large area of the Marlborough Sounds it is not financially or practically feasible to regularly patrol the entire fishery. Increased intercepts at the marinas would also not be fully effective as fishers with holiday homes do not have to return to marinas at the end of the day. However, even if it was possible to increase deterrence efforts to a much higher level, it is unlikely to significantly lower non-compliance. The best fitting compliance models (chapter four) revealed that even if factors such as probability of detection and the penalty if convicted had a significant influence on a fisher's compliance decision, the effect was minimal. If enforcement efforts were increased without addressing the normative reasons behind the violations, especially social norms, there would be a potentially minimal change at a high cost. But in order to increase voluntary compliance, a strategic action for the Ministry (Ministry of Fisheries 2009), fisher attitudes and behaviour must first be known.

Fisher behaviour under new regulations is a large source of uncertainty (Fulton et al. 2011) but is vital as it can determine the effectiveness of the regulation. Investigation into fisher attitudes towards the regulations and the influences can provide insight into these information requirements. Importantly, it can also limit the amount of assumptions made, something that fisheries managers should reduce (Enck and Decker 1997). The influence of the amount of discards on fishing satisfaction, regulation agreement and compliance demonstrates the value of human dimensions research. Reducing the number of discarded fish is important for the fishery in biological terms, but the potential to increase fisher satisfaction at the same time makes re-evaluation of the size limit even more critical. Even though it would be hypothesized that fishers do not like having to throw back fish, it is significant that this behaviour significantly influenced their agreement and compliance with the size limit.

Research into fisher attitude and behaviour can lead to a greater understanding of why fishers may agree or disagree with a regulation. If it is known prior to regulation implementation that an increase in discards is likely to lead to lower levels of support and compliance, alternatives can be sought. Rather than presupposing a regulation will work and/or have fisher support, it would be more beneficial to utilize human dimensions 
research to test this assumption. Once a management regime is in place, information on fisher attitudes and behaviour is still necessary to fully evaluate the success of the regulations. Even though the biological goals may be met, negative fisher attitudes may reveal a lack of support. In the long-term the odds of a successful management strategy are greatly increased if the fishers are satisfied.

\subsubsection{The current top-down management regime should be rethought}

The literature warns that a management regime that relies on biology whilst neglecting the human dimensions risks failure (Granek et al. 2008; Jentoft and McCay 1995; McGoodwin 2006). In the introduction to the thesis it was noted that fisheries researchers now contend that fisher participation is a necessary component of the management process (Hilborn 2007a, b; Jentoft 2000; Jentoft et al. 1998; Kaplan and McCay 2004), especially in way that the fishers perceive as meaningful (Plinkerton 1989). There is also a need for greater engagement, transparency and research into fisher behaviour that can undermine regulation effectiveness (Fulton et al. 2011). So far the management strategy for the Marlborough Sounds recreational blue cod fishery has been top-down and biologically focused, but the consequences of that approach were unknown prior to the research conducted for this thesis. The results of the thesis demonstrate high levels of noncompliance, especially with the size limit, and low levels of satisfaction and fisher-perceived participation. As the prospects for successful management increase if user groups influence the design of rules and management procedures (Robbins et al. 2006) a shift in the current management regime would be beneficial. The negative attitudes also suggest that, for the Marlborough Sounds recreational blue cod fishery, the Ministry may not be meeting their governance condition of public trust in the "effectiveness and integrity" of the management (Ministry of Fisheries 2009, p. 6).

How do fishers react to a regulatory regime they perceive is not in their best interest? According to Hirschman (1975) there are two potential responses to this question: (1) "exit", resulting in regulation non-compliance, and (2) "voice", where stakeholders carry their frustrations to a public forum. Overall the present thesis provides evidence for both types of response. First, this thesis has provided evidence of high rates of regulation noncompliance (Thomas et al. 2014a). Second and under the other strategy, fishers seek to 
influence the management process by gaining support for their criticisms, either publicly (e.g., newspapers) or directly to the managers or courts (Jentoft 2000). The current management strategy has been a focus and the subject of regular letters-to-the-editor in regional newspapers since 2011 (when the fishery reopened). Fishers have used the latter to air their complaints with the regulations, the lack of participation and consideration of fisher feedback.

The intercept survey detailed in chapter two found that half of the fishers were not even aware of the one official medium for fisher participation (i.e., the BCMG).

Furthermore, many of the fishers that had heard of the group only knew the name and were unclear as to the BCMG's purpose. Numerous fishers used the survey as an opportunity to express their frustrations with the regulations and their lack of perceived effectiveness (which was included on the online survey). A common lament was that in complying with the size limit more damage was actually being done to the fishery, compared with noncompliance. Feedback to the Ministry on this subject has been ongoing but a review of the regulation has been continually pushed back (Bell 2014b), reflecting the Ministry's conflicting view on the size limit's effectiveness.

In addition to the high rates of non-compliance with the two main blue cod regulations (i.e., daily and size limits for blue cod), chapter three also demonstrated a lack of fishing in the community established Long Island Marine Reserve. As non-compliance in this area would be relatively easy with large potential gains, the acceptance of the marine reserve suggests that participation in the process is likely to be a key factor. Additionally, the study on the drivers of non-compliance (chapter four) showed that social norms, rather than instrumental factors, are the largest influence on a fisher's compliance behaviour with the size and daily limits. Fishers are more likely to comply with regulations implemented by a legitimate management regime (Tyler 1990), and should be provided with a greater role in the process to facilitate voluntary compliance. During semi-structured interviews, one fisher mentioned that non-compliance occurs for this reason, that regulation violations are a way to send a message to the Ministry (Thomas, unpublished field notes).

Not all forms of representation will be viewed as legitimate (Jentoft 2000) and the nature of fisher involvement is also important (Pita et al. 2010), as nominal participation is unlikely to suffice. Furthermore, for a participatory strategy to be truly effective fisher 
participation should be continual (Thomas et al. 2014b). In the case of the study fishery, it appears that efforts to include fishers (although perceived as token and minimal by many fishers) largely stopped after the introduction of the new regulations. Instead the Ministry has repeatedly expressed their commitment to managing on the basis of scientific information on the biological aspect of the fishery (Moore 2012) and has paid little attention to fisher feedback and the human dimensions of the fishery.

Fishers' knowledge appears to be largely ignored under the current management strategy, further limiting their participation. In fact, the reluctance of the Ministry to listen to fisher feedback was the most frequent complaint throughout the course of this research. Fishers' ecological knowledge can offer valuable information to complement, extend, refine or initiate collection of scientific data (Carr 2004; Jentoft et al. 1998; Johannes et al. 2000). In ignoring fishers' knowledge, the government risks further alienating these stakeholders. As a result the potential effectiveness of a regulation can be lowered, undermining the legitimacy of the management regime.

Involving fishers and listening to their feedback can decrease non-compliance (e.g., Jentoft and McCay 1995) so fisheries managers would do well to utilise this information (Mackinson et al. 2011). The Ministry carries out biological surveys every three years but fishers could provide valuable information about the state of the fishery between those reports, potentially through community science; or "the interaction between conventional (university/agency/industry) and community-based scientific knowledge system used in a particular place to discover, map, model, or measure changes in species number and/or behaviour" (Carr 2004 p.843). For example, fishers have a better idea of how many blue cod are being discarded because of the size limit, as well as the fate of these fish. Regular fishers could also provide feedback on the relative abundance of both juvenile and large (above $40 \mathrm{~cm}$ ) blue cod, both key areas of concern for the ongoing sustainability of the fishery. In addition to providing scientific data, fisher involvement in community science can also repair relationships with and rebuild trust in the management and scientists (Carr 2004). Given the current level of distrust towards the Ministry and frustration over their apparent reluctance consider fisher feedback on the regulations, this would be an important benefit to increased fisher participation. 
Differences between the institutional scientific knowledge and fisher's ecological knowledge can be a source of conflict and when that institutional knowledge is used as the basis for a regulation the potential for non-compliance increases. For example, some of the fishers interviewed admitted to violating the size limit as they felt it was harming the fishery by continually throwing back fish in order to catch two within the slot. They did not want to break the rule but could not reconcile the discards with the future of the fishery. One fisher highlights this issue when suggesting the new regulations 'have made criminals out of them (fishers)'. As the Ministry defines "best available information" as "decisions need to be based on the best available and credible biological, economic, social and cultural information from a range of sources" (Ministry of Fisheries 2009, p. 12) I believe there is already a case for greater inclusion of fisher knowledge.

What might greater fisher participation in the management process look like? With the Blue Cod Management Group, there is already an established forum for fisher involvement. However, the group appears to have minimal power and influence; and is more token participation than truly involved. The final decisions are still made by the Ministry, with recommendations by a working group composed of scientists. Looking at figure 6.1, it appears that the Marlborough Sounds recreational blue cod fishery falls somewhere between instructive and consultative, possibly more towards instructive for reasons discussed above. Instead, I believe the fishery should be co-managed; thereby giving fishers a true voice in the management process. Regulation non-compliance may even decrease with greater fisher involvement and allowing the fishers to actually make final decisions lessens the chance of implementing an unpopular regulation.

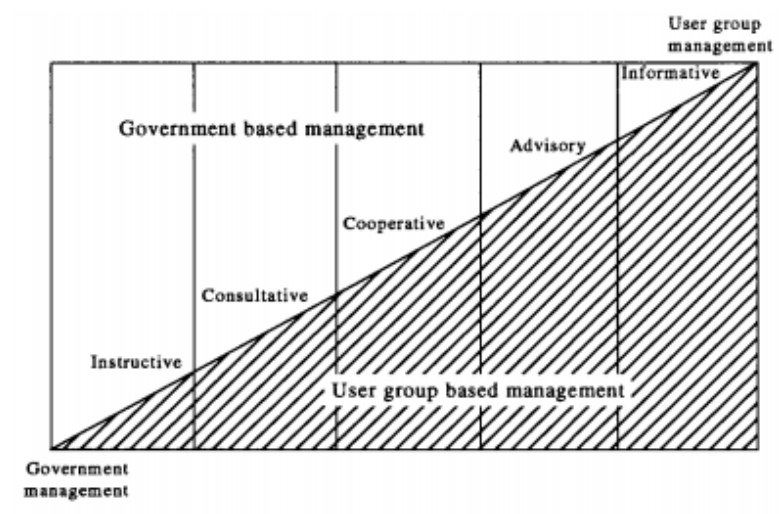

Figure 6.1: Spectrum of fisheries management arrangements

From Sen and Nielsen (1996) 
The fishers to sit on the Blue Cod Management group should also be chosen carefully to provide a greater diversity in representation as this thesis has demonstrated that fishers are not always a homogenous group. Public consultation could also be improved to reach more fishers. For example, upcoming consultations on potential changes to the regulations is limited to two meetings in the Marlborough region. Along with co-management, consultation should also include non-resident fishers, especially those in Wellington and Christchurch.

\subsubsection{The need for targeted behavioural interventions in response to non-compliance}

Effectively addressing the problem of non-compliance in a fishery is an important challenge for fisheries managers. But the scale and numerous drivers make it a daunting task that requires time and money, which are often lacking. As a result, essential questions about non-compliance with conservation rules remain unanswered. For example, Robbins et al. (2009) posed the following questions: "who, within and across diverse rural communities, is most likely to 'poach' resources? How do local management norms shape the intensity and nature of the illicit extraction from the nearby conservation zones? What form of governance would rule-breakers prefer? In the absence of answers to these basic questions and without knowing who rule breakers are and what they do, it is difficult to imagine or develop management schemes that are either sustainable or just" (p. 560). In order to minimize regulation violations, targeted behavioural interventions are needed. Otherwise the traditional approach of stricter rules and increased enforcement bring about the 'vicious circle' (Jentoft and Mikalsen 2004) previously mentioned and fails to actually address the causes of non-compliance.

But needing targeted behavioural interventions brings about further questions. How are priorities for management actions determined? Who should be targeted in these interventions? Which regulations are not currently effective? Section 6.3.1 discussed the valuable contribution from a better understanding of the human dimensions of the fishery. The design and implementation of effective behavioural interventions is dependent on knowledge of fisher attitudes and behaviour. But the diversity in fisher knowledge and attitudes displayed in chapter two highlights the need for such interventions to target specific groups of fishers. For example, knowledge of the transit rule was not consistent among fishers as more experienced fishers had greater knowledge of the rules. Given this 
finding, blanket efforts to improve regulation awareness would not be the most effective strategy. Instead, finding a way to target less experienced fishers would provide maximum benefits for increasing knowledge.

The extent of non-compliance with a regulation can provide data on which regulations need the most attention and should potentially be reviewed. In the absence of that information managers can only estimate which regulation has the most violations based on sources such as field intercepts or logbooks (in the case of commercial fisheries) which may not be accurate (Gavin et al. 2009). Other, more accurate methods of estimating regulation non-compliance are needed, as increasing enforcement over the entire fishery is not possible or advisable given the importance of normative factors in driving regulation non-compliance. High levels of non-compliance also suggest where research into the drivers of non-compliance would be beneficial.

There is substantial research detailing the drivers of non-compliance in different fisheries worldwide but the results are significantly varied. For example, in Swedish fisheries moral and social norms were the largest driver of compliance (Jagers et al. 2012) but in Danish fisheries instrumental factors such as potential economic gains and the probability of detection were the most important influences (Nielsen and Mathiesen 2003). Even though the largest driver of compliance with both the daily and size limits was social norms, the relative influence of the two types of social norms differed. Injunctive and social norms address two different aspects of social acceptance, what others think and what others do, and are best addressed in different ways. For example, injunctive social norms are best addressed when an individual's self-regulating capacity is high (Jacobson et al. 2011). Furthermore the influences on the social norm are not necessarily consistent between regulations. The best fitting model for the size limit showed an influence of problem awareness on social norms, but for the daily limit model there were no influencing variables. The factors influencing the legitimacy of the management regime (which is believed to affect social norms) are also likely to vary in importance. Looking at the median factor scores, the effectiveness of the size limit was perceived to be significantly lower than that for the daily limit.

Without researching the human dimensions there are "too many proposed solutions and not enough practical answers for improving management" (Fulton et al. 2011). So in the 
absence of this information for a specific fishery, assumptions will be made and/or efforts will rely on enforcement. There is a high likelihood these interventions may not be effective, wasting both time and money while undermining the health of the fishery. Furthermore, targeted behavioural interventions could assist the Ministry in meeting one of their overall objectives: "cost-effective management and services" (Ministry of Fisheries 2009 p. 8) which includes the use of "least cost policy tools" (p. 12). Therefore the drivers of non-compliance need to be modelled to determine which factors have largest influence. Under this approach managers can also identify the characteristics of violators, making it easier to determine the target groups for the interventions.

Once greater information on fisher attitudes and behaviour is known, behavioural interventions can be designed using that knowledge. Specifically, it seems such research can provide answers to important questions when designing behavioural interventions: who (what group of fishers needs to be targeted), what (what behaviour needs to be changed), why (how does the behavioural change benefit the fishery) and how (what type of intervention would be most effective). Answering these questions allows targeted behavioural interventions to be designed and implemented, effectively addressing the issue. Without knowing this information, management strategies to address non-compliance are likely to be only marginally effective.

\subsection{Reflections on research}

In writing this conclusion and reflecting on the process and results of the past few years, several important thoughts are worth noting. The first reflection came up towards the beginning of this entire process, my role as an outsider and scientist. When I first visited the Marlborough Sounds I attended a meeting of the Marlborough Sounds Recreational Fishing Association to discuss my proposed research and ask for volunteers to interview. Yet I was only allowed to say a few words before being asked to leave the room while they discussed my request. Although a few fishers agreed to talk with me, the overall atmosphere was one of distrust (what did I know about this issue and how was I going to use the data?). Previous scientific studies almost always resulted in stricter regulations, including the ban, so why would my research be any different? There was also the occasional fisher who believed I was working for the Ministry and not as a true independent researcher. Getting the fishers 
to trust me (and thus my work) took time, multiple visits and finally seeing the questions I was asking.

When it became clear to fishers that I was genuinely interested in their thoughts and asked about subjects important to them, I finally overcame their scepticism. Although, it should be noted that even after carrying out data collection, publication of multiple articles in newspapers, newsletters and magazines, and a presentation on the results, some fishers are still distrustful and questioning of the results. Other researchers (Jacobsen and others 2012) have noted this quandary; that fishers are likely to associate scientists with management efforts and regulation formation even when their research is independent. Notably, this scepticism was not limited to the fishers. When I approached the Ministry to discuss my research, I was once again met with distrust over my methods and background. As a social scientist, most of the methods and approaches employed in the research were new to the Ministry and outside the domain of their staff of fisheries biologists.

My role as an objective scientist has also caused dilemmas throughout this process. Yet as I analysed the data and continued writing up the results, I realized that the management strategy did not have to be a choice between listening to fishers and their concerns, or ensuring the recovery and sustainability of the blue cod population. Greater fisher involvement in the management process could benefit the fishery in many ways, including maximising regulation compliance, key to ensuring the success of the current management regime. But convincing the Ministry of the benefits of this management strategy change is likely to still be a difficult task.

Although I previously noted how pleased most fishers were that this research was being carried out, I was also surprised at the level of apathy and disillusionment shown by many fishers. When I invited fishers to take part in the online survey the most common reason for declining was that they felt it was no use and would not make a difference. These fishers felt the Ministry would not take any notice of the results, despite being carried out by an independent researcher. Even some of the fishers who provided emails commented that it would not change the situation. However, many of these fishers felt just as strongly about the regulations as fishers who did participate. I believe this apathy is by itself an important finding as it reflects the continued lack of fisher involvement and the Ministry's refusals to consider fisher feedback. Turnout at the meeting I organized to present my 
research was also extremely low, as previously noted. If fishers are often apathetic towards change it presents a challenge for their concerns to be heard. Greater participation in the management process would help address this issue as fishers would be more likely to feel they had a voice and their feedback could actually influence regulation design. Feedback on the presentation also reflected this feeling, as even fishers invested enough in the issue to attend the meeting did not believe the Ministry would consider the results. At the same time, it is also worth noting that the empirical studies were successful in terms of sample size, suggesting that despite this apathy many fishers were willing to voice their views. As several fishers stated, "it can't hurt".

\subsection{Further research}

The four studies that comprise this thesis offer important and useful information concerning the human dimensions of the Marlborough Sounds recreational blue cod fishery and also illuminate areas for further research. The first two areas of study are perhaps the most straightforward and follow on from the concerns raised by objective four (chapter five) over the number of blue cod currently discarded. Although it may be true that blue cod have a very high survival rate if a large, barbless hook is used, the Ministry does not currently have that information. Given that the use of small hooks significantly increased the likelihood of mortality in small blue cod (Carbines 1999b), making an assumption on this area of fisher behaviour seems imprudent. Further research to test this assumption is also merited since $53 \%$ of the blue cod currently discarded are less than $30 \mathrm{~cm}$, and Carbines (1999) considered 'small' blue cod to be those under $33 \mathrm{~cm}$. Similarly, the other study on blue cod post-release mortality (Davidson 1995) that showed no post-release predation is almost ten years old and the amount of blue cod discarded has substantially increased since that time (Humm 2013). Furthermore, the scientific literature has documented links between discards and increasing seabird populations (e.g., Oro et al. 2004).

Moreover, there has yet to be any research into seabirds' consumption of discards in recreational fisheries. As post-release mortality, whether from hooking injuries or predation, is the largest source of fishing mortality (Davis 2002), carrying out research on these two topics would allow the Ministry to have a more accurate estimate of fishing mortality and is in line with their principle of following a precautionary approach: "Particular care will be taken to ensure environmental sustainability where information is uncertain, 
unreliable or inadequate" (Ministry of Fisheries, 2009, p. 12). Specifically, a community science project would be a beneficial approach to obtaining these data given the lack of institutional information and high public interest. As the blue cod population has still not recovered (Bell 2014b), accurate and current information on the population is vital for sustainable management.

A second area that would benefit from future research is differences in fisher attitudes towards retaining undersized and oversized blue cod, as they are not likely to be the same. Minimum size restrictions are one of the most commonly used management strategies both worldwide (Radomski et al. 2001) and in New Zealand (Ministry of Fisheries 2014b), but the maximum size is unique to the blue cod fishery in this country. During conversations with fishers, there were suggestions to lower the minimum size but many fishers mentioned that a $33 \mathrm{~cm}$ minimum size would be preferable. Three presentation attendees mentioned this issue, although their preferred minimum size varied. Having to discard juvenile fish is something that fishers understand and agree with, resulting in negative social norms on this issue. In contrast, fishers are less likely to agree with throwing back a large fish especially as many are unclear on why the maximum size was implemented. The only socially acceptable reason for a fisher to keep an undersized blue cod is likely to be if it were fatally injured. But the drivers of non-compliance with the maximum size are likely to be more complex, even though primarily driven by social norms. It would also be worthwhile to explore what percentage of the $30 \%$ of non-compliance with the size limit is oversized blue cod. Once that was established, a similar approach to objective three could be used to differentiate the drivers of non-compliance between undersized and oversized blue cod. These findings would then allow for more targeted behavioural interventions.

The results of all four studies suggest a need to re-evaluate the size limit, particularly the maximum size, and the presentation feedback confirms the importance of this issue. Although chapter five demonstrates strong support for a $30-40 \mathrm{~cm}$ slot, further consultation and research should be undertaken around this issue prior to change. The prevalence and sensitivity of high-grading among fishers would be an important part of this study. If fishers high-grade too often under the $10 \mathrm{~cm}$ slot, it would negate some of the discard reductions from the larger slot. As the maximum size limit is unique within New Zealand, there are 
likely to be fishers who will disagree with the maximum size even if modified. Part of this research could include education on the reason for the maximum size to test if greater knowledge influenced their support for the size limit. It may be that many fishers currently opposed to any maximum size would be more supportive if they were aware of the benefits to the fishery (leaving large males in the population so large females do not change sex). As the first study (Thomas et al. 2014b) demonstrated that fishers are not a homogenous group, extensive consultation, via multiple modes, would be advised to ensure representation of the different groups.

A final area for future research would be evaluation of potential adaptive management approaches to behaviour change. Specifically, this approach could be used for testing potential interventions to influence social norms, the largest driver of noncompliance with both the daily and size limits. Prior research has suggested that descriptive norm interventions are most effective when targeted to different groups. As fisher attitudes and behaviours differ between groups based on factors such as experience and residency, the social norm influences may also differ. Regardless, further investigation of the reasons behind fisher attitudes will help design effective interventions. The Bamberg and Möser (2007) model used in the drivers of non-compliance suggests that problem awareness and internal attribution influence social norms and the four variables used to measure legitimacy (i.e., outcome fairness and effectiveness, participation and meaningful rule) are also likely to influence the social norm as well. For example, if a regulation is not viewed as fair, the injunctive social norm may not confer social sanctions on fishers breaking that rule.

A recent meta-review (Abrahamse and Steg 2013) found that another form of social influence, block leaders, was a more effective approach then social norms. Given the strained relationship between the Ministry and the fishers, this method of using stakeholders to convey information could be extremely effective when coupled with interventions targeting social norms. In order to help maximise the effectiveness of social norm interventions, Social Network Analysis would be extremely useful as it seeks to understand networks, their participants and the relationships between them (Scott 1988). Although frequently used in the social sciences (Luke 2005) natural resource managers are only recently realizing Social Network Analysis' potential. Results from carrying out this analysis, including how fishers get specific information and from whom, would allow more 
targeted behavioural interventions to change the social norm through the use of existing social networks.

\subsection{Study limitations}

One limitation that applies to all studies is the small sample size. Although initially disappointed in the number of responses to both the intercept and online surveys, reading journal articles on other studies showed that the sample size was comparable (or even larger) to other studies in the area. Despite this, 300-400 fishers are only a small proportion of the estimated 9000 fishers in 2008 (Batstone et al. 2009). Even though this number has probably decreased as a result of the ban and current strict regulations, the adjusted estimate would still be many times higher than my sample size. However, the results are still representative of the different groups of fishers and the methodological and theoretical contributions are not diminished. As this research was mainly self-funded and carried out without the help of any assistants, a significantly larger sample size would have been difficult. But these constraints did influence the data collection method for the intercept survey, which was also the initial source of emails for the online survey. Data collection was concentrated at the three marinas in the region and a nearby recreational area (Waikawa Bay) but boat ramps in other parts of the Marlborough Sounds were not sampled. Although the subsequent articles in newspapers and fishing magazines, as well as word-of-mouth and emails, provided an opportunity to participate in the online survey, these fishers may have been under-represented in the intercept survey.

As previously noted, fishers who believed the research would not make a difference to the Ministry were less likely to offer their email address, and also take the online survey. This group of fishers is likely to be under-represented in the final sample but the extent of this bias is unknown. It has been established that fishers with greatest investment greater psychological, social and monetary investments in the fishery are likely to voice the strongest opinions in response to management changes (Bryan 2000). Therefore, although it is likely that fishers who were satisfied with the regulations were less likely to take the survey, this group appears to be a minority based on the intercept surveys, which did not have this potential response bias. A greater inclusion of this group would therefore not significantly alter the findings. 
A response bias may have also influenced the number of respondents who completed the final study (chapter five) as the more invested or frustrated fishers would have been the most likely to take the time to get that far along in the survey. As a result, there is the potential that fisher satisfaction with an unchanged size limit may be underestimated; although again the intercept survey suggests this concern is small. Finally, two reported studies (chapters three and four) were based on the same sample of fishers. Although the scenario study was presented independently and used a between-group experimental design, it would have been better to gather data from two independent samples of fishers.

The length of the survey was also a main limitation with the response rate and small sample size. Because the online survey was quite long, it meant the response rate continued to decrease as more questions were answered. In recognition of this concern, the question order was carefully selected. After the initial questions on blue cod fishing in the Marlborough Sounds, the methodological questions for chapter three (estimating noncompliance) were presented next. The use of both indirect techniques required a large sample size to counteract the large variances under both methods. Next, the three 'blocks' of questions for the study on drivers of non-compliance (all regulations, daily limit then size limit) were given. Within each 'block,' there were several lots of seven to eight questions on the drivers and the question order was randomized. However, the order of the blocks was not randomized so there is the potential for order effects, especially on the statements concerning drivers of compliance with the size limit.

Chapter five's study on size limit scenarios was last as preliminary calculations had shown that a large sample size was not necessary to demonstrate potential differences between groups. Furthermore, this study was the most practical and also of the most interest to fishers given the frustration over the size limit. It was rationalized that the high level of fisher interest in the size limit and resulting discards would encourage respondents to continue on with the survey, even though they had already answered quite a few questions. But once again, there is the potential for order effects as fishers responses could have been influenced by previous answers. Nonetheless, I believe these effects to be minimal given the strong feelings on the size limit regulation. 
Using different sample populations for the different studies would have addressed the sample size problem and minimized potential order effects for the later questions and studies. Multiple samples may have also increased representation of less interested/more satisfied fishers and lower that potential bias.

\subsection{Final thoughts}

The introductory chapter of this thesis provided evidence of a crisis in the world's fisheries with most species overfished (Food and Agriculture Organization of the United Nations 2012); but only recently has the recreational fishing sector been acknowledged as a threat to fish stocks. This practice, which is growing in popularity (Arlinghaus and Cooke 2009; Coleman et al. 2004), shares many of the same effects as commercial fisheries including: environmental degradation, altered ecosystems, evolutionary changes through selective fishing pressure, stock collapse and a problem of discards and by-catch (Cooke and Cowx 2004). The most prevalent reason behind these management failures, in both commercial and recreational fisheries, has been the continued reliance on a top-down management approach (Froese and Proelß 2010; Nussman et al. 2005). But natural resource management is undergoing a change in perspective with greater recognition that the social and ecological aspects of fisheries are linked (Berkes 2010). In order to reverse the trend of fisheries management failures, a new approach is therefore needed; one that ensures a more participatory process with strong consideration of the human dimensions in addition to the biological (and economic) aspects.

The value of understanding fisher attitudes and behaviour, especially as they relate to non-compliance, has been stressed throughout the four studies comprising this thesis. Human dimensions research should not be disregarded nor fishers' responses to regulations viewed as externalities. Study results demonstrate how this information can actually improve the effectiveness of the management regime and that it 'must' be included to maximize effectiveness. Information on the heterogeneity in fisher attitudes and their influences can assist in designing regulations that are accepted by a majority of fishers and help create a legitimate management regime. This approach is even necessary to utilize targeted behavioural interventions to address the issue of non-compliance, at least without wasting time or money. 
Unfortunately, the most recent biological data, although not fully released, lends credence to fisher concerns over the consequences of the increased discards from the slot rule. The data show there are fewer blue cod than the 2010 survey (Beentjes and Carbines 2012) but these blue cod are heavier (Bell 2014b); suggesting high rates of mortality amongst smaller fish. As stated by Finlayson and McCay (1998) "when the accumulation of perceived failures significantly exceeds the perceived utility of management, the legitimacy and conceptual coherence of that management institution are weakened to the point where they are vulnerable to challenge and open to fundamental change" (p. 311). It appears that the Marlborough Sounds recreational blue cod fishery is currently at such a tipping point, making it an opportune time for a shift to a more inclusive management regime.

I also wish to note that this thesis does not represent the end of this research. In accordance with the desire for the results to be considered by the Ministry a report summarizing the main findings with reference to both the scientific literature, as well as the Ministry's noted objectives and actions, will be produced in advance of a meeting and potential presentation on the research. A second report will also be created for dissemination to interested fishers to continue the process of stakeholder engagement. It is my hope that this research will assist the Ministry in recognizing the value of a transition to a more participatory management strategy. As the existing literature on the human dimensions of fisheries is not being fully utilized (Arlinghaus et al. 2008; Hunt et al. 2013) this study demonstrates multiple benefits, for all stakeholders, to ending this information exclusion. This chapter has also shown how many of the suggestions from this thesis are aligned with the Ministry's own goal of using the fishery "in a manner that provides the greatest overall economic, social, and cultural benefit" (Ministry of Fisheries 2009, p. 5). As the legitimacy of a management regime is not static (Jentoft 2000) it is not too late for these changes to happen and avoid another ban on recreational blue cod fishing. Many of the fishers are passionate about the health of the fishery and spoke of wanting to ensure their children and grandchildren are able to go fishing in the Marlborough Sounds. Sadly, at this point it seems that future is far from guaranteed. 


\section{References}

Abbot, J.I.O., Mace, R., 1999. Managing protected woodlands: Fuelwood collection and law enforcement in Lake Malawi National Park. Conserv Biol 13, 418-421.

Abernathy, J.R., Greenberg, B.G., Horvitz, D.G., 1970. Estimates of induced abortion in urban North Carolina. Demography 7, 19-29.

Abrahamse, W., Steg, L., 2013. Social influence approaches to encourage resource conservation: a meta-analysis. Global Environmental Change 23, 1773-1785.

Agnew, D.J., Pearce, J., Pramod, G., Peatman, T., Watson, R., Beddington, J.R., Pitcher, T.J., 2009.

Estimating the worldwide extent of illegal fishing. PLoS ONE 4, e4570.

Ainsworth, C.H., Pitcher, T.J., 2005. Estimating illegal, unreported and unregulated catch in British Columbia's marine fisheries. Fish Res 75, 40-55.

Ajzen, I., 1991. The theory of planned behavior. Organizational Behavior and Human Decision Processes 50, 179-211.

Akella, A.S., Cannon, J.B., 2004. Strengthening the weakest link: Strategies for improving the enforcement of environmental laws globally, In Environmental Crime: A Reader. ed. R. White, pp. 528-567. Willan Publishing, Cullompton.

Al-Subhi, K.K.N., Bose, S., Al-Masroori, H.S., 2013. Fishers' compliance motivations: A case study of the Sultanate of Oman. Mar Policy 37, 141-148.

Anderson, L.G., 1989. Enforcement issues in selecting fisheries management policy. Mar Resour Econ 6, 261-277.

Anderson, L.G., 1994. An economic analysis of highgrading in ITQ fisheries regulation programs. Mar Resour Econ 9, 209-226.

Arcos, J.M., Oro, D., 2002. Significance of fisheries discards for a threatened Mediterranean seabird, the Balearic shearwater Puffinus mauretanicus. Mar Ecol Prog Ser 239, 209-220.

Arlinghaus, R., 2004. A Human Dimensions Approach Towards Sustainable Recreational Fisheries Management. Tumsare, London.

Arlinghaus, R., Cooke, S.J., 2009. Recreational fisheries: socioeconomic importance, conservation issues and management challenges, In Recreational Hunting, Conservation and Rural Livelihoods: Science and Practice. eds B. Dickson, J. Hutton, W.M. Adams, pp. 39-58. Wiley-Blackwell, Oxford. Arlinghaus, R., Cooke, S.J., Lyman, J., Policansky, D., Schwab, A., Suski, C.D., Sutton, S.G., al, e., 2007. Understanding the complexity of catch-and-release in recreational fishing: an integrative synthesis of global knowledge from historical, ethical, social, and biological perspectives. Rev Fish Sci 15, 75-167. Arlinghaus, R., Johnson, B.M., Wolter, C., 2008. The past, present and future role of limnology in freshwater fisheries science. Int Rev Hydrobiol 93, 541-549.

Arlinghaus, R., Mehner, T., 2005. Determinants of management preferences of recreational anglers in Germany: Habitat management versus fish stocking. Limnologica - Ecology and Management of Inland Waters 35, 2-17.

Arlinghaus, R., Mehner, T., Cowx, I.G., 2002. Reconciling traditional inland fisheries management with sustainability in industrialized countries, with emphasis on Europe. Fish Fish 3, 261-316.

Armitage, C.J., Conner, M., 2001. Efficacy of the theory of planned behaviour: a meta-analytic review. British Journal of Social Psychology 40, 471-499.

Balmford, A., Cowling, R.M., 2006. Fusion or failure? The future of conservation biology. Conserv Biol 20, 692-695.

Bamberg, S., Moser, G., 2007. Twenty years after Hines, Hungerford, and Tomera: A new meta analysis of psycho-social determinants of pro-environmental behaviour. Journal of Environmental Psychology 27, 14-25.

Bamberg, S., Möser, G., 2007. Twenty years after Hines, Hungerford, and Tomera: a new metaanalysis of psycho-social determinants of pro-environmental behaviour. Journal of Environmental Psychology 27, 14-25. 
Bartholomew, A., Bohnsack, J.A., 2005. A review of catch-and-release angling mortality with implications for no-take reserves. Rev Fish Biol Fish 15, 129-154.

Bartumeus, F., Giuggioli, L., Louzao, M., Bretagnolle, V., Oro, D., Levin, S.A., 2010. Fishery discards impact on seabird movement patterns at regional scales. Curr Biol 20, 215-222.

Batstone, C., Goodwin, E., Jiang, W., Keer, G., Sharp, B., Sinner, J., 2009. Marlborough Sounds recreational fisher characterisation. Prepared for New Zealand Ministry of Fisheries,

Bavinck, M., 1996. Fisher regulations along the Coromandel coast: A case of collective control of common pool resources. Mar Policy 20, 475-482.

Bavington, D., 2002. Managerial ecology and its discontents: exploring the complexities of control, careful use and coping in resource and environmental management. Environments 30, 3-21.

Baxter, M., 2012. Owner, Sounds Connection, 24 October.

Beard, T.D., Cox, S.P., Carpenter, S.R., 2003. Impacts of daily bag limit reductions on angler effort in Wisconsin Walleye Lakes. N Am J Fish Manage 23, 1283-1293.

Becker, G.S., 1968. Crime and punishment: an economic approach. Journal of Political Economy 76, 169-217.

Beentjes, M.P., Carbines, G., 2005a. Population structure and relative abundance of blue cod

(Parapercis colias) off Banks Penninsula and in Dusky Sound, New Zealand. N Z J Mar Freshwater Res 39, 77-90.

Beentjes, M.P., Carbines, G., 2012. Relative abundance, size and age structure, and stock status of blue cod from the 2010 survey in Marlborough Sounds, and review of historical surveys. Ministry for Primary Industries, Wellington, New Zealand.

Beentjes, M.P., Carbines, G.D., 2005b. Population structure and relative abundance of blue cod (Parapercis colias) off Banks Peninsula and in Dusky Sound, New Zealand. N Z J Mar Freshwater Res 39, 77-90.

Bell, C., 2014a. Candidate blasts slot rule, In Marlborough Express.

Bell, C., 2014b. No rush for cod fishery rule shift, In Marlborough Express.

Bell, M., 2012. A breeding survey of three species of shags in the Marlborough Sounds. Notornis 59, 60-65.

Benoît, H.P., Hurlbut, T., Chassé, J., 2010. Assessing the factors influencing discard mortality of demersal fishes using a semi-quantitative indicator of survival potential. Fish Res 106, 436-447. Berkes, F. ed., 1989. Common Property Resources: Ecology and Community-Based Sustainable Development. Belhaven Press, London.

Berkes, F., 2010. Shifting perspectives on resource management: resilience and the reconceptualization of 'natural resources' and 'management'. Maritime Studies 9, 13-40.

Blaber, S.J.M., Wassenberg, T.J., 1989. Feeding ecology of the piscivorous birds Phalacrocorax varius, P. melanoleucos and Sterna bergii in Moreton Bay, Australia: diets and dependence on trawler discards. Mar. Biol. 101, 1-10.

Blackwell, R.G., 1998. Abundance, size and age composition of recruited blue cod in the Marlborough Sounds, September 1996. National Institue of Water and Atmospheric Research, Blackwell, R.G., 2002. Abundance and size composition of recruited blue cod in the Marlborough Sounds, September 2001. National Institute of Water and Atmospheric Research, Wellington, New Zealand.

Blackwell, R.G., 2006. Abundance and size composition of blue cod in the Marlborough Sounds and Tasman Bay, September-October 2004. National Institute of Water and Atmospheric Research, Wellington, New Zealand.

Blackwell, R.G., 2009. Abundance and size composition of blue cod in the Marlborough Sounds, and Tasman Bay, September-October 2007. National Institute of Water and Atmospheric Research, Blank, S.G., Gavin, M., 2009. The randomized response technique as a tool for estimating noncompliance rates in fisheries: a case study of illegal red abalone (Haliotis rufescens) fishing in Northern California. Environ Conserv 36, 112-119. 
Blue Cod Management Group, 2010. Proposed management plan: Marlborough Sounds amateur blue cod fishery.

Bochenek, E., Powell, E.N., DePersenaire, J., 2012. Recall bias in recreational summer flounder party boat trips and angler preferences to new approaches to bag and size limits. Fisheries Science 78, 114.

Bochenek, E.A., Powell, E.N., DePersenaire, J., King, S.E., 2010. Evaluating catch, effort, and bag limits on directed trips in the recreational summer flounder party boat fishery. Marine and Coastal Fisheries 2, 412-423.

Boonstra, W.J., Bach Dang, N., 2010. A history of breaking laws-social dynamics of non-compliance in Vietnamese marine fisheries. Mar Policy 34, 1261-1267.

Borsari, B., Carey, K., 2003. Descriptive and injunctive norms in college drinking: A meta-analytic integration. Journal of Studies on Alcohol 64, 331-341.

Bose, S., Crees-Morris, A., 2009. Stakeholder's views on fisheries compliance: An Australian case study. Mar Policy 33, 248-253.

Botsford, L.W., Castilla, J.C., Peterson, C.H., 1997. The management of fisheries and marine ecosystems. Science 277, 509-515.

Bradford, E., 1998. Harvest Estimates from the 1996 national marine recreational fishing surveys, ed. National Institute of Water and Atmospheric Research. Unpublished report held in the NIWA library, Wellington.

Brashares, J.S., Arcese, P., Sam, M.K., Coppolillo, P.B., Sinclair, A.R.E., Balmford, A., 2004. Bushmeat hunting, wildlife declines, and fish supply in West Africa. Science 306, 1180-1183.

Brechin, S.R., Wilshusen, P.R., Fortwangler, C.L., West, P.C., 2002. Beyond the square wheel: Toward a more comprehensive understanding of biodiversity conservation as social and political process. Soc Nat Resour 15, 41-64.

Bright, I., 2012. Ministry for Primary Industries District Compliance Manager: Nelson/Marlborough, personal communication. 12 November.

Broadhurst, M.K., Gray, C.A., Reid, D.D., Wooden, M.E.L., Young, D.J., Haddy, J.A., Damiano, C., 2005. Mortality of key fish species released by recreational anglers in an Australian estuary. J Exp Mar Biol Ecol 321, 171-179.

Brouwer, S.L., Mann, B.Q., Lamberth, S.J., Sauer, W.H.H., Erasmus, C., 1997. A survey of the South African shore-angling fishery. S Afr J Mar Sci 18, 165-177.

Brown, T.A., 2006. Confirmatory Factor Analysis for Applied Research. Guilford Press, New York. Bryan, H., 2000. Recreation specialization revisited. Journal of Leisure Research 32.

Burnham, K.P., Anderson, D.R., 2002. Model Selection and Multimodel Inference: A Practical Information-Theoretic Approach. Springer, Berlin.

Burton, P.S., 2003. Community enforcement of fisheries effort restrictions. Journal of Environmental Economics and Management 45, 474-491.

Byrne, B.M., 2012. Structural Equation Modeling With Mplus: Basic Concepts, Applications And Programming. Taylor \& Francis Group, LLC, New York.

Carbines, G., 1998a. Blue cod age validation, tagging feasibility and sex inversion. Final report to the Ministry of Fisheries for Project SOBCO4, Wellington.

Carbines, G., 1998b. Determination of movement of blue cod in Southland. National Institute of Water and Atmospheric Research, Wellington, New Zealand.

Carbines, G., 1999a. Determination of movement of blue cod in Southland. National Institue of Water and Atmospheric Studies, Wellington.

Carbines, G., 1999b. Large hooks reduce catch-and-release mortality of blue cod Parapercis colias in the Marlborough Sounds of New Zealand. N Am J Fish Manage 19, 992-998.

Carbines, G., 2000. Comparisons of age and growth of blue cod within the Marlborough Sounds (BCO 7). National Institute of Water and Atmospheric Research, Wellington, New Zealand.

Carbines, G., 2004. Age determination, validation, and growth of blue cod Parapercis colias, in Foveaux Strait, New Zealand. N Z J Mar Freshwater Res 38, 201-214. 
Carbines, G., Jiang, W., Beentjes, M.P., 2004. The impact of oyster dredging on the growth of blue cod, Parapercis colias, in Foveaux Strait, New Zealand. Aquat Conserv 14, 491-504.

Carbines, G., McKenzie, J., 2004. Movement patterns and stock mixing of blue cod in Dusky Sound in 2002, ed. Ministry of Fisheries, p. 28.

Carr, A.J.L., 2004. Why do we all need community science? Soc Nat Resour 17, 841-849.

Castilla, J.C., Defeo, O., 2005. Paradigm Shifts Needed for World Fisheries. Science 309, 1324-1325.

Chaudhuri, A., Christofides, T.C., 2007. Item Count Technique in estimating the proportion of people with a sensitive feature. J Stat Plan Inference 137, 589-593.

Chen, X., Lupi, F., He, G., Liu, J., 2009. Linking social norms to efficient conservation investment in payments for ecosystem services. Proceedings of the National Academy of Sciences 106, 1181211817.

Chizinski, C.J., Martin, D.R., Hurley, K.L., Pope, K.L., 2014. Self-imposed length limits in recreational fisheries. Fish Res 155, 83-89.

Cho, J., Trent, A., 2006. Validity in qualitative research revisited. Qualitative Research 6, 319-340.

Christensen, V., 2011. Introduction: toward ecosystem-based management of fisheries, In Ecosystem

Approaches to Fisheries: A Global Perspective. eds V. Christensen, J. Maclean, pp. 1-8. Cambridge

University Press, Cambridge.

Cialdini, R., 2007. Descriptive social norms as underappreciated sources of social control.

Psychometrika 72, 263-268.

Cialdini, R., Reno, R.R., Kallgren, C.A., 1990. A focus theory of normative conduct: recycling the concept of norms to reduce littering in public places. Journal of Personality and Social Psychology 58, 1015-1026.

Cialdini, R.B., 2003. Crafting normative messages to protect the environment. Current Directions in Psychological Science 12, 105-109.

Cinner, J.E., Folke, C., Daw, T., Hicks, C.C., 2011. Responding to change: using scenarios to understand how socioeconomic factors may influence amplifying or dampening exploitation feedbacks among Tanzanian fishers. Global Environmental Change 21, 7-12.

Clark, S.J., Desharnais, R.A., 1998. Honest answers to embarassing questions: detecting cheating in the randomized response model. Psychol Methods 3, 160-168.

Coggins, L.G., Catalano, M.J., Allen, M.S., Pine, W.E., Walters, C.J., 2007. Effects of cryptic mortality and the hidden costs of using length limits in fishery management. Fish Fish 8, 196-210.

Cole, R.G., 1999. A comparison of abundance, population size structure, and sex ratio of blue cod Parapercis colias sampled by pot and diver count methods in Marlborough Sounds. National Institute of Water and Atmospheric Research, Wellington, New Zealand.

Cole, R.G., Alcock, N.K., Handley, S.J., Grange, K.R., Black, S., Cairney, D., Day, J., Ford, S., Jerrett, A.R., 2003. Selective capture of blue cod Parapercis colias by potting: behavioural observations and effects of capture method on peri-mortem fatigue. Fish Res 60, 381-392.

Cole, R.G., Villouta, E., Davidson, R.J., 2000. Direct evidence of limited dispersal of the reef fish Parapercis colias (Pinguipedidae) within a marine reserve and adjacent fished areas. Aquat Conserv 10, 421-436.

Coleman, F.C., Figueira, W.F., Ueland, J.S., Crowder, L.B., 2004. The impact of United States recreational fisheries on marine fish populations. Science 305, 1958-1960.

Cooke, S.J., Cowx, I.G., 2006. Contrasting recreational and commercial fishing: Searching for common issues to promote unified conservation of fisheries resources and aquatic environments. Biol Conserv 128, 93-108.

Cooke, S.J., Cowx, I.J., 2004. The role of recreational fishing in global fish crises. Bioscience 54, 857859.

Cooke, S.J., Schreer, J.F., Wahl, D.H., Philipp, D.P., 2002. Physiological impacts of catch-and-release angling practices on largemouth bass and smallmouth bass. Am Fish Soc Symp 31, 489-512.

Cooke, S.J., Sneddon, L.U., 2007. Animal welfare perspectives on recreational angling. Appl Anim Behav Sci 104, 176-198. 
Cooke, S.J., Wilde, G.R., 2007. The fate of fish released by recreational anglers, In By-Catch Reduction in the World's Fisheries. ed. S.J. Kennelly, pp. 181-234. Springer, New York, USA.

Copes, P., 1986. A critical review of the individual quota as a device in fisheries management. Land Econ 62, 278-291.

Costanza, R., Andrade, F., Antunes, P., Belt, M.v.d., Boersma, D., Boesch, D.F., Catarino, F., Hanna, S., Limburg, K., Low, B., Molitor, M., Pereira, J.G., Rayner, S., Santos, R., Wilson, J., Young, M., 1998.

Principles for sustainable governance of the oceans. Science 281, 198-199.

Couper, M.P., Kapteyn, A., Schonlau, M., Winter, J., 2007. Noncoverage and nonresponse in an Internet survey. Soc Sci Res 36, 131-148.

Coutts, E., Jann, B., 2011. Sensitive questions in online surveys: experimental results for the Randomized Response Technique (RRT) and the Unmatched Count Technique (UCT). Sociol Methods Res 40, 169-193.

Cowx, I.G., 2002. Recreational fishing, In Handbook of Fish Biology and Fisheries. eds P.J.B. Hart, J.D. Reynolds, pp. 367-390. Blackwell Science, Oxford.

Cowx, I.G., Arlinghaus, R., Cooke, S.J., 2010. Harmonizing recreational fisheries and conservation objectives for aquatic biodiversity in inland waters. J Fish Biol 76, 2194-2215.

Cox, S.P., Post, J., 2002. Modeling exploitation in recreational fisheries and implications for effort management on British Columbia rainbow trout lakes. N Am J Fish Manage 22, 21-34.

Crossland, J., 1977. Seasonal reproductive cycle of snapper Chrysophrys auratus (Forster) in the Hauraki Gulf. N Z J Mar Freshwater Res 11, 37-60.

Curcione, N., 1992. Deviance as delight: party-boat poaching in southern California. Deviant Behavior 13, 33-57.

Dallas, L.J., Shultz, A.D., Moody, A.J., Sloman, K.A., Danylchuk, A.J., 2010. Chemical excretions of angled bonefish Albula vulpes and their potential use as predation cues by juvenile lemon sharks Negaprion brevirostris. J Fish Biol 77, 947-962.

Dalton, D.R., Wimbush, J.C., Daily, C.M., 1994. Using the unmatched count technique (UCT) to estimate base rates for sensitive behavior. Pers Psychol 47, 817-828.

Davidson, R.J., 1995. Long Island-Kokomohua Marine Reserve. Subtidal biological baseline report.

Department of Conservation Nelson, New Zealand.

Davidson, R.J., 2001. Changes in population parameters and behaviour of blue cod (Parapercis colias; Pinguipedidae) in Long Island-Kokomohua Marine Reserve, Marlborough Sounds, New Zealand.

Aquat Conserv 11, 417-435.

Davidson, R.J., Abel, W., Richards, L.A., 2009. Biological monitoring update for Long Island-

Kokomohua Marine Reserve, Queen Charlotte Sound. Prepared by Davidson Environmental Limited for Department of Conservation, Nelson, New Zealand.

Davie, P.S., Kopf, R.K., 2006. Physiology, behaviour and welfare of fish during recreational fishing and after release. N Z Vet J 54, 161-172.

Davis, M.W., 2002. Key principles for understanding fish bycatch. Can J Fish Aquat Sci 59, 1834-1843.

Davis, M.W., Parker, S.J., 2004. Fish size and exposure to air: potential effects on behavioral

impairment and mortality rates in discarded sablefish. N Am J Fish Manage 24, 518-524.

De Jong, M.G., Pieters, R., Fox, J.-P., 2010. Reducing social desirability bias through item randomized response: an application to measure underreported desires. J Mark Res XLVII, 14-27.

de Leeuw, E.D., 2008. Choosing the method of data collection, In International Handbook of Survey

Methodology. eds E.D. de Leeuw, J.J. Hox, D.A. Dillman, pp. 113-135. Taylor \& Francis Group, LLC, New York.

Denny, C.M., Babcock, R.C., 2004. Do partial marine reserves protect reef fish assemblages? Biol Conserv 116, 119-129.

Denny, C.M., Willis, T.J., Babcock, R.C., 2003. Effects of Poor Knights Islands Marine Reserve on demersal fish populations, ed. Department of Conservation, Wellington, New Zealand.

Dillman, D.A., Smyth, J.D., Christian, L.M., 2009. Internet, mail and mixed-mode surveys: The tailored design method, 3rd edn. John Wiley \& Sons, Hoboken, New Jersey. 
Douglas, J., Brown, P., Hunt, T., Rogers, M., Allen, M., 2010. Evaluating relative impacts of recreational fishing harvest and discard mortality on Murray cod (Maccullochella peelii peelii). Fish Res 106, 18-21.

Droitcour, J., Caspar, R.A., Hubbard, M.L., Ezzati, T.M., 1991. The item count technique as a method of indirect questioning: a review of its development and a case study application, In Measurement Errors in Surveys. eds P.P. Biemer, R.M. Groves, L.E. Lyberg, N.A. Mathiowetz, S. Sudman, pp. 185210. Wiley, New York.

Droitcour, J.A., Larson, E.M., 2001. The three card method: estimating sensitive survey items-with permanent anonymity of response, In Proceedings of the Survey Research Methods Section, American Statistical Association. Alexandria, Virginia.

Eggert, H., Ellegård, A., 2003. Fishery control and regulation compliance: a case for co-management in Swedish commercial fisheries. Mar Policy 27, 525-533.

EIFAC (European Inland Fisheries Advisory Commission), 2008. EIFAC code of practice for recreational fisheries. Food and Agriculture Organization of the United Nations, Rome, Italy.

Elffers, H., van der Heijden, P., Hezemans, M., 2003. Explaining regulatory non-compliance: a survey study of rule transgression for two Dutch instrumental laws, applying the randomized response method. J Quant Criminol 19, 409-439.

Eliason, S.L., 1999. The illegal taking of wildlife: toward a theoretical understanding of poaching. Hum Dimens Wildl 4, 27-39.

Enck, J.W., Decker, D.J., 1997. Examining assumptions in wildlife management: a contribution of human dimensions inquiry. Hum Dimens Wildl 2, 56-72.

Evans, L., Milfont, T.L., Lawrence, J., 2014. Considering local adaptation increases willingness to mitigate. Global Environmental Change 25, 69-75.

Fenichel, E.P., Abbott, J.K., Huang, B., 2013. Modelling angler behaviour as a part of the management system: synthesizing a multi-disciplinary literature. Fish Fish 14, 137-157.

Ferter, K., Weltersbach, M.S., Strehlow, H.V., Vølstad, J.H., Alós, J., Arlinghaus, R., Armstrong, M., Dorow, M., de Graaf, M., van der Hammen, T., Hyder, K., Levrel, H., Paulrud, A., Radtke, K., Rocklin, D., Sparrevohn, C.R., Veiga, P., 2013. Unexpectedly high catch-and-release rates in European marine recreational fisheries: implications for science and management. ICES Journal of Marine Science: Journal du Conseil 70, 1319-1329.

Field, A., 2009. Discovering Statistics Using SPSS, Third Edition edn. SAGE Publications, LTD, London. Finlayson, C.A., McCay, B.J., 1998. Crossing the threshold of ecosystem resilience: the commercial extinction of northern cod, In Linking Social and Ecological Systems: Management Practices and Social Mechanisms For Building Resilience. eds F. Berkes, C. Folke. Cambridge University Press, Cambridge.

Fisher, M.R., 1997. Segmentation of the angler population by catch preference, participation, and experience: a management-oriented application of recreation specialization. N Am J Fish Manage 17, 1-10.

Flothmann, S., von Kistowski, K., Dolan, E., Lee, E., Meere, F., Album, G., 2010. Closing Loopholes: Getting Illegal Fishing Under Control. Science 328, 1235-1236.

Food and Agriculture Organization of the United Nations, 2012. The state of the world fisheries and aquaculture, Rome.

Foster, S.J., Vincent, A.C.J., 2010. Tropical shrimp trawl fisheries: fishers' knowledge of and attitudes about a doomed fishery. Mar Policy 34, 437-446.

Fox, J.A., Tracy, P.E., 1980. The randomized response approach: applicability to criminal justice research and evaluation. Eval Rev 4, 601-622.

Fox, J.A., Tracy, P.E., 1986. Randomized Response: A method for sensitive surveys. Sage Publications, Beverly Hills, California.

Friedlander, A.M., DeMartini, E.E., 2002. Contrasts in density, size, and biomass of reef fishes between the northwestern and the main Hawaiian islands: the effects of fishing down apex predators. Mar Ecol Prog Ser 230, 253-264. 
Froese, R., Proelß, A., 2010. Rebuilding fish stocks no later than 2015: will Europe meet the deadline? Fish Fish 11, 194-202.

Fulton, D.C., Adelman, I.R., 2003. Social science (the human dimension) in fisheries. Fisheries 28, 4. Fulton, E.A., Smith, A.D.M., Smith, D.C., van Putten, I.E., 2011. Human behaviour: the key source of uncertainty in fisheries management. Fish Fish 12, 2-17.

Furness, R.W., 1984. Seabird-fisheries relationships in the north-east Atlantic and North Sea, In Marine birds: Their Feeding Ecology and Commercial Fisheries Relationships. eds D.N. Nettleship, G.A. Sanger, P.F. Springer, pp. 162-169. Canadian Wildlife Service, Dartmouth, Nova Scotia.

Furness, R.W., 2003. Impacts of fisheries on seabird communities. Sci Mar 67, 33-45.

Furness, R.W., Edwards, A.E., Oro, D., 2007. Influence of management practices and scavenging seabirds on availability of fisheries discards to benthic scavengers. Mar Ecol Prog Ser 350, 235-244. Gallic, B.L., Cox, A., 2006. An economic analysis of illegal, unreported and unregulated (IUU) fishing: Key drivers and possible solutions. Mar Policy 30, 689-695.

Gavin, M.C., Solomon, J.N., Blank, S.G., 2009. Measuring and monitoring illegal use of natural resources. Conserv Biol 24, 89-100.

Gelcich, S., Godoy, N., Castilla, J.C., 2009. Artisanal fishers' perceptions regarding coastal comanagement policies in Chile and their potentials to scale-up marine biodiversity conservation. Ocean Coast Manag 52, 424-432.

Gell, F.R., Roberts, C.M., 2003. Benefits beyond boundaries: the fishery effects of marine reserves. Trends in Ecology and Evolution 18, 448-455.

Gezelius, S.S., 2004. Food, money, and morals: Compliance among natural resource harvesters. Hum Ecol 32, 615-634.

Gezelius, S.S., 2006. Monitoring fishing mortality: Compliance in Norwegian offshore fisheries. Mar Policy 30, 462-469.

Gezelius, S.S., Hauck, M., 2011. Toward a theory of compliance in state-regulated livelihoods: A comparative study of compliance motivations in developed and developing world fisheries. Law \& Society Review 45, 435-470.

Gigliotti, L.M., Taylor, W.W., 1990. The effect of illegal harvest on recreational fisheries. N Am J Fish Manage 10, 106-110.

Glynn, A.N., 2010. What can we learn from statistical truth serum? Design and analysis of the list experiment. Department of Government, Harvard University,

Grabosky, P.N., Braithwaite, J., 1986. Of Manners Gentle: Enforcement Strategies of Australian Business Regulatory Agencies. Oxford University Press, Melbourne.

Grafton, R.Q., Lane, D.E., 1998. Candian fisheries policy: challenges and choices. Canadian Public Policy 24, 133-147.

Granek, E., Madin, E., Brown, M., Figueira, W., Cameron, D., Hogan, Z., Kristianson, G., De Villiers, P., Williams, J., Post, J., 2008. Engaging recreational fishers in management and conservation: global case studies. Conserv Biol 22, 1125-1134.

Grose, R., 2014. Department of Conservation: Picton Conservation Services Manager, personal communication. 16 July.

Groves, R.M., Fowler, F.J.J., Couper, M.P., Lepkowski, J.M., Singer, E., Tourangeau, R., 2009. Survey Methodology, 2nd edn. John Wiley \& Sons, Hoboken, New Jersey.

Gubbay, S., 1995. Marine protected areas: Principles and techniques for management. Chapman and Hall, London.

Hall-Arber, M., Pomeroy, C., Conway, F., 2009. Figuring out the human dimensions of fisheries: illuminating models. Marine and Coastal Fisheries 1, 300-314.

Hall, R.J., Snell, A.F., Foust, M.S., 1999. Item parceling strategies in SEM: Investigating the subtle effects of unmodeled secondary constructs. Organizational Research Methods 2, 233-256.

Halpern, B.S., 2003. The impact of marine reserves: do reserves work and does reserve size matter? Ecol Appl 13, S117-S137. 
Hatcher, A., Gordon, D., 2005. Further investigations into the factors affecting compliance with U.K. fishing quotas. Land Econ 81, 71-86.

Hatcher, A., Jaffry, S., Thebaud, O., Bennett, E., 2000. Normative and social influences affecting compliance with fishery regulations. Land Econ 76, 448-461.

Hauck, M., 2008. Rethinking small-scale fisheries compliance. Mar Policy 32, 635-642.

Hauck, M., 2011. Small-scale fisheries compliance: Integrating social justice, legitimacy and detterence, In Small-scale fisheries management: frameworks and approaches for the developing world. eds R.S. Pomeroy, N. Andrew, pp. 196-215. CAB International, Oxfordshire, UK.

Heather, B., Roberston, H., 2000. The Field Guide to the Birds of New Zealand, revised edn. Viking, Auckland, New Zealand.

Henderson, I.M., 2009. Optimising recreational harvests of blue cod: the effects of catch-and-release mortality and size selectivity. Fish Res 99, 184-195.

Hilborn, R., 2007a. Defining success in fisheries and conflicts in objectives. Mar Policy 31, 153-158.

Hilborn, R., 2007b. Managing fisheries is managing people: what has been learned? Fish Fish 8, 285296.

Hilborn, R., Walters, C.J., 1992. Quantitative Fisheries Stock Assesment: Choice, Dynamics \&

Uncertainty. Kluwer Academic Publishers, Norwell, Massachusetts.

Hill, B., Wassenberg, T., 1990. Fate of discards from prawn trawlers in Torres Strait. Mar Freshw Res 41, 53-64.

Himmelfarb, S., 2008. The multi-item randomized response technique. Sociol Methods Res 36, 495514.

Hirschmann, O., 1975. Excit, voice and loyalty: responses to a decline in firms, organizations and states. Harvard University Press, Cambridge, MA.

Holbrook, A.L., Krosnick, J.A., 2010a. Measuring voter turnout by using the randomized response technique: evidence calling into question the method's validity. Public Opin Q 74, 328-343.

Holbrook, A.L., Krosnick, J.A., 2010b. Social desirability bias in voter turnout reports. Public Opin Q 74, 37-67.

Holmern, T., Muya, J., Røskaft, E., 2007. Local law enforcement and illegal bushmeat hunting outside the Serengeti National Park, Tanzania. Environ Conserv 34, 55-63.

Hønneland, G., 1998. Compliance in the fishery protection zone around Svalbard. Ocean Dev Int Law 29, 339-360.

$\mathrm{H} \varnothing$ nneland, G., 1999. A model of compliance in fisheries: theoretical foundations and practical

application. Ocean Coast Manag 42, 699-716.

$\mathrm{H} ø$ nneland, G., 2000. Compliance in the Barents Sea fisheries. How fishermen account for conformity with rules. Mar Policy 24, 11-19.

Howie, C., 2010. Fears blue-cod bans will destroy fishing charter businesses, In Marlborough Express. http://www.stuff.co.nz/marlborough-express/news/4059481/Fears-blue-cod-bans-will-destroy-

fishing-charter-businesses.

Hu, L.t., Bentler, P.M., 1999. Cutoff criteria for fit indexes in covariance structure analysis:

Conventional criteria versus new alternatives. Structural Equation Modeling: A Multidisciplinary

Journal 6, 1-55.

Humm, J., 2013. Havelock charter boat operator, Personal communication.

Hunt, L., Sutton, S., Arlinghaus, R., 2013. Illustrating the critical role of human dimensions research

for understanding and managing recreational fisheries within a social-ecological system framework.

Fish Manag Ecol.

Hutchings, J.A., 2000. Collapse and recovery of marine fishes. Nature 406, 882-885.

Hutchings, J.A., Myers, R.A., 1994. What can be learned from the collapse of a renewable resource?

Atlantic cod, Gadus morhua, of Newfoundland and Labrador. Canadian Journal of Fisheries \& Aquatic Sciences 51, 2126-2146.

Imai, K., 2011. Multivariate regression analysis for the item count technique. J Am Stat Assoc 106, 407-416. 
Jackson, J.B.C., Kirby, M.X., Berger, W.H., Bjorndal, K.A., Botsford, L.W., Bourque, B.J., Bradbury, R.H., Cooke, R., Jon, E., Estes, J.A., Hughes, T.P., Kidwell, S., Lange, C.B., Lenihan, H.S., Pandolfi, J.M., Peterson, C.H., Steneck, R.S., Tegner, M.J., Warner, R.R., 2001. Historical overfishing and the recent collapse of coastal ecosystems. Science 293, 629-638.

Jacobson, R.P., Mortensen, C.R., Cialdini, R.B., 2011. Bodies obliged and unbound: differentiated response tendencies for injunctive and descriptive social norms. Journal of Personality and Social Psychology 100, 433-448.

Jagers, S.C., Berlin, D., Jentoft, S., 2012. Why comply? Attitudes towards harvest regulations among Swedish fishers. Mar Policy 36, 969-976.

Janus, A.L., 2010. The influence of social desirability pressures on expressed immigration attitudes. Soc Sci Q 91, 928-946.

Jenkins, S.R., Mullen, C., Brand, A.R., 2004. Predator and scavenger aggregation to discarded bycatch from dredge fisheries: importance of damage level. J Sea Res 51, 69-76.

Jensen, F., Vestergaard, N., 2002. Moral hazard problems in fisheries regulation: the case of illegal landings and discard. Resource and Energy Economics 24, 281-299.

Jentoft, S., 1989. Fisheries co-management: delegating government responsibility to fishermen's organizations. Mar Policy 13, 137-154.

Jentoft, S., 2000. Legitimacy and disappointment in fisheries management. Mar Policy 24, 141-148.

Jentoft, S., 2004. Institutions in fisheries: what they are, what they do, and how they change. Mar

Policy 28, 137-149.

Jentoft, S., Chuenpagdee, R., 2009. Fisheries and coastal governance as a wicked problem. Mar Policy 33, 553-560.

Jentoft, S., Chuenpagdee, R., Bundy, A., Mahon, R., 2010. Pyramids and roses: alternative images for the governance of fisheries systems. Mar Policy 34, 1315-1321.

Jentoft, S., McCay, B., 1995. User participation in fisheries management: lessons drawn from international experiences. Mar Policy 19, 227-246.

Jentoft, S., McCay, B.J., Wilson, D.C., 1998. Social theory and fisheries co-management. Mar Policy 22, 423-436.

Jentoft, S., Mikalsen, K.H., 2004. A vicious circle? The dynamics of rule-making in Norwegian fisheries. Mar Policy 28, 127-135.

Jiang, W., Carbines, G., 2002. Diet of blue cod, Parapercis colias, living on undisturbed biogenic reefs and on seabed modified by oyster dredging in Foveaux Strait, New Zealand. Aquat Conserv 12, 257272.

Johannes, R.E., 1978. Traditional marine conservation methods in Oceania and their demise. Annu Rev Ecol Syst 9, 349-364.

Johannes, R.E., Freeman, M.M.R., Hamilton, R.J., 2000. Ignore fisher's knowledge and miss the boat. Fish Fish 1, 257-271.

Johannes, R.E., Neis, B., 2007. The value of anecdote, In Fishers Knowledge in Fisheries Science and Management. eds N. Haggan, B. Neis, I.G. Baird, pp. 41-58. UNESCO, Paris.

Johannesen, A.B., 2005. Wildlife conservation policies and incentives to hunt: An empirical analysis of illegal hunting in western Serengeti, Tanzania. Environment and Development Economics 10, 271292.

Johnston, F.D., Arlinghaus, R., Dieckmann, U., 2010. Diversity and complexity of angler behaviour drive socially optimal input and output regulations in a bioeconomic recreational-fisheries model. Can J Fish Aquat Sci 67, 1507-1531.

Jørgensen, C., Enberg, K., Dunlop, E.S., Arlinghaus, R., Boukal, D.S., Brander, K., Ernande, B., Gårdmark, A., Johnston, F., Matsumura, S., Pardoe, H., Raab, K., Silva, A., Vainikka, A., Dieckmann, U., Heino, M., Rijnsdorp, A.D., 2007. Managing evolving fish stocks. Science 318, 1247-1248. Jouvenel, J.Y., Pollard, D.A., 2001. Some effects of marine reserve protection on the population structure of two spearfishing target-fish species, Dicentrarchus labrax (Moronidae) and Sparus 
aurata (Sparidae), in shallow inshore waters, along a rocky coast in the northwestern Mediterranean Sea. Aquat Conserv 11, 1-9.

Kaplan, I.M., 1998. Regulation and compliance in the New England conch fishery: a case for comanagement. Mar Policy 22, 327-335.

Kaplan, I.M., McCay, B.J., 2004. Cooperative research, co-management and the social dimension of fisheries science and management. Mar Policy 28, 257-258.

Karper, M.A.M., Lopes, P.F.M., 2014. Punishment and compliance: exploring scenarios to improve the legitimacy of small-scale fisheries management rules on the Brazilian coast. Mar Policy 44, 457464.

Keane, A., Jones, J.P.G., Edwards-Jones, G., Milner-Gulland, E.J., 2008. The sleeping policeman: Understanding issues of enforcement and compliance in conservation. Anim Conserv 11, 75-82. Keane, A., Ramarolahy, A.A., Jones, J.P.G., Milner-Gulland, E.J., 2011. Evidence for the effects of environmental engagement and education on knowledge of wildlife laws in Madagascar.

Conservation Letters 4, 55-63.

Keeley, N., Forrest, B., Hopkins, G., Gillespie, P., Knight, B., Webb, S., Clement, D., Gardner, J., 2009. Sustainable aquaculture in New Zealand: Review of the ecological effects of farming shellfish and other non-finfish species. Cawthron Institute,, Nelson, New Zealand.

King, D.M., Sutinen, J.G., 2010. Rational noncompliance and the liquidation of Northeast groundfish resources. Mar Policy 34, 7-21.

Koehn, J.D., Todd, C.R., 2012. Balancing conservation and recreational fishery objectives for a threatened fish species, the Murray cod, Maccullochella peelii. Fish Manag Ecol 19, 410-425.

Krebs, C.P., Lindquist, C.H., Warner, T.D., Fisher, B.S., Martin, S.L., Childers, J.M., 2011. Comparing sexual assault prevalence estimates obtained with direct and indirect questioning techniques. Violence Against Wom 17, 219-235.

Kristofersson, D., Rickertsen, K., 2009. Highgrading in quota-regulated fisheries: evidence from the Icelandic cod fishery. AM J AGR ECON 91, 335-346.

Kritzer, J.P., 2004. Effects of noncompliance on the success of alternative designs of marine protected-area networks for conservation and fisheries management. Conserv Biol 18, 1021-1031. Kuperan, K., Sutinen, J.G., 1998. Blue water crime: deterrence, legitimacy, and compliance in fisheries. Law Soc Rev 32, 309-338.

LaBrie, J.W., Earleywine, M., 2000. Sexual risk behaviors and alcohol: higher base rates revealed using the unmatched-count technique. J Sex Res 37, 321-326.

Landsheer, J.A., Van Der Heijden, P., Van Gils, G., 1999. Trust and understanding, two psychological aspects of randomized response. Qual Quant 33, 1-12.

Larkin, P.A., 1978. Fisheries management: an essay for ecologists. Annu Rev Ecol Syst 9, 57-73. Lavender, J.M., Anderson, D.A., 2009. Effect of perceived anonymity in assessments of eating disorder behaviors and attitudes. Int J Eat Disord 42, 546-551.

Leader-Williams, N., Albon, S.D., Berry, P.S.M., 1990. Illegal exploitation of Black Rhinoceros and elephantpPopulations: Patterns of decline, law enforcement and patrol effort in Luangwa Valley, Zambia. J Appl Ecol 27, 1055-1087.

Leader-Williams, N., Milner-Gulland, E.J., 1993. Policies for the enforcement of wildlife laws: The balance between detection and penalties in Luangwa Valley, Zambia. Conserv Biol 7, 611-617. Lee, R.M., 1993. Doing Research on Sensitive Topics. SAGE Publications, London. Lee, R.M., Renzetti, C.M., 1990. The problems of researching sensitive topics: an overview and introduction. Am Behav Sci 33, 510-528.

Lensvelt-Mulders, G., J. L. M., Hox, J.J., Heijden, P.G.M.v.d., 2005a. How to improve the efficiency of randomised response designs. Qual Quant 39, 253-265.

Lensvelt-Mulders, G.J.L.M., Hox, J.J., Van Der Heijden, P.G.M., Maas, C.J.M., 2005b. Meta analysis of randomized response technique: thirty-five years of validation. Sociol Methods Res 33, 319-348. Lewin, W.-C., Arlinghaus, R., Mehner, T., 2006. Documented and potential biological impacts of recreational fishing: insights for management and conservation. Rev Fish Sci 14, 305-367. 
Ludwig, D., Hilborn, R., Waters, C., 1993. Uncertainty, resource exploitation and conservation: lessons from history. Science $260,17+36$.

Luke, D.A., 2005. Getting the big picture in community science: methods that capture context. Am J Community Psychol 35, 185-200.

Mace, J.T., Johnston, A.D., 1983. Tagging experiments on blue cod (Parapercis colias) in the Marlborough Sounds, New Zealand. N Z J Mar Freshwater Res 17, 207-211.

Mackinson, S., 1998. Combining local and scientific knowledge. Rev Fish Biol Fish 8, 481-490.

Mackinson, S., Wilson, D.C., Galiay, P., Deas, B., 2011. Engaging stakeholders in fisheries and marine research. Mar Policy 35, 18-24.

Mañosa, S., Oro, D., Ruiz, X., 2004. Activity and foraging behaviour of Audouin's gulls in the Ebro Delta, NW Mediterranean. Sci Mar 68, 605-614.

Marlborough District Council, 2014. Marlborough region land and water areas.

http://www.marlborough.govt.nz/About-Marlborough/Regional-Information/Land-Areas.aspx; 17

October 2014.

Marlborough Express, 2011. Blue cod rules help all. http://www.stuff.co.nz/marlborough-

express/news/4778678/Blue-cod-rules-help-all; 1 September 2014.

Marlborough Express, 2012. Blue cod 'massacre' as fish cast back.

http://www.stuff.co.nz/marlborough-express/news/6209782/Blue-cod-massacre-as-fish-cast-back;

1 September 2014.

Martin, C.C., 1995. Evaluation of slot length limits for largemouth bass in two Delaware ponds. N Am J Fish Manage 15, 713-719.

Mason, F., 2002. The Newfoundland Cod Stock Collapse: A Review and Analysis of Social Factors.

Electron Green J 1.

Mastrangelo, M.E., Gavin, M.C., Laterra, P., Linklater, W.L., Milfont, T.L., 2014. Psycho-social factors influencing forest conservation intentions on the agricultural frontier. Conservation Letters 7, 103110.

May, P.J., 2004. Compliance motivations: Affirmative and negative bases. Law \& Society Review 38, 41-68.

McClanahan, T., Davies, J., Maina, J., 2005. Factors influencing resource users and managers' perceptions towards marine protected area management in Kenya. Environ Conserv 32, 42-49.

McCluskey, S.M., Lewison, R.L., 2008. Quantifying fishing effort: a synthesis of current methods and their applications. Fish Fish 9, 188-200.

McGoodwin, J.R., 2006. Integrating fishers' knowledge into fisheries science and management, In Traditional Ecological Knowledge and Natural Resource Management. ed. C.R. Menzies, pp. 175-192. University of Nebraska Press, Lincoln, Nebraska.

McPhee, D.P., Leadbitter, D., Skilleter, G.A., 2002. Swallowing the bait: is recreational fishing in Australia ecologically sustainable? Pac Conserv Biol 8, 40-51.

Metzger, M.B., Dalton, D.R., 1991. Just say no to integrity testing. Univ Fla J Law Public Policy 4, 9. Miller, J.D., 1984. A new survey technique for studying deviant behaviour. George Washington University, Washington D.C.

Miller, J.D., 1985. The nominative technique: A new method of estimating heroin prevalence. NIDA Res Monogr 54, 104.

Ministry for Primary Industries, 2014. Fishery: Challenger scallops and oysters.

http://fs.fish.govt.nz/Page.aspx?pk=5\&fpid=33; 11 September 2014.

Ministry of Fisheries, 2001. Marlborough Sounds blue cod research starts.

http://www.fish.govt.nz/en-

nz/Press/Press+Releases+2001/September+2001/Marlborough+Sounds+Blue+Cod+Research+Starts. htm; 5 January 2014.

Ministry of Fisheries, 2008a. Blue cod in the Marlborough Sounds. http://www.fish.govt.nz/ennz/Press/Press+Releases+2008/July08/Blue+cod+in+the+Marlborough+Sounds.htm; 4 March 2013. 
Ministry of Fisheries, 2008b. Depletion of blue cod in the Marlborough Sounds:Final advice paper, Wellington, New Zealand.

Ministry of Fisheries, 2008c. Initial position paper: localised depletion of blue cod in the Marlborough Sounds, Wellington, New Zealand.

Ministry of Fisheries, 2008d. Localised depletion of blue cod in the Marlborough Sounds: summary of submissions, Wellington, New Zealand.

Ministry of Fisheries, 2009. Code of Practice when fishing for blue cod in the Marlborough Sounds. Ministry of Fisheries, 2010a. Final advice paper: management of the Marlborough Sounds amateur blue cod fishery, p. 29, Wellington.

Ministry of Fisheries, 2010b. Measures to support reopening of the Marlborough Sounds amateur blue cod fishery: consultation on the regulatory measures included in the proposed management plan developed by the Marlborough Sounds Blue Cod Management Group. Initial Position Paper. Wellington.

Ministry of Fisheries, 2010c. Recreational fisher's handbook.

Ministry of Fisheries, 2011a. Blue cod fishing in the Marlborough Sounds.

Ministry of Fisheries, 2011b. Marlborough Sounds blue cod. http://www.fish.govt.nz/en-

nz/Recreational/Most+Popular+Species/Blue+Cod/Default.htm; January 52014.

Ministry of Fisheries, 2014a. Blue Cod (BCO).

http://fs.fish.govt.nz/Page.aspx?pk=7\&tk=100\&ey=2013; 26 March

Ministry of Fisheries, 2014b. Recreational fishing-know the limits. http://www.fish.govt.nz/ennz/Recreational/default.htm; 5 January 2014.

Moore, B., 2012. Disputed blue cod rules stand, In Nelson Mail.

Moore, B., 2013. 'Slot rule' for cod annoys, study finds, In Nelson Mail.

Mora, C., Myers, R.A., Coll, M., Libralato, S., Pitcher, T.J., Sumaila, R., Zeller, D., Watson, R., Gaston, K.J., Worm, B., 2011. Management effectiveness of the world's marine fisheries, In Fisheries

Management and Conservation. ed. W.I. Hunter, pp. 87-109. Apple Academic Press, Oakville, Ontario.

Morandeau, G., Macher, C., Sanchez, F., Bru, N., Fauconnet, L., Caill-Milly, N., 2014. Why do fishermen discard? Distribution and quantification of the causes of discards in the Southern Bay of Biscay passive gear fisheries. Mar Policy 48, 30-38.

Muoneke, M.I., Childress, W.M., 1994. Hooking mortality: a review for recreational fisheries. Rev Fish Sci 2, 123-156.

Muth, R.M., Bowe, J.F., 1998. Illegal harvest of renewable natural resources in North America: Toward a typology of the motivations for poaching. Soc Nat Resour 11, 9-24.

Myers, R.A., Hutchings, J.A., Barrowman, N.J., 1997. Why do fish stocks collapse? The example of cod in Atlantic Canada. Ecol Appl 7, 91-106.

Myers, R.A., Worm, B., 2003. Rapid worldwide depletion of predatory fish communities. Nature 423, 280-283.

New Zealand Parliament, 1971. Marine Reserves Act.

New Zealand Parliament, 1986. Fishing (Amateur Fishing) Regulations.

New Zealand Parliament, 1996. The Fisheries Act.

Nicoll, J., 2012a. Fishermen see harm in cod size rules, In Marlborough Express. Picton.

Nicoll, J., 2012b. One in five breach size rule, In Marlborough Express.

Nielsen, J., Mathiesen, C., 2003. Important factors influencing rule compliance in fisheries: Lessons

from Denmark. Mar Policy 27, 409-416.

Nielsen, J.R., 2003. An analytical framework for studying: compliance and legitimacy in fisheries management. Mar Policy 27, 425-432.

Nielsen, J.R., Vedsmand, T., 1997. Fishermen's organisations in fisheries management. Perspectives for fisheries co-management based on Danish fisheries. Mar Policy 21, 277-288. 
Nkonya, E., Pender, J., Kato, E., 2008. Who knows, who cares? The determinants of enactment, awareness, and compliance with community Natural Resource Management regulations in Uganda. Environment and Development Economics 13, 79-101.

Nussman, M., Coleman, F.C., Figueira, W.F., Ueland, J.S., Crowder, L.B., 2005. The recreational fisher's perspective. Science 307, 1560-1561.

Oh, C.-O., Ditton, R.B., 2006. Using recreation specialization to understand multi-attribute management preferences. LEISURE SCI 28, 369-384.

Oh, C.-O., Ditton, R.B., Gentner, B., Riechers, R., 2005. A stated preference choice approach to understanding angler preferences for management options. Hum Dimens Wildl 10, 173-186.

Option 4, 2008. Minutes of Public Meeting on Ministry of Fisheries Blue Cod Marlborough Sounds Proposals, held at Blenheim Bowling Club, Wednesday 9 April 2008.

http://www.option4.co.nz/Fisheries Mgmt/documents/BCO7 meeting minutes 94 08.pdf; 28

February 2013.

Orman, T., 2009. Early end to blue cod ban, In New Zealand Fishing News.

http://www.stuff.co.nz/sport/fishing/news/2395967/Early-end-to-blue-cod-ban.

Oro, D., Cam, E., Pradel, R., Martínez-Abraín, A., 2004. Influence of food availability on demography and local population dynamics in a long-lived seabird. Proceedings of the Royal Society B: Biological Sciences 271, 387-396.

Oro, D., Jover, L., Ruiz, X., 1996. Influence of trawling activity on the breeding ecology of a threatened seabird, Audouin's gull Larus audouinii. Mar Ecol Prog Ser 139, 19-29.

Ostrom, E., 2000. Collective action and the evolution of social norms. The Journal of Economic Perspectives 14, 137-158.

Page, K.S., Grant, G.C., Radomski, P., Jones, T.S., Bruesewitz, R.E., 2004. Fish total length measurement error from recreational anglers: causes and contribution to noncompliance for the Mille Lacs walleye fishery. N Am J Fish Manage 24, 939-951.

Page, K.S., Radomski, P., 2006. Compliance with sport fishery regulations in Minnesota as related to regulation awareness. Fisheries 31, 166-178.

Parker, S.J., Rankin, P.S., Hannah, R.W., Schreck, C.B., 2003. Discard mortality of trawl-caught lingcod in relation to tow duration and time on deck. N Am J Fish Manage 23, 530-542.

Paul, L., 2000. New Zealand Fishes: Indentification, Natural History and Fisheries. Reed Publishing, Auckland.

Pauly, D., Watson, R., Alder, J., 2005. Global trends in world fisheries: impacts on marine ecosystems and food security. Philosophical Transactions of the Royal Society B: Biological Sciences 360, 5-12. Petering, R.W., Isbell, G.L., Miller, R.L., 1995. A Survey Method for Determining Angler Preference for Catches of Various Fish Length and Number Combinations. North American Journal of Fisheries Management 15, 732-735.

Peterson, G.D., Cumming, G.S., Carpenter, S.R., 2003. Scenario planning: a tool for conservation in an uncertain world. Conserv Biol 17, 358-366.

Peterson, M.J., Carothers, C., 2013. Whale interactions with Alaskan sablefish and Pacific halibut fisheries: surveying fishermen perception, changing fishing practices and mitigation. Mar Policy 42, 315-324.

Pierce, R.B., Tomcko, C.M., 1998. Angler noncompliance with slot length limits for northern pike in five small Minnesota lakes. N Am J Fish Manage 18, 720-724.

Pita, C., Pierce, G.J., Theodossiou, I., 2010. Stakeholders' participation in the fisheries management decision-making process: fishers' perceptions of participation. Mar Policy 34, 1093-1102.

Pita, C., Theodossiou, I., Pierce, G.J., 2013. The perceptions of Scottish inshore fishers about marine protected areas. Mar Policy 37, 254-263.

Plinkerton, E., 1989. Introduction: attaining better fisheries management through co-management -prospects, problems, and propositions, In Co-operative Management of Local Fisheries: New Directions For Improved Management and Community Development. ed. E. Pinkerton. University of British Columbia, Vancouver. 
Post, J., Parkinson, E.A., 2012. Temporal and spatial patterns of angler effort across lake districts and policy options to sustain recreational fisheries. Can J Fish Aquat Sci 69, 321-329.

Post, J.R., Sullivan, M., Cox, S., Lester, N.P., Walters, C.J., Parkinson, E.A., Paul, A.J., Jackson, L., Shuter, B.J., 2002. Canada's recreational fisheries: the invisible collapse? Fisheries 27, 6-17.

Powell, E.N., Bochenek, E., DePersenaire, J., 2010. Evaluation of bag-and-size-limit options in the management of summer flounder Paralichthys dentatus. Fish Res 105, 215-227.

Powell, E.N., Bochenek, E., DePersenaire, J., King, S.E., 2011. Injury frequency for discarded summer flounder in the recreational fishery of the Mid-Atlantic Bight: influence of landing size regulations.

Am Fish Soc Symp 75, 171-187.

Pratt, D., Macmillan, D., Gordon, I., 2004. Local community attitudes to wildlife utilisation in the changing economic and social context of Mongolia. Biodivers Conserv 13, 591-591-613.

Raby, G.D., Packer, J.R., Danylchuk, A.J., Cooke, S.J., 2014. The understudied and underappreciated role of predation in the mortality of fish released from fishing gears. Fish Fish 15, 489-505.

Radomski, P., Grant, G.C., Jacobson, P.C., Cook, M.F., 2001. Visions for recreational fishing regulations. Fisheries 26, 7-18.

Rapson, A.M., 1956. Biology of the blue cod (Parapercis colias) of New Zealand, p. 103. Victoria University of Wellington.

Read, A.D., West, R.J., Haste, M., Jordan, A., 2011. Optimizing voluntary compliance in marine protected areas: A comparison of recreational fishers and enforcement officer perspectives using multi-criteria analysis. J Environ Manage 92, 2558-2567.

Rettig, R.B., Berkes, F., Pinkerton, E., 1989. The future of fisheries co-management: a multidisciplinary assessment, In Co-operative Management of Local Fisheries. ed. E. Pinkerton. University of British Columbia Press, Vancouver.

Rice, J.C., Connolly, P.L., 2007. Fisheries management strategies: an introduction by the conveners. ICES J Mar Sci 64, 577-579.

Richardson, E.A., Kaiser, M.J., Edwards-Jones, G., 2005. Variation in fishers' attitudes within an inshore fishery: implications for management. Environ Conserv 32, 213-225.

Riddle, K., 2006. Illegal, unreported, and unregulated fishing: is international cooperation contagious? Ocean Dev Int Law 37, 265-297.

Robbins, P., McSweeney, K., Chhangani, A., Rice, J., 2009. Conservation as it is: illicit resource use in a wildlife reserve in India. Hum Ecol 37, 559-575.

Robbins, P., McSweeney, K., Waite, T., Rice, J., 2006. Even conservation rules are made to be broken: implications for biodiversity. Environ Manage 37, 162-169.

Roberts, C.M., 1997. Ecological advice for the global fisheries crisis. Trends Ecol Evol 12, 35-38.

Rosenberg, A.A., 2007. Fishing for certainty. Nature 449, 989.

Royce, W.F., 1983. Trends in fishery science. Fisheries 8, 10-13.

Salz, R.J., Loomis, D.K., 2005. Recreation specialization and anglers' attitudes towards restricted fishing areas. Hum Dimens Wildl 10, 187-199.

Sauer, W.H.H., Penney, A.J., Erasmus, C., Mann, B.Q., Brouwer, S.L., Lamberth, S.J., Stewart, T.J., 1997. An evaluation of attitudes and responses to monitoring and management measures for the South African boat-based line fishery. S Afr J Mar Sci 18, 147-163.

Schill, D.J., Kline, P.A., 1995. Use of random response to estimate angler non compliance with fishing regulations. N Am J Fish Manage 15, 721-731.

Schlager, E., Ostrom, E., 1992. Property-rights regimes and natural resources: A conceptual analysis. Land Econ 68, 249-262.

Schramm, H.L., Dennis, J.A., 1993. Characteristics and perceptions of users and nonusers of an urban fishery program in Lubbock, Texas. N Am J Fish Manage 13, 210-216.

Schreck, C.B., 2010. Stress and fish reproduction: The roles of allostasis and hormesis. Gen Comp Endocrinol 165, 549-556.

Schreck, C.B., Contreras-Sanchez, W., Fitzpatrick, M.S., 2001. Effects of stress on fish reproduction, gamete quality, and progeny. Aquaculture 197, 3-24. 
Schroder, D.M., Love, M.S., 2002. Recreational fishing and marine fish populations in California, ed. California Cooperative Oceanic Fisheries Investigations Reports, pp. 182-190.

Schultz, P.W., 2011. Conservation means behavior. Conserv Biol 25, 1080-1083.

Scott, J., 1988. Social network analysis. Sociology 22, 109-127.

Seafood New Zealand, 2014. Key facts. http://www.seafoodnewzealand.org.nz/our-industry/key-

facts; 7 October 2014.

SEDAR (Southeast Data, A., and Review),, 2009. Stock assessment of Gag in the Gulf of Mexico:

SEDAR Update Asssment.

Sen, S., Raakjaer Nielsen, J., 1996. Fisheries co-management: a comparative analysis. Mar Policy 20, 405-418.

Sethi, S.A., Hilborn, R., 2008. Interactions between poaching and management policy affect marine reserves as conservation tools. Biol Conserv 141, 506-516.

Sharp, B., 1997. From regulated access to transferable harvesting rights: policy insights from New

Zealand. Mar Policy 21, 501-517.

Shaw, A., Sheppard, S., Burch, S., Flanders, D., Wiek, A., Carmichael, J., Robinson, J., Cohen, S., 2009. Making local futures tangible-synthesizing, downscaling, and visualizing climate change scenarios for participatory capacity building. Global Environmental Change 19, 447-463.

Shears, N.T., Usmar, N.R., 2006. Response of reef fish to partial and no-take protection at Mayor Island (Tuhua). Science and Technical Publishing, Wellington.

Shepherd, S.A., Brook, J.B., Xiao, Y., 2010. Environmental and fishing effects on the abundance, size and sex ratio of the blue-throated wrasse, Notolabrus tetricus, on South Australian coastal reefs. Fish Manag Ecol 17, 209-220.

Silver, J.J., Campbell, L.M., 2005. Fisher participation in research: dilemmas with the use of fisher knowledge. Ocean Coast Manag 48, 721-741.

Simpson, H., 2014. Blue cod frustrations to be aired, In Marlborough Express.

Smith, A.H., 1994. Community involvement in coral reef monitoring for management in the Insular Caribbean, In Collaborative and Community-based Management of Coral Reefs, Lessons from Experience. ed. A.T. White, p. 130. Kumarian Press, USA.

Smith, C.L., Gilden, J.D., Cone, J.S., Steel, B.S., 1997. Contrasting views of coastal residents and coastal coho restoration planners. Fisheries 22, 8-15.

Smith, D.R., Anderson, D.R., Smeltzer, J.F., 1989. Assessment of the violation-simulation method. Wildl Soc Bull 17, 179-184.

Smith, R.G., Anderson, K., 2004. Understanding non-compliance in the marine environment, ed. Australian Institute of Criminology, Canberra, Australia.

Smyth, J.D., Pearson, J.E., 2011. Internet Survey Methods: A Review of Strengths, Weaknesses, and Innovations, In Social and Behavioral Research and the Internet. eds M. Das, P. Ester, L. Kaczmirek, pp. 11-44. Routledge, Taylor \& Francis Group, New York.

Solomon, J., Jacobson, S.K., Wald, K.D., Gavin, M., 2007. Estimating illegal resource use at a Ugandan park with the Randomized Response Technique. Hum Dimens Wildl 12, 75-88.

South Australian Recreational Fishing Industry Review Committee (SARFIRC), 2001. Review of recreational fishing in South Australia: a management strategy for the sustainable development of recreational fishing in South Australia. Ministry for Primary Industries and Resources, Adelaide. Sport and Recreation New Zealand, 2009. Sport and recreation profile: fishing-findings from the 2007/2008 Active New Zealand Survey. SPARC, Wellington.

St John, F.A.V., Edwards-Jones, G., Gibbons, J.M., Jones, J.P.G., 2010. Testing novel methods for assessing rule breaking in conservation. Biol Conserv 143, 1025-1030.

St John, F.A.V., Keane, A.M., Edwards-Jones, G., Jones, L., Yarnell, R.W., Jones, J.P.G., 2011. Identifying indicators of illegal behaviour: carnivore killing in human-managed landscapes. Proceedings of the Royal Society B: Biological Sciences.

Stern, M.J., 2008. Coercion, voluntary compliance and protest: the role of trust and legitimacy in combating local opposition to protected areas. Environ Conserv 35, 200-210. 
Stern, P.C., 2000. New Environmental Theories: Toward a Coherent Theory of Environmentally Significant Behavior. Journal of Social Issues 56, 407-424.

Stewart, J., 2008. A decision support system for setting legal minimum lengths of fish. Fisheries Management \& Ecology 15, 291-301.

Sue, V.M., Ritter, L.A., 2012. Conducting Online Surveys, 2nd edn. SAGE Publications, Los Angeles. Sullivan, M., 2003. Exaggeration of walleye catches by Alberta anglers. N Am J Fish Manage 23, 573580.

Sullivan, M.G., 2002. Illegal angling harvest of walleyes protected by length limits in Alberta. N Am J Fish Manage 22, 1053-1063.

Sumaila, U.R., Alder, J., Keith, H., 2006. Global scope and economics of illegal fishing. Mar Policy 30, 696-703.

Sutinen, J.G., Andersen, P., 1985. The economics of fisheries law enforcement. Land Econ 61, 387397.

Sutinen, J.G., Rieser, A., Gauvin, J.R., 1990. Measuring and explaining noncompliance in federally managered fisheries. Ocean Dev Int Law 21, 335-372.

Tavecchia, G., Pradel, R., Genovart, M., Oro, D., 2007. Density-dependent parameters and demographic equilibrium in open populations. Oikos 116, 1481-1492.

Taylor, N., Buckenham, B., 2003. Social impacts of marine reserves in New Zealand, ed. D.o.

Conservation. DOC Science Publishing, Wellington, New Zealand.

Teirney, L.D., Kilner, A.R., Millar, R.B., Bradford, E., Bell, J.D., 1997. Estimation of recreational catch from 1991-92 to 1993-94. . Unpublished report held in NIWA library, Wellington.

Tetzlaff, J.C., Pine, W.E., Allen, M.S., Ahrens, R.N., 2013. Effectiveness of size limits and bag limits for managing recreational fisheries: a case study of the Gulf of Mexico recreational gag fishery. Bull Mar Sci 89, 483-502.

Thomas, A., Gavin, M., Milfont, T., 2014a. Estimating non-compliance among recreational fishers: Insights into factors affecting the usefulness of the Randomized Response and Item Count techniques. Biol Conserv.

Thomas, A., Milfont, T., Gavin, M., 2014b. What determines fishers' knowledge of and attitudes towards regulations? A case study from the Marlborough Sounds, New Zealand. Mar Policy. Thomassin, A., White, C.S., Stead, S.S., David, G., 2010. Social acceptability of a marine protected area: The case of Reunion Island. Ocean Coast Manag 53, 169-179.

Torrance, H., 2012. Triangulation, respondent validation, and democratic participation in mixed methods research. Journal of Mixed Methods Research.

Tourangeau, R., Yan, T., 2007. Sensitive questions in surveys. Psychol Bull 133, 859-883.

Townsend, R.E., 1995. Fisheries self-governance: corporate or cooperative structures? Mar Policy 19, 39-45.

Tracy, P.E., Fox, J.A., 1981. The validity of randomized response for sensitive measurements. Am Sociol Rev 46, 187-200.

Tsuchiya, T., Hirai, Y., Ono, S., 2007. A study of the properties of the Item Count Technique. Public Opin Q 71, 253-272.

Tyler, T.R., 1990. Why People Obey The Law. Yale University Press, New Haven and London.

United Nations General Assembly (UNGA), 2006. UN General Assembly Resolution on Sustainable Fisheries.

van der Heijden, P.G.M., van Gils, G., Bouts, J., Hox, J.J., 2000. A comparison of randomized response, computer-assisted self-interview, and face-to-face direct questioning. Sociol Methods Res 28, 505-537.

van Hoof, L., 2010. Co-management: an alternative to enforcement? ICES Journal of Marine Science: Journal du Conseil 67, 395-401.

Viteri, C., Chávez, C., 2007. Legitimacy, local participation, and compliance in the Galápagos Marine Reserve. Ocean Coast Manag 50, 253-274. 
Vitousek, P.M., Mooney, H.A., Lubchenco, J., Melillo, J.M., 1997. Human domination of earth's ecosystems. Science 277, 494-499.

Votier, S.C., Furness, R.W., Bearhop, S., Crane, J.E., Caldow, R.W.G., Catry, P., Ensor, K., Hamer, K.C., Hudson, A.V., Kalmbach, E., Klomp, N.I., Pfeiffer, S., Phillips, R.A., Prieto, I., Thompson, D.R., 2004.

Changes in fisheries discard rates and seabird communities. Nature 427, 727-730.

Warner, S.L., 1965. Randomized response: a survey technique for eliminating evasive answer bias. J Am Stat Assoc 60, 63-69.

Waters, J.R., Huntsman, G.R., 1986. Incorporating mortality from catch and release into yield-perrecruit analyses of minimum-size limits. N Am J Fish Manage 6, 463-471.

Weithman, A.S., 1999. Socioeconomic benefits of fisheries, In Inland Fisheries Management in North America eds C.C. Kohler, W.A. Hubert. American Fisheries Society, Bethesda, Maryland.

Wellsmith, M., 2011. Wildlife crime: the problems of enforcement. Eur J Crim Pol Res 17, 125-148. Westera, M., Lavery, P., Hyndes, G., 2003. Differences in recreationally targeted fishes between protected and fished area of a coral reef marine park. J Exp Mar Biol Ecol 294, 145-168.

White, K.M., Smith, J.R., Terry, D.J., Greenslade, J.H., McKimmie, B.M., 2009. Social influence in the theory of planned behaviour: The role of descriptive, injunctive, and in-group norms. British Journal of Social Psychology 48, 135-158.

Whitehouse, A.M., Harley, E.H., 2001. Post-bottleneck genetic diversity of elephant populations in South Africa, revealed using microsatellite analysis. Mol Ecol 10, 2139-2149.

Wilde, G.R., Ditton, R.B., 1999. Differences in attitudes and fishing motives among Texas catfish anglers, In Am Fish Soc Symp. pp. 395-405.

Wilson, D.C., McCay, B.J., 1998. How the participants talk about "participation" in Mid-Atlantic fisheries management. Ocean Coast Manag 41, 41-61.

Wimbush, J.C., Dalton, D.R., 1997. Base rate for employee theft: convergence of multiple methods. J Appl Psychol 82, 756-763.

Witmer, G.W., 2005. Wildlife population monitoring: some practical considerations. Wildl Res 32, 259-263.

Woodward, R.T., Griffin, W.L., 2003. Size and bag limits in recreational fisheries: theoretical and empirical analysis. Mar Resour Econ 18, 239-262.

World Bank, 2012. Hidden harvest: the global contribution of capture fisheries. International Bank for Reconstruction and Development, Washington D.C.

Worm, B., Barbier, E.B., Beaumont, N., Duffy, J.E., Folke, C., Halpern, B.S., Jackson, J.B.C., Lotze, H.K., Micheli, F., Palumbi, S.R., Sala, E., Selkoe, K.A., Stachowicz, J.J., Watson, R., 2006. Impacts of biodiversity loss on ocean ecosystem services. Science 314, 787-790.

Wydoski, R.S., 1977. Relation of hooking mortality and sublethal hooking stress to quality fishery management, In Catch-and-release Fishing As A Management Tool. eds R.A. Barnhart, T.D. Roelofs, pp. 43-87. Humbolt State Univeristy, Arcata, California.

Young, G.C., Wise, B.S., Ayvazian, S.G., 1999. A tagging study on tailor (Pomatomus saltatrix) in Western Australian waters: their movement, exploitation, growth and mortality. Mar Freshw Res 50, 633-642.

Zeldis, J.R., Francis, R.I.C.C., 1998. A daily egg production method estimate of snapper biomass in the Hauraki Gulf, New Zealand. ICES J Mar Sci 55, 522-534. 


\section{Appendices}

\subsection{Management history of the Marlborough Sounds recreational blue cod fishery}

\begin{tabular}{|c|c|}
\hline Year & Blue Cod Management Event \\
\hline & Minimum Legal Size: $30 \mathrm{~cm}$ \\
\hline 1986 & Minimum Legal Size: $30 \mathrm{~cm}$ \\
\hline 1993 & Minimum Legal Size: $33 \mathrm{~cm}$ \\
\hline 1994 & Minimum Legal Size: $28 \mathrm{~cm}$ \\
\hline 2003 & $\begin{array}{c}\text { Minimum Legal Size: } 30 \mathrm{~cm} \\
\text { NIWA data shows the Sounds blue cod population declined 50\% } \\
\text { between 1995-1996 and } 2001 .\end{array}$ \\
\hline $\begin{array}{c}\text { March } \\
2008\end{array}$ & $\begin{array}{l}\text { Late } 2007 \text { NIWA data shows } 57 \% \text { decline of juvenile blue cod since } \\
2004 \text {. The Ministry of Fisheries opens consultation on a variety of } \\
\text { measures aimed at halting the blue cod population decline. }\end{array}$ \\
\hline $\begin{array}{l}\text { April } \\
2008\end{array}$ & $\begin{array}{l}\text { Over } 300 \text { recreational fishers attend two public meetings organised by } \\
\text { the Marlborough Recreational Fishers' Association. The Ministry } \\
\text { receives over } 1000 \text { submissions on the initial position paper. }\end{array}$ \\
\hline $\begin{array}{l}3 \text { July } \\
2008\end{array}$ & $\begin{array}{l}\text { The Minister of Fisheries announces the closure of the Marlborough } \\
\text { Sounds blue cod fishery for the next four years: October 2008-October } \\
2012 \text {. }\end{array}$ \\
\hline $\begin{array}{l}1 \text { October } \\
2008\end{array}$ & Four year blue cod ban begins. \\
\hline $\begin{array}{l}\text { May } \\
2009\end{array}$ & $\begin{array}{l}\text { The Blue Cod Management Group is formed with the task of drafting a } \\
\text { proposed management plan for the Marlborough Sounds blue cod } \\
\text { fishery that would allow it to reopen early. }\end{array}$ \\
\hline $\begin{array}{l}24 \\
\text { August } \\
2010\end{array}$ & $\begin{array}{l}\text { The Blue Cod Management Group's draft plan for managing the Sounds } \\
\text { blue cod population is released for consultation. }\end{array}$ \\
\hline $\begin{array}{l}16 \\
\text { December } \\
2010\end{array}$ & $\begin{array}{l}\text { The Minister of Fisheries announces new regulations in advance of } \\
\text { the re-opening of the Sounds blue cod fishery: } \\
\text { - The season is restricted to eight months ( } 20 \text { December to } 31 \\
\text { August), } \\
\text { - MLS of } 30 \mathrm{~cm} \text { and a new maximum legal size of } 35 \mathrm{~cm} \\
\text { - Daily Bag Limit of } 2 \text { with a maximum accumulation of two. }\end{array}$ \\
\hline $\begin{array}{l}\text { April } \\
2011\end{array}$ & $\begin{array}{l}\text { Marlborough Sounds blue cod fishery re-opens, } 18 \text { months ahead of } \\
\text { schedule. }\end{array}$ \\
\hline June 2014 & $\begin{array}{l}\text { Despite the frustrations of fishers, the Minister of Fisheries announces } \\
\text { there will be no review of the regulations until results of a } 2014 \text { stock } \\
\text { assessment are available, possibly not until } 2015 \text {. }\end{array}$ \\
\hline
\end{tabular}




\subsection{Blue Cod Management Group Code of Practice}

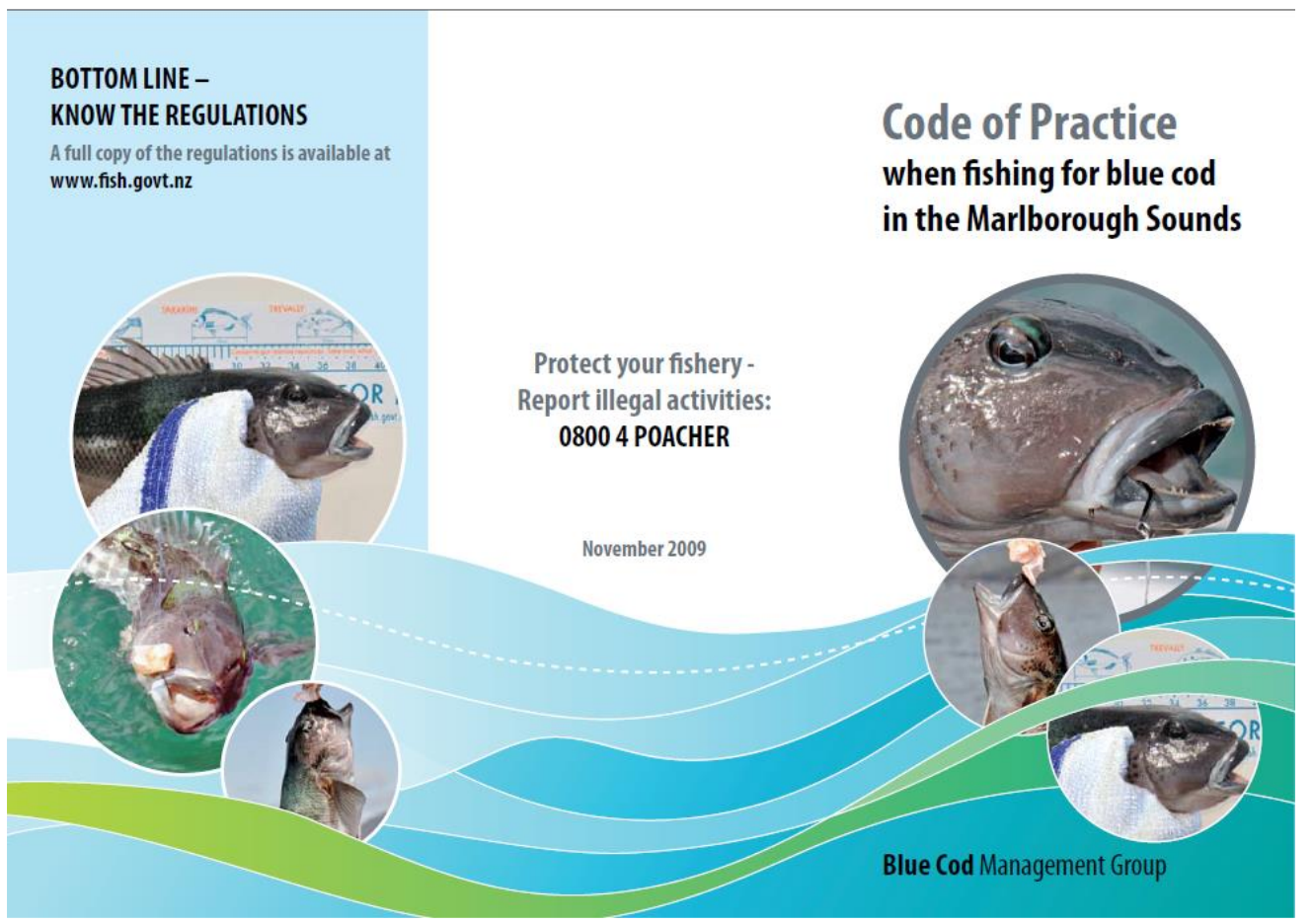

This Code of Practice has been developed by the Blue Cod Management Group to assist in rebuilding a sustainable blue cod fishery in the Marlborough Sounds.

\section{FISHING TACKLE}

When choosing a hook, use fishing tackle that minimises mortality from hook damage.

$>$ Use larger hooks (6/0 minimum) to prevent undersized fish from being hooked.

$>$ Use circle type hooks preferably with no offset.

$>$ Use a single hookrig, placed above the sinker.

$>$ Pinch or remove the barb of hooks for easier extraction.

$>$ Take all your tackle and artificial baits home for disposal.

Remember, small hooks kill fish!

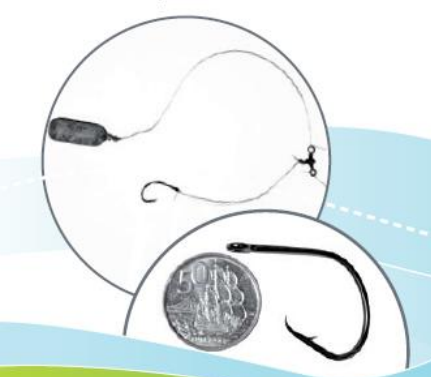

HANDLING BLUE COD

It is essential to return undersized fish to the water as quickly as

$>$ Minimise the length of time fish are out of the water.

$>$ Measure fish immediately and return fish smaller than $30 \mathrm{~cm}$ gently back to sea.

$>$ The best way to hold blue cod to extract hooks is behind the head.

$>$ Wear wet gloves or use a wet rag to lie fish on if you do need to handle them out of the water, and avoid placing them on hot, dry surfaces.

$>$ Cut the line if gut or gill hooked, do not use a gob stick.

PREDATION:

Released fish are the targets for predation by shags and barracouta.

$>$ Move location if returned fish are being predated - don't feed the shags.

$>$ Use a downpipe to lower fish back into the water.

\section{SUSTAINABILITY:}

Blue cod are very vulnerable to localised depletion. Every fisher can play a part:

$>$ Limityour catch.

$>$ Return some of your bigger fish to the water (but not those injured or bleeding)as large females contribute significant numbers of eggs and are vital to the future of the fishery.

$>$ Move location if you are repeatedly catching undersized fish.

$>$ Exdude blue cod as a category species in fishing competitions.

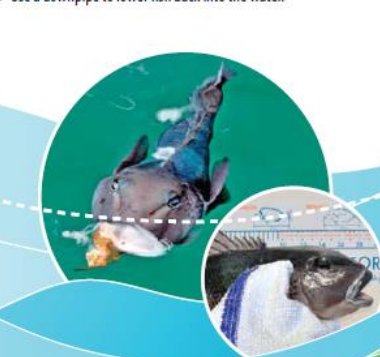




\subsection{What hook brochure}

\section{Ministry of}

Fisheries

Te Tautiaki i nga tini a Tangaroa

\section{What hook should I use?}

\section{Recreational fishing in the Marlborough Sounds}
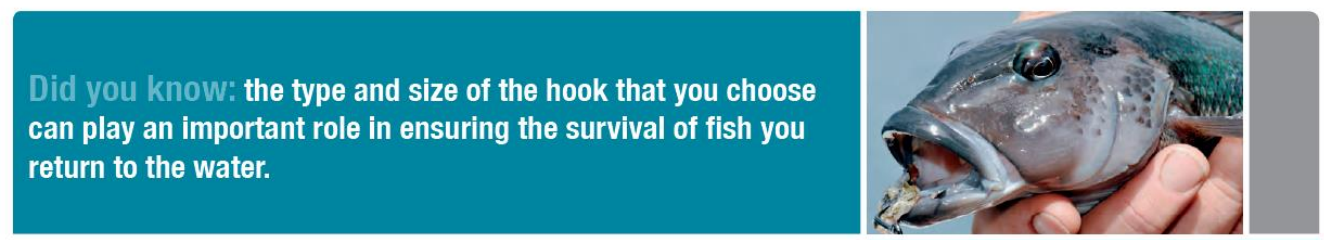

Find below the hook type and size you should be using to reduce the mortality of fish you return to the water and ensure that recreational fishing in the Marlborough Sounds is sustainable.

For blue cod other fish with smaller mouths

For trolling, spinning, using 'plastic' baits or jigging

For all other fishing, use circle hooks in the largest size to suit your target fish e.g. Hapuka.
Use only $6 / 0$ or larger circle hooks with no offset

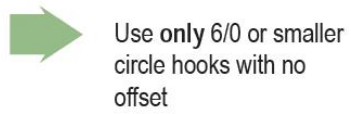
offset

Avoid treble hooks and pinch the barb of $\mathrm{J}$ hooks
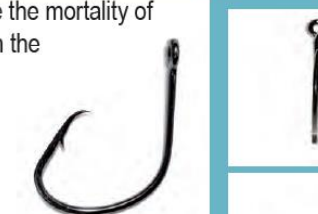

Do use

Circle hooks with zero offset

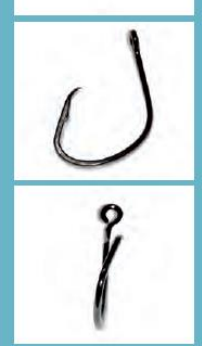

Circle hooks and pinch barb
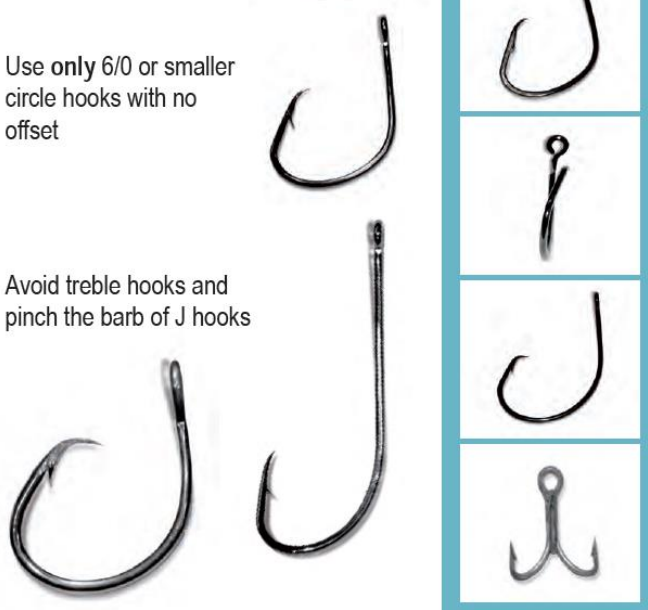

Don't use

Circle hooks with offset

Circle hooks with barbs

Treble hooks

\section{General things to consider when choosing a hook:}

- Always use circle hooks - avoid offset as this increases the risk of hooking fish in the throat and gut.

- Only use one hook per rod - using multi-hook rigs inevitably means fish are poorly handled and have less chance of surviving when returned.

- Pinch the barb on your hooks using fishing pliers to reduce the size of the entry wound of the hook.

- Use larger hooks to prevent undersized fish from being hooked.

- Use the finest wire hooks possible that are appropriate for your target species. Finer hooks do less damage to a fish's mouth.

The advantages of circle hooks are that fish are hooked in the front of the mouth and they are self-hooking by design. This means fish do not have deep hooking injuries and are easier to unhook. 


\subsection{Ethics approval}

(for semi-structured interviews, prior to final survey design)

TE WHARE WĀNANGA O TE ŪPOKO O TE IKA A MĀUI

MEMORANDUM

\begin{tabular}{l|l}
\hline TO & Alyssa Thomas \\
\hline COPY TO & $\begin{array}{l}\text { Michael Gavin } \\
\text { Taciano Milfont }\end{array}$ \\
\hline FROM & Dr Allison Kirkman, Convener, Human Ethics Committee \\
\hline
\end{tabular}

\begin{tabular}{l|l}
\hline DATE & 9 January 2012 \\
\hline PAGES & 1 \\
\hline
\end{tabular}

Ethics Approval: 19097

Understanding Fishers' Compliance with Fishing Regulations in New Zealand

Thank you for your application for ethical approval, which has now been considered by the Standing Committee of the Human Ethics Committee.

Your application has been approved from the above date and this approval continues until 1 March 2014. If your data collection is not completed by this date you should apply to the Human Ethics Committee for an extension to this approval.

Best wishes with the research.

Allison Kirkman

Human Ethics Committee 


\subsection{Semi-structured interviews}

\subsubsection{Information sheet}

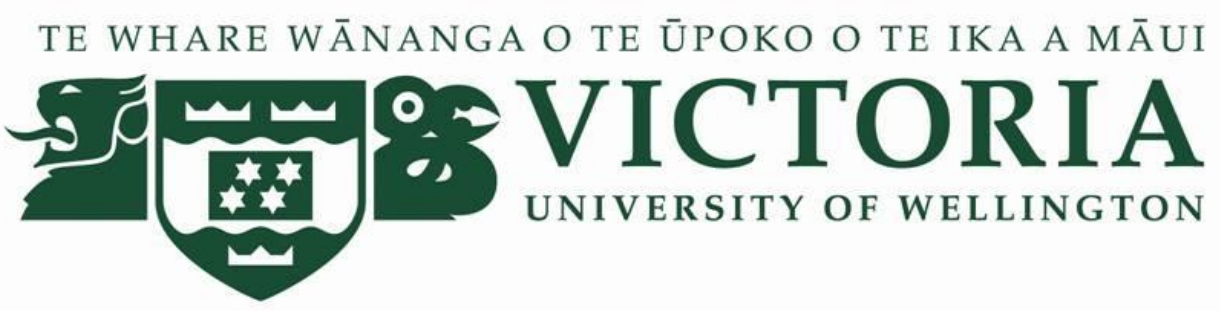

\section{Information Sheet: Semi-Structured Interview}

Researcher: Alyssa Thomas from the School of Geography, Environment and Earth Sciences at Victoria University of Wellington, New Zealand.

I am a PhD candidate in Environmental Studies at the above institution. In order to achieve this degree I am conducting research that will lead to a thesis. The purpose of this study is to understand compliance behaviour among recreational fishers in New Zealand. There are there parts to this study: 1) testing the effectiveness of two indirect (and anonymous) questioning methods on obtaining higher (and presumably more accurate) estimates of non compliance 2) Understanding what factors are the strongest influences on a fisher's decision to comply with a specific fishing regulation and 3) Looking at compliance with suggested best practices as well as discard rates under different scenarios.

As part of my research I would like to interview you to discuss your thoughts on this topic. This interview will remain anonymous unless you sign a consent form and agree to be quoted. Quotes from the interview may be used in my final thesis and papers published in academic journals or presentations at academic conferences. Before publication I will provide you with a copy of the transcript of the quotes and obtain your permission to use them.

If you have additional questions about any aspect of the research please contact me at: Alyssa Thomas, Department of Geography, Environment and Earth Sciences. Victoria University of Wellington. PO Box 600, Wellington, New Zealand; 044635233 ext. 8619. Alternatively you may contact my supervisor, Dr Taciano Milfont, Department of Psychology, Victoria University of Wellington. PO Box 600, Wellington, New Zealand. A summary of the research (once available) can be found on https://sites.google.com/site/bluecodcompliance/ 


\subsubsection{Consent form}

TE WHARE WĀNANGA O TE ŪPOKO O TE IKA A MĀUI

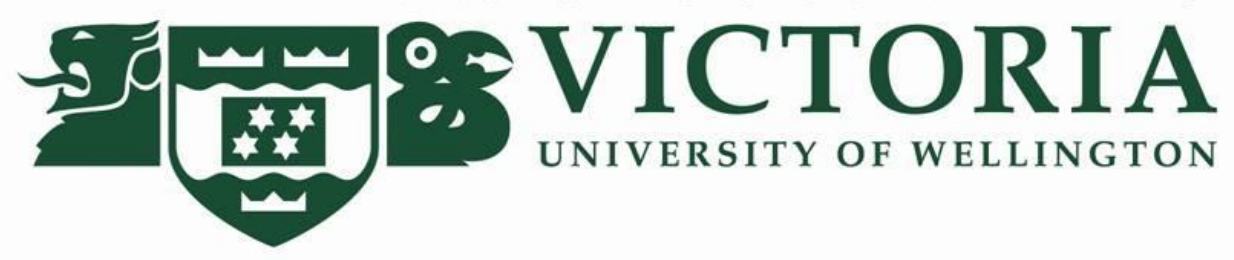

\section{Consent to participate in research: Semi-Structured Interview}

Project: Identifying and Understanding Fishers' Compliance with Fishing Regulations in New Zealand

I agree that I have been provided with and understand the explanation of this research and its goals. In addition I have been given the chance to mention any concerns or ask any questions related to the project, and the answers have been satisfactory. Furthermore, I may leave this research at any time before data collection \& analyses have finished; or change my mind about inclusion of my information. I may do so without providing any reason and there will be no penalty if I decide to do one of the above.

Before any work related to this research is published I will have the opportunity to check the interview transcript to verify any quotes attributed to me. The information from this interview will not be used for any other purpose or released to anyone else without express written consent.

Check the box and initial below if:

$\square$ You consent to information and/or opinions that I have given being credited to me in any written work on this research.

Initial

I have read the above and agree to be interviewed for this research.

Signed

Date 


\subsection{Information sheet for pilot study}

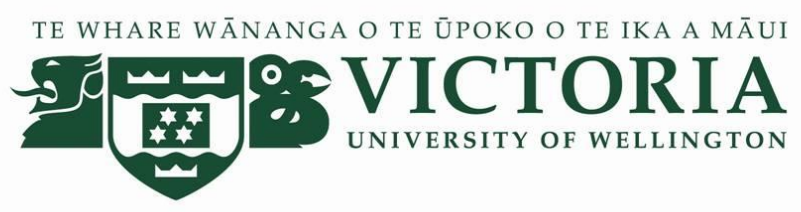

Researcher: Alyssa Thomas from the School of Geography, Environment and Earth Sciences at Victoria University of Wellington, New Zealand.

I am a PhD candidate in Environmental Studies at the above institution. In order to achieve this degree I am conducting research that will lead to a thesis. The purpose of this study is to understand compliance behaviour among recreational fishers in New Zealand. There are there parts to this study: 1 ) testing the effectiveness of two indirect (and anonymous) questioning methods on obtaining higher (and presumably more accurate) estimates of non-compliance 2) Understanding what factors are the strongest influences on a fisher's decision to comply with a specific fishing regulation and 3) Looking at compliance with suggested best practices, such as hook size.

Victoria University requires ethics approval for any research project involving human participants.

If you agree to participate you will be asked a series of questions on the regulations that you are supposed to follow while fishing in this area. You will also be asked to complete a series of questions concerning your compliance with these same regulations. Both Randomised Response (RRT) and Item Count (ICT) are strictly anonymous and I have no way of knowing what your answer is.

For RRT you will be asked to flip a coin and remembering the outcome without telling anyone. Next you will randomly select 1 of 2 questions from an envelope, again not telling anyone. One card will ask you about the coin toss "When you flipped the coin did you get tails?" and the other card is a question about fishing in the area. To answer you simply circle yes or no on the survey form. At no point should you reveal which question you answered. To make sure you understand this method and why your answer remains anonymous we can do a practice one first with the roles reversed.

For ICT you will be given two lists of common behaviors. For each list you need to report only the total number of these practices that you have done in the past year. It is important to not make any marks or checks next to the practices that apply, only write the total number from each list. We can also do a practice one of this method, if you would like.

The entire survey should last around 15 minutes. Participation is completely voluntary. The overall survey, as well as every section, is completely anonymous and confidential. There is no penalty for not participating or for withdrawing from participation at any stage. At no time will your name will never be asked for or recorded. The results of the study will form the basis of my thesis, and copies will be given to the School of Geography Environment and Earth Sciences at Victoria, Victoria University Library, and possibly also published in academic journals.

If you have additional questions about any aspect of the research please contact me at: Alyssa Thomas, Department of Geography, Environment and Earth Sciences. Victoria University of Wellington. PO Box 600, Wellington, New Zealand; 044635233 ext. 8619. Alternatively you may contact my supervisor, Dr Taciano Milfont, School of Psychology, Victoria University of Wellington. PO Box 600, Wellington, New Zealand. 


\subsection{Ethics approval amendment}

\section{(after survey design)}

MEMORANDUM

\begin{tabular}{l|l}
\hline TO & Alyssa Thomas \\
\hline COPY TO & $\begin{array}{l}\text { Michael Gavin } \\
\text { Taciano Milfont }\end{array}$ \\
\hline FROM & Dr Allison Kirkman, Convener, Human Ethics Committee \\
\hline
\end{tabular}

\begin{tabular}{l|l}
\hline DATE & 17 October 2012 \\
\hline PAGES & 1 \\
\hline
\end{tabular}

SUBJECT $\quad$ Ethics Approval: 19097

Understanding Fishers' Compliance with Fishing Regulations in New Zealand

Thank you for your request to amend your ethics approval. This has now been considered and the request granted.

Your application has approval until 1 March 2014. If your data collection is not completed by this date you should apply to the Human Ethics Committee for an extension to this approval.

Best wishes with your research.

Allison Kirkman

Human Ethics Committee 


\subsection{Intercept survey}

TE WHARE WĀNANGA O TE ŪPOKO O TE IKA A MĀUI

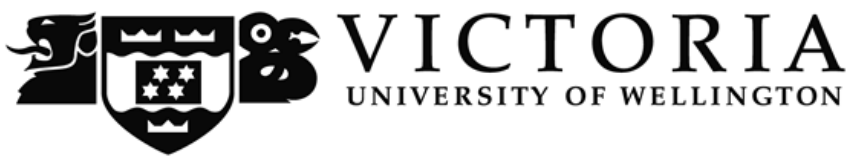

\section{Marlborough Sounds Blue Cod Survey 2013}

1. Overall, how would you rate your level of satisfaction with the blue cod regulations for the Marlborough Sounds?

(very dissatisfied) 1. $\square$ 2. $\square$ 3. $\square$ 4. $\square$ 5. $\square$ (very satisfied)

2. How much do the blue cod regulations influence your decision on how often to go fishing in the Marlborough Sounds? (no influence) 1. प2. प3. प4. 5 . $\square$ (strong influence)

3. Please rate your satisfaction with fishing for blue cod in the Marlborough Sounds in 2012

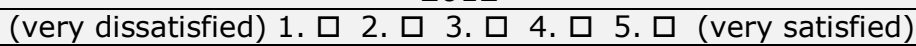

4. Please rate your satisfaction with fishing for blue cod in the Marlborough Sounds in 2011

(very dissatisfied) 1. $\square$ 2. $\square$ 3. $\square$ 4. $\square$ 5. (very satisfied)

5a. If you go fishing in the Cook Strait are you allowed to bring back more than two blue cod per person/day? 1. $\square$ Yes 2. $\square$ No 3. $\square$ Don't know

5b. And do you agree with this? 1. $\square$ Yes 2. $\square$ No

6a. Is filleting of blue cod at sea allowed? 1. $\square$ Yes 2. $\square$ No 3. $\square$ Don't know

6b. And do you agree with this? 1. $\square$ Yes 2. $\square$ No

7a. Have you heard of the Blue Cod Management Group before? 1. $\square$ Yes 2. $\square$ No

7b. If yes, what do you think the group's purpose is and/or what have they done in the past?

8. How many years have you been fishing in the Marlborough Sounds?

9. Finally, in which of the following areas do you live?

1. $\square$ Northland

2. $\square$ Auckland

3. $\square$ Waikato

4. $\square$ Bay of Plenty

5. $\square$ Gisborne

6. Hawke's Bay

7. $\square$ Taranaki

8. $\square$ Manawatu-Wanganui

9. $\square$ Wellington-Wairarapa

10. $\square$ Tasman

11. $\square$ Nelson

12. $\square$ Marlborough

13. $\square$ West Coast

14. $\square$ Canterbury

15. $\square$ Otago

16. $\square$ Southland

17. $\square$ Overseas

\begin{tabular}{|l|l|}
\hline Gender & Estimated Age \\
\hline Location & Marina or Ramp \\
\hline
\end{tabular}




\subsection{Measures used to predict compliance with blue cod fishing regulations}

\begin{tabular}{|c|c|c|}
\hline & Construct & Items \\
\hline & Meaningful Rule & $\begin{array}{l}\text { 1. There is valid science behind the } \\
\text { blue cod regulations* } \\
\text { 2. It is wrong to have to throw back a } \\
\text { fish that is severely injured } \\
\text { 3. MFish has the right to impose } \\
\text { regulations governing blue cod } \\
\text { fishing* } \\
\text { 4. It is difficult to respect the blue cod } \\
\text { regulations }\end{array}$ \\
\hline & $\begin{array}{l}\text { Involvement in decision-making } \\
\text { process }\end{array}$ & $\begin{array}{l}\text { 1. Recreational fishers were } \\
\text { adequately involved in forming the } \\
\text { blue cod regulations } \\
\text { 2. Recreational fishers were well- } \\
\text { represented in developing the blue } \\
\text { cod management plans } \\
\text { 3. My views were well-represented in } \\
\text { developing the blue cod } \\
\text { management plans } \\
\text { 4. MFish did not listen to recreational } \\
\text { fishers when developing the blue } \\
\text { cod management plans* }\end{array}$ \\
\hline & Problem Awareness & $\begin{array}{l}\text { 1. The blue cod population was } \\
\text { declining before the ban } \\
\text { 2. It was necessary to do something } \\
\text { about the overfishing of blue cod in } \\
\text { the Sounds } \\
\text { 3. The Sounds blue cod population } \\
\text { needs to be carefully managed } \\
\text { 4. The number of recreational fishers } \\
\text { in the Marlborough Sounds has } \\
\text { been increasing }\end{array}$ \\
\hline & Attribution & $\begin{array}{l}\text { 1. My fishing practices did not } \\
\text { contribute to the need for the blue } \\
\text { cod regulations* } \\
\text { 2. Going fishing in the Sounds puts } \\
\text { pressure on the blue cod population } \\
\text { 3. The blue cod regulations were } \\
\text { needed because of recreational } \\
\text { fishers }\end{array}$ \\
\hline
\end{tabular}


4. By following proper handling practices, my fishing does not harm the blue cod population* (deleted)

5. Probability of Detection

1. On a normal fishing trip I do not expect to see a MFish boat*

2. Enforcement by MFish is too focused on holiday periods* (deleted)

3. Enforcement by MFish is frequent enough to deter most fishers from violating the blue cod regulations

4. If you were to take more than the daily limit of blue cod, what would you consider to be the overall chance of being caught?

6. Probability of Conviction

7. Knowledge of Rules
1. If caught keeping more than the daily limit how likely is it that you would be penalised?

1. I have been informed of the daily limit (size limit) for blue cod

2. I have easy access to information about the daily limit for blue cod

3. It is easy to understand what is required by the daily limit for blue cod

8. Penalty if Convicted

1. Potential penalties are strict enough to deter most recreational fishers form exceeding the daily limit for blue cod

2. I do not exceed the daily limit for blue cod because of the potential penalty

3. The penalty for taking more than the daily limit for blue cod is a concern to me

9. Outcome Fairness
1. Marlborough-based recreational fishers are unfairly impacted by the daily limit*

2. The daily limit for blue cod has affected my fishing habits more than other people's habits* (deleted for size limit)

3. Daily limits for blue cod are fairly applied to everyone

4. The daily limit for blue cod has a fair and equitable impact on recreational fishers 
1. The daily limit is effective in leaving enough blue cod for the future

2. High levels of dissatisfaction among recreational fishers result from the daily limit for blue cod* (deleted for size limit)

3. Blue cod fish stocks are effectively conserved by the daily limit

4. A daily limit is not an effective way to manage the blue cod population*

11. Descriptive Social Norm

1. The majority of recreational fishers normally comply with the daily limit for blue cod*

2. Among recreational fishers I know, most sometimes keep more than the daily limit for blue cod

3. It is common practice among recreational fishers to sometimes keep more than the daily limit for blue cod

12. Injunctive Social Norm

1. If I kept more than the daily limit of blue cod my reputation as a fisher would be harmed

2. Doing what other recreational fishers think I should do regarding the daily limit for blue cod is important to me

3. Other recreational fishers would disapprove if I kept more than the daily limit for blue cod

4. People that are important to me, like my friends and family, would not disapprove if I took more than the daily limit for blue cod*

13. Guilt

1. I would not feel guilty taking more than the daily limit of blue cod* $^{*}$

2. I would feel guilty for taking more than my fair share if I exceeded the daily limit for blue cod

3. I would have a bad conscience if I exceeded the daily limit of blue cod

4. I would not feel guilty exceeding the daily limit for blue cod since I am not the only one* 
1. It is easy for me to comply with the daily limit for blue cod

2. On a normal fishing trip I would have trouble complying with the daily limit for blue cod*

3. I am confident in my control to not exceed the daily limit for blue cod

4. It is entirely up to me to not go over the daily limit for blue cod (deleted for both daily and size limits)

15. Attitude

1. I do not agree with the daily limit for blue cod

2. My fishing experience is made less enjoyable by complying with the daily limit for blue cod

3. I do not think it is wrong to take more than the daily limit of blue $\operatorname{cod}^{*}$ (deleted for size limit)

4. I would not like exceeding the daily limit for blue cod* (deleted for daily limit)

1. Complying with the daily limit for blue cod is the "right thing to do"

2. It is the moral thing to comply with the daily limit for blue cod

3. Regardless of what other fishers think, I do not feel I should comply with the daily limit for blue cod

4. Following my own values means I feel obligated to not exceed the daily limit for blue cod

* Reverse-scored item 


\subsection{Confirmatory Factor Analysis results}

(chapter four)

8.10.1 Fit indices for measures used to predict compliance: all regulations

\begin{tabular}{|c|c|c|c|c|c|c|c|c|c|}
\hline \multicolumn{7}{|c|}{ Model Fit } & \multicolumn{3}{|c|}{ Descriptive statistics } \\
\hline Model & $\chi^{2}$ & $d f$ & $\chi^{2} / d f$ & $\begin{array}{l}\text { RMSEA } \\
(90 \% \mathrm{CI})\end{array}$ & SRMR & CFI & $M$ & $S D$ & $\begin{array}{c}\text { Cronbach's } \\
\text { alpha }\end{array}$ \\
\hline Meaningful & 2.65 & 2 & 1.33 & $.03(.00-.12)$ & .02 & 1 & 3.25 & 0.80 & .63 \\
\hline Involvement & 0.70 & 2 & 0.35 & $.00(.00-.08)$ & .01 & 1 & 2.27 & 0.83 & .80 \\
\hline Awareness & 1.37 & 2 & 0.69 & $.00(.00-.10)$ & .01 & 1 & 3.82 & 0.72 & .70 \\
\hline Attribution ${ }^{1}$ & 0.51 & 1 & 0.51 & $.00(.00-.13)$ & .01 & 1 & 2.83 & 0.84 & .60 \\
\hline Detection $^{2}$ & 0.02 & 1 & 0.02 & $.00(.00-.08)$ & .003 & 1 & 2.80 & 0.68 & .67 \\
\hline
\end{tabular}

Note. $N=320 . \chi^{2} / d f=$ the ratio of chi-square to degrees of freedom; RMSEA = root mean square error of approximation; $90 \% \mathrm{CI}=90$ percent confidence interval; SRMR $=$ standardized root mean square residual; $\mathrm{CFI}=$ comparative fit index.

${ }^{1}$ : Item 4 (.18) removed, anchored on Item 3 and Item 2 fixed at 0.60

${ }^{2}$ : Item 2 (.05) removed, anchored on Item 3 and Item 1 fixed at 0.61 
8.10.2 Fit indices for measures used to predict compliance: daily limit

\begin{tabular}{|c|c|c|c|c|c|c|c|c|c|}
\hline \multicolumn{7}{|c|}{ Model Fit } & \multicolumn{3}{|c|}{ Descriptive statistics } \\
\hline Model & $\chi^{2}$ & $d f$ & $\chi^{2} / d f$ & $\begin{array}{l}\text { RMSEA } \\
(90 \% \mathrm{CI})\end{array}$ & SRMR & CFI & $M$ & $S D$ & $\begin{array}{c}\text { Cronbach's } \\
\text { alpha }\end{array}$ \\
\hline Knowledge & 2.72 & 1 & 2.72 & $.07(.00-.18)$ & .03 & .99 & 4.06 & .63 & .67 \\
\hline Penalty $^{1}$ & 3.16 & 1 & 3.16 & $.08(.00-.19)$ & .04 & .96 & 3.44 & .78 & .49 \\
\hline Fairness & 8.43 & 2 & 4.22 & $.10(.038-.18)$ & .03 & .98 & 2.96 & .88 & .73 \\
\hline Effectiveness & 2.58 & 2 & 1.29 & $.03(.00-.12)$ & .02 & 1 & 3.01 & .81 & .70 \\
\hline Descriptive $^{2}$ & 3.62 & 1 & 3.62 & $.09(.00-.20)$ & .03 & .99 & 3.53 & .75 & .78 \\
\hline Injunctive & 0.91 & 2 & 0.46 & $.00(.00-.09)$ & .01 & 1 & 3.63 & .63 & .54 \\
\hline Guilt & 12.74 & 2 & 6.37 & $.13(.07-.20)$ & .03 & .98 & 4.02 & .75 & .85 \\
\hline $\mathrm{PBC}^{3}$ & 4.05 & 1 & 4.05 & $.10(.01-.21)$ & .03 & .98 & 3.90 & .76 & .64 \\
\hline Attitude ${ }^{4}$ & 4.62 & 1 & 4.62 & $.11(.03-.21)$ & .04 & .96 & 3.30 & .84 & .56 \\
\hline Moral Norm & 0.97 & 2 & 0.49 & $.00(.00-.09)$ & .01 & 1 & 4.17 & .61 & .79 \\
\hline
\end{tabular}

Note. $N=320 . \chi^{2} / d f=$ the ratio of chi-square to degrees of freedom; RMSEA = root mean square error of approximation; $90 \% \mathrm{CI}=90$ percent confidence interval; $\mathrm{SRMR}=$ standardized root mean square residual; $\mathrm{CFI}=$ comparative fit index.

1: Anchored on Item 3 and Item 2 fixed at 0.53

2: Anchored on Item 2 and Item 3 fixed at 0.74

3: Item $4(0.22)$ removed, anchored on Item 1 and Item 2 fixed at 0.65

4: Item 4 (0.34) removed, anchored on Item 2 and Item 1 fixed at 0.66 
8.10.3 Fit indices for measures used to predict compliance: size limit

\begin{tabular}{|c|c|c|c|c|c|c|c|c|c|}
\hline \multicolumn{7}{|c|}{ Model Fit } & \multicolumn{3}{|c|}{ Descriptive statistics } \\
\hline Model & $\chi^{2}$ & $d f$ & $\chi^{2} / d f$ & $\begin{array}{l}\text { RMSEA } \\
(90 \% \mathrm{CI})\end{array}$ & SRMR & CFI & $M$ & $S D$ & $\begin{array}{c}\text { Cronbach's } \\
\text { alpha }\end{array}$ \\
\hline Knowledge & 3.0 & 1 & 3.0 & $.08(.00-.19)$ & .02 & .99 & 4.03 & .63 & .72 \\
\hline Penalty ${ }^{1}$ & 0.1 & 1 & 0.1 & $.00(.11-.19)$ & .003 & 1 & 3.47 & .65 & .32 \\
\hline Fairness $^{2}$ & 3.81 & 1 & 3.81 & $.09(.00-.12)$ & .03 & .99 & 2.72 & .96 & .74 \\
\hline Effectiveness $^{3}$ & 2.67 & 1 & 2.67 & $.07(.00-.18)$ & .02 & .99 & 2.60 & .99 & .70 \\
\hline Descriptive $^{4}$ & 1.77 & 1 & 1.77 & $.05(.00-.17)$ & .02 & 1.0 & 3.44 & .73 & .74 \\
\hline Injunctive & 2.65 & 2 & 1.32 & $.03(.00-.12)$ & .02 & 1.0 & 3.50 & .67 & .64 \\
\hline Guilt & 1.35 & 2 & 0.67 & $.00(.00-1.0)$ & .01 & 1 & 3.8 & .79 & .80 \\
\hline $\mathrm{PBC}^{5}$ & 2.67 & 1 & 2.67 & $.07(.00-.18)$ & .02 & .99 & 3.69 & .85 & .77 \\
\hline Attitude ${ }^{6}$ & 0.64 & 1 & 0.64 & $.00(.00-.14)$ & .02 & 1 & 2.71 & .82 & .49 \\
\hline Moral Norm & 3.08 & 2 & 1.54 & $.04(.00-.13)$ & .01 & 1.0 & 3.93 & .69 & .82 \\
\hline
\end{tabular}

Note. $N=320 . \chi^{2} / d f=$ the ratio of chi-square to degrees of freedom; RMSEA = root mean square error of approximation; $90 \% \mathrm{CI}=90$ percent confidence interval; SRMR $=$ standardized root mean square residual $\mathrm{CFI}=$ comparative fit index.

1. Anchored on Item 3 and Item 1 fixed at 0.19

2: Item 4 (0.40) removed, anchored on Item 3 and Item 2 fixed at 0.67

3: Item 4 (0.42) removed, anchored on Item 3 and Item 2 fixed at 0.78

${ }^{4}$ : Anchored on Item 2

$5:$ Item 1 (0.12) removed, anchored on Item 3 and Item 4 fixed at 0.75

6: Item 3 (0.24) removed, anchored on Item 4 and Item 1 fixed at 0.60 


\subsection{Results presentation feedback survey}

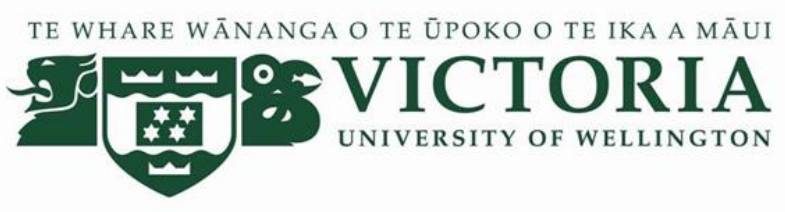

Thank you for taking the time to attend tonight's presentation. I would appreciate you answering a few quick questions to help me evaluate the usefulness of my research results.

\begin{tabular}{|c|c|c|c|c|c|c|c|c|}
\hline \multicolumn{9}{|c|}{ Please rate the following items between 1 (strongly disagree) and 5 (strongly agree) } \\
\hline $\begin{array}{c}1 \\
\text { Strongly Disagree }\end{array}$ & $\begin{array}{c}2 \\
\text { Disagree }\end{array}$ & $\begin{array}{c}3 \\
\text { Neutral }\end{array}$ & $\begin{array}{c}4 \\
\text { Agree }\end{array}$ & \multicolumn{5}{|c|}{$\begin{array}{c}5 \\
\text { Strongly } \\
\text { Agree }\end{array}$} \\
\hline \multicolumn{4}{|c|}{ I am happy that there was research into what the fishers think about the rules } & 1 & 2 & 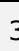 & 4 & 5 \\
\hline \multicolumn{4}{|c|}{ The research presented is important } & 1 & 2 & 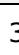 & 4 & 5 \\
\hline \multicolumn{4}{|c|}{ The presentation was informative } & 1 & 2 & 3 & 4 & 5 \\
\hline \multicolumn{4}{|c|}{ I believe the Ministry will take some of the results into consideration } & 1 & 2 & 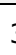 & 4 & 5 \\
\hline
\end{tabular}

1) What was the most interesting result you heard tonight?

2) What result do you think is the most important and why?

3) After hearing the results, which of the five rules (daily limit, size limit, transit rule, filleting rule, closed season):

a. Do you most want to see changed?

b. Do you think is the most important one to change?

4) What are the top three results that you would like to see communicated to the Ministry and why?

1)

2)

3)

5) Any other comments or feedback? 
8.12 Online Survey 


\section{Survey Introduction}

Kia Ora,

Thank you so much for agreeing to participate in this survey on blue cod fishing in the Marlborough Sounds. It is being carried out by Alyssa Thomas, a PhD student at Victoria University of Wellington. Ethics approval has been granted for this survey by Victoria University of Wellington. You consent to your participation by completing the survey.

Please note:

-Your views are important to me and all answers will be kept strictly confidential.

-None of the responses can be directly attributed to you and are therefore anonymous.

-Some of the questions will be a bit repetitive as I am interested in your views on the same aspect (e.g. fairness) of different blue cod rules. I would appreciate your understanding of this and still taking the time to answer each question thoughtfully.

To answer a question: Most questions have a round button to click. Select the button that best describes your answer to each question. Sometimes you may need to type your answer in the space provided.

If you forget to answer a question or miss part of question, a message reminding you that the question needs to be answered will appear. If this happens, you need to complete your answer to continue with the survey. Sometimes you will need to scroll across or down the page to see all of the possible answers.

To go to the next question: Once you have finished answering the question, click the >> button at the bottom of the screen.

To change an answer: For questions with a single choice, click on a different button. To change an answer for a previous question, click on the $\ll$ button at the bottom of the screen.

Completing the survey at a later time: You can leave the survey and come back and finish it later (that day or another day). Simply click on the link again and you will be taken to where you left off--all previous answers will be saved.

Please continue if you will take the time to carefully read each question and answer truthfully. The survey has been designed to provide a good level of detail on your views which will make for a stronger result.

\section{Fishing in the Marlborough Sounds}

What are the top three species of fish you normally target while fishing in the Marlborough Sounds? To select a species, click on the name and drag it into one of the boxes.

\begin{tabular}{l|l|l|}
\hline Blue Cod & 1st \\
Butterfish & & \\
Crayfish & & \\
Groper & & \\
Gurnard & & 2nd \\
Kahawai & & \\
Kingfish & & \\
Moki & & \\
Monkfish & &
\end{tabular}


Paua

Scallops

Sea Perch

Snapper

Terakihi

Other

To keep a blue cod it must be at least $\mathrm{cm}$ in length

The maximum size for a blue cod to be kept is
$45 \mathrm{~cm}$
$40 \mathrm{~cm}$
$33 \mathrm{~cm}$
$35 \mathrm{~cm}$
there isn't one

Next are four statements concerning your fishing experience and habits.

Please indicate the extent to which you agree or disagree with each of the following statements using the 5-point scale below.

\begin{tabular}{|c|c|c|c|c|c|}
\hline & $\begin{array}{l}\text { Strongly } \\
\text { Disagree }\end{array}$ & Disagree & $\begin{array}{c}\text { Neither Agree } \\
\text { nor Disagree }\end{array}$ & Agree & Strongly Agree \\
\hline I am an experienced fisher & 0 & O & $\bigcirc$ & $\mathrm{O}$ & $\mathrm{O}$ \\
\hline $\begin{array}{l}\text { I know the other fishers in the } \\
\text { Marlborough Sounds well }\end{array}$ & O & 0 & 0 & 0 & 0 \\
\hline $\begin{array}{l}\text { It is important to be able to } \\
\text { continue fishing in the } \\
\text { Marlborough Sounds }\end{array}$ & 0 & 0 & 0 & 0 & 0 \\
\hline $\begin{array}{l}\text { I am familiar with the } \\
\text { Marlborough Sounds and its } \\
\text { fishing community }\end{array}$ & 0 & 0 & 0 & O & O \\
\hline
\end{tabular}




\section{Queen Charlotte fishing}

In 2012 did you go fishing in the Queen Charlotte Sound? If you did not go fishing the Sounds in 2012 please answer this question for the most recent year you did go fishing, including 2013.
Yes

No

\section{RRT instructions}

On the following pages you will be asked a number of questions about blue cod fishing in the Marlborough Sounds.

While I understand that questions on fishing practices may be sensitive, honest information is crucial if the results of this study are to help improve your fishing experience. The questions are asked in a way that guarantees your privacy, in addition to the anonymous and confidential nature of the entire survey.

While these questions specifically ask about 2012, if you did not go fishing in the Sounds in 2012 please answer them for the most recent year you have been fishing in the Marlborough Sounds (including 2013).

In order to keep your answer a secret, you will be randomly asked one of two possible questions: either 1) about the results of a coin toss or 2) about fishing in the Marlborough Sounds.

There is no way anyone can know either the results of the coin toss or which question you answered. This means you can be completely honest with your answers.

Before we start with the questions, please start by going to the below website (it will open in a new tab) and flipping the coin once. Please remember what side it lands on. Then come back to this survey. http://www.coin.co.nz/coin-tosser.htm

\section{RRT 1}

Is the coin showing heads?

While fishing in the Marlborough Sounds in 2012 did you keep a blue cod that was less than $30 \mathrm{~cm}$ or more than $35 \mathrm{~cm}$ in length?

Now please answer the above question by selecting yes or no. 


\section{RRT 2}

Once again please go to the below website and flip the coin once. Please remember what side it lands on.

After flipping the coin, come back to this survey. You will then be asked one of two questions, either 1) the results of the coin toss or 2) a different question on fishing in the Marlborough Sounds.

\section{http://www.coin.co.nz/coin-tosser.htm}

Is the coin showing heads?

While fishing in the Marlborough Sounds in 2012 did you keep more than 2 blue cod per person in a day?

Now please answer the above question by selecting yes or no.

Yes

No

\section{RRT 3}

One final time please go to the below website and toss the coin once. Please remember what side it lands on. When done flipping the coin please return to this survey.

Once again you will be randomly asked one of two questions, either 1) the results of the coin toss or 2) a third question on fishing in the Marlborough Sounds

\section{http://www.coin.co.nz/coin-tosser.htm}

Is the coin showing heads?

Did you go fishing in the Long Island Marine Reserve in 2012?

Now please answer the above question by selecting yes or no
Yes
No 


\section{ICT 1}

Below are a number of fishing related activities that you may have done in 2012. Please carefuly read the individual activities and note, in your head, how many you have done at least once. Even if you have done that activity more than once it only counts as ' 1 '. The activities apply to all locations unless otherwise specified.

If you did not go fishing in the Marlborough Sounds in 2012, please answer the questions for the most recent year (including 2013) you went fishing in the Sounds.

When you are done, please answer at the bottom of each list only the TOTAL NUMBER of activities that you have done for each list.

The specific items that you have done will remain unknown and your reponse will also remain anonymous and confidential so please answer honestly.

\section{List 1}

-Took time off work to go fishing

-Entered a fishing competition

-Stayed at a bach while on a fishing trip

-Went freshwater fishing

\section{Total number of activities you have done from List 1:}
0
1
2
3
4

\section{List 2}

-Shared your catch with someone

-Was a member of a fishing club

-Kept a blue cod less than $30 \mathrm{~cm}$ or more than $35 \mathrm{~cm}$ in length while in the Marlborough Sounds

-Watched a fishing show on TV

-Caught a trophy fish

\section{Total number of activities you have done from List 2:}
0
1
2
3
4
5 


\section{List 3}

-Went fishing from a private vessel

-Went fishing overseas

-Visited the Ministry of Fisheries website

-Taught someone else how to fish

Total number of activities you have done from List 3:
0
1
2
3
4

\section{List 4}

-Bought bait from a store

-Kept more than 2 blue cod per person in a day (during the open season in the Marlborough Sounds) -Purchased a boat

-Visited a fishing-related website other than the Ministry of Fisheries

-Went on a fishing weekend

Total number of activities you have done from List 4:
0
1
2
3
4
5

\section{List 5}

-Read about fishing in a magazine or newspaper

-Attended a public meeting about fishing

-Went line fishing from shore

-Wrote an opinion piece on fishing

Total number of activities you have done from List 5: 


\section{List 6}

-Purchased new fishing equipment other than a boat

-Went on a fishing charter

-Took your kids or relatives fishing

-Fished in the Long Island Marine Reserve

-Did not catch any fish in a day

\section{Total number of activities you have done from List 6:}

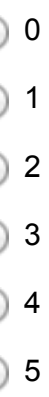

Below are a number of fishing related activities that you may have done in 2012. Please carefuly read the individual activities and note, in your head, how many you have done at least once. Even if you have done that activity more than once it only counts as ' 1 '. The activities apply to all locations unless otherwise specified.

If you did not go fishing in the Marlborough Sounds in 2012, please answer the questions for the most recent year (including 2013) you went fishing in the Sounds.

When you are done, please answer at the bottom of each list only the TOTAL NUMBER of activities that you have done for each list.

The specific items that you have done will remain unknown and your reponse will also remain anonymous and confidential so please answer honestly.

\section{List 1}

-Took time off work to go fishing

-Entered a fishing competition

-Kept a blue cod less than $30 \mathrm{~cm}$ or more than $35 \mathrm{~cm}$ in length while in the Marlborough Sounds

-Stayed at a bach while on a fishing trip

-Went freshwater fishing

Total number of activities you have done from List 1:
0
1
2
3
4
5 


\section{List 2}

-Shared your catch with someone

-Was a member of a fishing club

-Watched a fishing show on TV

-Caught a trophy fish

Total number of activities you have done from List 2:
0
1
2
3
4

\section{List 3}

-Went fishing from a private vessel

-Kept more than 2 blue cod per person in a day (during the open season in the Marlborough Sounds)

-Went fishing overseas

-Visited the Ministry of Fisheries website

-Taught someone else how to fish

\section{Total number of activities you have done from List 3:}
0
1
2
3
4
5

\section{List 4:}

-Bought bait from a store

-Purhased a boat

-Visited a fishing-related website other than the Ministry of Fisheries

-Went on a fishing weekend

\section{Total number of activities you have done from List 4:}
0
2
3
4

1 


\section{List 5}

-Read about fishing in a magazine or newspaper

-Attended a public meeting about fishing

-Went line fishing from shore

-Fished in the Long Island Marine Reserve

-Wrote an opinion piece on fishing

Total number of activities you have done from List 5:
0
1
2
3
4
5

\section{List 6}

-Purchased new fishing equipment other than a boat

-Went on a fishing charter

-Took your kids or relatives fishing

-Did not catch any fish in a day

Total number of activities you have done from List 6:
0
1
2
3
4

\section{Method evaluation}

Did you answer the previous questions for a year besides $2012 ?$
Yes
No

Thank you for answering those questions. Now I would like to know your opinion on the two methods used for the previous questions.

The next set of statements refer to the first method: you flip a coin and then randomly answer one of two questions (either the result of the coin toss or fishing in the Marlborough Sounds) 


\begin{tabular}{l|ccccc}
\hline & $\begin{array}{l}\text { Strongly } \\
\text { Disagree }\end{array}$ & Disagree & $\begin{array}{c}\text { Neither Agree } \\
\text { nor Disagree }\end{array}$ & Agree & Strongly Agree \\
\hline $\begin{array}{l}\text { I understood why my answer } \\
\text { would not be known }\end{array}$ & 0 & & 0 & \\
$\begin{array}{l}\text { I felt comfortable answering } \\
\text { honestly }\end{array}$ & 0 & 0 & 0 & \\
I found this method confusing & 0 & 0 & 0 & 0 \\
$\begin{array}{l}\text { I believed my privacy was } \\
\text { protected with this method }\end{array}$ & 0 & 0 & 0 & 0
\end{tabular}

And now please think about the other method where you had a list of activities and were instructed to provide a total number done

\begin{tabular}{|c|c|c|c|c|c|}
\hline & $\begin{array}{l}\text { Strongly } \\
\text { Disagree }\end{array}$ & Disagree & $\begin{array}{c}\text { Neither Agree } \\
\text { nor Disagree }\end{array}$ & Agree & Strongly Agree \\
\hline $\begin{array}{l}\text { I understood why my answer } \\
\text { would not be known }\end{array}$ & $\bigcirc$ & O & O & $\bigcirc$ & O \\
\hline $\begin{array}{l}\text { I felt comfortable answering } \\
\text { honestly }\end{array}$ & $\bigcirc$ & $\bigcirc$ & O & $\bigcirc$ & $\bigcirc$ \\
\hline I found this method confusing & 0 & 0 & 0 & O & 0 \\
\hline $\begin{array}{l}\text { I believed my privacy was } \\
\text { protected with this method }\end{array}$ & $\bigcirc$ & 0 & 0 & $\bigcirc$ & 0 \\
\hline
\end{tabular}

\section{Blue Cod Regulations}

Blue cod in particular are subject to strict regulation by the Ministry of Fisheries (MFish). The current management plan regulates the size (the slot rule) and number (daily limit) of blue cod that recreational fishers may keep, closes the Sounds for several months a year and restricts fishers coming back from the Cook Strait.

\section{The following statements ask about the development of the blue cod regulations and your experiences with} MFish.

Please indicate the extent to which you agree or disagree with each of the following statements using the 5-point scale below.

\begin{tabular}{|c|c|c|c|c|c|}
\hline & $\begin{array}{l}\text { Strongly } \\
\text { Disagree }\end{array}$ & Disagree & $\begin{array}{c}\text { Neither Agree } \\
\text { nor Disagree }\end{array}$ & Agree & Strongly Agree \\
\hline $\begin{array}{l}\text { MFish has the right to impose } \\
\text { regulations governing blue cod } \\
\text { fishing }\end{array}$ & 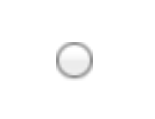 & 0 & 0 & O & 0 \\
\hline $\begin{array}{l}\text { It is difficult to respect the blue } \\
\text { cod regulations }\end{array}$ & & & 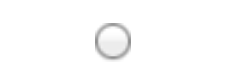 & C & \\
\hline $\begin{array}{l}\text { Enforcement by MFish is } \\
\text { frequent enough to deter most } \\
\text { fishers from violating the blue } \\
\text { cod regulations }\end{array}$ & & & $\cap$ & $\mathrm{C}$ & \\
\hline $\begin{array}{l}\text { Going fishing in the Sounds } \\
\text { puts pressure on the blue cod } \\
\text { population }\end{array}$ & 2 & & r & $C$ & \\
\hline $\begin{array}{l}\text { The Sounds blue cod } \\
\text { population needs to be } \\
\text { carefully managed }\end{array}$ & $\cap$ & & $\cap$ & , & \\
\hline
\end{tabular}


My views were wellrepresented in developing the blue cod management plans

Recreational fishers were adequately involved in forming the blue cod regulations

My fishing practices did not contribute to the need for the blue cod regulations

It is wrong to have to throw back a fish that is severely injured

MFish did not listen to recreational fishers when developing the blue cod management plans

By following proper handling practices my fishing does not harm the blue cod population

The blue cod regulations were needed because of recreational fishers

The number of recreational fishers in the Sounds has been increasing

It was necessary to do something about the overfishing of blue cod in the Sounds

Strongly Disagree

Strongly Disagree

Recreational fishers were wellrepresented in developing the blue cod management plans

There is valid science behind the blue cod regulations

Enforcement by MFish is too focused on holiday periods

The blue cod population was declining before the ban

On a normal fishing trip I do not expect to see a MFish boat

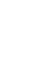

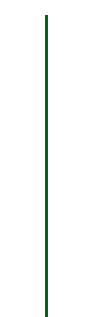




\begin{tabular}{|c|c|c|c|c|c|}
\hline & $\begin{array}{l}\text { Strongly } \\
\text { Disagree }\end{array}$ & Disagree & $\begin{array}{c}\text { Neither Agree } \\
\text { nor Disagree }\end{array}$ & Agree & Strongly Agree \\
\hline $\begin{array}{l}\text { Potential penalties are strict } \\
\text { enough to deter most } \\
\text { recreational fishers from } \\
\text { exceeding the daily limit for } \\
\text { blue cod }\end{array}$ & $b$ & & 0 & O & $\mathrm{O}$ \\
\hline $\begin{array}{l}\text { I have easy access to } \\
\text { information about the daily limit } \\
\text { for blue cod }\end{array}$ & & & ) & & 0 \\
\hline $\begin{array}{l}\text { The penalty for taking more } \\
\text { than the daily limit for blue cod } \\
\text { is a concern to me }\end{array}$ & & & & & \\
\hline $\begin{array}{l}\text { I do not exceed the daily limit } \\
\text { for blue cod because of the } \\
\text { potential penalty }\end{array}$ & 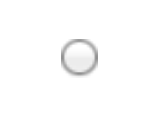 & & & & $\mathrm{O}$ \\
\hline $\begin{array}{l}\text { I have been informed of the } \\
\text { daily limit for blue cod }\end{array}$ & $\cap$ & 0 & $\Omega$ & & \\
\hline $\begin{array}{l}\text { It is easy to understand what is } \\
\text { required by the daily limit for } \\
\text { blue cod }\end{array}$ & $\cap$ & ค & 0 & & 0 \\
\hline
\end{tabular}

The effectiveness and fairness of the daily limit for blue cod

\begin{tabular}{|c|c|c|c|c|c|}
\hline & $\begin{array}{l}\text { Strongly } \\
\text { Disagree }\end{array}$ & Disagree & $\begin{array}{c}\text { Neither Agree } \\
\text { nor Disagree }\end{array}$ & Agree & Strongly Agree \\
\hline $\begin{array}{l}\text { A daily limit is not an effective } \\
\text { way to manage the blue cod } \\
\text { population }\end{array}$ & O & 0 & O & O & 0 \\
\hline $\begin{array}{l}\text { Marlborough-based } \\
\text { recreational fishers are unfairly } \\
\text { impacted by the daily limit for } \\
\text { blue cod }\end{array}$ & & & & & 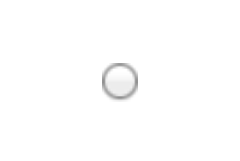 \\
\hline $\begin{array}{l}\text { The daily limit for blue cod has } \\
\text { affected my fishing habits more } \\
\text { than other people's habits }\end{array}$ & $\cap$ & & & & \\
\hline $\begin{array}{l}\text { Blue cod fish stocks are } \\
\text { effectively conserved by the } \\
\text { daily limit }\end{array}$ & 0 & & O & $\cap$ & 0 \\
\hline $\begin{array}{l}\text { Daily limits for blue cod are } \\
\text { fairly applied to everyone }\end{array}$ & & & & & \\
\hline $\begin{array}{l}\text { High levels of dis-satisfaction } \\
\text { among recreational fishers } \\
\text { result from the daily limit for } \\
\text { blue cod }\end{array}$ & & & & & \\
\hline $\begin{array}{l}\text { The daily limit for blue cod has } \\
\text { a fair and equitable impact on } \\
\text { recreational fishers }\end{array}$ & 0 & $\mathrm{~h}$ & & & \\
\hline $\begin{array}{l}\text { The daily limit is effective in } \\
\text { leaving enough blue cod for the } \\
\text { future }\end{array}$ & $\cap$ & 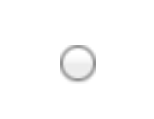 & $\cap$ & & \\
\hline
\end{tabular}

The behaviour and attitude of other fishers in regards to the daily limit for blue cod 
People that are important to me, like my family and friends, would not disapprove if I took more than the daily limit for blue cod

Doing what other recreational fishers think I should do regarding the daily limit for blue cod is important to me

Among recreational fishers that I know, most sometimes keep more than the daily limit for blue cod

It is common practice among recreational fishers to sometimes exceed the daily limit for blue cod

Other recreational fishers would disapprove if I kept more than the daily limit for blue cod

The majority of recreational fishers normally comply with the daily limit for blue cod

If I kept more than the daily limit of blue cod my reputation as a fisher would be harmed

Your attitude towards the daily limit for blue cod

\begin{tabular}{|c|c|c|c|c|c|}
\hline & $\begin{array}{l}\text { Strongly } \\
\text { Disagree }\end{array}$ & Disagree & $\begin{array}{c}\text { Neither Agree } \\
\text { nor Disagree }\end{array}$ & Agree & Strongly Agree \\
\hline $\begin{array}{l}\text { It is easy to comply with the } \\
\text { daily limit for blue cod }\end{array}$ & & & & & 0 \\
\hline $\begin{array}{l}\text { Following my own values } \\
\text { means I feel obligated to not } \\
\text { exceed the daily limit for blue } \\
\text { cod }\end{array}$ & & & & & D \\
\hline $\begin{array}{l}\text { I would not feel guilty taking } \\
\text { more than the daily limit of blue } \\
\text { cod }\end{array}$ & & & & & ) \\
\hline $\begin{array}{l}\text { I would feel guilty for taking } \\
\text { more than my 'fair share' if I } \\
\text { exceeded the daily limit for blue } \\
\text { cod }\end{array}$ & & & & & \\
\hline $\begin{array}{l}\text { It is the moral thing to comply } \\
\text { with the daily limit for blue cod }\end{array}$ & & & & & $\bigcirc$ \\
\hline \multirow[t]{2}{*}{$\begin{array}{l}\text { I do not agree with the daily } \\
\text { limit for blue cod }\end{array}$} & & 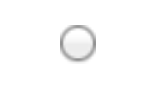 & & & ) \\
\hline & $\begin{array}{l}\text { Strongly } \\
\text { Disagree }\end{array}$ & Disagree & $\begin{array}{c}\text { Neither Agree } \\
\text { nor Disagree }\end{array}$ & Agree & Strongly Agree \\
\hline $\begin{array}{l}\text { I would have a bad conscience } \\
\text { if I exceeded the daily limit of } \\
\text { blue cod }\end{array}$ & 7 & 0 & $\Omega$ & & O \\
\hline $\begin{array}{l}\text { It is entirely up to me to not go } \\
\text { over the daily limit for blue cod }\end{array}$ & $\Omega$ & $\cap$ & 0 & $\Omega$ & $\mathrm{O}$ \\
\hline $\begin{array}{l}\text { I do not think it is wrong to take } \\
\text { more than the daily limit of blue } \\
\text { cod }\end{array}$ & 0 & 0 & 0 & & \\
\hline
\end{tabular}


I would not like exceeding the daily limit for blue cod

I would not feel guilty exceeding the daily limit of blue cod since I am not the only one

Regardless of what other fishers think, I do not feel I should comply with the daily limit for blue cod

On a normal fishing trip I would

Strongly

Disagree

have trouble complying with the daily limit for blue cod

I am confident in my control to not exceed the daily limit for blue cod

Complying with the daily limit for blue cod is the 'right thing' to do

My fishing experience is made less enjoyable by complying with the daily limit for blue cod

$\mid$

If you were to take more than the daily limit of blue cod, what would you consider to be the overall chance of being caught?
very high
fairly high
a slight possibility
fairly low
very low
don't know

If caught keeping more than the daily limit of blue cod, how likely is it that you would be penalised?
very high
fairly high
a slight possibility
fairly low
very low
don't know

What penalty would you expect for exceeding the daily limit for blue cod?

small fine ( $\$ 500$ or under)

large fine (over $\$ 500)$ 
loss of boat

fine and loss of boat

don't know

Considering the specific groups of fishers below, please answer the question: how many fishers in each group do you think normally comply with the daily limit for blue cod?

\begin{tabular}{|c|c|c|c|c|c|c|c|}
\hline & $\begin{array}{c}\text { Almost all } \\
\text { (90\% or } \\
\text { more) }\end{array}$ & $\begin{array}{l}\text { More than } \\
\text { half }\end{array}$ & About half & $\begin{array}{l}\text { Less than } \\
\text { half }\end{array}$ & $\begin{array}{c}\text { Almost } \\
\text { none }(10 \% \\
\text { or less) }\end{array}$ & None & Don't know \\
\hline $\begin{array}{l}\text { Residents of the greater } \\
\text { Marlborough Region }\end{array}$ & 0 & 0 & 0 & 0 & 0 & 0 & 0 \\
\hline Permanent Sounds residents & 0 & O & 0 & 0 & $\bigcirc$ & 0 & 0 \\
\hline Bach owners & 0 & 0 & 0 & 0 & $\mathrm{O}$ & $\mathrm{O}$ & 0 \\
\hline Visitors & 0 & 0 & 0 & 0 & 0 & 0 & 0 \\
\hline
\end{tabular}

\section{Slot Rule}

Next, please take a minute to think about the size limitations for blue cod in the Marlborough Sounds, the so-called 'slot rule'.

Please indicate the extent to which you agree or disagree with each of the following statements using the displayed 5-point scale.

Your knowledge of the slot rule and the risks involved with keeping blue cod outside the allowed slot.

\begin{tabular}{|c|c|c|c|c|c|}
\hline & $\begin{array}{l}\text { Strongly } \\
\text { Disagree }\end{array}$ & Disagree & $\begin{array}{c}\text { Neither Agree } \\
\text { nor Disagree }\end{array}$ & Agree & Strongly Agree \\
\hline $\begin{array}{l}\text { Potential penalties are strict } \\
\text { enough to deter most } \\
\text { recreational fishers from not } \\
\text { following the slot rule }\end{array}$ & O & $\mathrm{O}$ & 0 & $\mathrm{O}$ & 0 \\
\hline $\begin{array}{l}\text { The penalty for breaking the } \\
\text { slot rule is a concern to me }\end{array}$ & $\bigcirc$ & $\mathrm{O}$ & O & $\bigcirc$ & O \\
\hline $\begin{array}{l}\text { I have easy access to } \\
\text { information about the slot rule }\end{array}$ & $\bigcirc$ & O & $\bigcirc$ & $\bigcirc$ & $\bigcirc$ \\
\hline $\begin{array}{l}\text { I do not keep blue cod outside } \\
\text { of the slot because of the } \\
\text { potential penalty }\end{array}$ & 0 & 0 & 0 & $\mathrm{O}$ & 0 \\
\hline $\begin{array}{l}\text { I have been informed of the } \\
\text { minimum and maximum sizes } \\
\text { for blue cod }\end{array}$ & 0 & 0 & 0 & 0 & 0 \\
\hline $\begin{array}{l}\text { It is easy to understand what is } \\
\text { required by the slot rule }\end{array}$ & 0 & O & O & $\mathrm{O}$ & $\mathrm{O}$ \\
\hline
\end{tabular}

The effectiveness and fairness of the slot rule 
Marlborough recreational fishers are unfairly impacted by the slot rule

The slot rule is effective in leaving high numbers of large blue cod

The size limits for blue cod are fairly applied to everyone

The slot rule is effective in leaving large numbers of juvenile blue cod

There is a fair and equitable impact on recreational fishers from the slot rule

A slot rule is not an effective way to manage the blue cod population

The slot rule has affected my fishing habits more than others' habits

High levels of dis-satisfaction among recreational fishers result from the slot rule

The behaviour and attitude of other fishers towards the slot rule

\begin{tabular}{|c|c|c|c|c|c|}
\hline & $\begin{array}{l}\text { Strongly } \\
\text { Disagree }\end{array}$ & Disagree & $\begin{array}{c}\text { Neither Agree } \\
\text { nor Disagree }\end{array}$ & Agree & Strongly Agree \\
\hline $\begin{array}{l}\text { The majority of recreational } \\
\text { fishers normally comply with } \\
\text { the slot rule }\end{array}$ & 0 & 0 & 0 & 0 & 0 \\
\hline $\begin{array}{l}\text { Other recreational fishers } \\
\text { would disapprove if I kept blue } \\
\text { cod outside of the slot }\end{array}$ & 0 & 0 & 0 & 0 & 0 \\
\hline $\begin{array}{l}\text { If I kept oversized or } \\
\text { undersized blue cod my } \\
\text { reputation as a fisher would be } \\
\text { harmed }\end{array}$ & 0 & 0 & 0 & 0 & 0 \\
\hline $\begin{array}{l}\text { Among recreational fishers that } \\
\text { I know, most do not break the } \\
\text { slot rule }\end{array}$ & 0 & 0 & 0 & 0 & 0 \\
\hline $\begin{array}{l}\text { It is common practice among } \\
\text { recreational fishers to } \\
\text { occasionally disregard the slot } \\
\text { rule }\end{array}$ & 0 & 0 & 0 & 0 & 0 \\
\hline $\begin{array}{l}\text { People that are important to } \\
\text { me, like my family and friends, } \\
\text { would not disapprove if I took } \\
\text { undersized or oversized blue } \\
\text { cod }\end{array}$ & 0 & 0 & 0 & 0 & 0 \\
\hline $\begin{array}{l}\text { Doing what other recreational } \\
\text { fishers think I should do } \\
\text { regarding the slot rule is } \\
\text { important to me }\end{array}$ & 0 & 0 & 0 & 0 & 0 \\
\hline
\end{tabular}


I do not agree with the slot rule

I would have a bad conscience if I kept undersized or oversized blue cod

It is entirely up to me to not keep blue cod outside of the slot

I would not feel guilty keeping blue cod outside the allowed range

I would feel guilty for taking more than 'my fair share' if I disregarded the slot rule

It is easy for me to comply with the slot rule

It is the moral thing to comply with the slot rule

On a normal fishing trip I would have trouble complying with the slot rule

Regardless of what other fishers think, I do not feel I should comply with the slot rule

I do not think it is wrong to keep blue cod that are outside the slot

Complying with the slot is the 'right thing' to do

I would not like keeping undersized or oversized blue cod

My fishing experience is made less enjoyable by complying with the slot rule

I am confident in my control to keep only blue cod that are within the slot

I would not feel guilty breaking the slot rule since I am not the only one

Following my own values means I feel obligated to follow the slot rule

$\begin{array}{ccc}\begin{array}{c}\text { Strongly } \\ \text { Disagree }\end{array} & \text { Disagree } & \begin{array}{c}\text { Neither Agree } \\ \text { nor Disagree }\end{array} \\ 0 & & \\ 0 & & \\ \begin{array}{c}\text { Strongly } \\ \text { Disagree }\end{array} & \text { Disagree } & \begin{array}{c}\text { Neither Agree } \\ \text { nor Disagree }\end{array}\end{array}$

Strongly

Disagree

Disagree

Neither Agree

nor Disagree

Agree

Strongly Agree

If you were to keep blue cod outside of the allowed size range, what would you consider to be the overall chance of being caught?

very high

fairly high 
a slight possibility

fairly low

very low

don't know

If caught keeping undersized or oversized blue cod, how likely is it that you would be penalised?
very high
fairly high
a slight possibility
fairly low
very low
don't know

What penalty would you expect for keeping undersized or oversized blue cod?

small fine ( $\$ 500$ or less)

large fine (over $\$ 500$ )

loss of boat

fine and loss of boat

don't know

Considering the specific groups of fishers below, please answer the question: how many fishers in each group do you think normally follow the slot rule?

\begin{tabular}{|c|c|c|c|c|c|c|c|}
\hline & $\begin{array}{c}\text { Almost all } \\
\text { (90\% or } \\
\text { more) }\end{array}$ & $\begin{array}{l}\text { More than } \\
\text { half }\end{array}$ & About half & $\begin{array}{l}\text { Less than } \\
\text { half }\end{array}$ & $\begin{array}{c}\text { Almost } \\
\text { none (10\% } \\
\text { or less) }\end{array}$ & None & Don't know \\
\hline $\begin{array}{l}\text { Residents of the greater } \\
\text { Marlborough region }\end{array}$ & O & O & O & $\mathrm{O}$ & O & $\mathrm{O}$ & 0 \\
\hline Permanent Sounds residents & 0 & 0 & O & O & O & 0 & 0 \\
\hline Bach owners & 0 & 0 & 0 & O & O & $\mathrm{O}$ & 0 \\
\hline Visitors & 0 & 0 & O & O & $\bigcirc$ & O & 0 \\
\hline
\end{tabular}

\section{Scenario Intro}

This final set of questions goes into more detail about the blue cod that are being put back because of the slot rule. This seems to be the biggest source of frustration for most fishers, hence the additional questions.

These blue cod will be returned to the water (discarded) because they are either 1) outside the allowed side range (forced discards) or 2) returned in the hope of catching a larger, but still legal-sized fish (voluntary discards). 
Currently, on a normal day fishing, I discard an average of (number) blue cod

Thinking of these discarded blue cod, what percentage is

Because of the minimum size?

Because of the maximum size?

Voluntary?

Total

\section{Blue Cod Discarding}

As you may be aware, the Blue Cod Management Group has suggested best practices for fishers to follow while fishing for blue cod. These practices are suggested in order to minimise the mortality of any fish that are returned to the water.

The following statements ask about your knowledge of these suggestions.

How familiar are you with the Code of Practice for best handling of blue cod?

Extremely familiar-I know all of the suggestions

Very famililar--I know most of the suggestions

Somewhat familar-I have heard of it and know the general ideas

Not very familar-I have heard of it but don't know the details

Not at all familar-I have never heard of it

Now please think about the effectiveness of some of the practices suggested by the code

\begin{tabular}{|c|c|c|c|c|c|}
\hline & $\begin{array}{l}\text { Extremely } \\
\text { Uneffective }\end{array}$ & Uneffective & $\begin{array}{l}\text { Neither effective } \\
\text { or not }\end{array}$ & Effective & $\begin{array}{l}\text { Extremely } \\
\text { Effective }\end{array}$ \\
\hline $\begin{array}{l}\text { Wearing wet gloves or using a } \\
\text { wet rag when handling fish }\end{array}$ & 0 & 0 & 0 & 0 & 0 \\
\hline $\begin{array}{l}\text { Using size } 6 / 0 \text { hooks or larger } \\
\text { when fishing for blue cod }\end{array}$ & 0 & 0 & 0 & 0 & 0 \\
\hline $\begin{array}{l}\text { Holding the fish behind the } \\
\text { head to take out the hook }\end{array}$ & $\bigcirc$ & $\bigcirc$ & 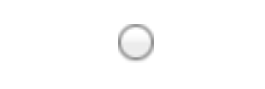 & O & 0 \\
\hline $\begin{array}{l}\text { Pinching or removing the barb } \\
\text { of hooks }\end{array}$ & $\bigcirc$ & $\bigcirc$ & O & O & $\bigcirc$ \\
\hline $\begin{array}{l}\text { Minimizing the time a caught } \\
\text { fish is out of the water }\end{array}$ & $\bigcirc$ & 0 & 0 & 0 & 0 \\
\hline
\end{tabular}


or gill-hooked

The fish is not placed on a hot or dry surface to be measured

And how often do you follow these suggested best practices?

\begin{tabular}{l|l}
\hline & Never \\
I wear wet gloves or use a wet \\
rag when handling caught fish \\
I do not pinch or remove the \\
barb of hooks \\
When fishing for blue cod I use \\
size 6/0 hooks or larger \\
If the fish is gut or gill-hooked I \\
cut the line \\
The length of time a caught fish \\
is out of the water is minimized \\
I told the fish behind the head \\
to extract hooks \\
I put the fish on a hot, dry \\
surface for measuring
\end{tabular}

Now considering the specific groups of fishers below, please answer the question: How many of the fishers do you think are aware of the Blue Cod Management Group suggested best practices?

\begin{tabular}{|c|c|c|c|c|c|c|c|}
\hline & $\begin{array}{l}\text { Almost all } \\
\text { (90\% or } \\
\text { more) }\end{array}$ & $\begin{array}{l}\text { More than } \\
\text { half }\end{array}$ & About half & $\begin{array}{l}\text { Less than } \\
\text { half }\end{array}$ & $\begin{array}{c}\text { Almost } \\
\text { none }(10 \% \\
\text { or less) }\end{array}$ & None & Don't know \\
\hline $\begin{array}{l}\text { Year round residents of the } \\
\text { Marlborough Area }\end{array}$ & 0 & $\bigcirc$ & $\cap$ & $\cap$ & & ᄀ & \\
\hline Permanent Sounds residents & ) & O & O & O & & O & 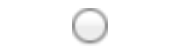 \\
\hline Bach owners & 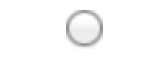 & 0 & $\bigcirc$ & $\bigcirc$ & O & $\cap$ & 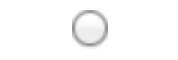 \\
\hline Visitors & O & O & O & O & O & O & 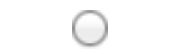 \\
\hline
\end{tabular}

And how many fishers in each group do you think normally follow most of the suggestions:

\begin{tabular}{|c|c|c|c|c|c|c|c|}
\hline & $\begin{array}{l}\text { Almost all } \\
(90 \% \text { or } \\
\text { more })\end{array}$ & $\begin{array}{l}\text { More than } \\
\text { half }\end{array}$ & About half & $\begin{array}{l}\text { Less than } \\
\text { half }\end{array}$ & $\begin{array}{c}\text { Almost } \\
\text { none }(10 \% \\
\text { or less) }\end{array}$ & None & $\begin{array}{l}\text { Don't } \\
\text { know }\end{array}$ \\
\hline $\begin{array}{l}\text { Year round residents of the Marlborough } \\
\text { Area }\end{array}$ & 0 & & $\cap$ & $\cap$ & & & \\
\hline Permanent Sounds residents & $\bigcirc$ & O & $\bigcirc$ & $\bigcirc$ & $\bigcirc$ & & 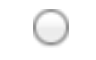 \\
\hline Bach owners & $\bigcirc$ & & O & O & $\bigcirc$ & 0 & C \\
\hline Visitors & 0 & 0 & 0 & 0 & 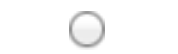 & & \\
\hline
\end{tabular}

\section{Scenario 1: No change}


Now please take a minute to envision what the next blue cod season (starting 20 December 2013) might be like.

Imagine the current regulations will be unchanged by the next season.

As a recreational fisher you are allowed to keep two blue cod/ per person a day, as long as they are between 30 and $35 \mathrm{~cm}$.

Considering this scenario please answer the questions below:

Thinking about the blue cod you personally discard...

\begin{tabular}{|c|c|c|c|c|c|}
\hline & Much Lower & Lower & About the Same & Higher & Much Higher \\
\hline $\begin{array}{l}\text { On a normal day fishing my } \\
\text { blue cod discards would be... }\end{array}$ & & & C & C & \\
\hline $\begin{array}{l}\text { I think my forced discards } \\
\text { would be... }\end{array}$ & 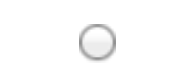 & & $\cap$ & $C$ & \\
\hline $\begin{array}{l}\text { And I think my voluntary } \\
\text { discards would be... }\end{array}$ & $\cap$ & . & O & 0 & $\mathrm{O}$ \\
\hline
\end{tabular}

And thinking about the scenario...

\begin{tabular}{|c|c|c|c|c|c|}
\hline & $\begin{array}{l}\text { Strongly } \\
\text { Disagree }\end{array}$ & Disagree & $\begin{array}{c}\text { Neither Agree } \\
\text { nor Disagree }\end{array}$ & Agree & Strongly Agree \\
\hline $\begin{array}{l}\text { I would enjoy fishing for blue } \\
\text { cod under this scenario }\end{array}$ & & $\cap$ & $\Omega$ & & \\
\hline $\begin{array}{l}\text { The majority of recreational } \\
\text { fishers would not be happy with } \\
\text { this scenario }\end{array}$ & & $\cap$ & 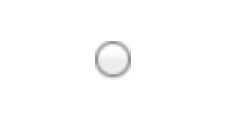 & 8 & $\cap$ \\
\hline $\begin{array}{l}\text { This scenario would be less } \\
\text { frustrating than the current } \\
\text { season }\end{array}$ & 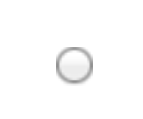 & 0 & 0 & $\mathrm{O}$ & $\mathrm{O}$ \\
\hline
\end{tabular}

\section{Scenario 2: Larger Slot}

Now please take a minute to envision what the next blue cod season (starting 20 December 2013) might be like.

Imagine that the Ministry of Fisheries has decided to increase the maximum size for blue cod from $35 \mathrm{~cm}$ to $40 \mathrm{~cm}$ for the next season. You will then be allowed to keep two blue cod/per person a day, as long as they are between 30 and $40 \mathrm{~cm}$.

Considering this scenario please answer the questions below:

Thinking about the blue cod you personally discard...

\begin{tabular}{l|ccc}
\hline & Much Lower & Lower & About the Same \\
\hline $\begin{array}{l}\text { On a normal day fishing my } \\
\text { blue cod discards would be... }\end{array}$ & \\
I think my forced discards \\
would be...
\end{tabular}


And I think my voluntary discards would be...

And thinking about the scenario...

\begin{tabular}{l|ccccc}
\hline & $\begin{array}{l}\text { Strongly } \\
\text { Disagree }\end{array}$ & Disagree & $\begin{array}{c}\text { Neither Agree } \\
\text { nor Disagree }\end{array}$ & Agree & Strongly Agree \\
\hline $\begin{array}{l}\text { I would enjoy fishing for blue } \\
\text { cod under this scenario }\end{array}$ & 0 & 0 & & \\
$\begin{array}{l}\text { The majority of recreational } \\
\text { fishers would not be happy with } \\
\text { this scenario }\end{array}$ & 0 & 0 & & \\
$\begin{array}{l}\text { This scenario would be less } \\
\text { frustrating than the current } \\
\text { season }\end{array}$ & 0 & & & \\
\end{tabular}

\section{Scenario 3: No Slot}

Now please take a minute to envision what the next blue cod season (starting 20 December 2013) might be like.

Imagine that the Ministry of Fisheries has decided to eliminate the maximum size for blue cod for the next season. You will then be allowed to keep two blue cod/person a day as long as they are a minimum of $30 \mathrm{~cm}$.

Considering this scenario please answer the questions below:

Thinking about the blue cod you personally discard...

\begin{tabular}{|c|c|c|c|c|c|}
\hline & Much Lower & Lower & About the Same & Higher & Much Higher \\
\hline $\begin{array}{l}\text { On a normal day fishing my } \\
\text { blue cod discards would be... }\end{array}$ & 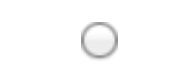 & 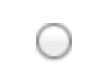 & O & C & \\
\hline $\begin{array}{l}\text { I think my forced discards } \\
\text { would be... }\end{array}$ & $\cap$ & $\cap$ & 0 & ( & \\
\hline $\begin{array}{l}\text { And I think my voluntary } \\
\text { discards would be... }\end{array}$ & 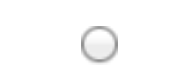 & $\cap$ & 0 & 0 & \\
\hline
\end{tabular}

And thinking about the scenario...

\begin{tabular}{|c|c|c|c|c|c|}
\hline & $\begin{array}{l}\text { Strongly } \\
\text { Disagree }\end{array}$ & Disagree & $\begin{array}{c}\text { Neither Agree } \\
\text { nor Disagree }\end{array}$ & Agree & Strongly Agree \\
\hline $\begin{array}{l}\text { I would enjoy fishing for blue } \\
\text { cod under this scenario }\end{array}$ & $\Omega$ & $\Omega$ & & & 0 \\
\hline $\begin{array}{l}\text { The majority of recreational } \\
\text { fishers would not be happy with } \\
\text { this scenario }\end{array}$ & $\cap$ & 7 & & ( & $\cap$ \\
\hline $\begin{array}{l}\text { This scenario would be less } \\
\text { frustrating than the current } \\
\text { season }\end{array}$ & 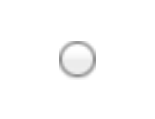 & $\cap$ & $\cap$ & $C$ & 0 \\
\hline
\end{tabular}

\section{Final Comments}


While fishing in the Marlborough Sounds in 2012 did you keep a blue cod that was less than $30 \mathrm{~cm}$ or more than $35 \mathrm{~cm}$ in length?

Yes

No

While fishing in the Marlborough Sounds in 2012 did you keep more than 2 blue cod per person in a day?
Yes
No

In 2012 did you go fishing in the Long Island Marine Reserve?

Yes

No

Is there anything else regarding blue cod fishing in the Marlborough Sounds you would like to comment on?

\section{Socio-economic questions}

Now just a few final background questions.

What is your gender?

Male

Female

What is your age? (years)

Number of years fishing? 
Number of years fishing in the Marlborough Sounds?

Do you own a boat?

Yes

No

What is the type and length of the boat?

What type of motor does your boat have and what is the horsepower?

In which of the following areas do you live?

Northland

Auckland

Waikato

Bay of Plenty

Gisborne

Hawke's Bay

Taranaki

Manawatu-Wanganui

Wellington-Wairarapa

Tasman

Nelson

Marlborough

West Coast

Canterbury

Otago

Southland

() 
Overseas

Do you own a bach in the Sounds?

Yes

No

What is the highest level of education you have completed?

Fifth or sixth form qualification

High school qualification

Vocational qualification

Undergraduate degree (Bachelor's Degree)

Postgraduate Degree

What was your total income before taxes last year?

Less than $\$ 20,000$

$\$ 20,000-\$ 29,999$

$\$ 30,000-\$ 39,999$

$\$ 40,000-\$ 49,999$

$\$ 50,000-\$ 59,999$

$\$ 60,000-\$ 79,999$

$\$ 80,000-\$ 100,000$

Over $\$ 100,000$ 